Florida International University FIU Digital Commons

$7-2-2014$

\title{
Biocompatibility Assessment of Biosorbable Polymer Coated Nitinol Alloys
}

Chandan Pulletikurthi

Florida International University, cpull001@fiu.edu

DOI: $10.25148 /$ etd.FI14071184

Follow this and additional works at: https://digitalcommons.fiu.edu/etd

\section{Recommended Citation}

Pulletikurthi, Chandan, "Biocompatibility Assessment of Biosorbable Polymer Coated Nitinol Alloys" (2014). FIU Electronic Theses and Dissertations. 1552.

https://digitalcommons.fiu.edu/etd/1552 


\section{FLORIDA INTERNATIONAL UNIVERSITY \\ Miami, Florida}

\section{BIOCOMPATIBILITY ASSESSMENT OF BIOSORBABLE POLYMER COATED NITINOL ALLOYS}

A dissertation submitted in partial fulfillment of the requirements for the degree of DOCTOR OF PHILOSOPHY in

MATERIAL SCIENCE \& ENGINEERING

by

Chandan Pulletikurthi 
To: Dean Amir Mirmiran

College of Engineering and Computing

This thesis, written by Chandan Pulletikurthi, and entitled as Biocompatibility Assessment of Biosorbable Polymer Coated Nitinol Alloys", having been approved in respect to style and intellectual content, is referred to you for judgment.

We have read this dissertation and recommend that it be approved.

Anthony McGoron

$\begin{array}{r}\hline \text { Kinzy Zones } \\ \hline \text { Surendra Saxena }\end{array}$

Surendra Saxena

Rao Bezawada

Norman Munroe, Major Professor

Date of Defense: July 2, 2014

The dissertation of Chandan Pulletikurthi is approved.

Dean Amir Mirmiran College of Engineering and Computing

Dean Lakshmi N. Reddi

University Graduate School

Florida International University, 2014 


\section{DEDICATION}

I dedicate this dissertation to my parents, family and friends - without their patience, understanding, support and most of all love, it would have been impossible to complete this research. 


\section{ACKNOWLEDGMENTS}

I am deeply grateful to my Major Professor, Norman Munroe, for his guidance, vision and support throughout the course of my $\mathrm{PhD}$ work. I express my special thanks to him for reviewing the research manuscripts and providing constructive comments and criticism during the past years. I also appreciate his constant inspiration and invaluable encouragement for me to become better. From the beginning, he had confidence in my abilities to not only complete a degree, but to complete it with excellence.

My gratitude is extended to my dissertation committee members for their willingness to participate in this process and provide invaluable support and encouragement. I wish to thank them for their support, patience, and good humor. Their gentle but firm direction has been most appreciated.

I have found my coursework throughout the Curriculum and Instruction program to be stimulating and thoughtful, providing me with the tools with which to explore both past and present ideas and issues.

I would like to thank my research group members Puneet, Vishal, Smith, Waseem and especially, Sushma for their constant support in my research. I want to thank Abhignyan for helping me with the cell culture studies. I would like to thank Kiran for assisting in dip coating setup. I would like to say a special thanks to Dr. Ramaswamy and Mr. Dugrot who guided me through hemocompatibility studies. I would also like to thank the staff at AMERI and FCAEM for letting me to use their analytical equipment during my research. Last but not least, I would like to thank the staff of MME department and Dean's office. 
I sincerely thank Mr. Rokicki from Electrobright ${ }^{\circledR}$ for magnetoelectropolishing; Dr. Hakan from Upsala University for XPS analysis and Nano-scratch tests; Dr. Rao for supplying polymeric raw materials and finally Dr.Cai and Dr. Liu for ICPMS analysis.

During these years, the support of my family and friends has been extremely valuable. I would like to thank my family for all the love and support, especially my sister and brother-in-law, who have always been supportive. To my Mom and Dad, thank you for being so understanding and wonderful parents. Mom, this is for you. You have been my source of happiness, confidence, and inspiration. I appreciate your continuing support in everything I do. I also want to thank my dear friends, Abi, Neha, Sudheer, Aditya, Aishwarya, Raghu, Mouna, Parija and Bala for their constant support and encouragement.

I wish to express my loving thanks to my fiance, without whom this work never could have been a success and whose patience and love kept me motivated. I am very much looking forward to recapturing the time we have missed!

I would also like to acknowledge various funding sources, which have enabled the completion of my degree. For the first two years of my $\mathrm{PhD}$, I was awarded a graduate assistantship by MME department; I was also supported by Dr. Munroe's projects from the National Institute of General Medical Sciences (Award Number SC3GM084816) and the Coral Gables Police Department. I am very thankful for the University Graduate School (UGS) for selecting me for the Dissertation Evidence Acquisition Fellowship and Dissertation Year Fellowship, which covered my tuition and living expenses for three consecutive semesters. 


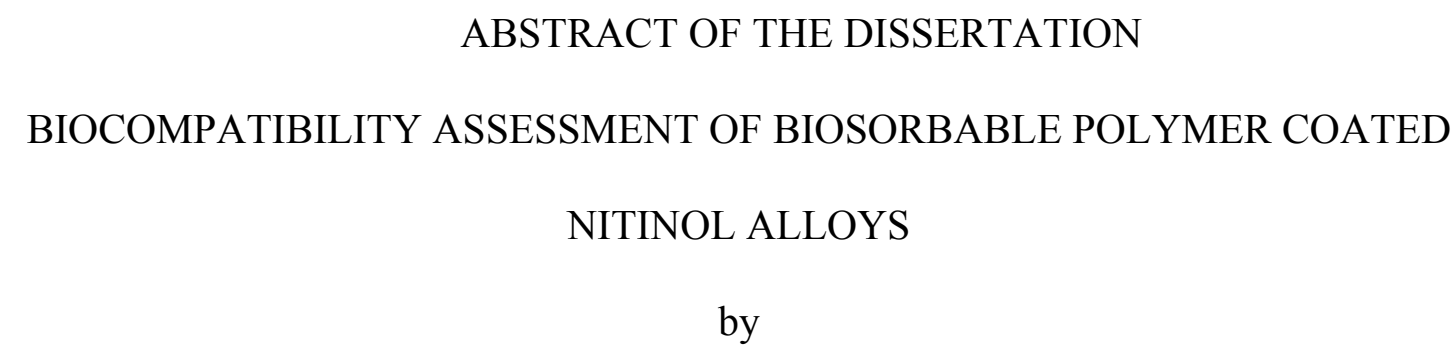

Chandan Pulletikurthi

Florida International University, 2014

Miami, Florida

\section{Professor Norman Munroe, Major Professor}

Owing to an increased risk of aging population and a higher incidence of coronary artery disease (CAD), there is a need for more reliable and safer treatments. Numerous varieties of durable polymer-coated drug eluting stents (DES) are available in the market in order to mitigate in-stent restenosis. However, there are certain issues regarding their usage such as delayed arterial healing, thrombosis, inflammation, toxic corrosion byproducts, mechanical stability and degradation. As a result, significant amount of research has to be devoted to the improvement of biodegradable polymer-coated implant materials in an effort to enhance their bioactive response.

In this investigation, magneto-electropolished (MEP) and a novel biodegradable polymer coated ternary Nitinol alloys, NiTiTa and NiTiCr were prepared to study their bio and hemocompatibility properties. The initial interaction of a biomaterial with its surroundings is dependent on its surface characteristics such as, composition, corrosion resistance, work of adhesion and morphology. In-vitro corrosion tests such as potentiodynamic polarization and electrochemical impedance spectroscopic (EIS) studies were conducted to determine the coating stability and longevity. In-vitro 
hemocompatibility studies and HUVEC cell growth was performed to determine their thrombogenic and biocompatibility properties. Critical delamination load of the polymer coated Nitinol alloys was determined using Nano-scratch analysis. Sulforhodamine B (SRB) assays were performed to elucidate the effect of metal ions leached from Nitinol alloys on the viability of HUVEC cells. Scanning Electron Microscopy (SEM), X-ray Photoelectron Spectroscopy (XPS), contact angle meter and X-ray diffraction (XRD) were used to characterize the surface of the alloys.

MEP treated and polymer coated (PC) Nitinol alloys displayed a corrosion resistant polymer coating as compared to uncoated alloys. MEP and PC has resulted in reduced $\mathrm{Ni}$ and $\mathrm{Cr}$ ion leaching from $\mathrm{NiTi5Cr}$ and subsequently low cytotoxicity. Thrombogenicity tests revealed significantly less platelet adhesion and confluent endothelial cell growth on polymer coated and uncoated ternary MEP Nitinol alloys. Finally, this research addresses the bio and hemocompatibility of MEP + PC ternary Nitinol alloys that could be used to manufacture blood contacting devices such as stents and vascular implants which can lead to lower U.S. healthcare spending. 


\section{TABLE OF CONTENTS}

CHAPTER

PAGE

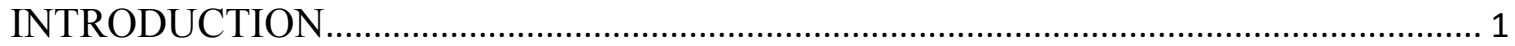

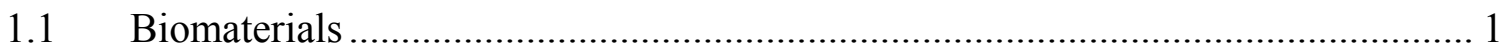

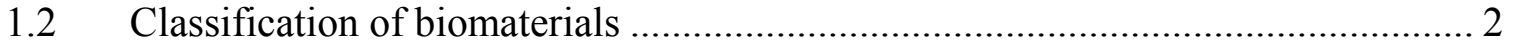

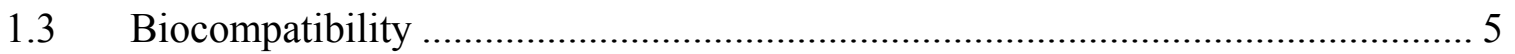

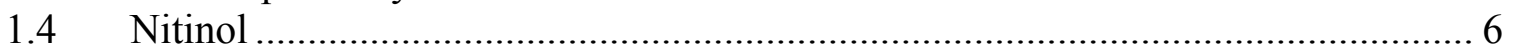

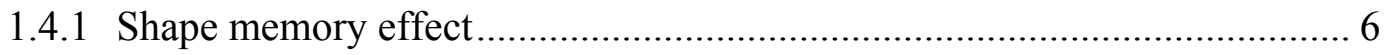

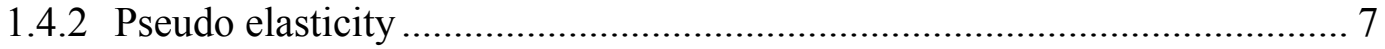

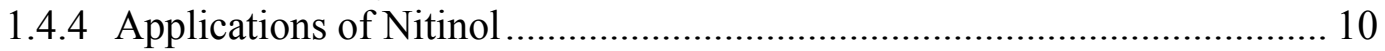

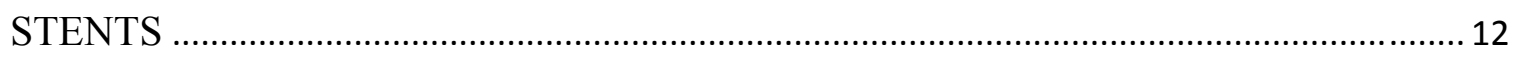

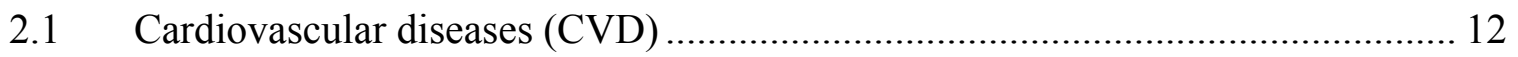

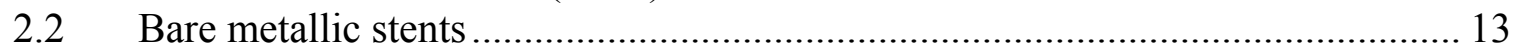

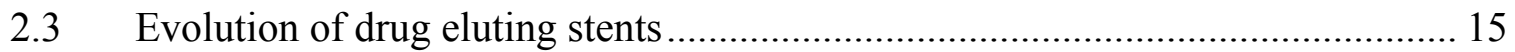

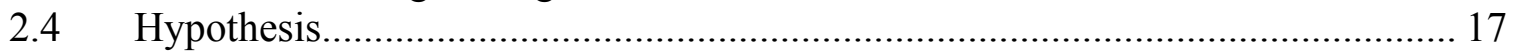

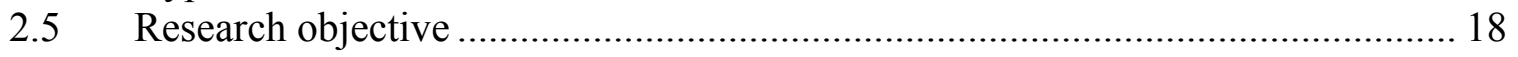

2.6 Potential polymers that can be used as coatings for stents ................................. 20

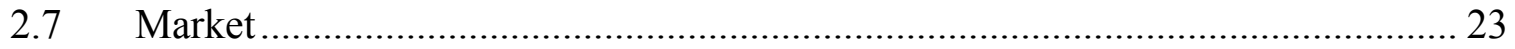

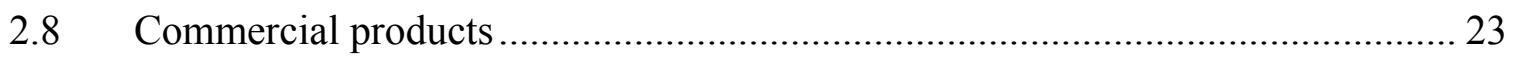

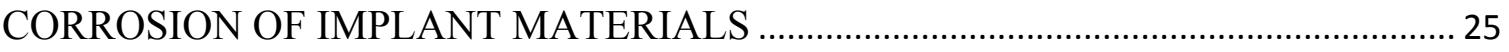

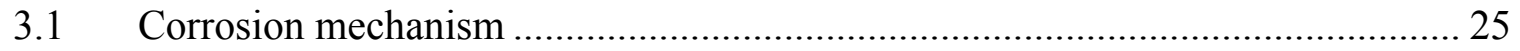

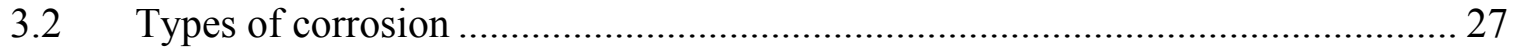

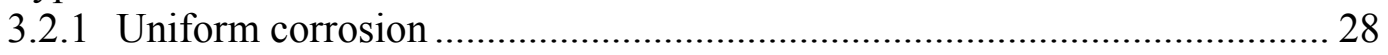

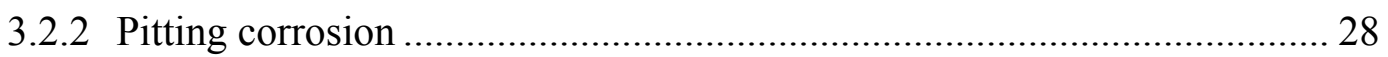

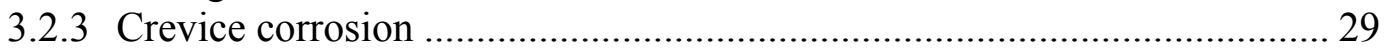

3.2.4 Fretting corrosion/erosion corrosion ....................................................... 30

3.2.5 Stress induced cracking corrosion .......................................................... 30

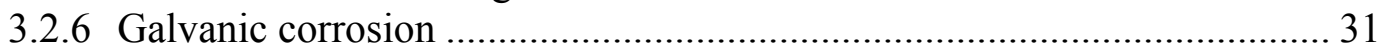

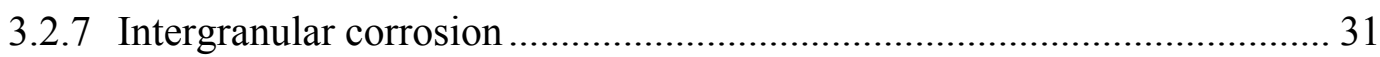

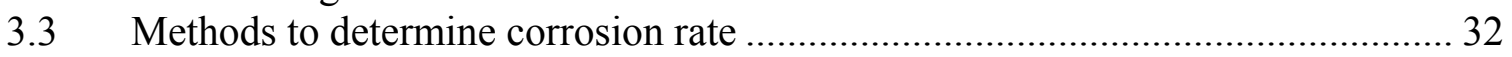

3.3.1 Potentiodynamic corrosion studies ........................................................ 32

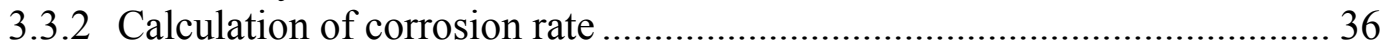

3.3.3 Cyclic potentiodynamic polarization tests ………..................................... 38

3.3.4 Cyclic potentiodynamic polarization curves ………................................... 40

$3.4 \quad$ Electrochemical impedance spectroscopy (EIS) ................................................. 43

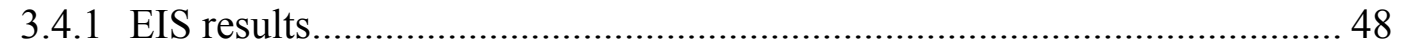

3.5 Methodology for cyclic polarization and EIS tests.......................................... 55

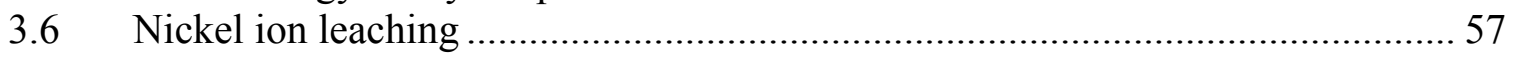

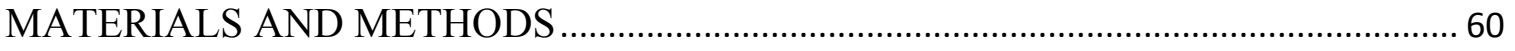

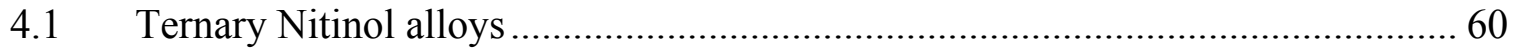




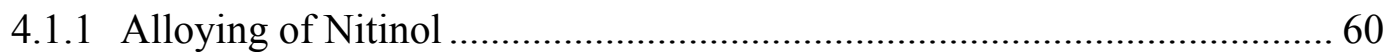

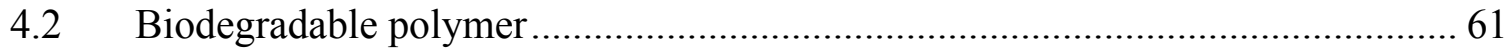

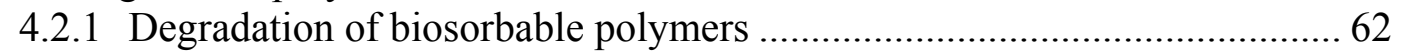

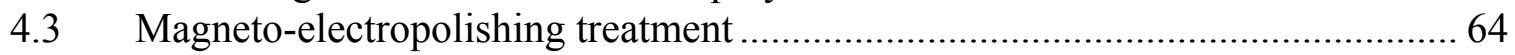

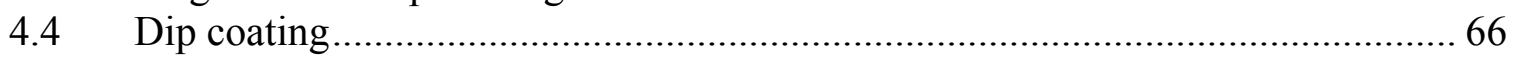

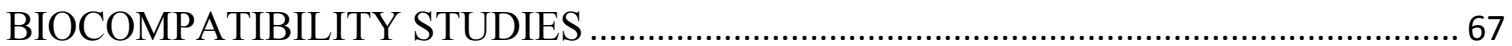

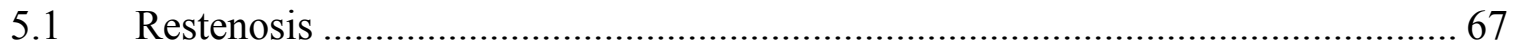

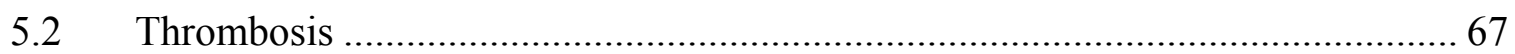

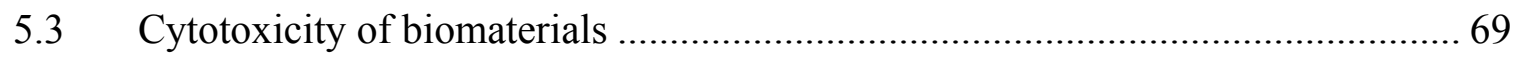

5.3.2 Inductively coupled plasma mass spectroscopic analysis ........................... 69

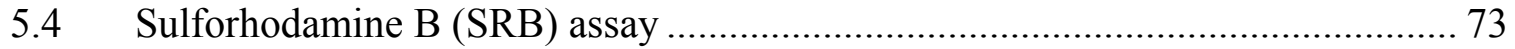

5.4.1 Cell culturing and media for SRB assay ............................................... 73

5.4.2 Cytotoxicity assay (SRB assay) protocol ……………............................. 74

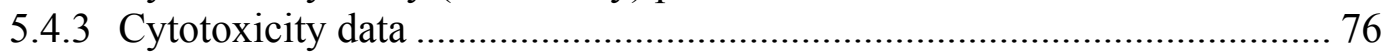

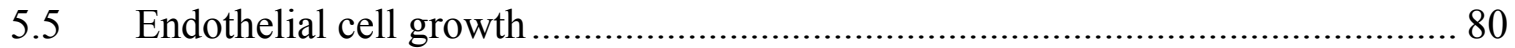

5.5.1 Cell growth on metallic and polymer coated samples................................. 81

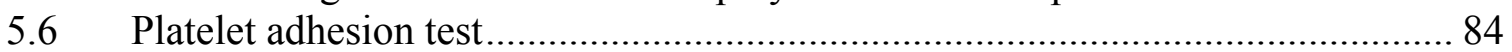

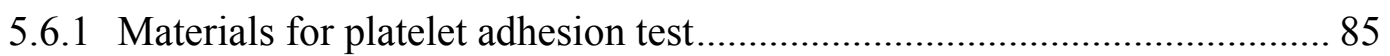

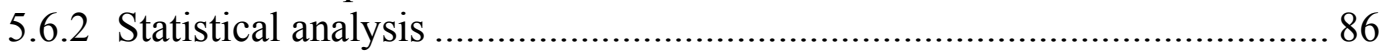

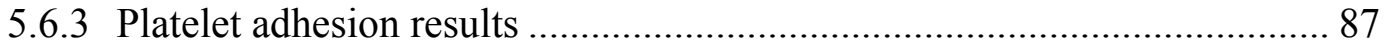

5.6.4 Correlation between platelet adhesion and surface free energy ................. 89

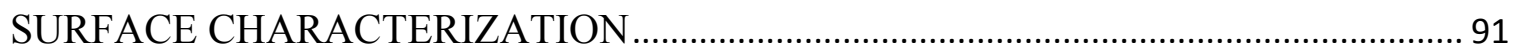

6.1 Surface morphology by scanning electron microscopy (SEM) analysis .............. 91

6.1.1 Secondary electron image (SEI) ......................................................... 91

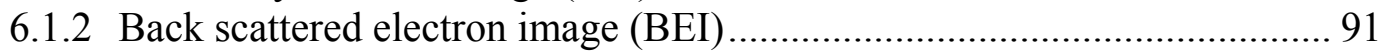

6.2 Energy dispersive X-ray spectroscopy (EDS) ………..................................... 92

6.3 Roughness of Nitinol alloys and polymer coating thickness by optical

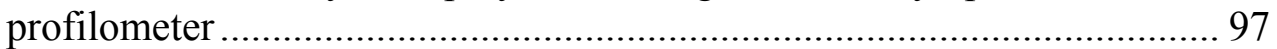

6.4 Morphology of polymer coated alloys before and after corrosion by SEM ......... 99

6.5 Surface chemistry of bare Nitinol alloys by XPS analysis ................................ 100

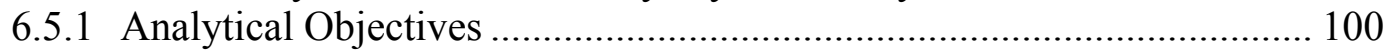

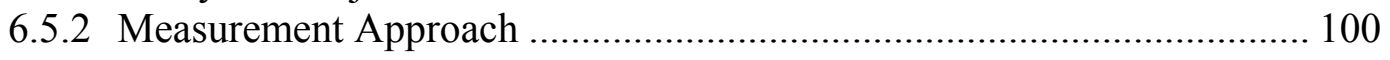

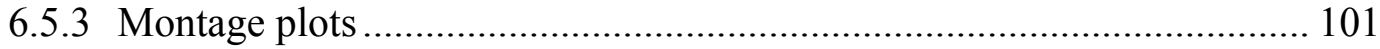

6.6 XRD analysis of surface oxides on Nitinol alloys ............................................. 106

6.7 Determination of mechanical properties of NiTi alloys by Nano-indentation ... 108

6.8 Surface composition of polymer coated Nitinol by FTIR analysis...................... 109

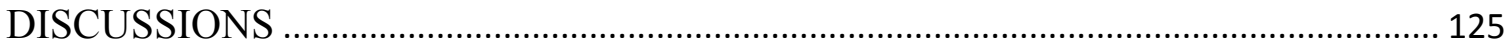

7.1 Biocompatibility of Nitinol alloys ........................................................... 125

7.2 Surface characterization of Nitinol alloys......................................................... 125

7.3 Corrosion analysis of polymer coated Nitinol alloys........................................... 126

7.4 Adhesion and interfacial bond between polymer and substrate........................... 128 
7.4 Endothelial cell viability and cytotoxicity of polymer coated Nitinol alloys ..... 131

7.5 Hemocompatibility of polymer coated Nitinol alloys ..................................... 132

7.6 Correlation between work of adhesion and cellular adhesion ........................... 133

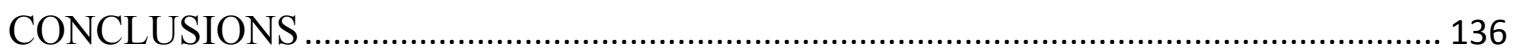

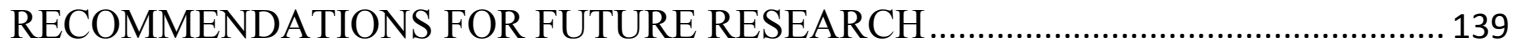

REFERENCES ......................................................... 140

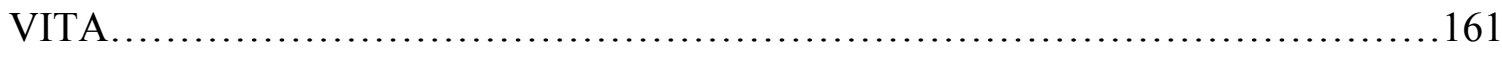




\section{LIST OF TABLES}

TABLE

PAGE

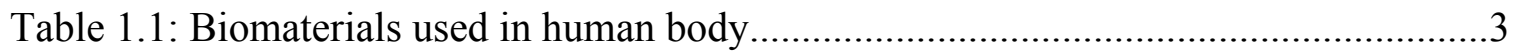

Table 2.1: Various metals that can be used to manufacture implants.................................14

Table 2.2: Hydrolytically degradable polymers........................................................20

Table 2.3: Commercially available DES and their properties .........................................24

Table 3.1: Tafel and corrosion rate parameters of MP, MEP and MEP + PC Nitinol

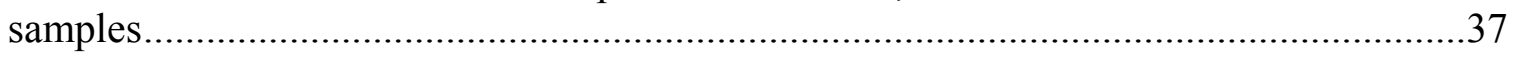

Table 3.2: Cyclic potentiodynamic corrosion data for Nitinol alloys................................43

Table 3.3: Significance of different equivalent elements used in an equivalent circuit ....53

Table 3.4: EIS fitted parameters for MEP Nitinol alloys (mean \pm SD, $n=5) \ldots \ldots \ldots \ldots \ldots \ldots \ldots . . .54$

Table 3.5: EIS fitted parameters for MEP + PC Nitinol alloys (mean $\pm \mathrm{SD}, \mathrm{n}=5$ ) ............55

Table 4.1: Ternary Nitinol alloys composition in atomic percentages .............................60

Table 4.2: Physical and chemical properties of PGA and PCL polymers .........................61

Table 5.1: ICPMS analysis of $\mathrm{Cr}$ and $\mathrm{Ni}$ ions leached from the surface of Nitinol

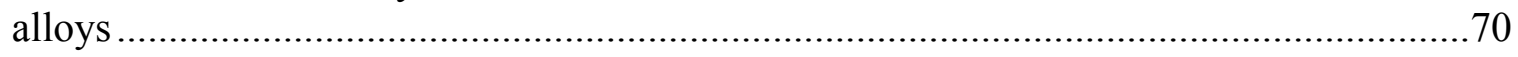

Table 6.1: XPS binding energies for different elements present on the surface of MEP ternary Nitinol alloys .................................................................................................104

Table 6.2: Ta element XPS peaks obtained on the surface of MEP NiTi10Ta ................105

Table 6.3: The amount (at\%) of different species of Ni present on the surface of MEP

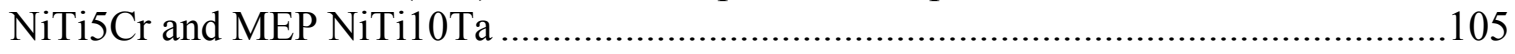

Table 6.4: Modulus and hardness calculated from Nano-indentation .............................109

Table 6.5: Interpretation of FTIR spectra for PGA/PCL polymer coatings .....................111

Table 6.6: Surface free energy parameters (in $\mathrm{mN} / \mathrm{m}$ ) ………..................................116

Table 6.7: Surface free energy parameters (in $\mathrm{mN} / \mathrm{m}$ ) ….............................................116 
Table 6.8: Interfacial tension $\left(\gamma_{\mathrm{ij}}\right)$ and work of adhesion (W) parameters for different substrate materials with respect to platelets.....................................................................117

Table 6.9: Work of adhesion between polymer and MEP Nitinol substrates..................119

Table 6.10: The operating parameters for nano scratch tests........................................122

Table 6.11: Adhesion energies of polymer coated Nitinol obtained from nano- scratch

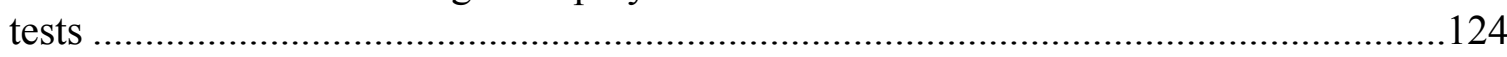




\section{LIST OF FIGURES}

\section{FIGURE}

Figure 1.1: Classification of biomaterials according to FDA

Figure 1.2: Different implants and devices used to replace or enhance the functions of

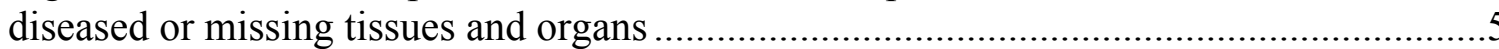

Figure 1.3: Stress-strain-temperature diagram of Nitinol ...............................................

Figure 2.1: Prevalence of CVD in adults $\geq 20$ years of age............................................12

Figure 2.2: Deaths due to heart diseases in the United States ..........................................13

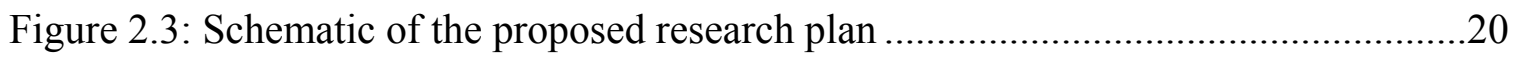

Figure 3.1: Occurrence of pitting corrosion on Nitinol in the presence of the complex physiological environment that prevails inside a human body

Figure 3.2: Potentiodynamic curve with anodic, cathodic curves and a Tafel plot to

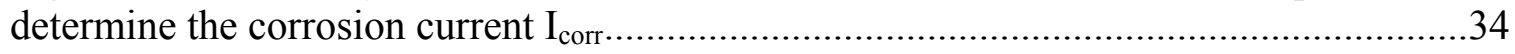

Figure 3.3: General anodic dissolution curve for an active passive metal.........................35

Figure 3.4: Potentiodynamic curves for NiTi10Ta alloys ................................................36

Figure 3.5: Potentiodynamic curves for NiTi5Cr alloys..................................................37

Figure 3.6: a) \& b) Typical cyclic potentiodynamic curves illustrating different corrosion parameters

Figure 3.7: Cyclic potentiodynamic polarization curves for NiTi10Ta alloys

Figure 3.8: Cyclic potentiodynamic polarization curves for NiTi5Cr alloys

Figure 3.9: Equivalent circuit model used to represent a simple electrochemical interface undergoing corrosion in the absence of diffusion control. $\mathrm{R}_{\mathrm{s}}-$ Solution resistance, $\mathrm{R}_{\mathrm{p}}$-polarization resistance, $\mathrm{C}_{\mathrm{dl}}$-capacitance of double layer .

Figure 3.10: A typical Nyquist plot that depicts the real and imaginary impedance values, on the $\mathrm{X}$ and $\mathrm{Y}$ - axis, respectively, for the aforementioned equivalent circuit .....45 
Figure 3.11: A typical Bode plot that shows log frequency on the $x$-axis, and both the absolute value of the impedance $\log Z$ and phase-shift $\theta$ on the $y$-axis for the aforementioned equivalent circuit.....

Figure 3.12 a) Equivalent circuit of a bare Nitinol alloy, b) Equivalent circuit of a Nitinol alloy with a polymer coating....

Figure 3.13: A comparative Bode plot analysis for different surface treated NiTi5Cr alloys

Figure 3.14: A comparative Bode plot analysis for different surface treated NiTi15Cr alloys .....

Figure 3.15: A comparative Nyquist plot analysis for different surface treated NiTi5Cr alloys

Figure 3.16: A comparative Bode plot analysis for different surface treated NiTi10Ta alloys

Figure 3.17: A comparative Bode plot analysis for different surface treated NiTi10Ta alloys

Figure 3.18: A comparative Nyquist plot analysis for different surface treated NiTi10Ta alloys

Figure 3.19: Effect of changing $\mathrm{R}_{\mathrm{p}}$ in terms of a) Nyquist plot; b) \& c) Bode plots

Figure 3.20: a) Equivalent EIS circuit for MEP Nitinol alloys, b) schematic of corresponding metal - metal oxide - electrolyte interface.

Figure 3.21: a) Equivalent EIS circuit for a two-layer model: MEP + PC Nitinol alloys, b) schematic of corresponding metal/metal oxide/polymer/electrolyte interface.

Figure 3.22: Gamry corrosion cell kit used for cyclic potentiodynamic polarization tests

Figure 3.23: EIS cell with counter, reference and working electrodes

Figure 3.24: Formation of non-stoichiometric titanium oxide layer and Ni-rich intermediate layers on Nitinol

Figure 4.1 a) Surface erosion and b) bulk erosion in polymer matrix 63

Figure 4.2: Schematic of dip coating setup .66 
Figure 5.1: ICPMS results showing the concentration of $\mathrm{Ni}$ ions in the corrosion liquids obtained from different surface treated Nitinol alloys

Figure 5.2: ICPMS results showing the concentration of $\mathrm{Cr}$ ions in the corrosion liquids obtained from different surface treated $\mathrm{NiTi}$ Cr alloys

Figure 5.3: Net growth rate of HUVEC cells after 2 days of exposure to leached ions from potentiodynamic corrosion tests of different surface treated NiTi5Cr (mean \pm $\mathrm{SD}, \mathrm{n}=3)$.

Figure 5.4: Net growth rate of HUVEC cells after 4 days of exposure to leached ions from different surface treated NiTi5Cr during potentiodynamic corrosion tests (mean $\pm \mathrm{SD}, \mathrm{n}=3)$.

Figure 5.5: Net growth rate of HUVEC cells after 7 days of exposure to leached ions from different surface treated NiTi5Cr during potentiodynamic corrosion tests (mean $\pm \mathrm{SD}, \mathrm{n}=3)$.

Figure 5.6: Net growth rate of HUVEC cells after 2 days of exposure to leached ions from different surface treated NiTi10Ta during potentiodynamic corrosion tests (mean $\pm \mathrm{SD}, \mathrm{n}=3$ ).

Figure 5.7: Net growth rate of HUVEC cells after 4 days of exposure to leached ions from different surface treated NiTi10Ta during potentiodynamic corrosion tests (mean $\pm \mathrm{SD}, \mathrm{n}=3)$.

Figure 5.8: Net growth rate of HUVEC cells after 7 days of exposure to leached ions from different surface treated NiTi10Ta during potentiodynamic corrosion tests (mean $\pm \mathrm{SD}, \mathrm{n}=3$ ).

Figure 5.9: SEM photomicrographs of HUVEC cell growth on a) MP NiTi10Ta, b) MPE NiTi10Ta, c) MEP + PC NTi10Ta and d) A comparative analysis on polymercoated and uncoated MEP NiTi10Ta alloy....

Figure 5.10: SEM photomicrographs of HUVEC cell growth on a) MP NiTi5Cr, b) MPE NiTi5Cr, c) MEP + PC NiTi5Cr and d) A comparative analysis on polymercoated and uncoated MEP NiTi5Cr alloy

Figure 5.11: (a) Schematic of a closed-loop system for platelet adhesion studies, (b) Five flow chambers connected in a parallel circuit to the main inlet and outlet paths, (c) The dynamic flow chamber for platelet adhesion studies

Figure 5.12: SEM photomicrograph of platelets adhered on MEP NiTi5Cr (a) $1000 \mathrm{X}$ and (b) $3300 \mathrm{X}$ 
Figure 5.13: Fluorescent microscopic images of porcine platelets adhered on various alloys, a) MP NiTi, b) MP SS, c) MP NiTi5Cr, d) MP NiTi10Ta, e) MEP NiTi5Cr, f) MEP NiTi10Ta, g) MEP + PC NiTi5Cr and h) MEP + PC NiTi10Ta

Figure 5.14: Porcine platelets adhered on the surface of different alloys; NiTi Nitinol, SS - stainless steel, NiTi5Cr and NiTi10Ta - ternary Nitinol alloys, MP mechanically polished, MEP - magneto electropolished; $* p<0.05$ indicates values are significantly different......

Figure 5.15 Correlation between the number of platelets adhered and interfacial free energy.

Figure 6.1: SEM photomicrographs/EDS analysis of MP NiTi5Cr

Figure 6.2: SEM photomicrographs/EDS analysis of MEP NiTi5Cr

Figure 6.3: SEM photomicrograph of a) MEP + PC NiTi5Cr, inset view is b) MEP NiTi5Cr.

Figure 6.4: SEM photomicrographs/EDS analysis of MP NiTi10Ta

Figure 6.5: SEM photomicrographs/EDS analysis of MEP NiTi10Ta

Figure 6.6: SEM photomicrographs of MEP NiTi10Ta a) 2000X BEI image, b) inset view at $6000 \mathrm{X}$ BEI image.

Figure 6.7: Phenom SEM photomicrographs of MEP NiTi10Ta a) at grain, b) at grain Boundary

Figure 6.8: Phenom SEM photomicrographs of MEP NiTi5Cr, a) at grain, b) at grain Boundary

Figure 6.9: Roughness of surface treated and untreated ternary Nitinol alloys.

Figure 6.10: Schematic of the thickness measurement using optical profilometer .98

Figure 6.11: Phenom SEM image of thickness of a polymer coating .98

Figure 6.12: SEM photomicrographs of the surface of PC + MEP NiTi10Ta, a) before corrosion and b) after corrosion.....

Figure 6.13: SEM photomicrographs of the surface of PC + MEP NiTi5Cr a) before corrosion and $b$ ) after corrosion

Figure 6.14: Schematic diagram of XPS analysis 100 
Figure 6.15: Deconvoluted montage plot for titanium Ti 2p spectra from a MEP NiTi10Ta surface; a - Ti metal, b - TiO oxide and c- $\mathrm{TiO}_{2}$.

Figure 6.16: Deconvoluted montage plot for titanium Ti $2 p$ spectra from a MEP NiTi5Cr surface; a - Ti metal, b - TiO oxide and c- $\mathrm{TiO}_{2}$

Figure 6.17: Deconvoluted montage plot for titanium Ni 2p spectra from a MEP NiTi10Ta surface; $a$ - Ni metal and $b-\mathrm{NiO}$ oxide

Figure 6.18: Deconvoluted montage plot for titanium Ni $2 p$ spectra from a MEP NiTi5Cr surface; a - Ni metal and b - NiO oxide

Figure 6.19: Montage plot of tantalum Ta 4f peak obtained for MEP NiTi10Ta surface

Figure 6.20: Montage plot for chromium Cr 2p spectra from MEP NiTi5Cr surface; $\mathrm{a}-\mathrm{Cr}$ metal and $\mathrm{b}-\mathrm{Cr}_{2} \mathrm{O}_{3}$ oxide

Figure 6.21: Depth profile analysis obtained from the surface of MEP NiTi5Cr. 106

Figure 6.22: XRD analysis of MP NiTi, MEP NiTi5Cr and MEP NiTi10Ta

Figure 6.23: Nano-indentation: (a) Peak load vs. displacement and (b) load vs. hardness curves for NiTi Alloys

Figure 6.24: FTIR spectrum of PGA/PCL polymer coated MEP NiTi5Cr and MEP + PC NiTi10Ta

Figure 6.25: A comparison of CA values for different bio-materials

Figure 6.26: Comparison of contact angles for PGA/ PCL co-polymer with that of monomeric polymers

Figure 6.27: A comparison of work of adhesion and platelet adhesion for various alloys

Figure 6.28: Correlation between work of adhesion and platelet adhesion

Figure 6.29: A typical scratch test curve for MEP + PC NiTi5Cr. The measurement signals are identified and color coded as $\mathrm{F}_{\mathrm{N}}$ : Applied normal load (Brown), $\mathrm{P}_{\mathrm{D}}$ : Penetration depth during scratch (Turquoise) $\mathrm{R}_{\mathrm{D}}$ : Residual Depth after scratch (Green), AE: Acoustic Emission (Dark Blue), $\mu$ : Friction coefficient (Red), and $F_{f}$ : Friction force (Purple). 
Figure 7.1: Relative bond strengths for a range of potential interfacial bonding

Figure 7.2: Formation of hydrogen bond at the interface of polymer/substrate due to

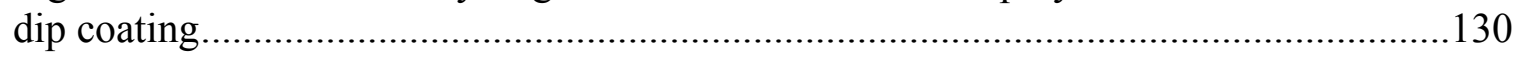

Figure 7.3: Variation of platelet adhesion w. r. to work of adhesion for different

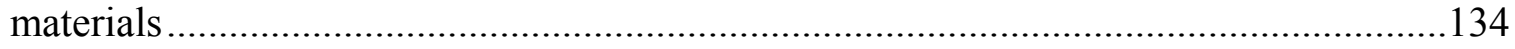

Figure 7.4: A correlation between work of adhesion and platelet adhesion....................135 


\section{LIST OF ACRONYMS}

NiTi

SMA

TTR

ASTM

ISO

FDA

CAD

CVD

PBS

SEM

EDS

ICPMS

XPS

FTIR

XRD

SRB

HUVEC

MP

MEP

PC

DCM

DES
Nitinol

Shape Memory Effect

Transformation Temperature Range

American Standards for Testing of Materials

International Organization for Standardization

Food and Drug Administration

Coronary artery disease

Cardiovascular diseases

Phosphate Buffer Solution

Scanning Electron Microscopy

Energy Dispersive X-ray Spectroscopy

Inductive Coupled Plasma Mass Spectroscopy

X-ray Photoelectron Spectroscopy analysis

Fourier transform infrared spectroscopy

X-ray Diffractometry

Sulforhodamine B

Human umbilical vein endothelial cells

Mechanically polished

Magento-elecropolished

Polymer coated

Dichloromethane

Drug-eluting stents 
PGA

PCL

PLA

PLGA

SD
Polyglycolic acid

Polycaprolactone

Polylactic acid

Polylactic-co-glycolic acid

Standard deviation 


\section{LIST OF NOMENCLATURE}

Symbol

$\mathrm{A}_{\mathrm{s}}$

$\mathrm{M}_{\mathrm{s}}$

$\mathrm{M}_{\mathrm{f}}$

$\mathrm{T}_{\mathrm{m}}$

$\mathrm{T}_{\mathrm{g}}$

$\Delta \mathrm{H}_{\mathrm{f}}$

CA

SFE

$\gamma_{\mathrm{xy}}$

WA

$\mathrm{R}_{\mathrm{a}}$

$\mathrm{L}_{\mathrm{c} 1}$

$\mathrm{F}_{\mathrm{N}}$

$\mathrm{F}_{\mathrm{T}}$

$\mathrm{P}_{\mathrm{D}}$

E

$\mathrm{Ni}$

$\mathrm{Ti}$

$\mathrm{Cr}$
DEFINITION

SI Units

Temperature

Finish of austenitic formation temperature

Start of austenitic transformation temperature

Start of martensitic transformation temperature

Finish of martensitic transformation temperature

Melting temperature

Glass transition temperature

Heat of formation

Contact angle

Surface free energy

Interfacial free energy between $\mathrm{x}$ and $\mathrm{y}$ phases

work of adhesion

Average roughness

critical failure load

normal force

Tangential force

Penetration depth

Polymer adhesion energy values

Nickel

Titanium

Chromium
${ }^{\circ} \mathrm{C}$

${ }^{\circ} \mathrm{C}$

${ }^{\circ} \mathrm{C}$

${ }^{\circ} \mathrm{C}$

${ }^{\circ} \mathrm{C}$

${ }^{\circ} \mathrm{C}$

${ }^{\circ} \mathrm{C}$

$\mathrm{Cal} / \mathrm{g}$

$\Theta$

$\mathrm{mJ} / \mathrm{m} 2$

$\mathrm{mN} / \mathrm{m}$

$\mathrm{mN} / \mathrm{m}$

$\mathrm{nm}$

$\mathrm{mN}$

$\mathrm{mN}$

$\mathrm{mN}$

$\mu \mathrm{m}$

J

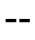

$-$

-- 
$\mathrm{Ta}$

C

$\mathrm{Cl}$

mpy
Tantalum

Carbon

Chlorine

mills per year
$--$

$--$

xxii 


\section{CHAPTER 1}

\section{INTRODUCTION}

\subsection{Biomaterials}

A biomaterial is defined as "any material used to make devices to replace a part or a function of the body in a safe, reliable, economic, and physiologically acceptable manner"[1]. It is also defined as "a material intended to interface with biological systems to evaluate, treat, augment or replace any tissue, organ or function of the body" by D. F. Williams et al. [2].

\subsubsection{History of biomaterials}

The history of biomaterials can be traced back to various civilizations, such as in early 600 A.D., the Mayans used sea shells for nacre teeth, and in around 130- 200 A.D., Greeks used gold sutures for wound healing [3]. The introduction of aseptic surgical procedures by Dr. Joseph Listerin in the 1860 s dramatically reduced the post-operative infections and failure of biomaterials[4]. In 1891, Glück [5] developed an ivory ball and socket joint that was attached to the bone with nickel-plated screws. By the early 1900s, ivory and boiled cadaver bones were successfully used as bone graft materials [6]. In 1930, Alexis Carrel, a French surgeon and noble laureate, in collaboration with aviator Charles Lindbergh, invented a mechanical heart that circulated vital fluids through excised organs [7]. By the 1950s-1960s, blood vessel replacements were in clinical trials [6],[8]. From 1960 onward, development of synthetic biomaterials, such as silicones, polyurethanes, teflon, hydrogels, poly ethylene glycol (PEG), hydroxy apatite, bioglass and titanium led to large-scale production of several medical products for enhancement of 
the quality of human life [9]. Aforementioned biomaterials are used in various medical devices, such as intravascular access devices, replacement for infected or injured body parts, devices for repairing broken bones, internal and external pacemakers, implantable pulse generators (IPGs), implantable cardiac defibrillators (ICDs), ophthalmic implants and components for cosmetic surgeries, etc.[10]. In 1982, Dr. Robert Jarvik successfully implanted the first permanent artificial heart [7]. However, there has been a prevailing and steady increase in health problems associated with cardiovascular diseases (CVD), such as coronary heart disease, stroke, and heart failure (mortality rate 40.6\%) [11] in patients due to their lifestyle (obesity, physical inactivity, improper food habits, etc.) [10, 11]. Subsequently, there is a great need for cardiovascular implants that are more efficient, durable and could effectively overcome the drawbacks of currently used implants in coronary angioplasty.

\subsection{Classification of biomaterials}

Biomaterials can be classified into two groups based on their origin, namely 1) natural and 2) synthetic biomaterials. Collagen, gelatin, cellulose, starch, polysaccharides and fibrin are some of the natural biomaterials used in tissue engineering, drug delivery, wound closures, capsule coatings, dental and orthopedic applications, etc.[3]. Polymers, metals, ceramics and composites were considered as man-made or artificial biomaterials that were used for cardiovascular, ophthalmic, orthopedic, urological, carnio-facial and dental applications. Also, biomaterials can be categorized based on their physical and chemical properties. 
Table 1.1 shows the classification of biomaterials based on the type of material used.

Table 1.1: Biomaterials used in human body $[10,12,13]$

\begin{tabular}{|c|c|c|}
\hline Type of material & Examples & Applications \\
\hline Polymers & $\begin{array}{l}\text { Nylon, silicones, teflon, } \\
\text { polyester fibers, high strength } \\
\text { acrylics, polyurethane, hydro } \\
\text { gels, polycarbonate, } \\
\text { polypropylene, dacron, poly } \\
\text { (methyl methacrylate) }\end{array}$ & $\begin{array}{c}\text { Contact lenses, vascular grafts, } \\
\text { wound dressings, maxillo } \\
\text { facial operations, absorbable } \\
\text { sutures, drug- release systems, } \\
\text { renal dialysis cartridges, } \\
\text { trocars, extra cellular matrices }\end{array}$ \\
\hline Metals & $\begin{array}{c}\text { Titanium, titanium alloys, } \\
\text { cobalt-chromium alloys, } 316 \mathrm{~L} \\
\text { stainless steels, platinum } \\
\text { alloys, silver, magnesium } \\
\text { alloys }\end{array}$ & $\begin{array}{l}\text { Joint replacements, dental } \\
\text { root implants, bone screws, } \\
\text { bone plates, bone grafts, } \\
\text { cardiac stents, electrodes, } \\
\text { anti-bacterial material }\end{array}$ \\
\hline Ceramics & $\begin{array}{c}\text { Alumina, zirconia, } \\
\text { hydroxyapatite, bio-glass }\end{array}$ & $\begin{array}{c}\text { Joint replacements, bone } \\
\text { spacers, tooth implants, bone } \\
\text { bonding applications, bone } \\
\text { cement fillers }\end{array}$ \\
\hline Composites & $\begin{array}{l}\text { Carbon - carbon, calcium } \\
\text { Phosphate cement }\end{array}$ & Joint implants, heart valves \\
\hline
\end{tabular}

Based on the potential risk for illness or injuries presented by a malfunction or failure of an implant, the Food and Drug Administration (FDA) has classified them into three categories $[14-16][17,18]$. Class I devices do not come in direct contact with body fluids, present the lowest safety risk and are subjected to general controls. Class II devices intermittently come in contact with tissues. They have to go through general and special controls involving labeling requirements, mandatory performance standards (require a $510(\mathrm{k})$, or premarket notification) and adequate surveillance. Class III devices 
(implants) always stay in contact with tissues and body fluids. Additionally, they fulfill the screening standards for Class I and II, and undergo scientific reviews and clinical trials. Depending on the interaction of the biomedical implant with the human body (physiological environment), Class III devices are again classified into three groups [15, 19], as shown in Figure 1.1. Bio-inert materials (alumina, titanium and partially stabilized zirconia) are those that have minimal tissue interactions, which do not lead to immunological host reactions and retain their structure after implantation. Bio-active materials (synthetic hydroxyapatite $\left(\mathrm{Ca}_{10}\left(\mathrm{PO}_{4}\right)_{2}(\mathrm{OH})_{2}\right)$, Nitinol, bio-glass) in general mimic and interact with their surrounding physiological environment and generate required host response. Bio-degradable materials (magnesium alloys, tri-calcium phosphate implant $\left(\mathrm{Ca}_{3}\left(\mathrm{PO}_{4}\right)_{2}\right)$, biodegradable polymers, etc. $)$, after serving the purpose of their implantation, will eventually degrade into biosorbable degradation products and will be slowly replaced by the regenerating tissues[19] [20,21].

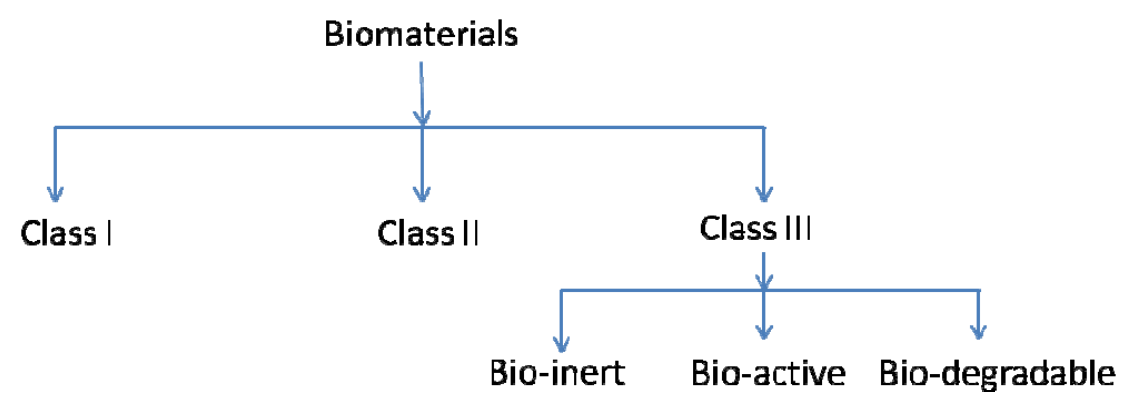

Figure 1.1: Classification of biomaterials according to FDA [15].

As shown in Figure 1.2, the medical device industry is currently using the aforementioned biomaterials to manufacture different implants for numerous medical applications. 


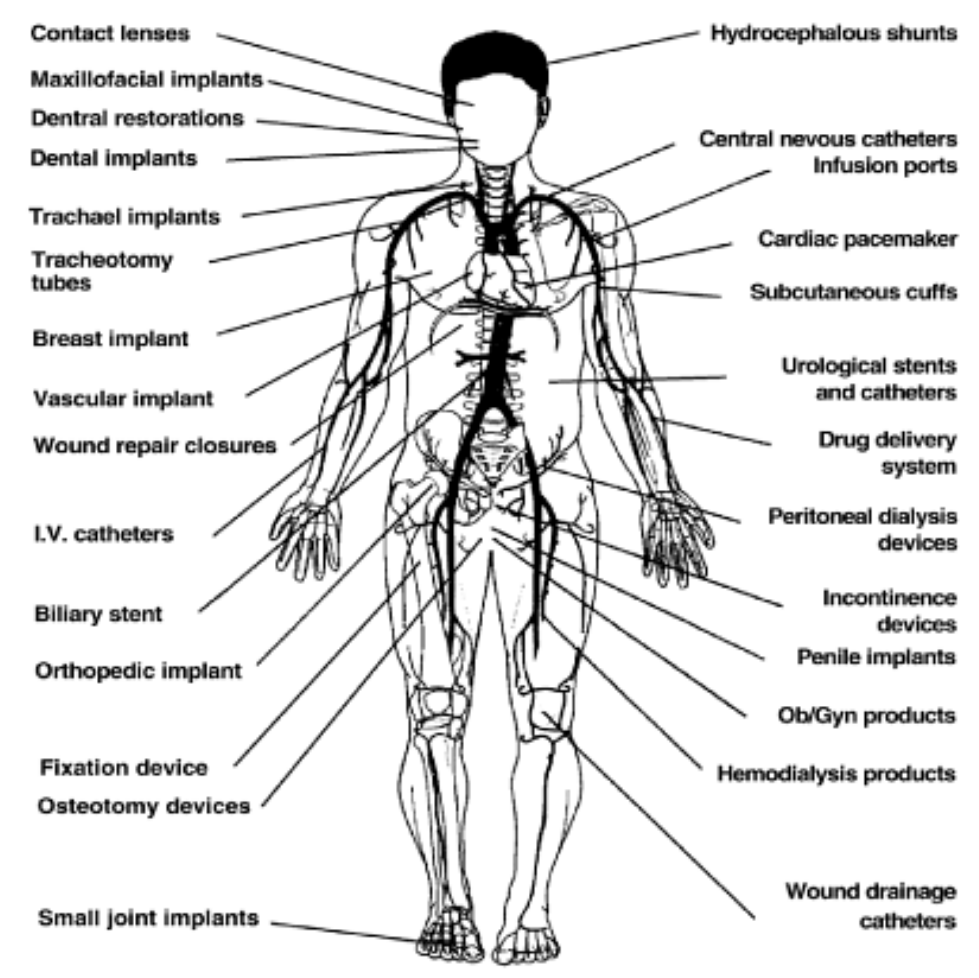

Figure 1.2: Different implants and devices used to replace or enhance the functions of diseased or missing tissues and organs [10]

\subsection{Biocompatibility}

From the 1940 s to the $1980 \mathrm{~s}$, the concept of biocompatibility for the firstgeneration implantable medical devices was assumed as the long lasting durability of implant materials in the human body [22]. However, in 1987, this concept was redefined as "the ability of a material to perform with an appropriate host response in a specific situation [23].

This can be understood more clearly by looking at three categories. The first one considers the ability of the material to interact and perform with the host body rather than to remain inert. The second focuses on the implant's responsibility to generate an 
appropriate response from the host for the required application. The third category addresses the nature of the response to a material, which may vary from one situation to another [24]. The two main factors which influence the first category of biocompatibility are: 1) the degradation of the material once implanted; and 2) the reaction of the host in response to the implanted material. These two factors were the focus of this investigation.

\section{$1.4 \quad$ Nitinol}

Nitinol was first invented in 1958 by a metallurgist named William J Buehler. The term "Nitinol" was derived by taking the first two letters of the constituent elements nickel and titanium, followed by the first letters of the name of the laboratory in which it was discovered - the Naval Ordinance Laboratory. The shape memory effect of Nitinol was serendipitously found in 1961, when the alloy came in contact with a lit cigarette. This invention has resulted in a vast number of industrial applications. Generally, Nitinol exhibits shape memory effect as well as super elastic properties at a composition corresponding to approximately $55 \mathrm{wt} \% \mathrm{Ni}$ and $45 \mathrm{wt} \% \mathrm{Ti}(49.5$ to $53 \mathrm{at} \% \mathrm{Ni})$. The phenomenon of shape memory effect and super elasticity of Nitinol were explained through crystallography by Dr. Frederick E. Wang [25].

\subsubsection{Shape memory effect}

Shape memory effect can be described as a thermal effect in which solid to solid phase transformation occurs due to a temperature change, or in other words, the material regains its predetermined shape once it is heated above its transformation temperature (thermal shape memory effect). In the case of Nitinol, it consists of two phases: 
Austenite, which is a stable parent phase that exists above the transformation temperature range (TTR) and Martensite, a less stable phase, which exists below the TTR [25]. When Nitinol in its austenitic phase is cooled, it transforms to martensite, which when deformed and heated above its TTR, regains its original shape. The shape memory effect of Nitinol is schematically illustrated in Figure 1.2, where austenite is cooled to twinned martensite, which can be deformed. After heating, Nitinol is converted into austenite and returns to its original shape. As was previously mentioned, this transformation temperature range depends mainly on the atomic composition of $\mathrm{Ni}$ and $\mathrm{Ti}$ in Nitinol. Subsequently, the TTR can vary from $100{ }^{\circ} \mathrm{C}$ to very low temperatures [26]. The application of Nitinol in diverse fields, such as the manufacturing of medical devices, electrical components and military applications, was feasible due to the production of Nitinol with varied TTRs.

\subsubsection{Pseudo elasticity}

Austenitic Nitinol behaves like a plastic material. When a force is applied just above the TTR, the material yields to the applied stress by changing its crystal structure to a martensitic phase (stress-induced martensitic transformation) [27]. However, removal of stress converts the martensitic phase back to austenite, thus regaining its original shape (non-linear super elasticity) [28]. This occurs due to the reversible motion

of domain boundaries during the phase transformation, rather than just bond stretching or the introduction of defects in the crystal lattice [29]. In this temperature range, even with multiple loading and unloading cycles, Nitinol does not exhibit any plastic deformation due to its elastic properties [30]. Unlike the shape memory effect, here the transformation 
from austenite to martensite occurs because of the application and removal of stress, once above the austenitic formation temperature $\left(\mathrm{A}_{\mathrm{f}}\right)$.

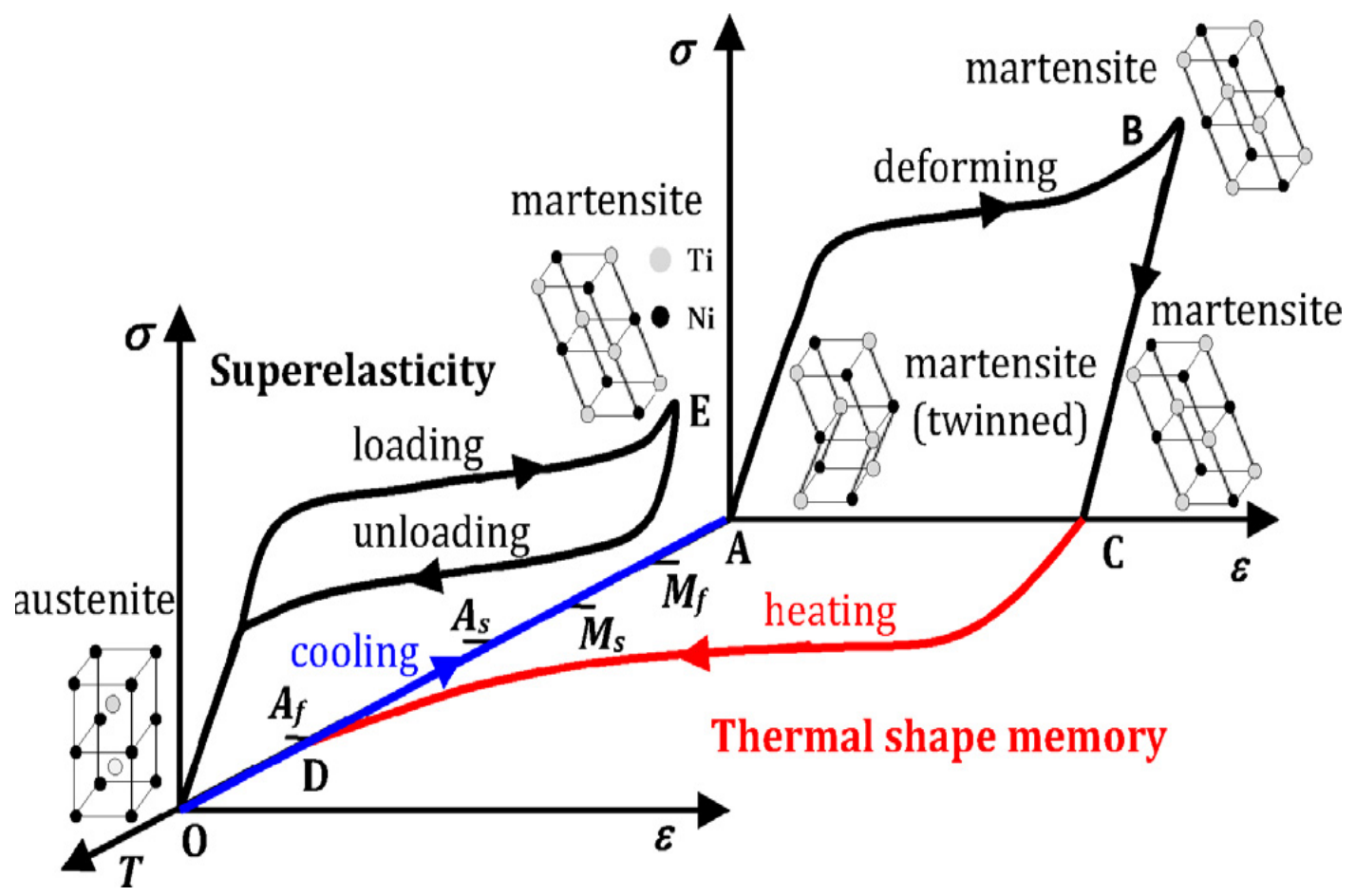

Figure 1.3: Stress-strain-temperature diagram of Nitinol

Figure 1.3 illustrates a combined diagram of thermal shape memory effect and super elastic properties of Nitinol, where $A_{s}-$ Start of austenitic transformation temperature, $A_{f}-$ finish of austenitic transformation temperature, $M_{s}-$ Start of martensitic transformation temperature, $\mathrm{M}_{\mathrm{f}}$ - finish of martensitic transformation temperature. The stress-strain curve (loading and unloading curve), which starts from "O" austenitic phase and reaches "A" martensitic phase by application of stress and returns to its original austenitic phase (point O) by removal of stress, depicts the pseudoelastic behavior of Nitinol. The thermal shape memory effect of Nitinol is explained by 
three different sections: the curve "OA" shows the transformation of austenitic phase to twinned martensitic phase by lowering the temperature below TTR; the curve "AB" show the transformation of twinned martensite to martensite by application of stress; the curve "BC" shows the plastic deformation that has occurred by the application of stress; the curve from "C" to "O" depicts the conversion of deformed martensitic phase to original austenitic phase, by the application of temperature.

\subsubsection{Biocompatibility of Nitinol}

Metallic biomaterials are known for their widespread usage in the fields of dental, cardiovascular, maxillofacial and orthopedic implants [31]. Bio and hemocompatibility of an implant, which are dependent on its corrosion resistance, surface and mechanical properties, will in turn decide its longevity. Initially, usage of copper, silver, nickel, aluminum and magnesium alloys for long-term implantation was restricted due to their high reactivity and toxic nature [32]. Later on, steel, chromium, and titanium alloys which were known to spontaneously form a stable passive oxide layer on their surface, with improved biocompatibility, were used to manufacture the long-term metallic implants [33]. However, after implantation, these alloys were subjected to highly corrosive and a complex physiological environment, which consists of water, dissolved oxygen, proteins, minerals, chloride and hydrogen ions, etc., that can eventually lead to corrosion degradation. This results in limited longevity of the implants [34, 35] and repetitive implant replacement surgeries.

Nitinol (an equiatomic alloy of nickel and titanium) that belongs to the class of titanium alloys has been successfully employed in manufacturing several medical 
devices, such as peripheral vascular products (self-expanding stents, graft support systems, guide wires) [36], endovascular aneurysm repair devices (filters and baskets), inferior vena cava filters and embolic protection devices. Its wide applications in the field of medical implants were due to its super elastic, shape memory and excellent biocompatibility properties. Nitinol, under normal atmospheric conditions, forms a protective passive surface oxide layer that mainly consists of $\mathrm{TiO}_{2}$ oxide (free energy of formation, $\Delta \mathrm{G}$ at $298 \mathrm{~K}$ of $\mathrm{TiO}_{2}, \mathrm{NiO}$ and $\mathrm{TiO}$ are $-212.6,-50.6$ and $118.3 \mathrm{Kcal} \mathrm{mol}^{-1}$ ) [37]. This is known to render good corrosion resistance to this alloy. However, due to the harsh physiological environment present inside the human body, Nitinol implants are known to undergo pitting and crevice corrosion [38]. The other factors that influence the corrosion properties of Nitinol are discussed in detail in Chapter 3. Additionally, after implantation there are concerns regarding the toxic and allergenic effects of Ni released by corrosion of Nitinol (which consists of high amount of $\mathrm{Ni} \sim 50$ at\% in its microstructure) [39-42]. Alloying, surface preparation [29] and manufacturing methods are some of the ways through which the corrosion properties of Nitinol can be modified.

\subsubsection{Applications of Nitinol}

Nitinol in various shapes (wires, rods, porous scaffold, plates, screws and meshes) and sizes is used for a range of implantable medical devices. Excellent biocompatibility, unique shape memory affect and super elasticity properties exhibited by Nitinol, resulted in a boom of its applications in medical industries. Listings of typical applications are as follows $[26,43-50]$ :

- Cardiovascular stents 
- Orthodontic tooth alignment wires

- Inferior vena cava filter

- guide wires for catheters

- Needle wire localizers

- Intervertebral body fusion device (artificial disc)

- Vertebral Body staples

- Lumbar inter body fusion devices

- Anterior cervical inter body fusion devices

- Intramedullary nails

- Porous dental implants

- Surface coating for hip and knee prostheses

- Maxillo-facial and cranial repairs

- Bone graft substitutes

- Hybrid vascular grafts

- Soft tissue repair and replacement

- Effective material in plastic surgery and osseous oncology

- Manufacture of cryosurgery tools

- Manufacture of minimally invasive implant surgical devices 


\section{CHAPTER 2}

\section{STENTS}

\subsection{Cardiovascular diseases (CVD)}

According to American Heart Association (AHA) statistics, each day more than 2,150 Americans die due to CVD, which is an average of 1 death every 40 seconds [51]. Additionally, in America, 34\% of deaths before the average life expectancy of 78.5 years were related to CVD. In 2009, one out of every six deaths in the United States was caused by coronary heart diseases [51]. Each year, an estimate of $\approx 635,000$ Americans have a new coronary attack (defined as first hospitalized myocardial infarction or coronary heart disease death) and $\approx 280,000$ have a recurrent attack. It is estimated that an additional 150,000 silent first myocardial infarctions occur each year. [51]. In 2009, the Center for Disease Control and Prevention (CDCP) estimated that around 785,000 Americans had experienced a coronary attack, and about 470,000 will have a recurrent attack [52].

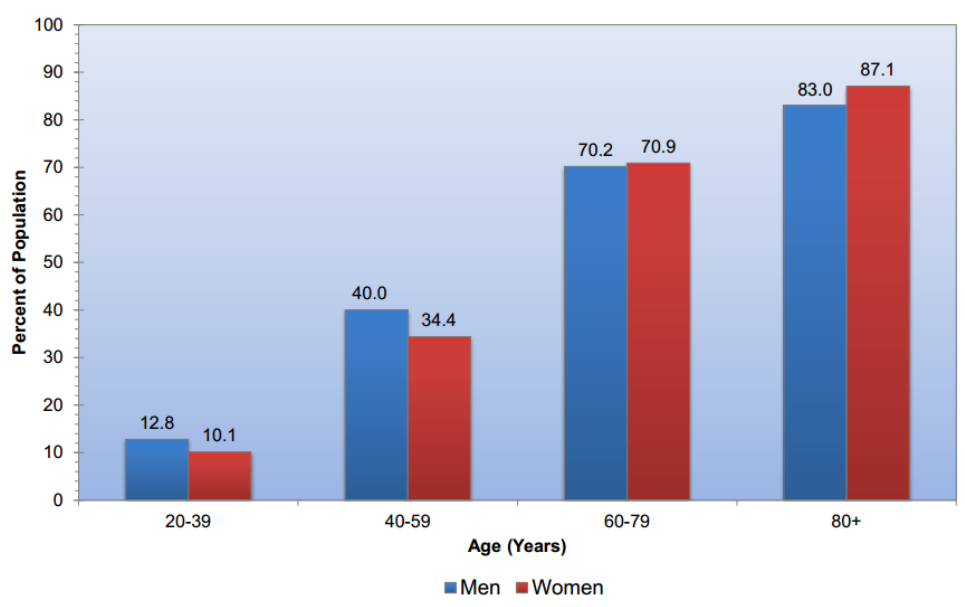

Figure 2.1: Prevalence of CVD in adults $\geq 20$ years of age [53] 


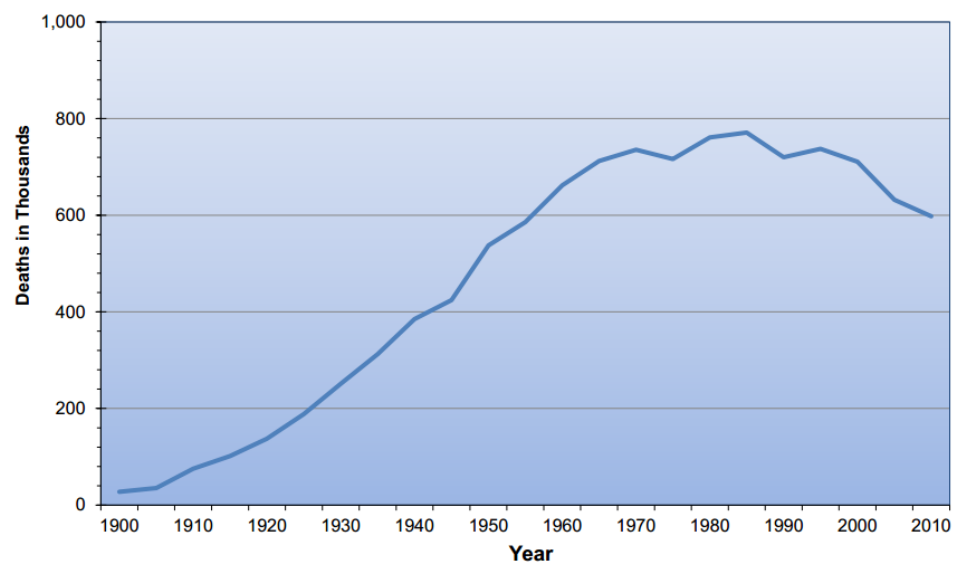

Figure 2.2: Deaths due to heart diseases in the United States [53]

According to the National Health Interview Survey (NHIS), in 2011, about 15.3 million cases of coronary diseases were observed [54] due to atherosclerosis (buildup of fat, cholesterol, etc., that lead to formation of plaque and hardening of the arteries). It is projected that by 2015, there will be 133 million Americans over 45, the age at which the incidence of heart disease is documented and at least $40 \%$ of those will have some form of CVD by 2030 [55]. Also, due to the present lifestyle, there is an increased risk of coronary artery disease that will result in a growth rate of percutaneous coronary intervention (PCI) procedures of roughly 3\%-5\% overall [56]. Thus, the largest growth factor for the medical device market in developed countries is found in the aged population.

\subsection{Bare metallic stents}

Bare metallic stents (BMS) were first launched into the medical field in order to avoid restenosis, which leads to blockage of arteries after angioplasty [57]. BMS act as a mechanical scaffold for blood vessels and helps to prevent the artery from re-narrowing and the need for a repeat procedure. The medical term for this narrowing is stenosis and 
when it reappears, it is called "re-stenosis" or simply, restenosis. However, about $25 \%$ of the time, the arteries may become blocked again after placement of a BMS.

Metallic stents have been manufactured from a variety of alloys, such as stainless steel, Nitinol, CP Ti, Ti-6Al-4V alloy and cobalt-nickel that are compatible with the human body [58]. Micro patterned surfaces have been introduced in an effort to influence cell adhesion and proliferation [59]. However, even with this improvement, in some patients based on their health conditions, the problem of in-stent restenosis reappeared. Many techniques, such as heat treatments (annealing, cold drawing and oxidation), surface treatments (passivation, electropolishing and anodization) [60] and application of protective coatings were adopted to improve the bio-compatibility properties of BMS [61]. Table 2.1 lists various metals [58],[62] that have been used for manufacturing stents.

Table 2.1: Various metals that can be used to manufacture implants [63-67]

\begin{tabular}{|c|c|c|c|}
\hline Type of material & $\begin{array}{c}\text { Modulus of } \\
\text { elasticity (GPa) }\end{array}$ & $\begin{array}{c}\text { Tensile } \\
\text { strength (MPa) }\end{array}$ & $\begin{array}{c}\text { Corrosion resistance } \\
(\mathbf{m m} / \text { Year) }\end{array}$ \\
\hline $\begin{array}{c}\text { Stainless steel - 316 L } \\
\text { (annealed ASTM 138) }\end{array}$ & 200 & 490 & $29 \times 10^{-3}$ \\
\hline Co-Cr alloy & 210 & $860-790$ & - \\
\hline Ti-6Al-4V alloy (Gr. 23) & 105 & 950 & $35 \times 10^{-3}$ \\
\hline WE43 magnesium alloy & 44 & 220 & 9.0 \\
\hline Nitinol & $75-83$ & $195-690$ & $0.10-2.26$ \\
\hline Nitinol alloys & $96-99$ & $630-680$ & $0.02-0.11$ \\
\hline Arterial wall & 0.001 & $0.50-1.72$ & - \\
\hline Cortical bone & $5-23$ & $35-283$ & - \\
\hline
\end{tabular}




\subsection{Evolution of drug eluting stents}

The main reason behind the usage of drug eluting stents (DES) as compared to BMS is to avoid renarrowing of coronary arteries that is caused by "in-stent restenosis". In-stent restenosis occurs usually 3 to 6 months [68] after the implantation of BMS, which results in the growth of a scar tissue at the place of contact between the stent material and inner surface of the blood vessel, which eventually leads to re-blockage of the artery [68]. In an effort to mitigate in-stent restenosis, BMS were covered with a thin polymer coating programmed to release anti-proliferative drugs over an extended period. This technique obviated the development of scar tissues or in-stent restenosis and led to the evolution of DES [69]. Depending on the nature of the drug and the carrier polymer used, such as the drug's water solubility and oil/water partition coefficient [70], the drug elution rate will change. In smaller coronary arteries (diameter $<3.0 \mathrm{~mm}$ ), DES are more effective than BMS in overcoming restenosis and neointimal hyperplasia (natural vessel response to injury healing) as compared with larger coronary arteries (diameter $>3.0 \mathrm{~mm}$ ) [71],[72],[73]. In the treatment of multi-vessel coronary disease, the mean total number of stents implanted in a patient is $2.68 \pm 0.95$ (2.25 \pm 1.25 DES and $0.43 \pm 0.72$ BMS) [56]. The mean total length of the stents was $62.78 \pm 29.13 \mathrm{~mm}$, and the mean stent diameter was $3.05 \pm 0.46 \mathrm{~mm}$ [56]. Over six million DES have been implanted and it is only after very widespread use that the rare complications emerge (worldwide complications $0-3 \%$ ); most researchers are currently saying that the chance of late stent thrombosis is around $0.6 \%$ - less than 1 in 100 . However, there has been a decline in DES sales due in part to thrombosis (development of a blood clot) $[74,75]$. Thrombosis occurs in about two out of 
1000 stable patients per year equipped with DES. Clinical trials conducted with more than 8,000 patients over three years revealed that thrombosis occurred in $2.9 \%$ of patients, but only in $1.2 \%$ after 30 days (similar to BMS) [76]. In order to avoid longterm thrombosis after DES implantation, patients are advised to use anticoagulants, such as aspirin $(75 \mathrm{mg} /$ day) and clopidogrel $(100 \mathrm{mg} /$ day $)$, for $6-12$ months following the percutaneous coronary intervention (PCI) [77]. DES available in the U.S market are mainly composed of durable polymer coatings for drug delivery. The presence of the non-degradable polymer coating on DES after drug delivery is known to create complications, such as delayed arterial healing due to lack of endothelial coverage [78], thrombus formation [79], chronic arterial wall inflammation [80], aneurism formation [81], polymer disruption during stent delivery (bridging, peeling, blistering, cracking, etc.), late stent thrombosis (LST) and late-acquired stent mal-apposition [82-88]. Usage of anti-proliferative drugs, such as sirolimus, zotarolimus and paclitaxel, in DES not only reduces in-stent restenosis but also inhibits proper endothelialization near the stented arterial wall [89]. Delayed arterial healing due to the persistent fibrin deposition and poor re-endothelialization on DES, even after 30 days of implantation, might act as trigger sites for LST formation [84]. Discontinuation of antiplatelet therapy after DES implantation might lead to late restenosis and late stent thrombosis. Finally, DES are much more expensive than BMS [77].

As such, a new generation of DES equipped with biodegradable polymer coating has been developed and is currently under clinical studies [90]. Biodegradable polymer coatings on DES provide an initial platform to carry and regulate the release of the 
embedded drug and then eventually degrade into harmless bi-products that can be processed by the human body. Also, they are expected to overcome some of the aforementioned drawbacks that were observed in DES equipped with durable polymer coatings. In-vivo studies conducted by Joner M. et al. [91], demonstrated an improved reendothelialization in rabbits iliofemoral artery by the usage of DES. However, an excess of late loss (reduction in vessel diameter after stent implantation) [90], lack of reduction in stent thrombosis $[92,93]$, and a high inflammatory reaction due to major particle debris (coating degradation), were some of the limitations of DES with biodegradable polymers. Consequently, the complex process of designing and developing a DES with biodegradable polymer coating remains a challenge.

As a result, the Food and Drug Administration (FDA), the AHA and others are calling for a new generation of stents and new designs that are more adaptable to the arteries. The future of biomaterials, therefore, depends on a better understanding of mechanisms, by which they can be rendered stable and inert but yet retain flexibility, machinability, good biocompatibility and hemocompatibility.

\section{$2.4 \quad$ Hypothesis}

The hypothesis of this research is that the application of a novel biosorbable polymer coating on MEP ternary Nitinol alloys will improve their biocompatibility with reduced thrombogenicity. 


\subsection{Research objective}

The objective of this research is to focus on the biocompatibility, hemocompatibility and corrosion resistance of polymer coated ternary MEP Nitinol alloys.

The surface characteristics of ternary Nitinol alloys were expected to improve by employing magnetoelectropolishing (MEP) treatment and biodegradable polymer coatings to enhance their bio and hemo-compatibility properties. These treatments affect the below-mentioned properties:

1. Corrosion resistance

2. Surface chemistry, speciation and depth profile

3. Hemocompatibility

4. Polymer coating stability

5. Wettability, surface free energy and work of adhesion

6. Toxicity of leached ions

Different analytical techniques, such as In Vitro corrosion tests, ICPMS analysis, SEM, SEM/EDS, XPS analysis, FTIR, nano-scratch tests and contact angle, were employed to evaluate the aforementioned phenomenon.

The cytotoxic effect of the $\mathrm{Ni}$ ions released during the corrosion of polymer coated alloys on HUVEC cells was studied by performing Sulforhodamine B (SRB) 
assays. Additionally, hemocompatibility of the samples was studied by platelet adhesion tests, which was conducted in a laminar flow chamber.

The purpose of this research is to:

1. Develop a biodegradable polymer coated ternary Nitinol alloy.

2. Determine in-vitro corrosion rates and polymer coating stability via potentiodynamic polarization and electrochemical impedance spectroscopy (EIS), respectively.

3. Characterize the polymer coated alloys and determine the polymer/substrate adhesion.

4. Assess biocompatibility and hemo-compatibility via endothelialization and invitro platelet adhesion studies on polymer coated and uncoated Nitinol surfaces.

A schematic of the proposed research plan is shown in Figure 2.3. 


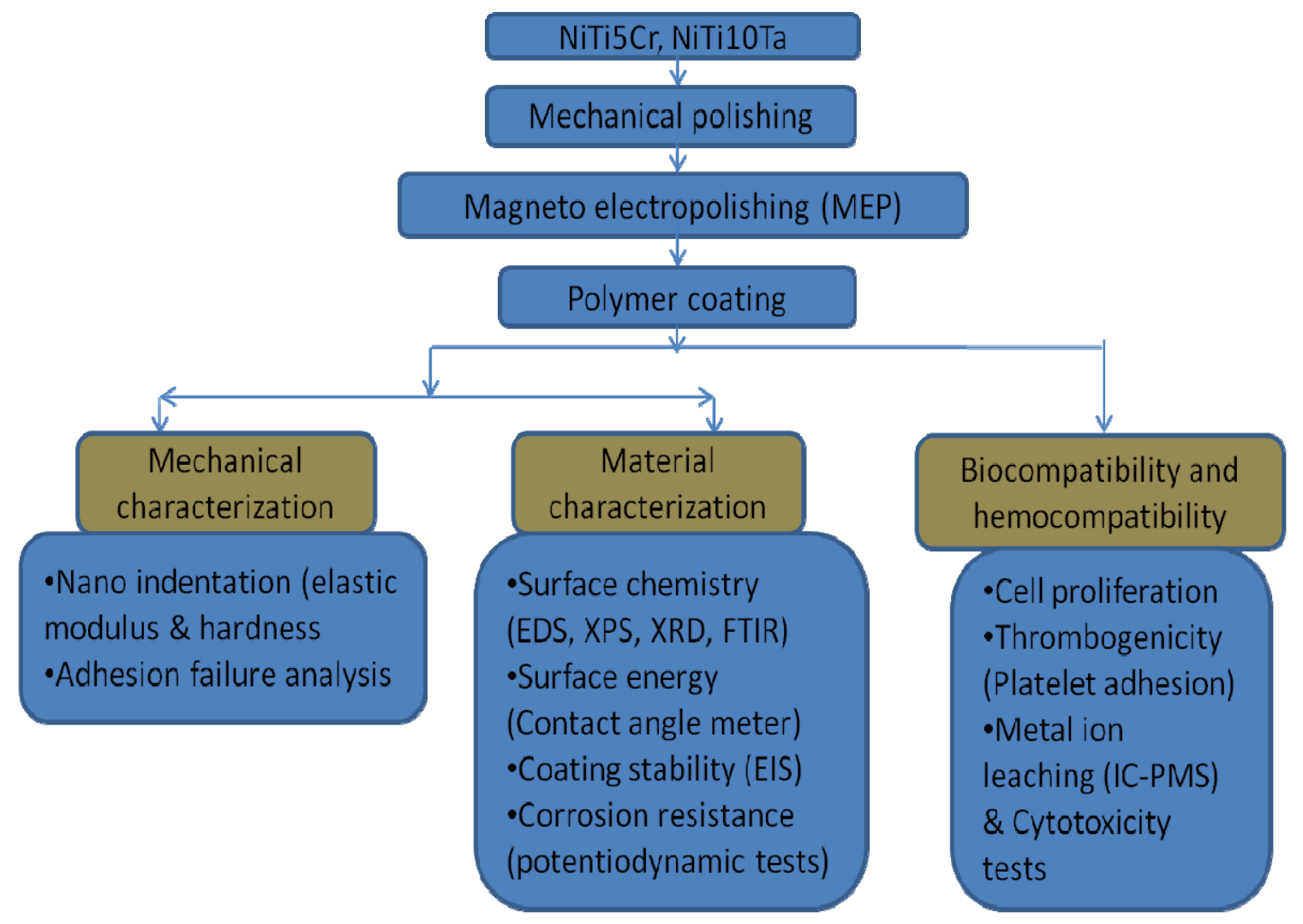

Figure 2.3: Schematic of the proposed research plan.

\subsection{Potential polymers that can be used as coatings for stents}

Various biodegradable polymers that are used in medical device industry and their properties are shown in Table 2.2.

Table 2.2: Hydrolytically degradable polymers [94],[95].

\begin{tabular}{|c|c|c|c|c|c|}
\hline \multicolumn{2}{|l|}{ Name } & $\begin{array}{l}\text { Monomer } \\
\text { structure }\end{array}$ & Properties & Applications & $\begin{array}{l}\text { Degradati } \\
\text { on }\end{array}$ \\
\hline $\begin{array}{l}\text { Poly }(\alpha \\
\text { esters) }\end{array}$ & $\begin{array}{l}\text { Polyglycol } \\
\text { ide (PGA) }\end{array}$ & Clycolide & $\begin{array}{l}\mathrm{T}_{\mathrm{g}}=35 \text { to } \\
40^{\circ} \mathrm{C}, \mathrm{T}_{\mathrm{m}}> \\
3000^{\circ} \mathrm{C}, 45 \\
\text { to } 55 \% \\
\text { crystallinity, } \\
\text { biodegradab } \\
\text { le synthetic }\end{array}$ & $\begin{array}{l}\text { Resorbable } \\
\text { sutures }\left(\text { Dexon }^{\circledR}\right) \text {, } \\
\text { bone internal } \\
\text { fixation devices } \\
\left(\text { Biofix }^{\circledR}\right)\end{array}$ & $\begin{array}{l}\text { Strength is } \\
\text { lost in } 1 \text { to } \\
2 \text { months } \\
\text { by } \\
\text { hydrolysis } \\
\text { and mass } \\
\text { is lost }\end{array}$ \\
\hline
\end{tabular}




\begin{tabular}{|c|c|c|c|c|}
\hline & & $\begin{array}{l}\text { polymer, } \\
\text { elastic } \\
\text { modulus } ~ \\
12.5 \mathrm{GPa}\end{array}$ & & $\begin{array}{ll}\text { within } \quad 6 \\
\text { to12 } \\
\text { months }\end{array}$ \\
\hline $\begin{array}{l}\text { Polylactid } \\
\text { es (PLA) }\end{array}$ & Lactide & $\begin{array}{l}\mathrm{T}_{\mathrm{g}}=60 \text { to } \\
65^{\circ} \mathrm{C}, \mathrm{Tm}> \\
175^{\circ} \mathrm{C}, \sim \\
37 \% \\
\text { crystallinity, } \\
\text { elastic } \\
\text { modulus } \sim \\
4.8 \quad \mathrm{GPa}, \\
\text { semi- } \\
\text { crystalline } \\
\text { polymers }\end{array}$ & $\begin{array}{l}\text { Orthopaedic } \\
\text { fixation devices } \\
\text { (BioScrew }^{\circledR} \text {, Bio- } \\
\text { Anchor }{ }^{\circledR}, \\
\text { Meniscal } \\
\text { Stinger }^{\circledR}- \\
\text { Linvatec), and }_{\text {ligament }} \\
\text { replacement } \\
\text { devices }\end{array}$ & $\begin{array}{l}\text { Strength is } \\
\text { lost in } 6 \\
\text { months by } \\
\text { hydrolysis } \\
\text { and toal } \\
\text { mass } \\
\text { resorption } \\
\text { in } 2 \text { to } 5.6 \\
\text { years }\end{array}$ \\
\hline $\begin{array}{l}\text { Polydioxa } \\
\text { none } \\
\text { (PDS) }\end{array}$ & p-dioxanone & $\begin{array}{l}\mathrm{T}_{\mathrm{g}}=-10 \text { to } \\
0^{\circ} \mathrm{C}, \mathrm{Tm}= \\
110-115^{0} \mathrm{C}, \\
\text { elastic } \\
\text { modulus } ~ \\
1.5 \text { GPa, } \\
\text { crystallinity } \\
37 \% \text { and } \\
\text { hydrophobic } \\
\text { ity }\end{array}$ & $\begin{array}{l}\text { monofilament } \\
\left.\text { suture (Dixon }{ }^{\circledR}\right) \text {, } \\
\text { suture clip, bone } \\
\text { pin } \\
\left(\text { OrthoSorb }{ }^{\circledR}\right), \text { Fix } \\
\text { ation screws }\end{array}$ & $\begin{array}{l}\text { Strength is } \\
\text { lost in } 1 \text { to } \\
2 \text { months } \\
\text { by } \\
\text { hydrolysis } \\
\text { and Mass is } \\
\text { lost within } \\
6 \text { to } 12 \\
\text { months }\end{array}$ \\
\hline $\begin{array}{l}\text { Polycaprol } \\
\text { actone } \\
\text { (PCL) }\end{array}$ & Caprolactone & $\begin{array}{l}\mathrm{Tg}=-60 \mathrm{o} \mathrm{C}, \\
\mathrm{Tm}=55 \text { to } \\
60 \mathrm{o} \mathrm{C}, \text { non- } \\
\text { toxic, low } \\
\text { tensile } \\
\text { strength } ~ \\
23 \mathrm{MPa} \text {, high } \\
\text { elongation } \\
\text { at breakage } \\
>700 \%, \\
\text { high } \\
\text { permeability } \\
\text { to many } \\
\text { drugs }\end{array}$ & $\begin{array}{l}\text { Long-term } \\
\text { contraceptive } \\
\text { device } \\
\left(\text { Capronor }^{\circledR}\right) \text {, } \\
\text { monofilament } \\
\text { suture } \\
\left(\text { Monacryl }{ }^{\circledR}\right) \text {, } \\
\text { biologically } \\
\text { active molecules } \\
\left(\text { SynBiosys }{ }^{\circledR}\right)\end{array}$ & $\begin{array}{l}\text { Slow } \\
\text { hydrolytic } \\
\text { degradation } \\
\text {, Mass } \\
\text { resorption } \\
\text { in } 2 \text { to } 3 \\
\text { years }\end{array}$ \\
\hline
\end{tabular}




\begin{tabular}{|c|c|c|c|c|c|}
\hline & $\begin{array}{l}\text { Poly(trime } \\
\text { thylene } \\
\text { carbonate) }\end{array}$ & Trimethyl carbonate & $\begin{array}{l}\text { excellent } \\
\text { flexibility, } \\
\text { poor } \\
\text { mechanical } \\
\text { strength }\end{array}$ & $\begin{array}{l}\text { Flexible suture } \\
\text { materials } \\
\left(\text { Maxon }^{\circledR}\right), \\
\text { orthopaedic tacks } \text { and screws } \\
\left(\text { Acufex }{ }^{\circledR}\right) \text {, } \\
\text { Suture(BioSyn }{ }^{\circledR} \text { ) }\end{array}$ & $\begin{array}{l}\text { Mass } \\
\text { resorption } \\
\text { in } 3 \text { to } 4 \\
\text { months }\end{array}$ \\
\hline & $\begin{array}{l}\text { Bacterial } \\
\text { polyesters: } \\
\text { poly(3- } \\
\text { hydroxybu } \\
\text { tyrate) }\end{array}$ & & $\begin{array}{l}\text {-High } \\
\text { crystallinity, }\end{array}$ & & \\
\hline $\begin{array}{l}\text { Polyur } \\
\text { ethane }\end{array}$ & $\begin{array}{l}\text { Polyuretha } \\
\text { ne }\end{array}$ & & $\begin{array}{l}\text { Excellent } \\
\text { biocompatib } \\
\text { ility, } \\
\text { mechanical } \\
\text { properties, } \\
\text { favourable } \\
\text { cell } \\
\text { adhesion } \\
\text { and } \\
\text { proliferation }\end{array}$ & $\begin{array}{l}\text { Cardiac } \\
\text { pacemakers, } \\
\text { vascular } \\
\text { grafts,porous } \\
\text { scaffold } \\
\left(\text { Degrapol }^{\circledR}\right) \text {, } \\
\text { injectable } \\
\text { hydrogels } \\
\text { systems } \\
\left(\text { PolyNova }{ }^{\circledR}\right) \text {, } \\
\text { bone cements }\end{array}$ & $\begin{array}{l}\text { Degradatio } \\
\mathrm{n} \text { occurs by } \\
\text { hydrolysis } \\
\text { of urethane } \\
\text { and } \\
\text { aliphatic } \\
\text { bonds }\end{array}$ \\
\hline $\begin{array}{l}\text { Poly(e } \\
\text { ster } \\
\text { amide) } \\
{[96]}\end{array}$ & $\begin{array}{l}\text { Polydepsi } \\
\text { peptide }\end{array}$ & & $\begin{array}{l}\text { good } \\
\text { mechanical } \\
\text { and thermal } \\
\text { properties }\end{array}$ & $\begin{array}{l}\text { Site specific drug } \\
\text { and peptide } \\
\text { delivery system }^{\left(C^{\circledR}\right)} \\
\left(\text { Cameo }^{\circ}\right.\end{array}$ & \\
\hline $\begin{array}{l}\text { Poly(o } \\
\text { rtho } \\
\text { esters) }\end{array}$ & $\begin{array}{l}\text { Poly(ortho } \\
\text { ester) IV }\end{array}$ & 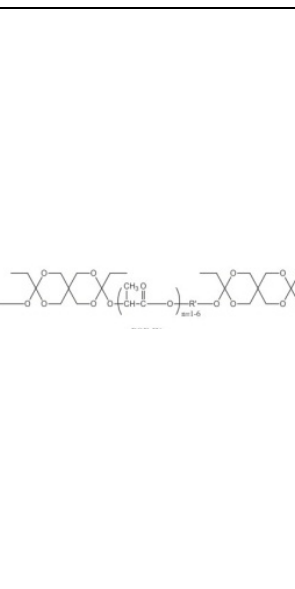 & $\mathrm{pH}$ sensitive & $\begin{array}{l}\left(\text { Alzamer }^{\circledR}\right) \text { as a } \\
\text { hydrophobic, } \\
\text { surface eroding } \\
\text { polymer for drug } \\
\text { delivery } \\
\text { applications }\end{array}$ & $\begin{array}{l}\text { Usually } \\
\text { very slow } \\
\text { degradation } \\
\text { rate but can } \\
\text { be } \\
\text { controlled } \\
\text { using diols } \\
\text { with } \\
\text { varying } \\
\text { levels of } \\
\text { chain } \\
\text { flexibility }\end{array}$ \\
\hline
\end{tabular}




\begin{tabular}{|l|l|l|l|l|l|}
\hline $\begin{array}{l}\text { Poly } \\
\text { anhydr } \\
\text { ides }\end{array}$ & $\begin{array}{l}\text { Poly } \\
\text { anhydride }\end{array}$ & Sydrolytic & & $\begin{array}{l}\text { Hylk } \\
\text { bulk } \\
\text { degradation } \\
\text { occurs over } \\
\text { days to } \\
\text { months by } \\
\text { varying the } \\
\text { type and } \\
\text { ratio of the } \\
\text { monomers }\end{array}$ \\
\hline
\end{tabular}

\subsection{Market}

Due to a $3-5 \%$ increase in percutaneous coronary intervention (PCI), the worldwide market for coronary stents increased to $\$ 7$ billion by 2008 [97]. This stent market is mainly composed of BMS, DES, and novel bio-absorbable stents, which are currently under clinical trials. The DES market in the US is expected to increase by $9.0 \%$ from 2011 to 2016, due to the aging population, increase in obesity rate and a demand for minimally invasive procedures [98]. Usage of DES replacing BMS has led to a significant reduction in in-stent restenosis, repeat revascularization and mortality rate of dialysis patients with cardiac problems [99],[100]. However, DES is fraught with certain patho-physiological factors, such as stent-thrombosis, which can ultimately lead to myocardial infarction and mortality [101, 102].

\subsection{Commercial products}

As previously mentioned, the worldwide market for coronary stents is estimated to be greater than $\$ 7$ billion, with annual growth estimated at more than $5 \%$. The different kinds of DES that were approved by the FDA through a major clinical trial and introduced into the United States market are given in Table 2.3. 
Table 2.3: Commercially available DES and their properties [91]

\begin{tabular}{|c|c|c|c|c|c|c|}
\hline Name & $\begin{array}{c}\text { Drug } \\
\left(\mu \mathrm{g} / \mathrm{mm}^{2}\right)\end{array}$ & \multicolumn{2}{|c|}{ Carrier polymer } & $\begin{array}{l}\text { Polymer } \\
\text { thicknes } \\
\text { s }(\mathrm{mm})\end{array}$ & $\begin{array}{c}\text { Strut } \\
\text { thickne } \\
\text { ss (mm) }\end{array}$ & $\begin{array}{c}\text { Stent } \\
\text { platform }\end{array}$ \\
\hline Cypher & $\begin{array}{l}\text { Sirolimus } \\
\quad(1.4)\end{array}$ & $\begin{array}{l}\text { polyethylene-co- } \\
\text { vinyl acetate } \\
\text { (PEVA) and } \\
\text { poly n-butyl } \\
\text { methacrylate } \\
\text { (PBMA). }\end{array}$ & Durable & 12.6 & 140 & $\begin{array}{r}\text { Stainless } \\
\text { steel 316L }\end{array}$ \\
\hline $\begin{array}{l}\text { Taxus } \\
\text { Liberté }\end{array}$ & $\begin{array}{l}\text { Paclitaxel } \\
\text { (1.0) }\end{array}$ & $\begin{array}{c}\text { SIBS } \\
\text { [poly(styrene- } \\
\text { bisobutylene- } \\
\text { b-styrene)] }\end{array}$ & $\begin{array}{c}\text { Bio- } \\
\text { degradable }\end{array}$ & 16 & 97 & $\begin{array}{c}\text { Stainless } \\
\text { steel 316L }\end{array}$ \\
\hline Endeavor & $\begin{array}{l}\text { Zotarolimus } \\
\text { (10) }\end{array}$ & $\begin{array}{c}\text { Phosphorylcholi } \\
\text { ne (PC) }\end{array}$ & & 5.3 & 91 & $\begin{array}{c}\text { Cobalt } \\
\text { alloy }\end{array}$ \\
\hline $\begin{array}{c}\text { XIENCE } \\
\mathrm{V}\end{array}$ & $\begin{array}{l}\text { Everolimus } \\
\quad(1.0)\end{array}$ & Fluoropolymer & Durable & 7.6 & 81 & $\begin{array}{l}\text { Cobalt- } \\
\text { chromium } \\
\text { alloy } \\
\end{array}$ \\
\hline EXCEL & Sirolimus & $\begin{array}{c}\text { Poly } \\
\text { lactic acid } \\
\text { (PLA) }\end{array}$ & $\begin{array}{c}\text { Bio- } \\
\text { degradable }\end{array}$ & - & - & $\begin{array}{c}\text { Stainless } \\
\text { steel }\end{array}$ \\
\hline $\begin{array}{c}\text { LUC- } \\
\text { Chopin2T } \\
\text { M, } \\
\text { Balton } \\
\text { (Poland) }\end{array}$ & $\begin{array}{l}\text { Paclitaxel } \\
\quad(1.0)\end{array}$ & $\begin{array}{l}\text { copolymer of } \\
\text { lactic and } \\
\text { glycolic acid }\end{array}$ & $\begin{array}{c}\text { Bio- } \\
\text { degradable }\end{array}$ & - & 0.12 & $\begin{array}{c}\text { Stainless } \\
\text { steel } 316 \mathrm{~L}\end{array}$ \\
\hline
\end{tabular}




\section{CHAPTER 3}

\section{CORROSION OF IMPLANT MATERIALS}

\subsection{Corrosion mechanism}

Corrosion is defined as "the destructive attack of a metal by chemical or electrochemical reaction with its environment [103]. Corrosion of a metallic implant is mainly controlled by two features, namely corrosion thermodynamics and corrosion kinetics [104-106]. Corrosion of a metal occurs due to its basic thermodynamic tendency to restore to a more stable compound, thereby bringing its free energy to a lower state, such as oxides and hydroxides, and etc. [103]. Corrosion thermodynamics is dependent on the energy released or absorbed during the redox (oxidation and reduction) reaction that occurs at the interface of the implant and its surrounding environment. From an electrochemical point of view, when a metal $(\mathrm{M})$ is immersed in a solvent, the metallic ions $\left(\mathrm{M}^{+}\right)$from the metal's surface start moving into the solution (anodic reaction) and this leads to accumulation of electrons $\left(\mathrm{e}^{-}\right)$on the surface of the metal. Eventual build of negative charge on the metal's surface will start attracting $\mathrm{M}^{+}$ions back on to its surface (cathodic reaction). Depending on the composition, $\mathrm{pH}$, and temperature of the electrolyte, both the anodic and cathodic reactions reach an equilibrium point. This potential observed on the surface of the metal when no external potential was applied to the metal is called its equilibrium potential or rest potential $\left(\mathrm{E}_{0}\right)$. The basic oxidation reaction (anodic reaction) that occurs during the corrosion process involves conversion of metal to metallic ions (increase of valence or loss of electrons).

$$
\mathrm{M} \leftrightarrow \mathrm{M}^{\mathrm{n}+}+\mathrm{ne}^{-}
$$


The thermodynamic driving force for the oxidation of metal to metallic ions is called free energy $(\Delta \mathrm{G})$ and the corresponding equation is

$$
\Delta \mathrm{G}_{\mathrm{red}}=\Delta \mathrm{G}^{\mathrm{o}}+\mathrm{RT} \ln [\mathrm{M}] /\left[\mathrm{M}^{\mathrm{n}+}\right][\mathrm{e}]^{\mathrm{n}}
$$

where $\Delta \mathrm{G}_{\mathrm{red}}$ is the free energy of reduction.

The corrosion process will take place only when a counter reduction reaction (cathodic reaction) occurs in the electrochemical system depending on its surrounding conditions, such as ionic concentration, dissolved oxygen and $\mathrm{pH}$. Various reduction reactions that might occur during a corrosion process are [106]:

$$
\begin{array}{ccc}
2 \mathrm{H}^{+}+2 \mathrm{e}^{-} \rightarrow \mathrm{H}_{2} & \text { at } & \mathrm{pH}<7 \\
2 \mathrm{H}_{2} \mathrm{O}+2 \mathrm{e}^{-} \rightarrow \mathrm{H}_{2}+2 \mathrm{OH}^{-} & \text {at } & \mathrm{pH} \geq 7 \\
4 \mathrm{H}^{+}+4 \mathrm{e}^{-}+\mathrm{O}_{2} \rightarrow 2 \mathrm{H}_{2} \mathrm{O} & \text { at } & \mathrm{pH}<7 \\
2 \mathrm{H}_{2} \mathrm{O}+4 \mathrm{e}^{-}+\mathrm{O}_{2} \rightarrow 4 \mathrm{OH}^{-} & \text {at } & \mathrm{pH} \geq 7 \\
\mathrm{M}^{\mathrm{n}+} \rightarrow \mathrm{M}(\mathrm{n}-1)++\mathrm{e}^{-} & &
\end{array}
$$

Equations 3.3 and 3.4 are considered as hydrogen evolution reactions that occur in the absence of dissolved oxygen. However, Equations 3.5 and 3.6 are considered as oxygen reduction reactions and they occur in the presence of dissolved oxygen [107]. Corrosion kinetics is dependent on external factors such as temperature, solution concentration and velocity gradients that can impede the corrosion process [105].

The spontaneity of a metal to oxidize (to form oxides) is dependent on its free energy of oxide formation. For Ti, Ta, Ni and Cr elements, the free energy of pure oxides and the reactions involved are as follows:

$$
\mathrm{Ti}+\mathrm{O}_{2} \rightarrow \mathrm{TiO}_{2} \quad \Delta \mathrm{G}=-208.3 \mathrm{kcal} / \mathrm{mol}
$$




$$
\begin{array}{lc}
\mathrm{Ti}+2 \mathrm{H}_{2} \mathrm{O} \rightarrow \mathrm{TiO}_{2}+4 \mathrm{H}^{+}+4 \mathrm{e}^{-} & \Delta \mathrm{G}=-82.92 \mathrm{kcal} / \mathrm{mol} \\
\mathrm{Ni}+\mathrm{O}_{2} \rightarrow \mathrm{NiO}_{2} & \Delta \mathrm{G}=-55.45 \mathrm{kcal} / \mathrm{mol} \\
2 \mathrm{Cr}+3 / 2 \mathrm{O}_{2} \rightarrow \mathrm{Cr}_{2} \mathrm{O}_{3} & \Delta \mathrm{G}=-268.88 \mathrm{kcal} / \mathrm{mol}[108] \\
2 \mathrm{Ta}+5 / 2 \mathrm{O}_{2} \rightarrow \mathrm{Ta}_{2} \mathrm{O}_{5} & \Delta \mathrm{G}=-509.56 \mathrm{kcal} / \mathrm{mol}[109]
\end{array}
$$

According to Cabrera et al. [110] and Fehlenr et al. [111], from an atomic point of view, oxides form on the surface of a metal due to adsorption of oxygen atoms. This leads to formation of a thin oxide layer on its surface and results in a potential difference across the surface. This potential difference further promotes the diffusion of oxygen ions (anions) towards titanium present in the bulk of the alloy and results in the increase of oxide layer thickness. Since the oxide layer is formed mainly due to mobility of anions, this layer acts as an N-type semiconductor [111]. This process ceases when the thick oxide layer results in higher activation energy for oxygen ion transport across the film. In the presence of an externally applied potential difference to this metal, the anions will overcome the increased activation barrier and continue to form more oxide.

\subsection{Types of corrosion}

Metallic implants after implantation are subjected to various types of corrosion [105] due to highly corrosive and complex physiological environment consisting of water, dissolved oxygen, proteins, minerals, chloride and hydrogen ions, etc., that can eventually lead to corrosion. Corrosion of implants will cause their premature failure and release toxic corrosion by products that results in adverse biological and tissue responses. 


\subsubsection{Uniform corrosion}

Corrosion occurs all over the exposed metal's surface at a uniform rate and involves reduction of metal to metal oxides and hydroxides. This type of corrosion is feasible when the corrosive electrolyte is accessible to all parts of a metallurgically homogenous metallic surface.

\subsubsection{Pitting corrosion}

Pitting corrosion occurs when the potential of a passive protective film on a metal exceeds its breakdown potential. This leads to formation of a pit, where active dissolution of metal occurs and acts as an anodic site, whereas the undamaged passive oxide film behaves as a cathodic site. In general, pitting corrosion occurs on metals and alloys, relying on a passive surface film for their corrosion resistance in environments containing halides, e.g. $\mathrm{Cl}^{-}[112]$. This corrosion arises due to access of so-called aggressive anions [113]. It involves the formation of a local anode separated from the cathode where electrochemical reactions take place. At the cathodic site, i.e. the passivated surface, cathodic reactions occur, and at the anodic site, i.e. the "pit," anodic reactions take place. The metal or alloy is the conductor for electrons moving between the sites. Metallic and non-metallic inclusions often play a decisive role in the initiation of pitting corrosion. As mentioned above, the presence of aggressive anions is necessary for breakdown of passivity and stable pit growth [113].

However, due to the harsh physiological environment present inside the human body, Nitinol implants are known to undergo pitting and crevice corrosion [38], as shown in Figure 3.1. 


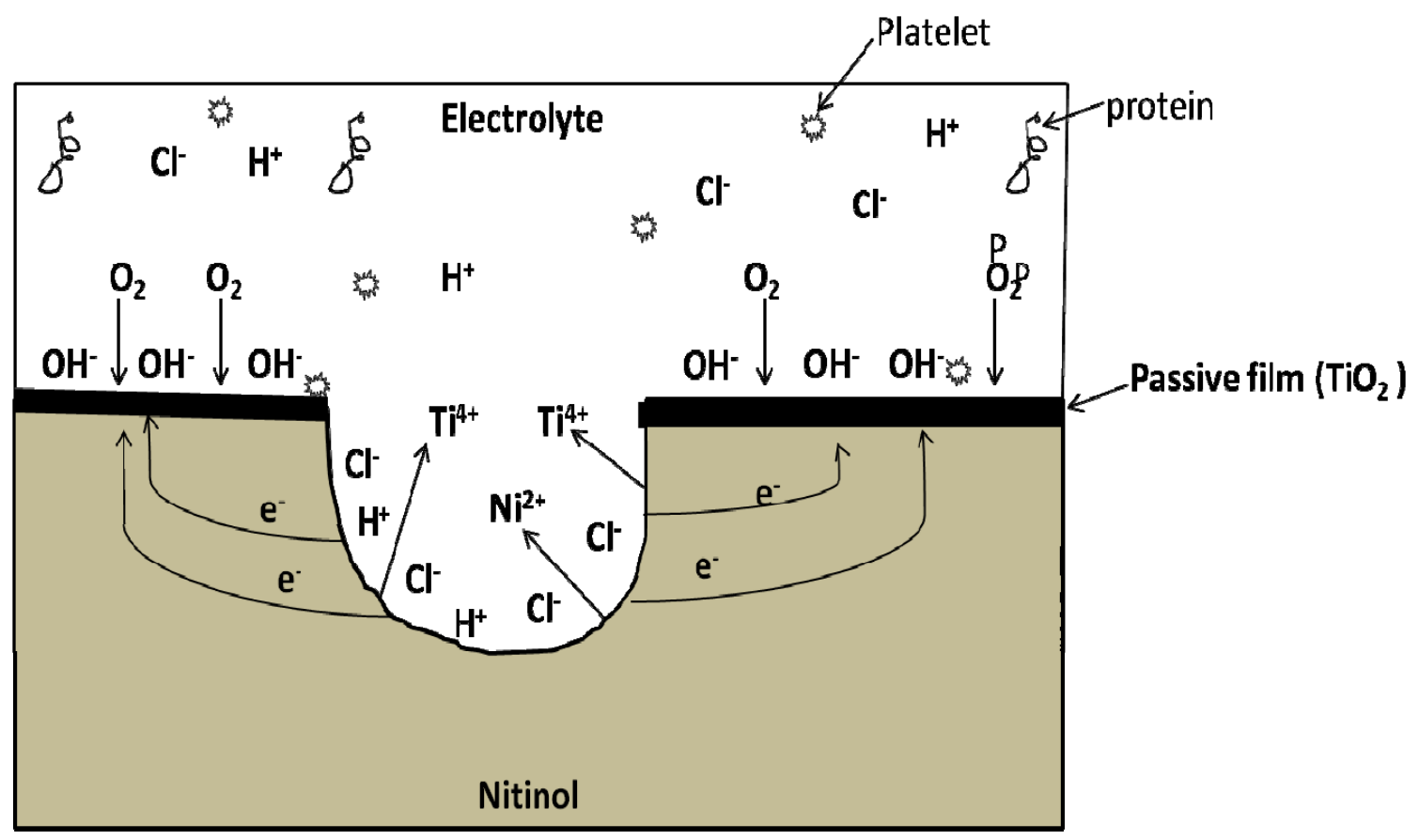

Figure 3.1: Occurrence of pitting corrosion on Nitinol in the presence of the complex physiological environment that prevails inside a human body.

The other factors that influence pitting corrosion of Nitinol are $\mathrm{pH}$ and temperature. Trepanier et al. [114] [115] has shown that an increase in temperature during corrosion of Nitinol will not affect its overall corrosion rate, but its ability to repassivate after breakdown of the oxide layer will be reduced. Additionally, an increase in $\mathrm{pH}$ resulted in no change in corrosion resistance of Nitinol, but it resulted in lowering its oxygen reduction potential [116].

\subsubsection{Crevice corrosion}

Crevice corrosion occurs in regions of restricted flow, i.e. limited mass transport, resulting in exhaustion of reactants, e.g. dissolved oxygen [113]. The oxygen depletion and the accumulation of corrosion products lead to formation of a small concentration 
cell, which enhances the anodic reaction (corrosion) inside the crevice. In the case of Nitinol, implantation of multiple overlapping stents to treat long vascular lesions (which arise in the Superior Femoral Artery), might create gaps (crevices) between the two stents, which can act as crevices and eventually lead to crevice corrosion [114]. ASTM F746 standard is used to determine the in-vitro crevice corrosion of overlapped stents.

\subsubsection{Fretting corrosion/erosion corrosion}

When two metallic implants, such as stents or bone implants, are in contact and constant motion with respect to each other, surface wear occurs due to shearing forces. This leads to disruption of protective oxide layers or drug eluting coatings on implants and exposes the underlying material to fretting corrosion. In the case of multiple overlapping stents, fretting corrosion was observed in locations such as crossing points of the braided stent wires.

\subsubsection{Stress induced cracking corrosion}

In general, stress corrosion cracking (SSC) is feasible with a combination of three factors: a tensile stress, a susceptible material, and a particular environment (fluorides and chlorides, or very low $\mathrm{pH}$ ) [117]. After implantation, stents, bone, hip and dental implants are under constant stress applied by the surroundings. This stress leads to the formation of microscopic crack tips, which act as cathodic sites for corrosion initiation. Generation of hydrogen and vacancies due to these localized anodic and cathodic dissolution reactions at the crack tip will cause the material to transform from a ductile to 
a brittle nature [118]. As a result, these cracks steadily grow deep into the material and lead to mechanical failure of implants.

Xiaoji li, et al.[119] has showed that the presence of high fluoride content in human oral environment will accelerate the crack initiation at the surface of Nitinol orthodontic wires and leads to SSC.

\subsubsection{Galvanic corrosion}

When two dissimilar metals (a noble and an active metal) are in contact with each other in the presence of an electrolyte (a corrosive environment that acts as a closed electrical circuit), a preferential dissolution of active metal (anodic reaction), as compared with more noble metal (cathodic reaction), occurs [120-122]. Venugopalan et al. [123] showed that negligible galvanic corrosion occurred when passivated Nitinol is coupled with Ta. Whereas, an increase in the corrosion rate of Nitinol alloy by two orders of magnitude was observed when coupled with noble metals, such as, Platinum and goldpalladium alloys [123].

\subsubsection{Intergranular corrosion}

Intergranular corrosion occurs when the composition of the material within a grain and at its grain boundary is sufficiently different to create a variation in corrosion rates at these locations. In the case of surgical grade $316 \mathrm{SS}$, precipitation of chromium carbides will lead to chromium grain boundary depletion, and it leads to intergranular corrosion. However, reduction of carbon content $(<0.03 \%)$ or addition of elements such as Ti and Ta to surgical grade 316 has been shown to reduce this corrosion [124]. 


\subsection{Methods to determine corrosion rate}

Corrosion resistance of implantable materials is a very important factor that affects their overall biocompatibility. Device implantation will always lead to some extent of inflammation and wound healing near the implantation site, which prompts the inflammatory cells to release super oxide and hydrogen peroxide molecules, as shown in Equation 3.13. This hydrogen peroxide is known to act as a corrosive agent for implanted materials $[125,126]$.

$$
\mathrm{O}_{2}^{-}+\mathrm{O}_{2}^{-}+2 \mathrm{H}^{+} \rightarrow \mathrm{H}_{2} \mathrm{O}_{2}+\mathrm{O}_{2}
$$

The presence of proteins such as albumin and fibrinogen in the simulated body fluid will increase the in-vitro corrosion rates of implant materials[127]. There are mainly two different ways to determine corrosion rates. The first method consists of weight loss measurements and the second method consists of electrochemical characterization techniques, which include potentiodynamic and voltammetry studies.

\subsubsection{Potentiodynamic corrosion studies}

Corrosion behavior of a metal over a wide range of oxidizing conditions can be understood by observing its polarization behavior. A polarization curve is a plot of the current from the working electrode's surface versus the electrochemical potential applied to the electrode [107].

A metal immersed in electrolyte is said to be polarized when it is forced to deviate from its equilibrium potential $\left(E_{0}\right)$ or rest potential $\left(E_{r}\right)$. A potentiostat is used to either 
vary the potential of a working electrode as a function of time with respect to a standard reference electrode or maintain it at a constant value and simultaneously measure its current as a function of potential. A potentiostat connected to a three electrode corrosion cell (working electrode, counter electrode and reference electrode) is used to measure the resulting current between the working and counter electrode.

During potentiodynamic corrosion studies, the potential across the working electrode is changed continuously at a constant scan rate (for example, $1 \mathrm{mV} / \mathrm{min}$ ) and its corresponding response current is measured. Potentiodynamic corrosion tests provide important information regarding a metal's ability to passivate in a given medium; stability of the passive oxide layer over a given range of potential; and corrosion rate [107]. Potentiodynamic polarization test produce log I vs. E curve, from which the polarization resistance $\left(\mathrm{R}_{\mathrm{p}}\right)$, i.e., slope of $\mathrm{dE} / \mathrm{dI}$ at corrosion potential is determined. The current measured during potentiodynamic corrosion indicates the rate of corrosion at a given potential.

In general, the polarization curve of a metal consists of two sections, the anodic curve and cathodic curve, as shown in Figure 3.2. Based on the Tafel plot analysis, the cathodic or anodic current at the cross section of extrapolated portions of cathodic and anodic curves, represents the corrosion current $\left(\mathrm{I}_{\text {corr }}\right)$. Tafel analysis considers that, the rates of both the anodic and cathodic reactions are controlled by the kinetics of the electron transfer reaction at the metal/electrolyte interface surface. Stern-Geary equation and Tafel plot analysis parameters were used to determine $\mathrm{I}_{\text {corr }}$ value, as shown in Equation 3.14 [128]. 


$$
I_{\text {corr }}=\beta_{\mathrm{a}} \beta_{\mathrm{c}} / 2.3 \mathrm{R}_{\mathrm{p}}\left(\beta_{\mathrm{a}}+\beta_{\mathrm{c}}\right)
$$

Where, $\beta_{\mathrm{a}}$ is the anodic Beta Tafel constant in volts/decade, $\beta_{\mathrm{c}}$ is the cathodic Beta Tafel constant in volts/decade, $R_{p}$ is the polarization resistance in volts.

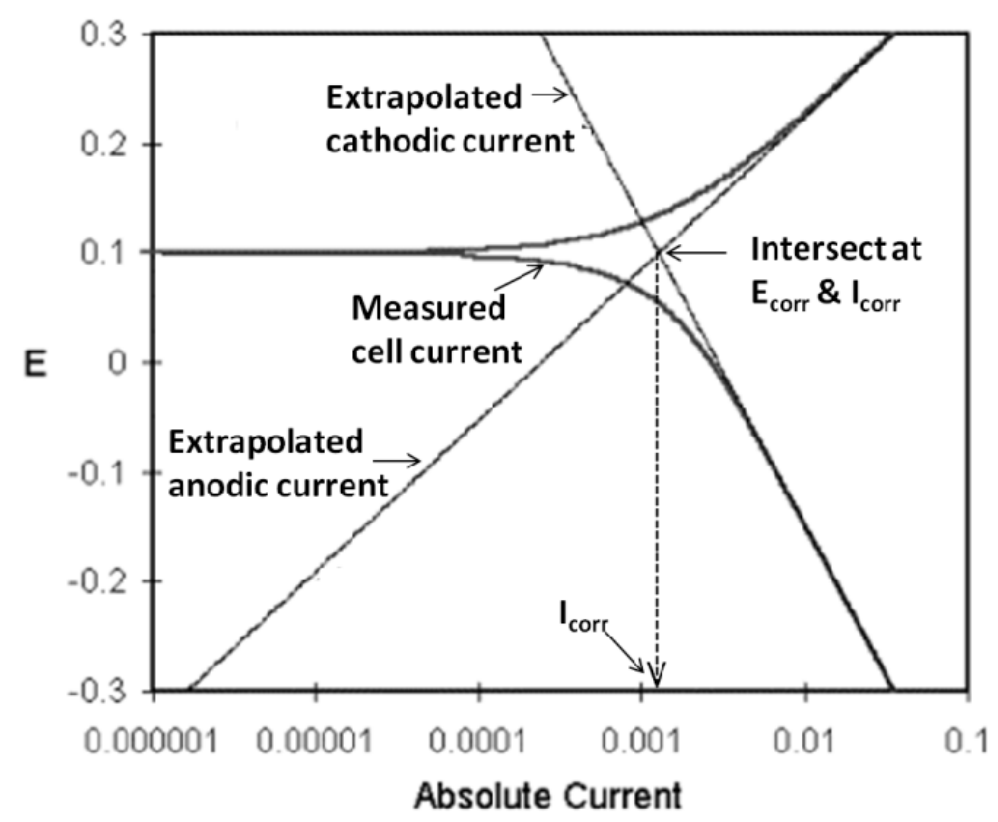

Figure 3.2: Potentiodynamic curve with anodic, cathodic curves and a Tafel plot to determine the corrosion current $\mathrm{I}_{\text {corr }}$.

In general, the polarization curve of a metal's anodic dissolution consists of three different stages: (see schematic diagram in Figure 3.3) the active, passive and transpassive stages $[129,130]$. In the active region or active metallic dissolution stage, an increase in the anodic potential leads to an increase in the corrosion current. This happens due to corrosion of metal, since the potential of the metal is less noble than the applied potential. 


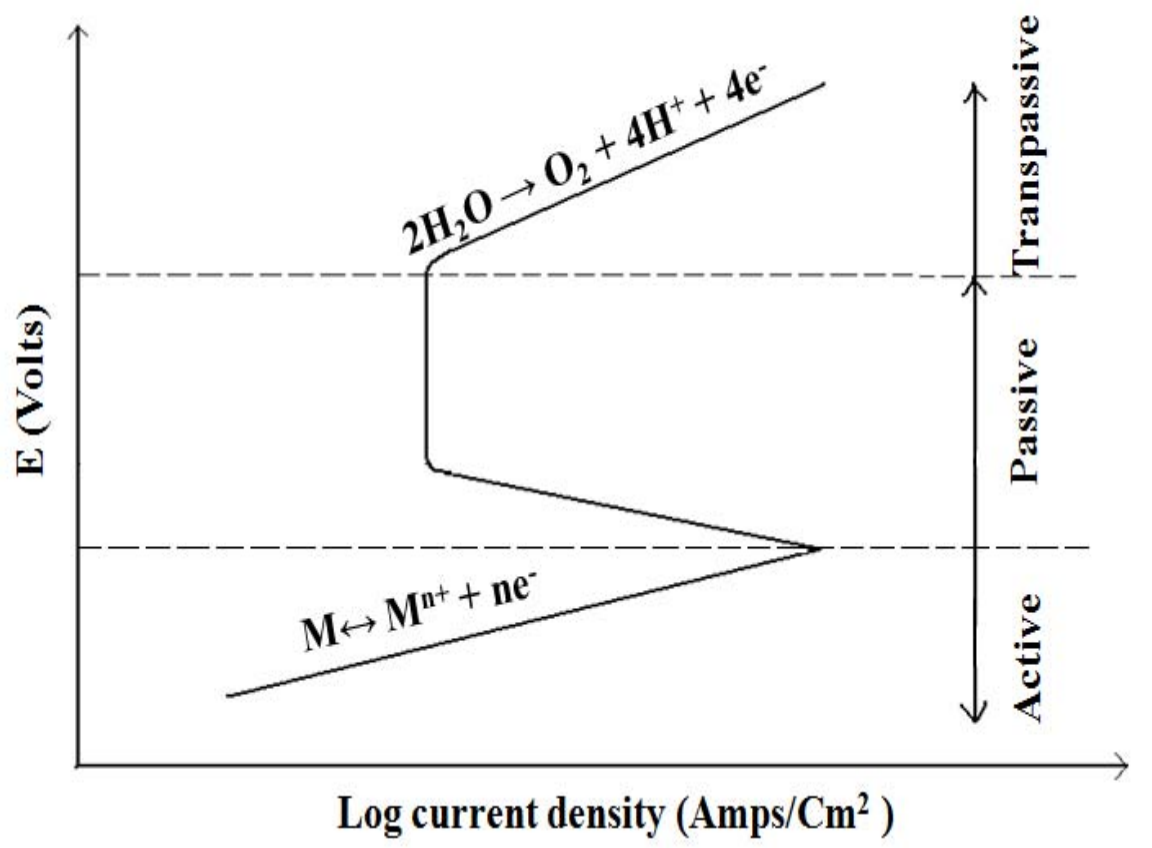

Figure 3.3: General anodic dissolution curve for an active passive metal [131].

As the applied potential increases from the active to passive region, the metal is at a more noble potential due to the formation of a passive film on its surface and results in the reduction of the corrosion current. Once a thick passive layer is formed, the change in corrosion current becomes negligible with respect to the potential change. Generally, the difference between the corrosion current in the active and passive regions is very significant. In the transpassive region, when the applied potential reaches a very high value, once again the dissolution of metal ions takes place because of breakdown of the passive layer [129]. 


\subsubsection{Calculation of corrosion rate}

Corrosion rate (CR) of a metal under simulated electrochemical conditions can be

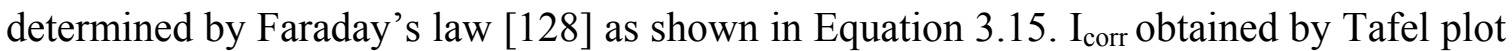
analysis is inserted into this equation to obtain a corrosion rate value.

$$
\mathrm{CR}=\mathrm{KI}_{\text {corr }} \mathrm{EW} / \mathrm{A} \rho
$$

Where $\mathrm{CR}$ is the penetration rate ( $\mathrm{mm} / \mathrm{yr}$ or $\mathrm{mpy}), \mathrm{K}$ is a constant that defines the units for the corrosion rate, $\mathrm{EW}$ is the equivalent weight in grams/equivalent, $\rho$ is density in grams $/ \mathrm{cm}^{3}, \mathrm{I}_{\text {corr }}$ is the corrosion current in milli amps, A is the surface area of the metal that undergoes corrosion in $\mathrm{cm}^{2}$.

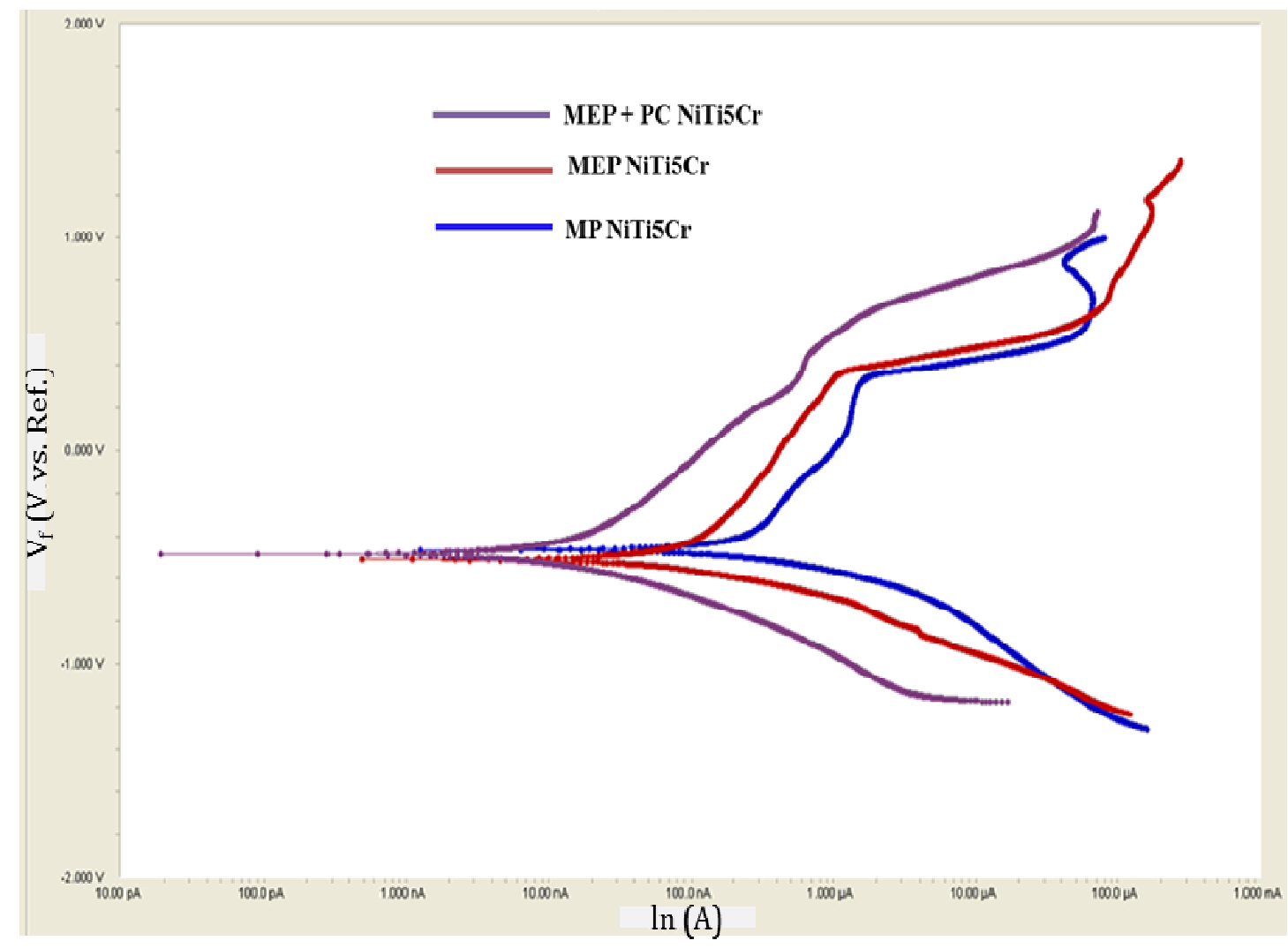

Figure 3.4: Potentiodynamic curves for NiTi5Cr alloys 


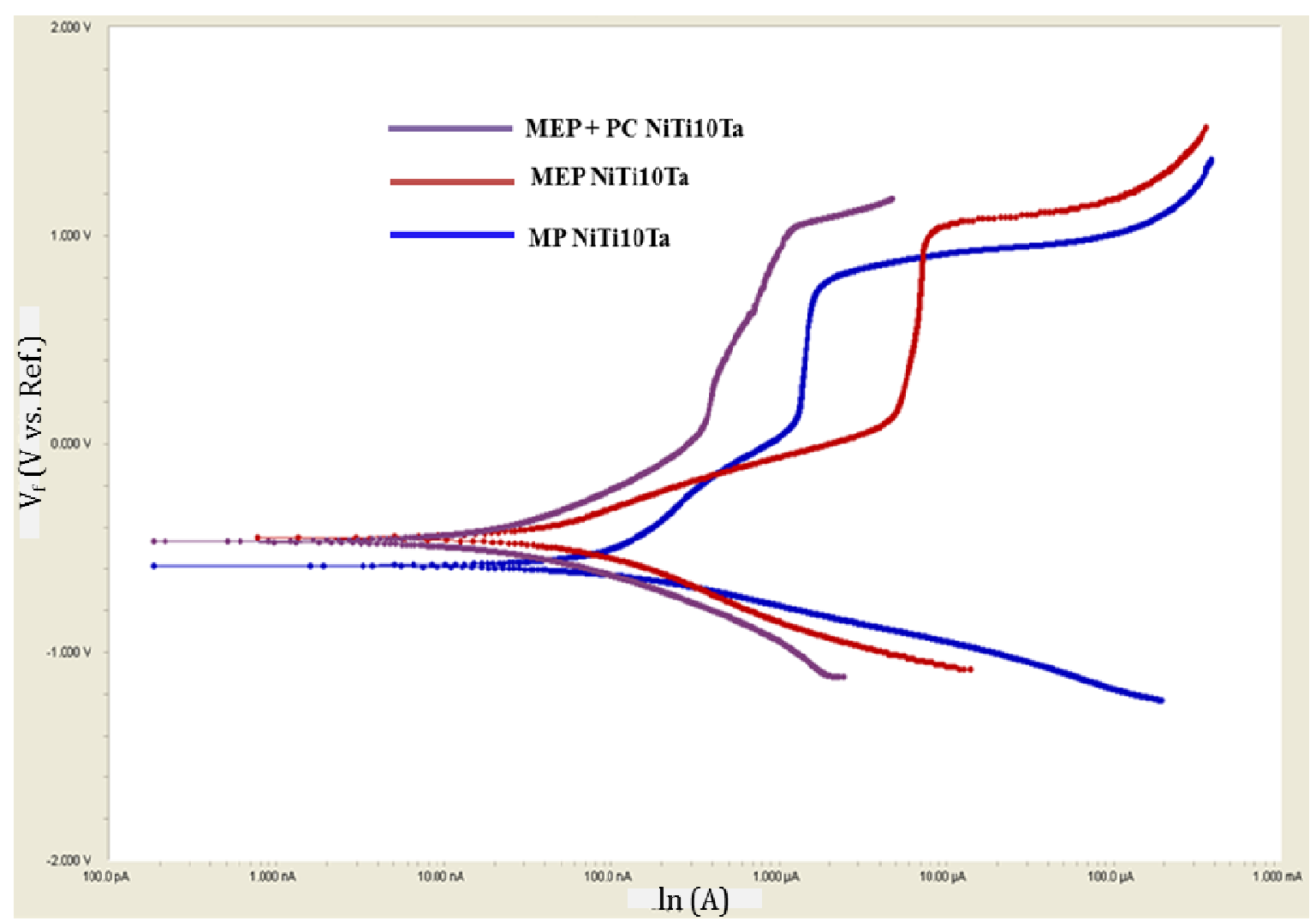

Figure 3.5: Potentiodynamic curves for NiTi10Ta alloys

Figures 3.4 and 3.5 depict the potentiodynamic curves of MP, MEP and MEP + PC NiTi5Cr and NiTi10Ta alloys respectively. The Tafel plot and corrosion rate (CR) parameters of MP, MEP and MEP + PC Nitinol samples, obtained from potentiodynamic polarization curves are tabulated as shown in Table 3.

Table 3.1: Tafel and corrosion rate parameters of MP, MEP and MEP + PC Nitinol samples

\begin{tabular}{|c|c|c|c|c|}
\hline Alloy & $\boldsymbol{\beta}_{\mathbf{a}}$ (V/decade) & $\boldsymbol{\beta}_{\mathbf{c}}$ (V/decade) & $\mathbf{I}_{\text {corr }}(\mathbf{m A})$ & CR (mpy) \\
\hline MP NiTi5Cr & $1.65 \mathrm{E}+00$ & $3.36 \mathrm{E}-01$ & $5.20 \mathrm{E}-04$ & $3.80 \mathrm{E}-01$ \\
\hline MEP NiTi5Cr & $7.35 \mathrm{E}-01$ & $2.37 \mathrm{E}-01$ & $1.03 \mathrm{E}-04$ & $9.43 \mathrm{E}-02$ \\
\hline MEP + PC NiTi5Cr & $5.55 \mathrm{E}-01$ & $2.77 \mathrm{E}-01$ & $1.75 \mathrm{E}-05$ & $1.27 \mathrm{E}-02$ \\
\hline
\end{tabular}


Table 3.1: Tafel and corrosion rate parameters of MP, MEP and MEP + PC Nitinol samples (continued)

\begin{tabular}{|c|c|c|c|c|}
\hline MP NiTi10Ta & $1.09 \mathrm{E}+00$ & $2.06 \mathrm{E}-01$ & $1.47 \mathrm{E}-04$ & $1.35 \mathrm{E}-01$ \\
\hline MEP NiTi10Ta & $7.44 \mathrm{E}-01$ & $2.36 \mathrm{E}-01$ & $9.62 \mathrm{E}-05$ & $8.81 \mathrm{E}-02$ \\
\hline MEP + PC NiTi10Ta & $1.11 \mathrm{E}+00$ & $4.35 \mathrm{E}-01$ & $6.79 \mathrm{E}-05$ & $4.79 \mathrm{E}-02$ \\
\hline
\end{tabular}

A comparison of corrosion rates (Table 3.1) for different surface treated alloys shows that, the application of a polymer coating on MEP treated Nitinol resulted in a reduction of the corrosion rates. In the case of $\mathrm{NiTi5Cr}$, the corrosion rate of $\mathrm{MEP}+\mathrm{PC}$ NiTi5Cr (1.27E-2 mpy) was reduced by 10 times as compared with that of MP NiTi5Cr (3.80E-1 mpy). In the case of NiTi10Ta, the corrosion resistance of MEP + PC NiTi10Ta (4.79E-2 mpy) was less than that of MP NiTi10Ta (1.35E-1 mpy). The typical corrosion rates for bare Nitinol have been elsewhere reported in the range of $0.1-2.26 \mu \mathrm{m} / \mathrm{y}$ [132],[133].

\subsubsection{Cyclic potentiodynamic polarization tests}

A cyclic potentiodynamic polarization curve is obtained when the electrochemical behavior of a metal is studied under a controlled potential. The potential initially starts at a value below or equal to the metal's rest potential and proceeds in a forward direction until it reaches a potential value in its transpassive region. Then, it is reversed until it reaches a value below its repassivation potential $[129,134]$. 


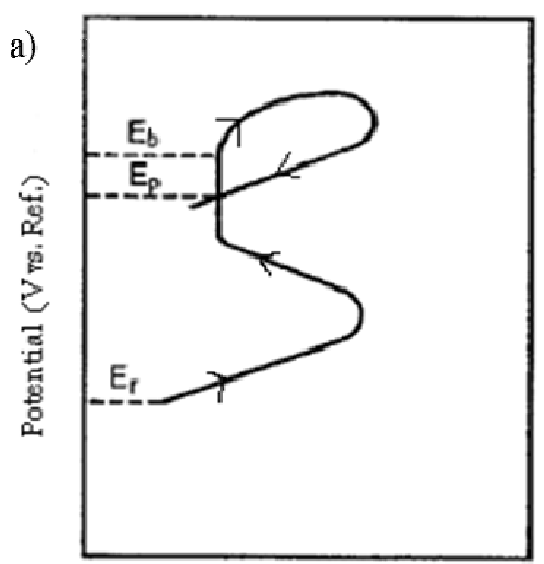

Current

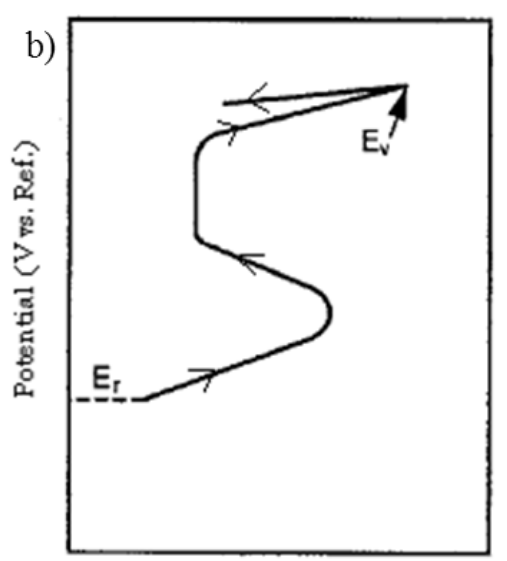

Cument

Figure 3.6: a) \& b) Typical cyclic potentiodynamic curves illustrating different corrosion parameters [129].

As the potential reaches the breakdown potential $\left(\mathrm{E}_{\mathrm{b}}\right)$ in the forward direction of the scan, the passive oxide layer (steady state surface structure) will start disrupting with an increase in potential. This leads to an increase in corrosion current, as shown in Figure 3.6.a. As per ASTM $\mathrm{f} 2129-08$, the difference between $\mathrm{E}_{\mathrm{b}}$ and $\mathrm{E}_{\mathrm{r}}$ indicates the resistance to pitting corrosion for a given metallic material. Later, when the direction of scanning potential is reversed, the curve forms a loop in a clockwise direction and meets the forward scan at a potential called repassivation potential $\left(\mathrm{E}_{\mathrm{p}}\right)$. At this potential, the steady state surface structure is restored and no localized corrosion occurs below this potential. The hysteresis formed in the cyclic potentiodynamic polarization curve, as shown in Figure 3.6 a, is caused by the current density difference produced between the forward and reverse portions of the scan at a given potential. It denotes the ease or difficulty with which that initial structure is restored as the scanning potential reaches $E_{p}[135]$. As the area of the hysteresis loop increases, the disruption of surface passivity (occurrence of localized corrosion) increases with a higher difficulty in restoring a passive surface [136]. 
The severity of crevice corrosion susceptibility increases with increasing hysteresis of the polarization curve, which is the difference between $\mathrm{E}_{\mathrm{b}}$ and $\mathrm{E}_{\mathrm{p}}$. Figure 3. 6. $\mathrm{b}$ corresponds to the cyclic potentiodynamic polarization curve of a material with anti-clockwise loop or no hysteresis. It happens when the reverse anodic curve is shifted to a lower current density before the scanning potential crosses the breakdown potential [137]. This suggests that no pitting corrosion occurs during the reverse anodic portion of the cyclic potentiodynamic curve [138] and these type of material are highly resistant to localized corrosion $[137,139]$.

The general anodic dissolution curve for an active passive metal described in Section 3.3.1 serves as a fundamental example to study the cyclic polarization curves of Nitinol alloys. In the present research, in-vitro cyclic potentiodynamic polarization tests were conducted as per the ASTM F2129 - 08 [129] standard on MP, MEP and polymercoated Nitinol alloys to determine their susceptibility to pitting and crevice corrosion. This standard is generally used to determine the corrosion susceptibility of small implant devices.

\subsubsection{Cyclic potentiodynamic polarization curves}

The cyclic potentiodynamic polarization curves for each surface treated ternary Nitinol was plotted against its MP alloy's curve for comparative analysis. Figure 3.7 and 3.8 show the cyclic potentiodynamic polarization curves of MP, MEP, MEP + PC Nitinol alloys.

It was observed that the MP NiTi10Ta had a lower resistance to localized corrosion when compared with that of MEP, MEP +PC NiTi10Ta alloy (Fig. 3.7). 
NiTi10Ta displayed a positive hysteresis loop which is an indicative of susceptibility to pitting corrosion [140].

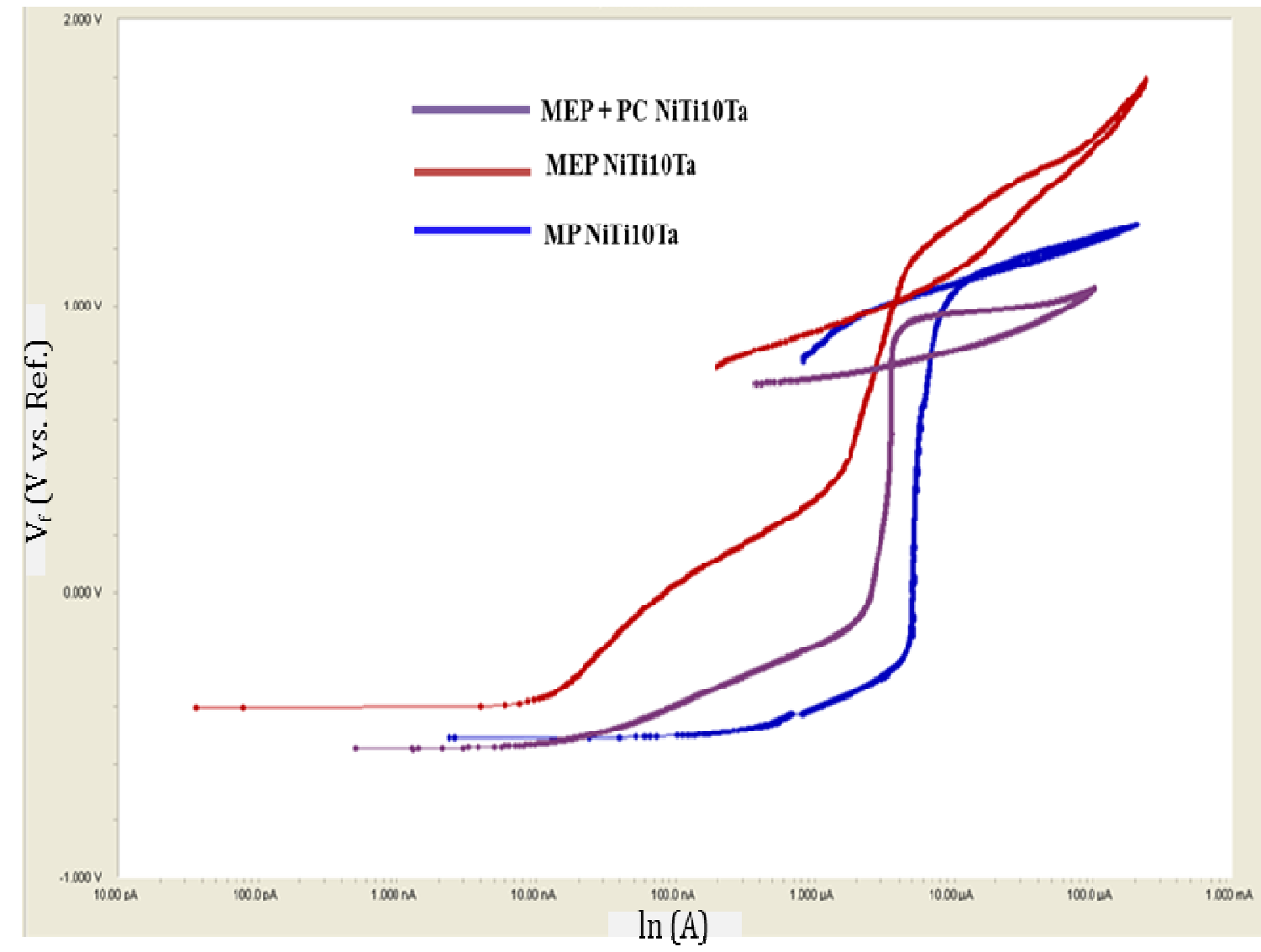

Figure 3.7: Cyclic potentiodynamic polarization curves for NiTi10Ta alloys

As shown in Fig 3.8, NiTi5Cr displayed no hysteresis loop, which is a characteristic of an alloy that is highly resistant to localized corrosion. Additionally, the MP NiTi5Cr had a lower resistance to localized corrosion as compared with that of MEP, MEP +PC NiTi10Ta alloy. 


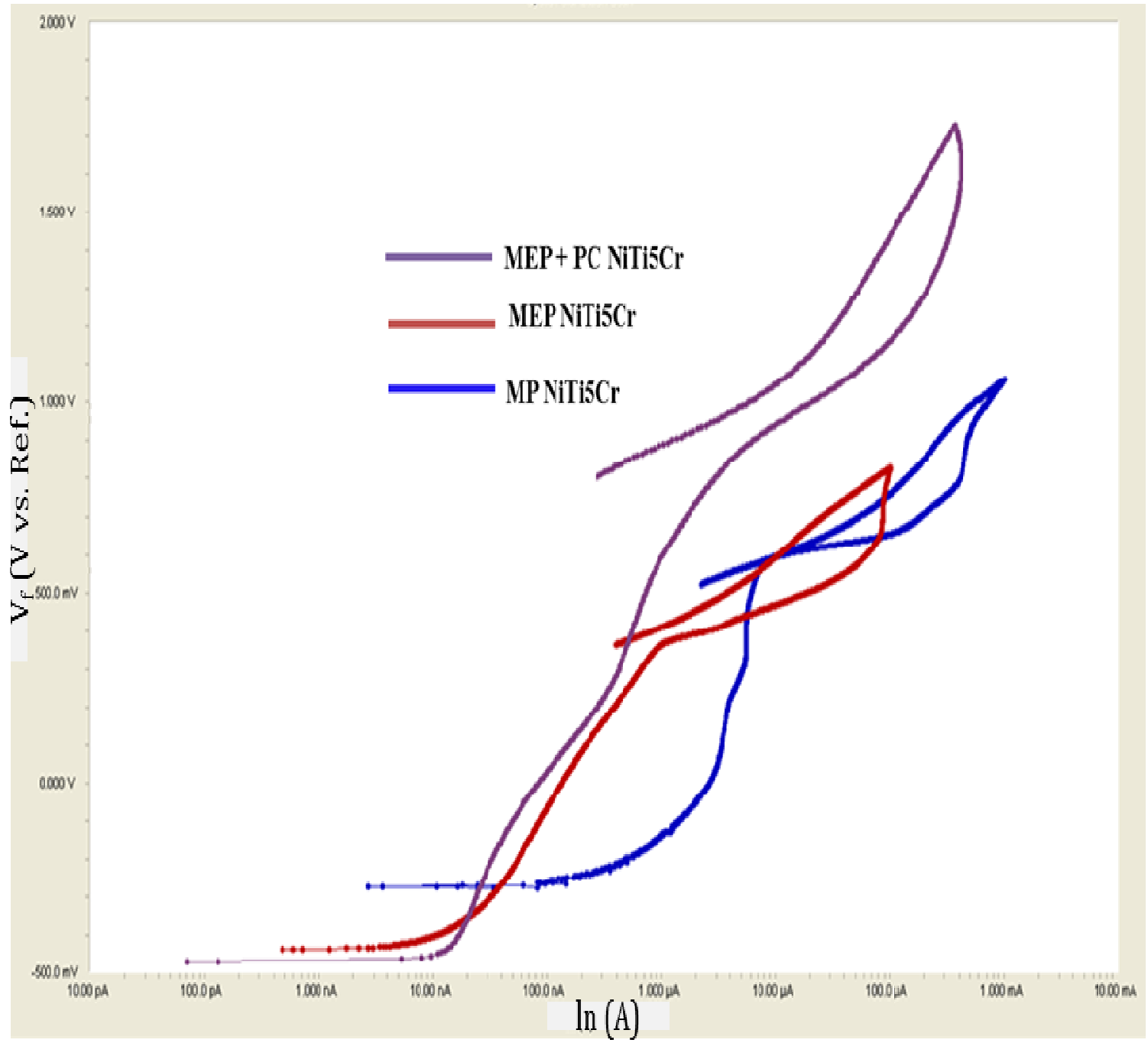

Figure 3.8: Cyclic potentiodynamic polarization curves for NiTi5Cr alloys

For metals with positive hysteresis loop, the difference between its $\mathrm{E}_{\mathrm{b}}$ (break down potential) and $\mathrm{E}_{\mathrm{r}}$ (rest potential) during anodic dissolution serves as a measure of its resistance to pitting corrosion. In the case of metals with negative hysteresis loop, the vertex potential serves as a measure of its corrosion resistance. The average corrosion parameters, such as $E_{b}, E_{r}, E_{p}$ (protection potential), $E_{v}$ (vertex potential) and $E_{b}-E_{r}$ (resistance to pitting corrosion) obtained during cyclic polarization tests for the aforementioned Nitinol alloys are given in Table 3.2. 
Table 3.2: Cyclic potentiodynamic corrosion data for Nitinol alloys

\begin{tabular}{|c|c|c|c|c|c|}
\hline Alloy & $\mathbf{E}_{\mathbf{b}}(\mathbf{V})$ & $\mathbf{E}_{\mathbf{r}}(\mathbf{V})$ & $\mathbf{E}_{\mathbf{p}}(\mathbf{V})$ & $\mathbf{E}_{\mathbf{v}}(\mathbf{V})$ & $\mathbf{E}_{\mathbf{b}}-\mathbf{E}_{\mathbf{r}}(\mathbf{V})$ \\
\hline NiTi10Ta-MP & 0.812 & -0.434 & 0.634 & - & 1.246 \\
\hline NiTi5Cr-MP & & -0.614 & - & 1.074 & - \\
\hline NiTi10Ta-MEP & 0.954 & -0.548 & 0.791 & - & 1.502 \\
\hline NiTi10Ta-MEP+ PC & 1.146 & -0.397 & 0.971 & - & 1.543 \\
\hline NiTi5Cr-MEP & 0.485 & -0.473 & - & 0.825 & - \\
\hline NiTi5Cr-MEP+PC & 0.986 & -0.467 & - & 1.73 & - \\
\hline
\end{tabular}

It can be observed that the resistance to pitting corrosion $\left(\mathrm{E}_{\mathrm{b}}-\mathrm{E}_{\mathrm{r}}\right)$ was high for MEP NiTi10Ta $(1.502 \mathrm{mV})$ and MEP + PC NiTi10Ta $(1.543 \mathrm{mV})$ as compared with that of MP NiTi10Ta $(1.246 \mathrm{mV})$. This is attributed to the formation of protective oxide layer during MEP treatment on NiTi10Ta alloy. Additionally, the vertex potential $\left(\mathrm{E}_{\mathrm{v}}\right)$ of MEP + PC NiTi5Cr $(1.73 \mathrm{mV})$ was high as compared with that of the MP NiTi5Cr $(1.074$ $\mathrm{mV})$. These results confirm that the polymer coating on MEP treated Nitinol alloys acts as a barrier and reduces the localized corrosion on their surfaces.

\subsection{Electrochemical impedance spectroscopy (EIS)}

In electrochemical impedance spectroscopy (EIS), the response of an electrode to alternating potential signals of varying frequency (AC voltage) is interpreted on the basis of circuit models of the electrode/electrolyte interface [104]. EIS was used to determine polarization resistance and to model the corrosion process by fitting impedance data with corresponding equivalent circuits (Fig. 3.9). The modeling procedure uses electrical 
circuits built from components such as resistors and capacitors to represent the electrochemical behavior of the coating and the metal substrate. EIS is known to be very useful to evaluate electrochemical performance of coatings, batteries, etc. [141]. In the present research, EIS was used to study the corrosion properties of the biodegradable polymer-coated Nitinol alloys.

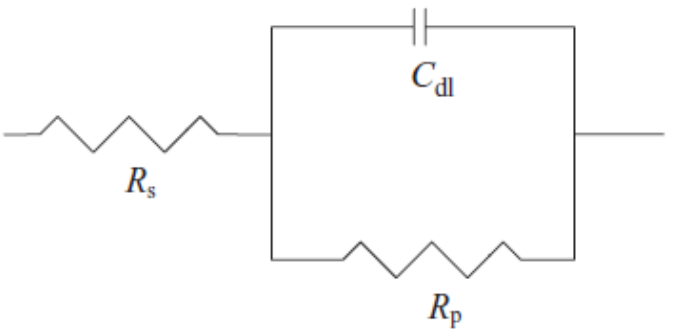

Figure 3.9: Equivalent circuit model used to represent a simple electrochemical interface undergoing corrosion in the absence of diffusion control. $R_{s}-$ Solution resistance, $R_{p}-$ polarization resistance, $\mathrm{C}_{\mathrm{dl}}$ - capacitance of double layer

In EIS, the impedance of the corroding metal (working electrode) due to an applied sinusoidal potential change (AC voltage) is analyzed as a function of frequency $\omega$. At each frequency, the resulting sinusoidal current waveform and the applied potential are out of phase by phase angle $(\theta)$, whereas the current amplitude is inversely proportional to the impedance of the interface [104]. The electrochemical impedance, $\mathrm{Z}$ $(\omega)$, is the frequency-dependent proportionality factor in the relationship between the voltage signal and the current response,

$$
Z(\omega)=E(\omega) / i(\omega)
$$

where $E$ is the voltage signal, $E=E_{0} \sin (\omega t) ; i$ is the current density, $i=i_{0} \sin (\omega$ $\mathrm{t}+\theta) ; \mathrm{Z}$ is the impedance $\left(\mathrm{ohm}-\mathrm{cm}^{2}\right)$; and $\mathrm{t}$ is the time (seconds) [142]. 
Impedance is a complex number that is described by the frequency-dependent modulus, $|Z|$, and the phase angle, $\theta$, or, alternatively, by the real component, $Z^{\prime}$, and the imaginary component, Z" [104]. In electrochemical impedance analysis, three different types of plots are commonly used. Figure 3.10 depicts the Nyquist plot which shows complex plane $Z^{\prime \prime}$ vs. $Z^{\prime}$ and the capacitive arc provides an estimate of corrosion resistance of the material, in terms of its relative diameter, which is directly proportional to the charge transfer resistance or polarization resistance $\left(\mathrm{R}_{\mathrm{p}}\right)$. Thus, an increase in semicircle diameter corresponds to an increase in corrosion resistance [127].

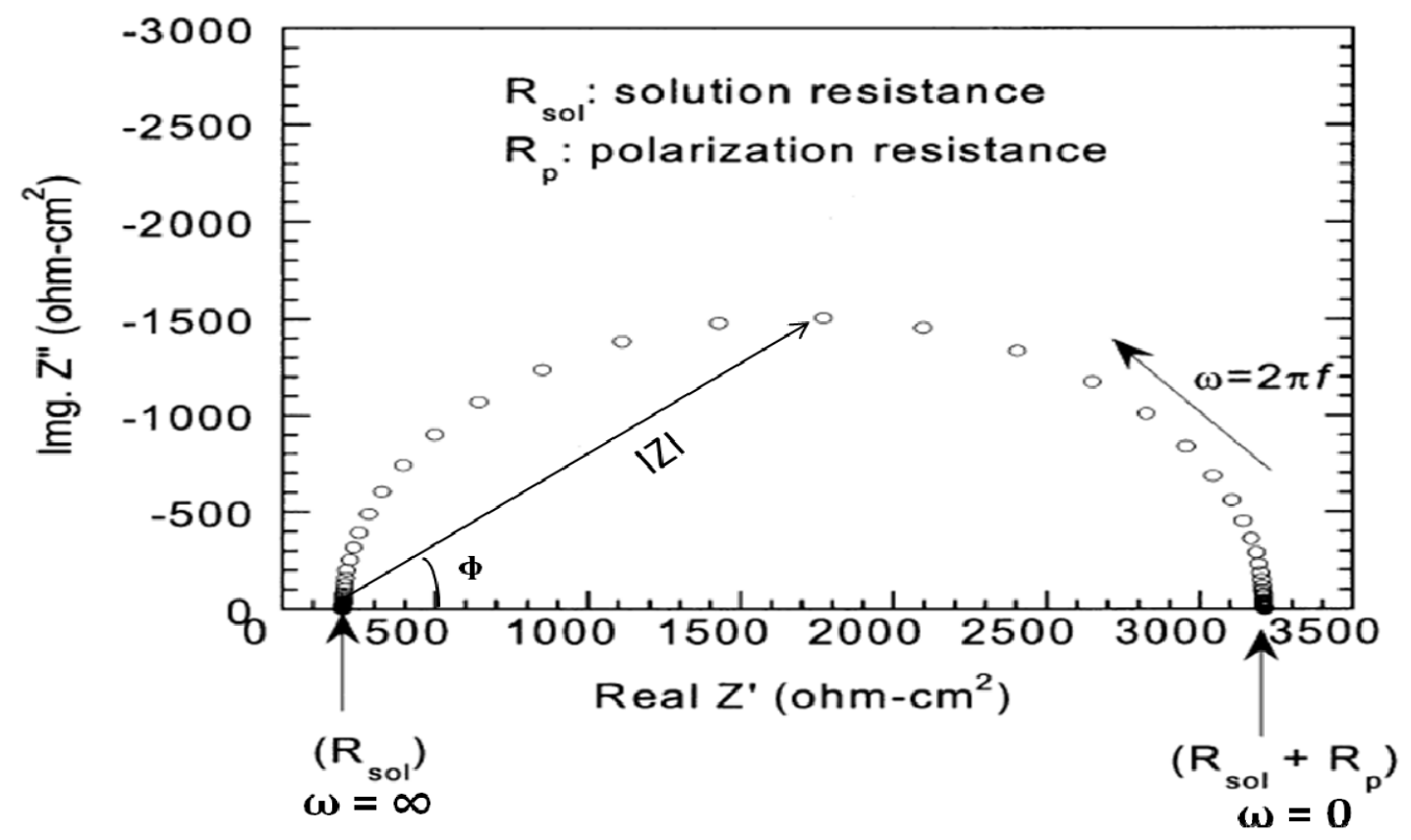

Figure 3.10: A typical Nyquist plot that depicts the real and imaginary impedance values, on the $\mathrm{X}$ and $\mathrm{Y}$ - axis, respectively, for the aforementioned equivalent circuit.

Figure 3.11 depicts the two different Bode plots, showing the impedance magnitude $(\log Z)$ vs. $\log$ frequency $(\log$ f) and the phase angle vs. $\log$ frequency [104]. 

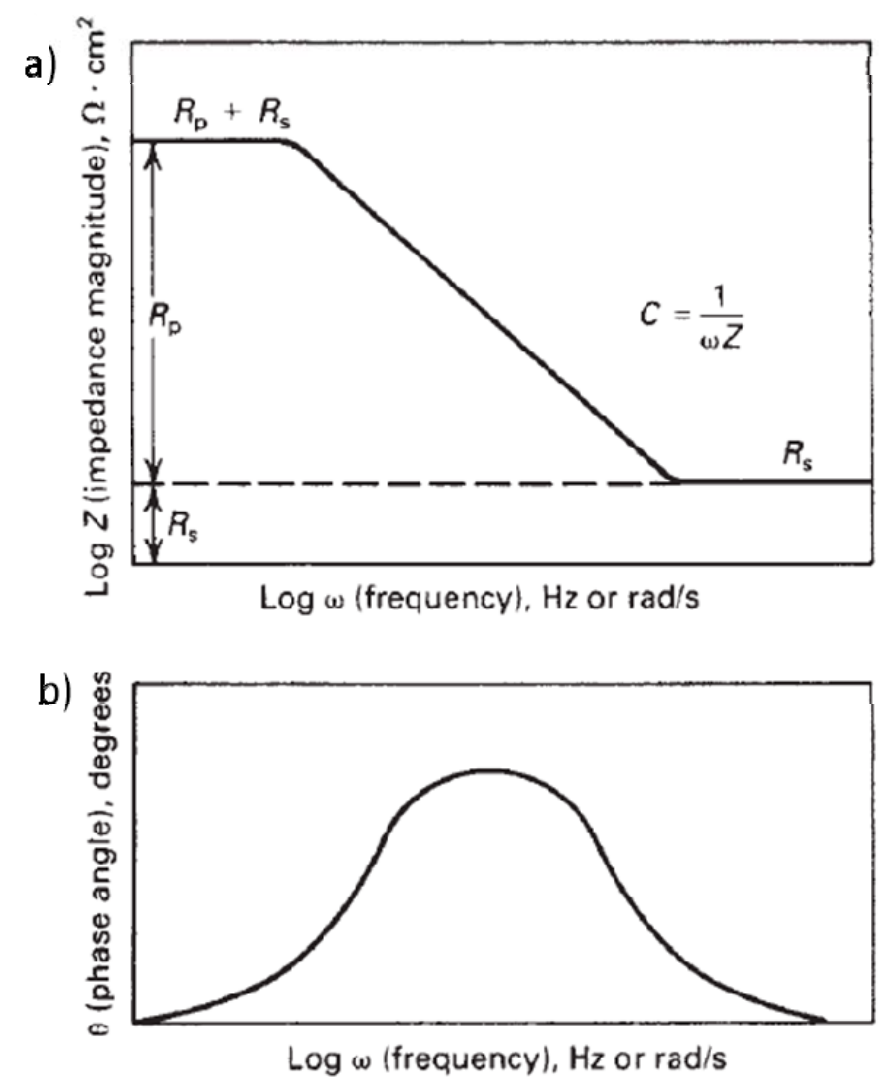

Figure 3.11: A typical Bode plot that shows log frequency on the $\mathrm{x}$-axis, and both the absolute value of the impedance $\log Z$ and phase-shift $\theta$ on the y-axis [143] for the aforementioned equivalent circuit.

Since real electrochemical processes hardly show pure capacitance, during EIS analysis, the non-ideal response of the corrosion system is represented by a CPE to obtain accurate impedance values [144-146]. Bryan $\mathrm{H}$ et al. [147] has shown that CPE behavior can be attributed to the distribution of physical properties of coatings in a direction normal to the electrode's (substrate) surface. Systems with a CPE element have a Nyquist plot that consists of an arc of a circle with the center somewhere below the $\mathrm{x}$-axis instead of a semicircle, as shown in Figure 3.10. Geometric distributions, such as surface 
inhomogenities [148] and porosity of the electrode [149], are known to lead to CPE behavior in EIS measurements.

The two general equivalent circuit models used to represent the bare and polymer coated Nitinol alloys in this research are shown in Figure 3.12.a and 3.12.b, respectively.
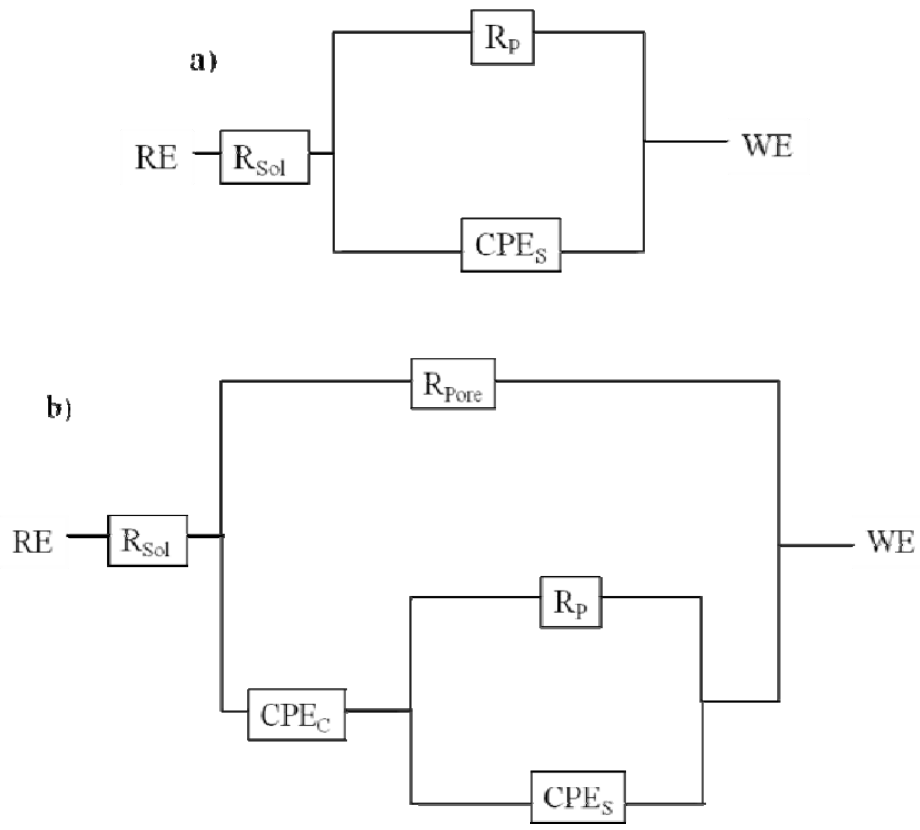

Figure 3.12 a) Equivalent circuit of a bare Nitinol alloy, b) Equivalent circuit of a Nitinol alloy with a polymer coating

Parameter $\mathrm{R}_{\mathrm{p}}$, coupled with $\mathrm{Q}_{\mathrm{s}}$ or $\mathrm{CPE}_{\mathrm{s}}(\mathrm{s}$ - substrate), represent the processes that occur at the substrate layer (at the electrolyte/substrate layer interface). $\mathrm{R}_{\text {pore }}$ corresponds to the charge transfer resistance associated with the penetration of the electrolyte through the pores or pinholes that exist in the external coating and $R_{p}$ is the polarization resistance at the electrolyte/substrate interface in the pores. $Q_{c}$ corresponds to capacitance of the coating layer and $\mathrm{Q}_{\mathrm{s}}$ to the capacitance at the electrolyte/substrate interface, which seems to be associated with the double layer formation $[150,151] . \mathrm{R}_{\text {sol }}$ is the ohmic resistance 
of the electrolyte. The impedance of a constant phase element (CPE) Q is given by Equation 3.14 [152]:

$$
\mathrm{Q}=\mathrm{Z}_{\mathrm{CPE}}=\left(1 / \mathrm{Y}_{0}\right) /(j \omega)^{\mathrm{n}}
$$

where $\mathrm{Y}_{0}$ corresponds to the admittance of the electrode, $\mathrm{j}$ is the imaginary number $(j=\sqrt{ }(-1)), \omega$ is the angular frequency $(\omega=2 \Pi f$ and $f$ is the frequency) and $n$ $(0 \sim 1)$ is an exponential term, which is related to the slope of the $\log (\mathrm{Zmod}) \mathrm{vs} . \log \mathrm{f}$ in Bode plot [150]. CPE has the unit $\mathrm{Ss}^{\wedge} \mathrm{n}$ (Siemens-second $\left.{ }^{\wedge} \mathrm{n}\right)$. CPE is a mathematical construct that characterizes the response of a process with a constant phase shift over a large frequency range. In Equation 3.14, when $n=1$, CPE behaves as a pure capacitor and when $\mathrm{n}=0, \mathrm{CPE}$ behaves as a resistor [150].

\subsubsection{EIS results}

The Nyquist and bode plots for different surface treated NiTi10Ta and NiTi5Cr alloys were as shown in Figures 3.13 to 3.18 .

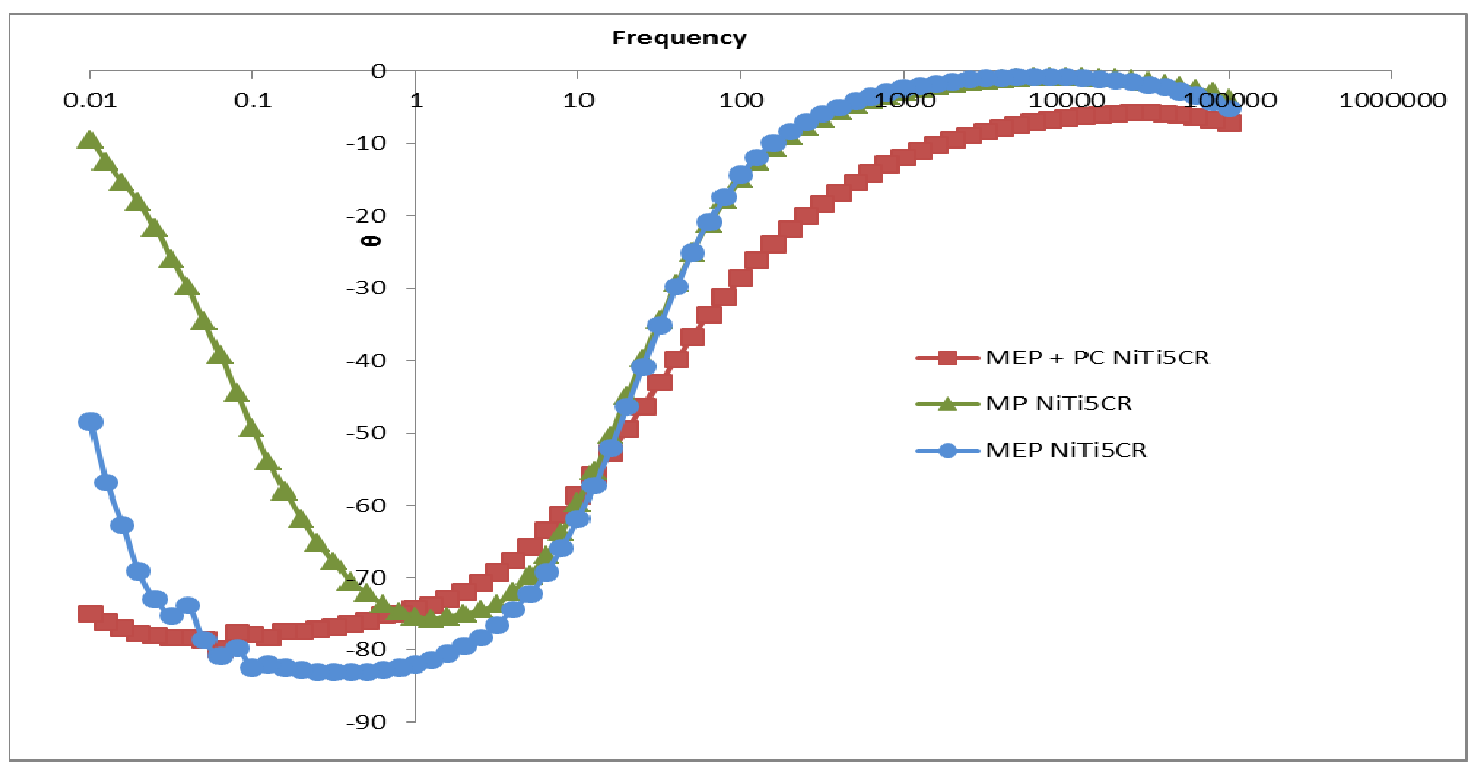

Figure 3.13: A comparative Bode plot analysis for different surface treated NiTi5Cr 
alloys

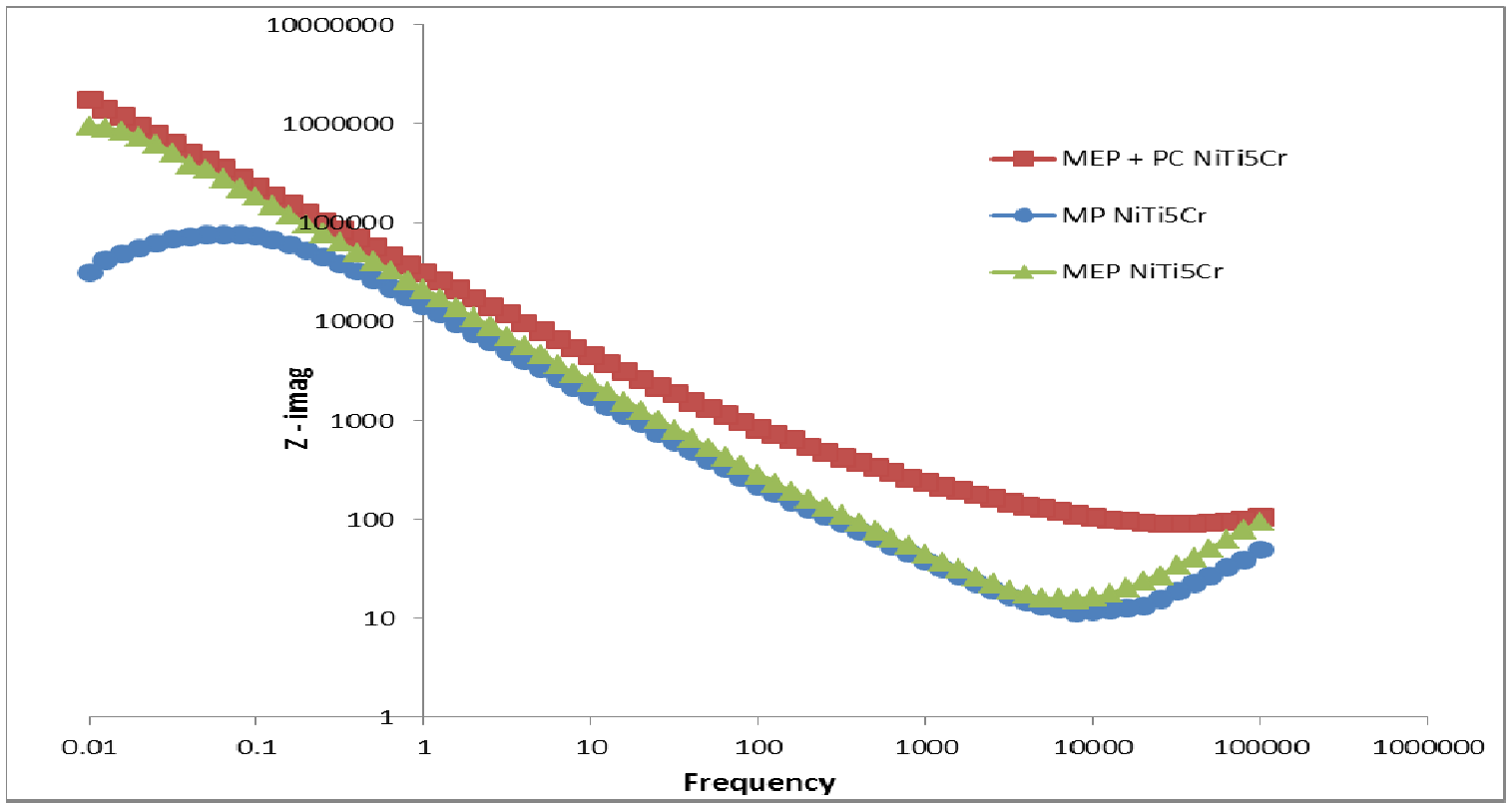

Figure 3.14: A comparative Bode plot analysis for different surface treated NiTi15Cr alloys

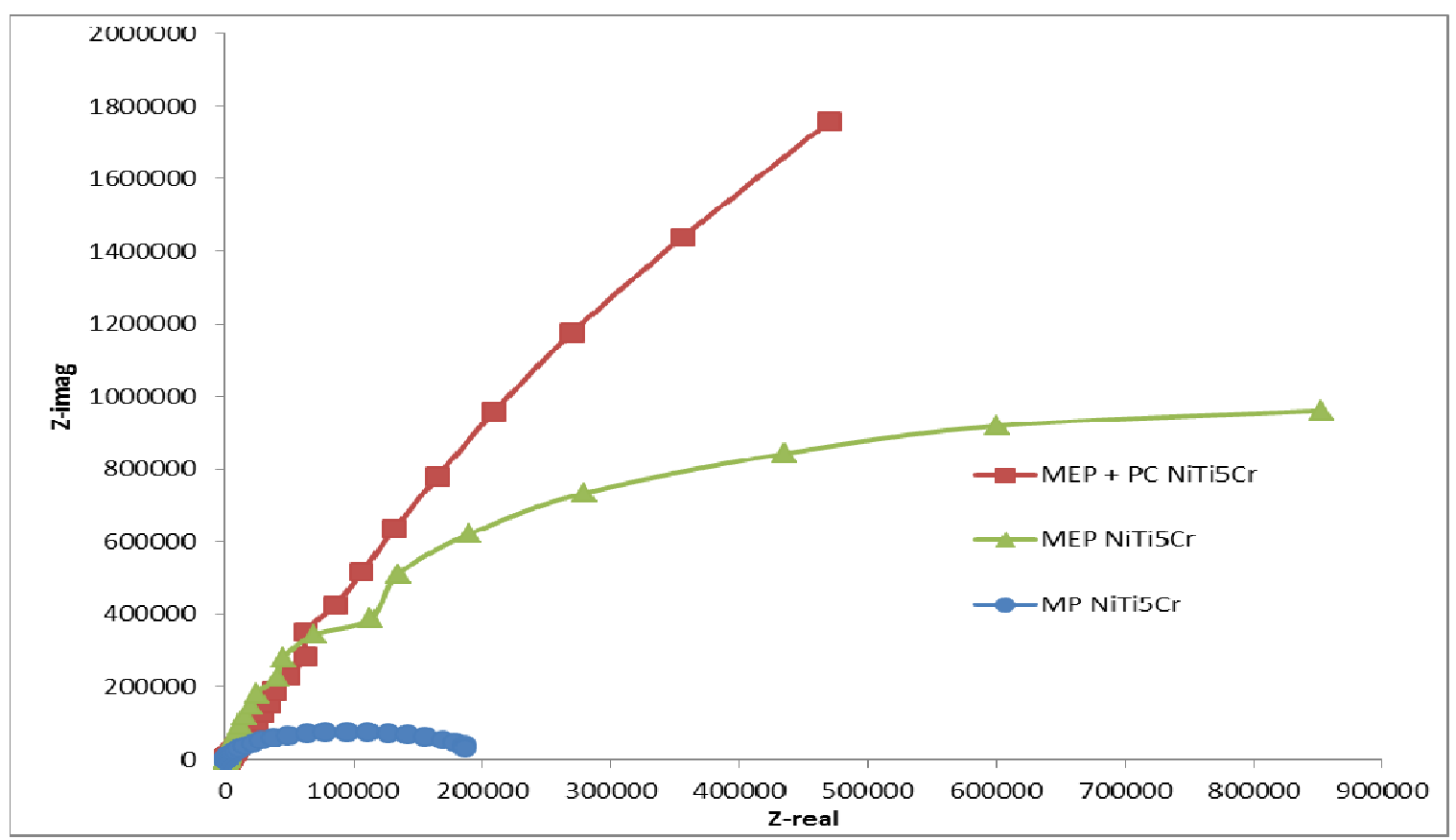

Figure 3.15: A comparative Nyquist plot analysis for different surface treated NiTi5Cr alloys 


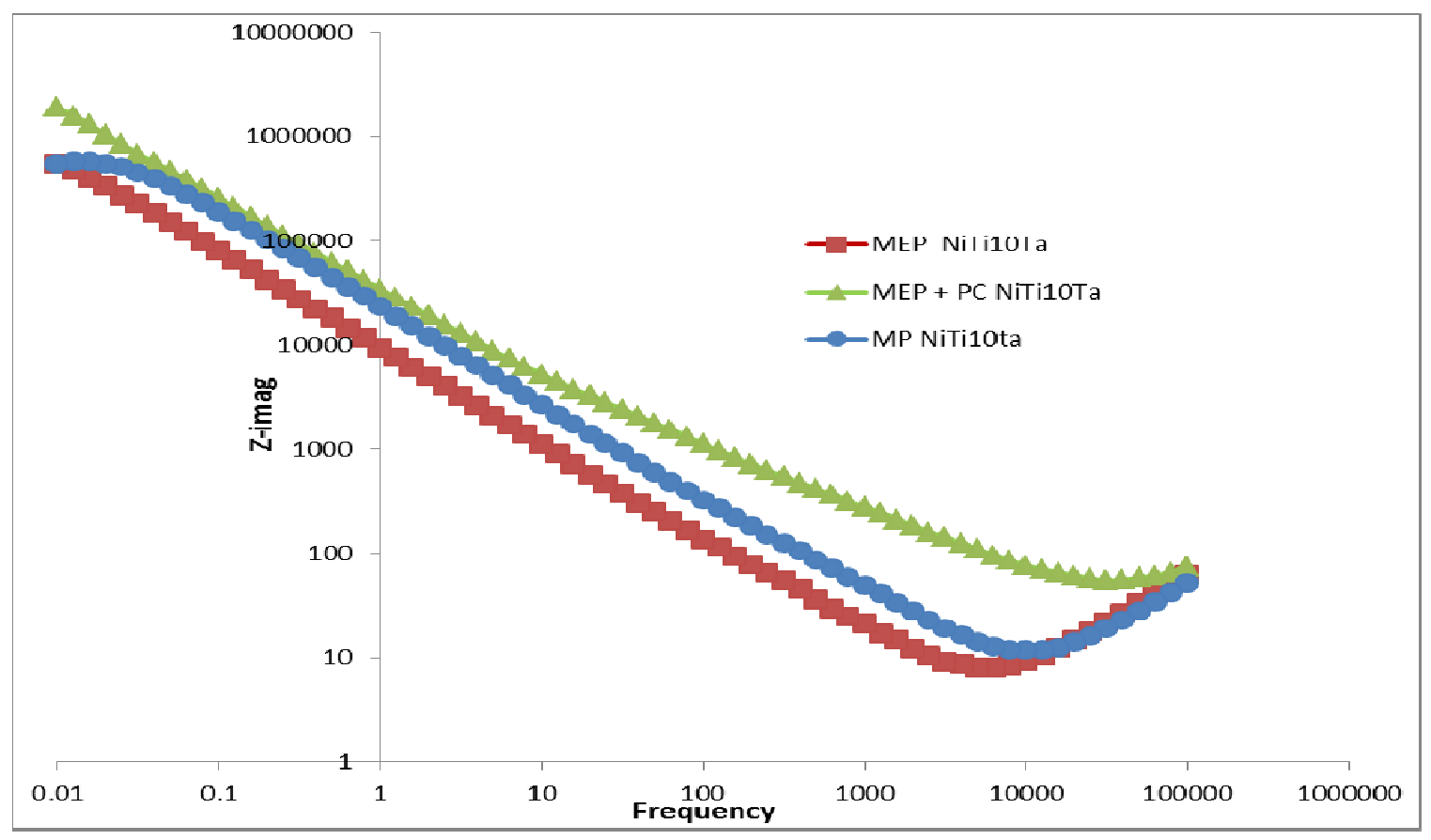

Figure 3.16: A comparative Bode plot analysis for different surface treated NiTi10Ta

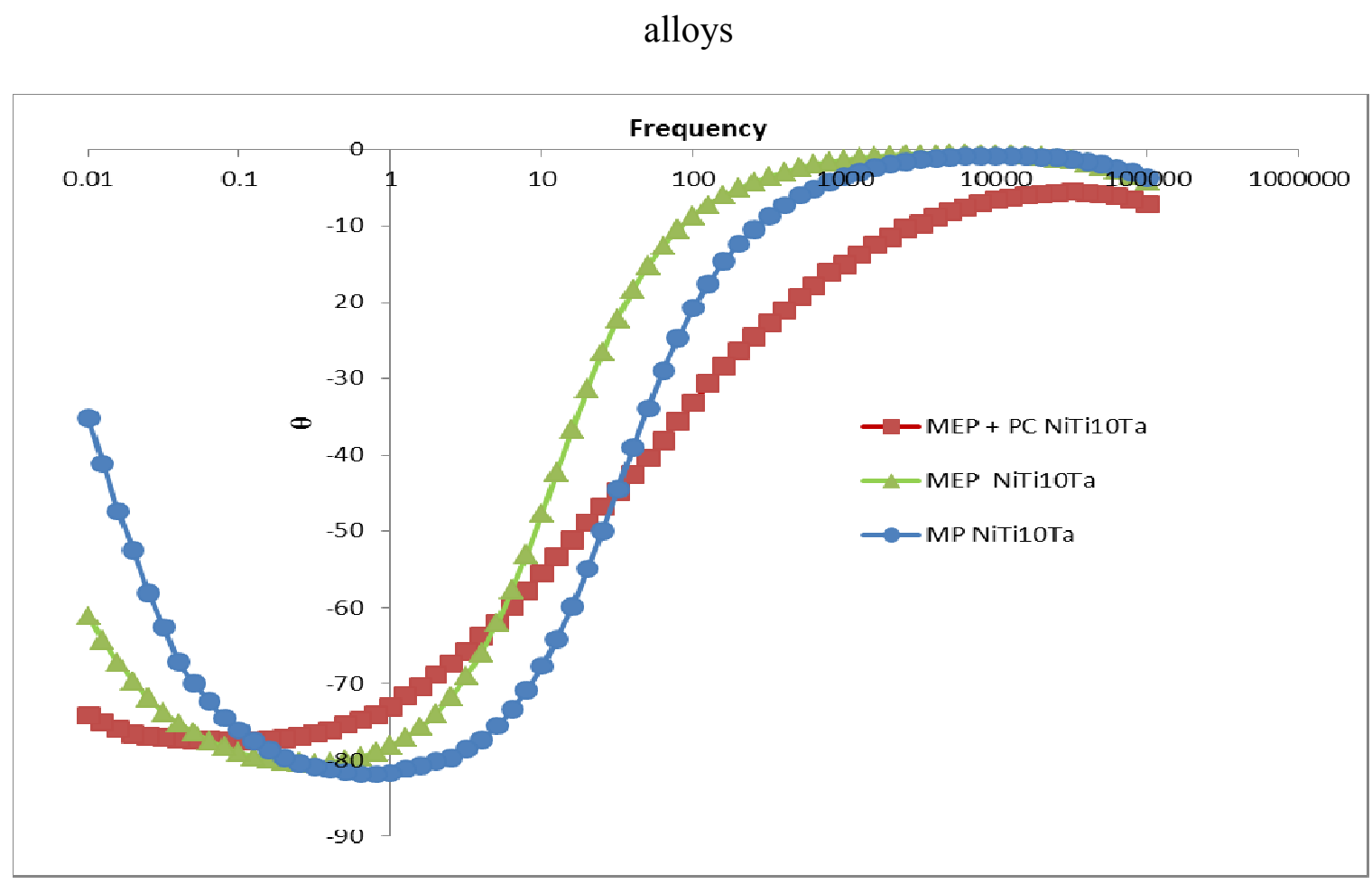

Figure 3.17: A comparative Bode plot analysis for different surface treated NiTi10Ta alloys 


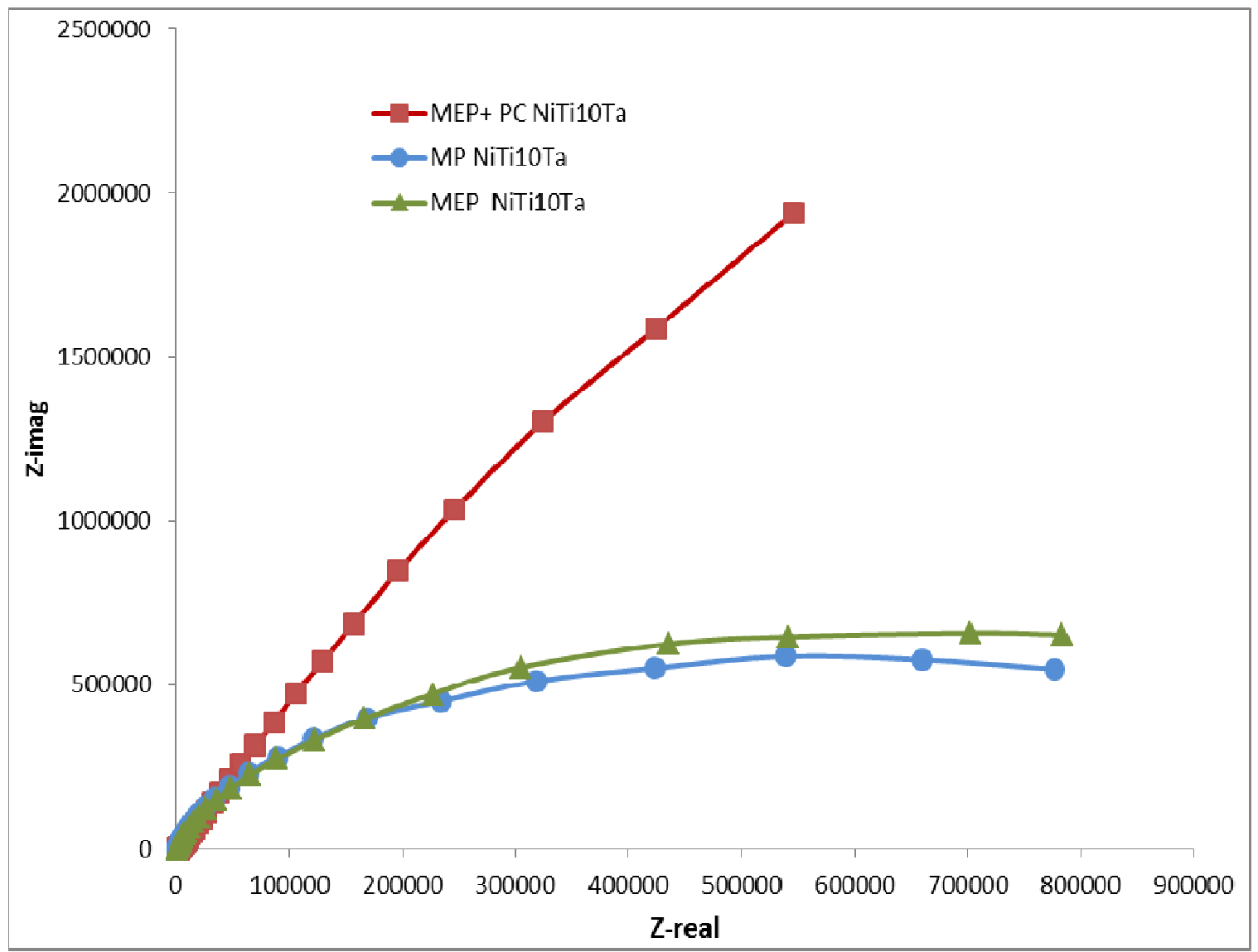

Figure 3.18: A comparative Nyquist plot analysis for different surface treated NiTi10Ta alloys

A variation in the polarization resistance $\left(\mathrm{R}_{\mathrm{p}}\right)$ of a metal due to the change in its surface properties can be observed in terms of its Nyquist and Bode plots as shown in Figure 3.19. An increase in $R_{p}$ value of a metal signifies an improvement in its corrosion resistance ie., the diameter of the arc in the Nyquist plot increases and even the magnitude of the impedance ( $|Z|)$ increases towards a lower frequency in the Bode plot. 

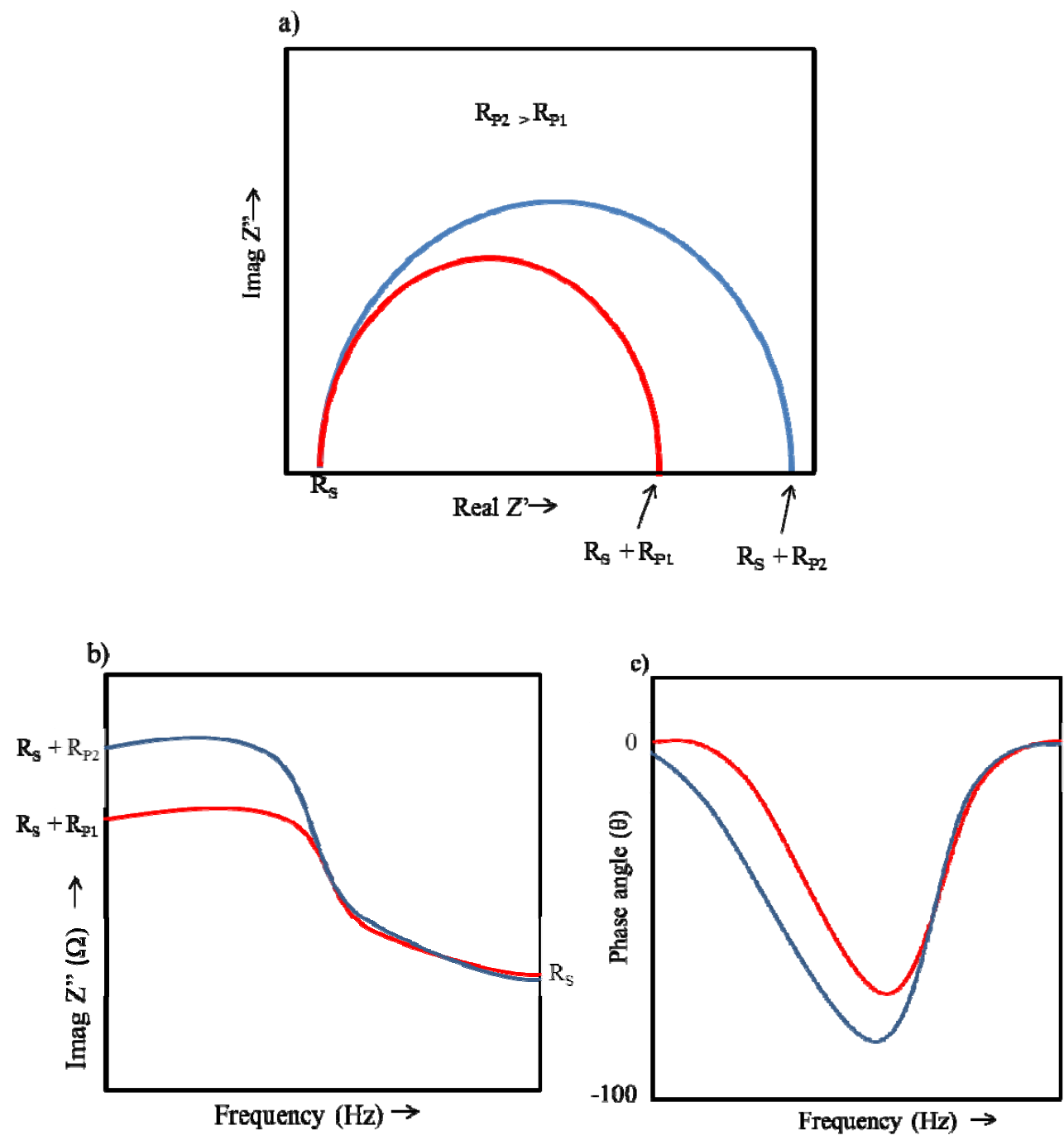

Figure 3.19: Effect of changing $R_{p}$ in terms of illustrative a) Nyquist plot; b) \& c) Bode

$$
\text { plots }
$$

The value of the reaction resistance $R_{\text {pore }}$ is characteristic of the corrosion resistance of the polymer coatings and is worth comparing to determine the relative protective effect of each polymer [120].

In this research, Bode and Nyquist plots obtained for surface coated and uncoated Nitinol alloys were analyzed using appropriate equivalent circuit models. 
Table 3.3: Significance of different equivalent elements used in an equivalent circuit

\begin{tabular}{|c|c|c|c|}
\hline Symbol & Equivalent element & Admittance & Impedance \\
\hline & Resistor $(\mathrm{R})$ & $1 / \mathrm{R}$ & $\mathrm{R}$ \\
\hline$\square$ & Capacitor $(\mathrm{C})$ & $\mathrm{J} \omega \mathrm{C}$ & $1 / \mathrm{j} \omega \mathrm{C}$ \\
\hline$\square$ & Constant Phase Element $(\mathrm{Q})$ & $\mathrm{Y}_{0}(\mathrm{j} \omega)^{\mathrm{n}}$ & $\left(1 / \mathrm{Y}_{0}\right) /(\mathrm{j} \omega)^{\mathrm{n}}$ \\
\hline
\end{tabular}

Table 3.3 depicts the impedance and admittance values of different equivalent elements used in an equivalent circuit.

The EIS curves for both polymer coated and uncoated Nitinol alloys were fitted into their respective equivalent circuits to determine their EIS coating parameters, such as, $R_{\text {sol }}$ and $R_{p}$. The equivalents circuits and their corresponding coating parameters for aforementioned ternary Nitinol alloys are shown below.

a)

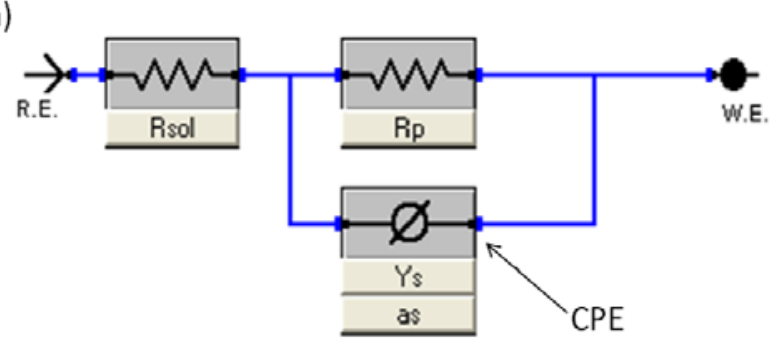

b)

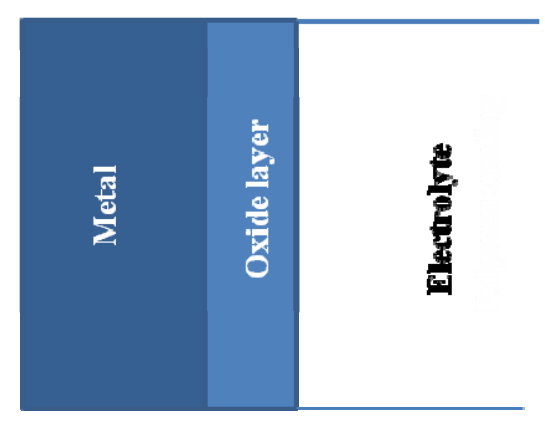

Figure 3.20: a) Equivalent EIS circuit for MEP Nitinol alloys, b) schematic of corresponding metal - metal oxide - electrolyte interface 
Table 3.4: EIS fitted parameters for MEP Nitinol alloys (mean $\pm \mathrm{SD}, \mathrm{n}=5$ )

\begin{tabular}{|c|c|c|c|c|}
\hline Parameter & $\mathbf{R}_{\text {Sol }}(\boldsymbol{\Omega})$ & $\mathbf{R}_{\mathbf{p}}(\boldsymbol{\Omega})$ & $\mathbf{Y}_{\mathbf{S}}\left(\mathbf{S}^{*} \mathbf{s}^{\wedge} \mathbf{a}\right)$ & $\mathbf{a s}_{\mathbf{S}}$ \\
\hline NiTi10Ta - MEP & $876 \pm 4$ & $1.51 \mathrm{e} 6 \pm 6.4 \mathrm{e} 4$ & $18.8 \mathrm{e}-6 \pm 10.2 \mathrm{e}-8$ & $936.2 \mathrm{e}-3 \pm 2.08 \mathrm{e}-3$ \\
\hline NiTi5Cr-MEP & $1.07 \mathrm{e} 3 \pm 5$ & $2.46 \mathrm{e} 6 \pm 7.4 \mathrm{e} 4$ & $8.3 \mathrm{e}-6 \pm 4.5 \mathrm{e}-8$ & $943.2 \mathrm{e}-3 \pm 1.88 \mathrm{e}-3$ \\
\hline
\end{tabular}

where $\mathrm{R}_{\text {sol }}$, the testing solution resistance, is in series with a parallel circuit consisting of $R_{p}$ and $Y_{s}$, the reaction resistance associated with interfacial charge transfer reaction process and capacitance associated with the electrolyte double layer established at the interface, respectively [120].

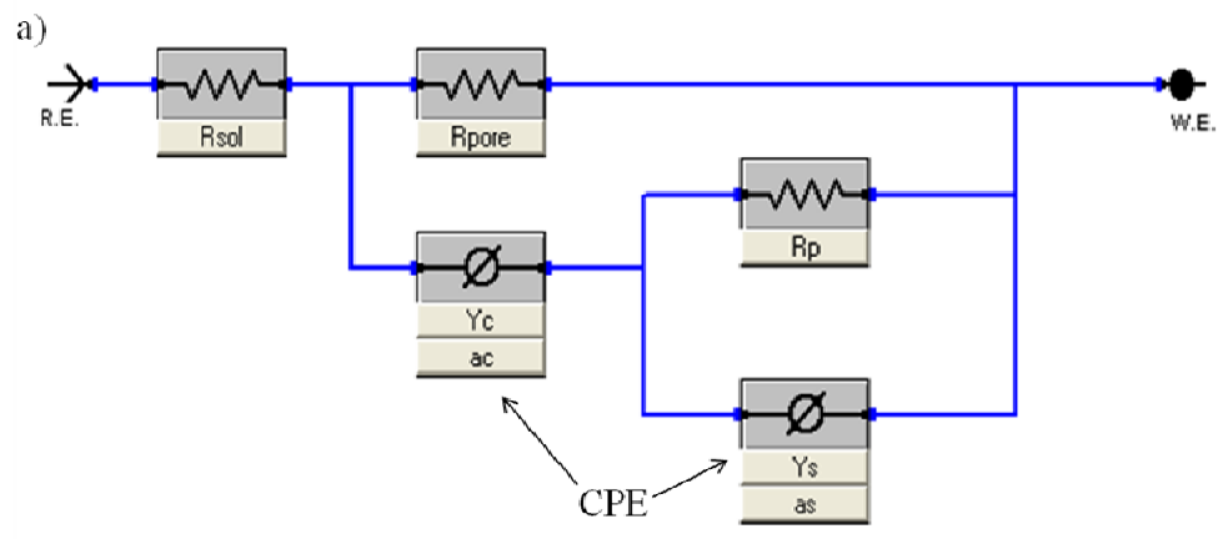

b)

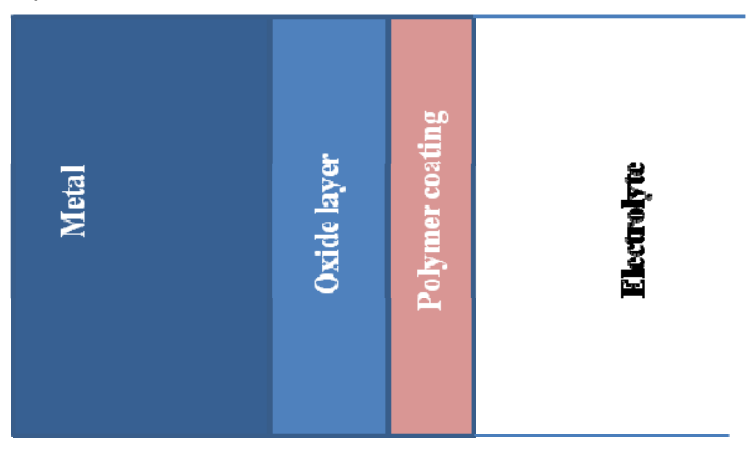

Figure 3.21: a) Equivalent EIS circuit for a two-layer model: MEP + PC Nitinol alloys, b) schematic of corresponding metal/metal oxide/polymer/electrolyte interface 
Table 3.5: EIS fitted parameters for MEP $+\mathrm{PC}$ Nitinol alloys (mean $\pm \mathrm{SD}, \mathrm{n}=5$ )

\begin{tabular}{|c|c|c|c|c|c|c|c|}
\hline Parameter & $\mathbf{R}_{\text {Sol }}(\mathbf{\Omega})$ & $\mathbf{R}_{\text {pore }}(\mathbf{\Omega})$ & $\mathbf{R}_{\mathbf{P}}(\mathbf{\Omega})$ & $\begin{array}{c}\mathbf{Y}_{\mathbf{C}} \\
\left(\mathbf{S *}^{\wedge} \mathbf{a}\right)\end{array}$ & $\mathbf{a}_{\mathbf{C}}$ & $\begin{array}{c}\mathbf{Y}_{\mathbf{S}} \\
\left(\mathbf{S}^{*} \mathbf{s}^{\wedge} \mathbf{a}\right)\end{array}$ & $\mathbf{a}_{\mathbf{S}}$ \\
\hline NiTi10Ta & $771 \pm 26$ & $5.3 \mathrm{e} 6 \pm 4$. & $280 \pm 50$ & $7.5 \mathrm{e}-6 \pm$ & $898.7 \mathrm{e}-$ & $117.1 \mathrm{e}-$ & $431.7 \mathrm{e}-$ \\
$\mathrm{MEP}+\mathrm{PC}$ & & $3 \mathrm{e} 5$ & & $51.2 \mathrm{e}-9$ & $3 \pm 3.1 \mathrm{e}-3$ & $6 \pm 1.4 \mathrm{e}-6$ & $\begin{array}{c}3 \pm 143.2 \mathrm{e} \\
-3\end{array}$ \\
\hline NiTi5Cr & $114 \pm 31$ & $13.8 \mathrm{e} 6 \pm$ & $24.6 \mathrm{e} 3 \pm 8$ & $5.49 \mathrm{e}-6 \pm$ & $775.4 \mathrm{e}-$ & $107.0 \mathrm{e}-$ & $\begin{array}{c}174.6 \mathrm{e}- \\
\mathrm{MEP}+\mathrm{PC}\end{array}$ \\
& & $3.8 \mathrm{e} 5$ & 2 & $84.9 \mathrm{e}-9$ & $3 \pm 8.9 \mathrm{e}-3$ & $6 \pm 75.3 \mathrm{e}-6$ & $\begin{array}{c}3 \pm 69.9 \mathrm{e}- \\
3\end{array}$ \\
\hline
\end{tabular}

From Table 3.5 it can be observed that $\mathrm{R}_{\text {pore }}$ and $\mathrm{R}_{\mathrm{p}}$ of $\mathrm{MEP}+\mathrm{PC}$ NiTi5Cr were high as compared with that of MEP + PC NiTi10Ta alloy. This shows that the polymer coating on $\mathrm{MEP}+\mathrm{PC} \mathrm{NiTi5Cr}$ has a better corrosion resistance than $\mathrm{MEP}+\mathrm{PC}$ NiTi10Ta alloy.

\subsection{Methodology for cyclic polarization and EIS tests}

A Gammry corrosion cell, as shown in Figure 3.22, was used to perform the corrosion tests.

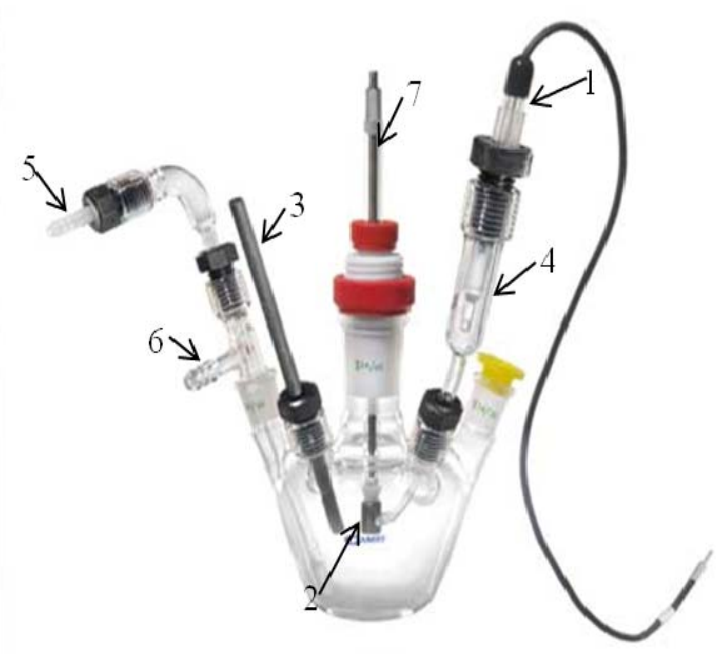

Figure 3.22: Gamry corrosion cell kit used for cyclic potentiodynamic polarization tests. 
1- Standard reference calomel electrode, 2 - Working electrode (PNT), 3 - Counter electrode (Carbon rod), 4 - Lugging capillary, $5-\mathrm{N}_{2}$ gas inlet , $6-\mathrm{N}_{2}$ gas outlet , 7 Sample holder.

Deionized water was used to rinse the corrosion cell before performing the tests. The cell with the PBS electrolyte was brought up to $37{ }^{\circ} \mathrm{C}$ by placing it in a thermostatically controlled temperature water bath. A saturated calomel electrode was inserted into the Luggin capillary. The surface area of the pellet in contact with PBS was carefully calculated in order to increase the accuracy of the corrosion parameters. The PBS solution was purged with ultra-high purity nitrogen for 30 minutes, prior to immersion of the pellet. Later, the working electrode that was immersed in the electrolyte was subjected to nitrogen purging for an additional 30 minutes, before starting the cyclic polarization tests, at which stage the rest potential was obtained. A GAMRY® potentiostat (G-750) was employed with a scan rate of $1 \mathrm{mV} / \mathrm{s}$ over a potential range of 0.1 to 3.0 vs. a Saturated Calomel Electrode (SCE).

EIS tests were conducted in a specially developed EIS cell, as shown in Figure 3.23 .

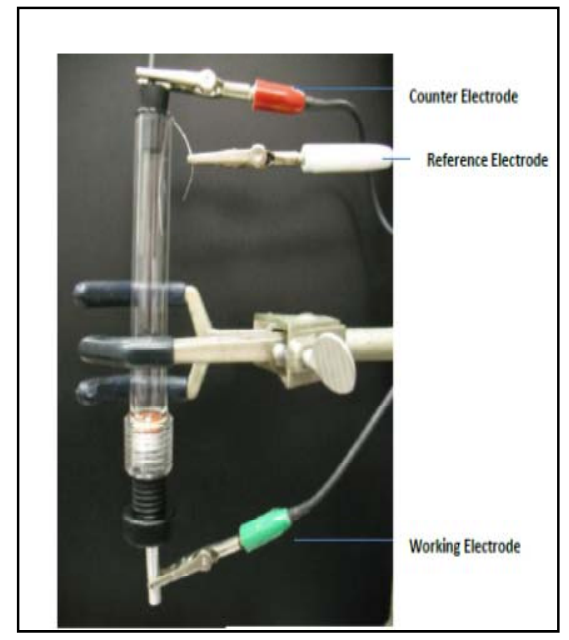

Figure 3.23: EIS cell with counter, reference and working electrodes 
EIS tests were conducted in accordance with ASTM G 3-89 at $37^{\circ} \mathrm{C}$, employing a GAMRY ${ }^{\circledR}$ potentiostat (G-750). PBS was purged with high-purity nitrogen for 30 minutes prior to conducting the EIS tests to remove any dissolved oxygen. The experiment was conducted in a frequency range from $1.0^{-2} \mathrm{~Hz}$ to $1.0^{+5} \mathrm{~Hz}$ with 10 points per decade. The evolution of impedance spectra is presented as a Bode plot from which the magnitude of polarization resistance and characteristic corrosion behavior are seen.

\subsection{Nickel ion leaching}

The regular standard dietary intake of $\mathrm{Ni}$ in the human body is about $150-900$ $\mu \mathrm{g} /$ day [153]. The concentration of Ni ions in human blood varies from 25-67 ppb [154]. Arndt et al. [155] showed that the amount of Ni ions leached from orthodontic Nitinol wires under in-suit conditions varied between 0.2 to $0.7 \mu \mathrm{g} \mathrm{cm}^{-2}$. Depending on the surface preparation and surface composition of Ni in Nitinol, Ni leaching will vary [156]. Shabalovskaya et al. [157] observed that, based on the type of Nitinol's surface finishing, Ni ion leaching has varied from $0.03 \mathrm{mg} / \mathrm{ml}$ to $1.8 \mathrm{mg} / \mathrm{ml}$ and it occurred even after five months of implantation. For example, formation of a thick external $\mathrm{TiO}_{2}$ layer during high-temperature annealing of Nitinol in air leads to accumulation of $\mathrm{Ni}$ in the sub-surface layers and this can act as a reservoir for Ni leaching when the surface oxide is damaged [156]. Shabalovskaya et al. [157] described that, since nickel has a smaller atomic radius as compared with titanium and oxygen atoms, and also due to the spontaneous formation of non-stoichiometric titanium oxide layers (oxygen vacancy defects), formation of Ni-rich reservoirs (interstitial atomic defects) in the intermediate 
layers will occur. This leads to $\mathrm{Ni}$ diffusion through the oxygen vacancies after implantation of Nitinol, as shown in Figure 3.24.

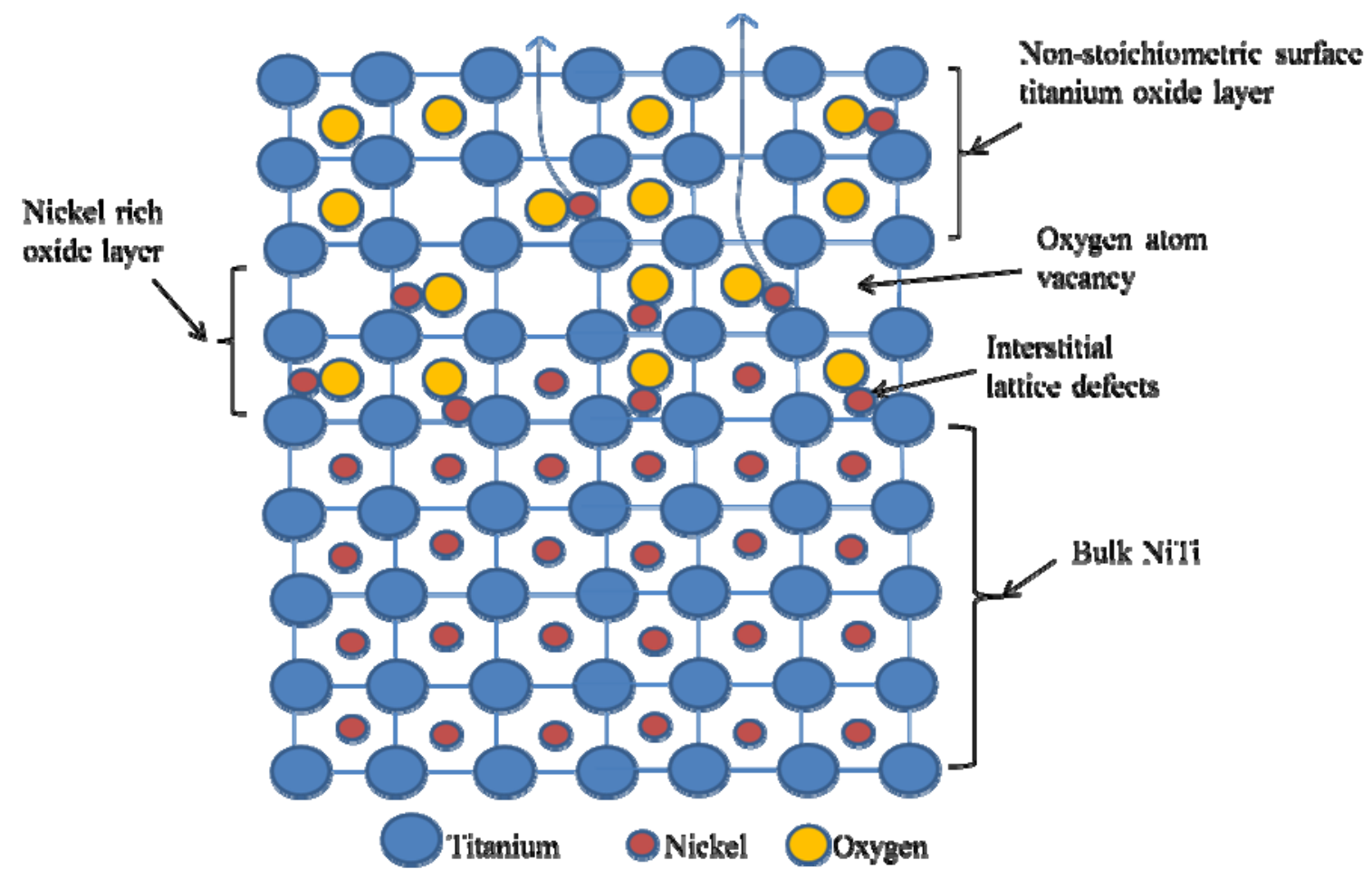

Figure 3.24: Formation of non-stoichiometric titanium oxide layer and Ni-rich intermediate layers on Nitinol.

The rate of metal ion transfer through the passive oxide film and its stability against dissolution will control Ni leaching [158]. According to Haider et al. [39], the concentration of $\mathrm{Ni}$ released from Nitinol after 24 hours of immersion in phosphate buffer saline solution under static and dynamic conditions range between 12.4 and 23.4 $\mu \mathrm{g} / \mathrm{L}$. Systemic accumulation of Ni ions takes place mainly in the kidneys and lungs of the human body [159]. In addition, the presence of $\mathrm{Ni}$ ions in the human body poses problems for the immune, cardiovascular, blood, and respiratory systems [160]. Furthermore, nickel compounds, such as $\mathrm{Ni}_{\mathrm{x}} \mathrm{S}_{\mathrm{y}}, \mathrm{Ni}_{\mathrm{x}} \mathrm{Se}_{\mathrm{y}}$, and $\mathrm{Ni}_{\mathrm{x}} \mathrm{As}_{\mathrm{y}}$ ( $\mathrm{x}$ and y are integers) 
act as carcinogenic agents [161], which could result in the formation of tumors. As leaching of $\mathrm{Ni}$ is a surface-related phenomenon, in the case of bone implants such as porous Nitinol (PNT), due to its large surface area-to-volume ratio, higher Ni ion release can be expected $[41,162,163]$. In the case of self-expanding cardiovascular stents prepared from Nitinol, Ni leaching was believed to promote neointimal proliferation[42]. Additionally, Ni leaching is dependent on other factors, such as surface roughness, thickness of surface oxide layer, its composition, bulk composition and presence of nonequiatomic chemical species on its surface (Ti2Ni, Ni3Ti, and Ni) [164]. Oxidation, water boiling, passivation, dry heating, electropolishing and magneto electropolishing of Nitinol were some of the surface treatments that were known to improve the aforementioned properties of the passivating oxide layer, and can lead to variation in surface Ni concentrations [162] [114] and reduced Ni leaching [165]. Michiardi et al. [166] demonstrated that oxidation of Nitinol in $\mathrm{O}_{2}$ at a pressure of $3 \times 10^{-2}$ mbar at 400 ${ }^{\circ} \mathrm{C}$ for 2 hours and 30 minutes can lead to a Ni-free $\mathrm{TiO}_{2}$ surface. Surface characteristics, such as morphology, roughness [167-169], surface energy [169], corrosion resistance, and surface layer chemical composition [170, 171], play an important role in the interaction between Nitinol implants and cellular adhesion and their proliferation in the human body $[167,172]$. As a result, surface treatment of Nitinol before implantation can be employed to modify its chemical, physical, and biological interaction properties [173]. 


\section{CHAPTER 4}

\section{MATERIALS AND METHODS}

\subsection{Ternary Nitinol alloys}

Cylindrical ingots of ternary Nitinol alloys NiTi5Cr and NiTi10Ta (atomic \%) were prepared by arc melting (AM) at the National Institute of Standards and Technology (NIST). The compositions of these alloys in at $\%$ are shown in Table 4.1.

Table 4.1: Ternary Nitinol alloys composition in atomic percentages

\begin{tabular}{|c|c|c|c|}
\hline Nickel & Titanium & Chromium & Tantalum \\
\hline 48.45 & 46.45 & 5 & - \\
\hline 45.90 & 44.10 & - & 10 \\
\hline
\end{tabular}

Experimental samples were prepared by cutting the cylindrical ingots with a highspeed linear precision saw (ISOMET 4000) into cylindrical discs of dimension (10mm x $2 \mathrm{~mm})$.

\subsubsection{Alloying of Nitinol}

Tantalum (Ta) alloys are recognized for their promising in-vivo biocompatibility $[174,175]$ and bioactivity [176] due to their excellent corrosion resistance [177], low toxicity, good osteointegration and mechanical properties. Porous Ta alloys and Ta coatings have been studied for bone implant applications [178]. Tantalum acts as a radioopaque [125] material, since its high density $\left(16.654 \mathrm{~g} / \mathrm{cm}^{3}\right)$ resist the passage of $\mathrm{x}$-rays. Jinalu et al. [179] showed that addition of Ta to Nitinol improved the alloy's X-ray visibility (subject contrast). Since Nitinol alloys have very low x-ray visibility, usage of Ta and its oxides as markers $[180,181]$ in implants (stents, cardiac defibrillators, etc.) enable surgeons to track them during and after implantation procedures. 
The addition of chromium $(\mathrm{Cr})$ is known to create a corrosion resistant and passive oxide layer on the surface of Nitinol alloy. This happens due to a greater affinity of $\mathrm{Cr}$ for oxygen rather than chloride ions as discussed by Horvath and Uhlig [182]. Additionally, $\mathrm{Cr}$ is known to increase the yield stress, stiffness and torqueability of Nitinol alloy [183].

\subsection{Biodegradable polymer}

In this investigation, a biodegradable co-polymer consisting of polycaprolactone (PCL)/poly glycolic acid (PGA) in the ratio of 90/10 was used as a coating. The properties of each constituent polymer are shown in Table 4.2.

Table 4.2: Physical and chemical properties of PGA [184] and PCL [185] polymers

\begin{tabular}{|c|c|}
\hline PGA & PCL \\
\hline Poly (glycolide) - linear aliphatic polyester & Poly ( $\varepsilon$ - caprolactone) \\
\hline Monomer - glycolide & Monomer - e caprolactone \\
\hline $\begin{array}{l}\text { Ring opening polymerization of glycolide } \\
\text { yields high molecular weight materials }\end{array}$ & $\begin{array}{l}\text { Ring opening polymerization of } \mathrm{e}- \\
\text { caprolactone }\end{array}$ \\
\hline Crystalline $(45 \%-55 \%)$ & Semi crystalline \\
\hline Melting temperature, $\mathrm{T}_{\mathrm{m}}=220-225{ }^{0} \mathrm{C}$ & $\mathrm{T}_{\mathrm{m}}=59-64{ }^{0} \mathrm{C}$ \\
\hline Glass transition temperature, $\mathrm{T}_{\mathrm{g}}=35-40{ }^{0} \mathrm{C}$ & $\mathrm{T}_{\mathrm{g}}=-65$ to $-60{ }^{0} \mathrm{C}$ \\
\hline Degradation time 6-12 months & Degradation time $>24$ months \\
\hline Elastic modulus, 6.0-7.0 GPa & $0.21-0.44 \mathrm{GPa}$ \\
\hline Tensile strength, 60-99.7 MPa & $20.7-42 \mathrm{MPa}$ \\
\hline Tensile elongation, $1.5-20(\%)$ & $300-1000$ \\
\hline 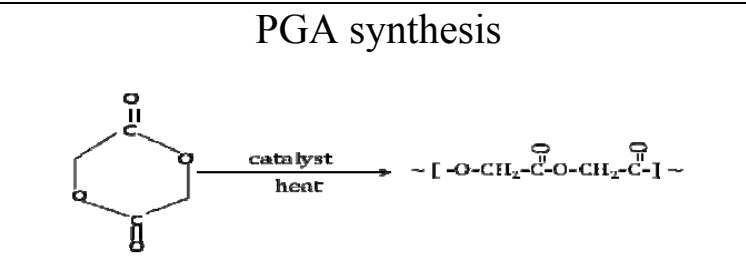 & 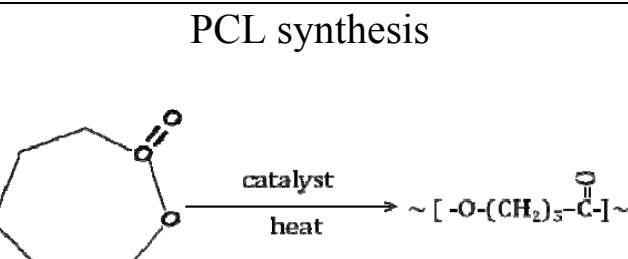 \\
\hline
\end{tabular}




\subsubsection{Degradation of biosorbable polymers}

A biomaterial is defined as a material intended to interface with biological systems to evaluate, treat, augment or replace any tissue, organ or function of the body [23]. A polymer is defined as a non-metallic solid material with high molecular weight [186]. Polymers generally consist of a single or multiple monomer units depending on their nature and repeat themselves to form a high molecular weight substance. In general, polymers used for biomedical applications can be broadly categorized into biodegradable and non-biodegradable polymers. The word 'biodegradable' itself suggests that these polymers, both in in-vitro and in-vivo conditions, will degrade into either normal metabolites or degradation products that could be completely eliminated from the body without further transformations [187-189].

Biodegradable polymers when placed in a complex biological environment, such as that prevailing inside a human body, will dissolve by a combination of two processes, namely degradation and erosion $[187,188]$. They undergo degradation through a chain scission process in which long polymer chains will be broken down into small oligomers and then eventually into single monomer units either hydrolytically or enzymatically [190]. Hydrolytic degradation of a polymer is dependent on many factors, such as its molecular weight, type of chemical bond, $\mathrm{pH}$, co-polymer composition and mainly its hydrophilicity or hydrophobicity [187]. Hydrophilic polymer coatings were shown to

display lower levels of monocyte adhesion (an indicator of platelet adhesion) as compared with hydrophobic polymer coatings. The addition of $\mathrm{pH}$ varying compounds to the polymer matrix will also affect its degradation rate [187]. The erosion of polymers 
occurs due to dissolution and diffusion of the aforementioned low molecular weight polymer products by the liquids in contact with them [187, 188, 191]. Erosion process can occur by two different methods namely, surface erosion and bulk erosion [187]. During surface erosion, only the surface layers of a polymer matrix undergo erosion and results in a predictable drug release kinetics [187] [191]. Bulk erosion is not limited to the surface of the polymer matrix but the bulk of the polymer erodes and it results in a diffusion dependent drug release [187] [191]. Additionally, during bulk erosion the shape of the polymer is retained before its degradation [192]. Figure 4.1(a) shows surface erosion of a polymer matrix and its layer by layer drug release pattern, and Figure 4.1(b) shows bulk erosion of polymer matrix and its bulk drug release pattern. Although, PGA and PCL belong to the polyester group, PCL's structure differs from PGA by two extra carbon atoms in its polymer's backbone. PCL has a lower in-vivo biodegradation rate as compared to PGA and so it is applied for more controlled drug release applications [193].

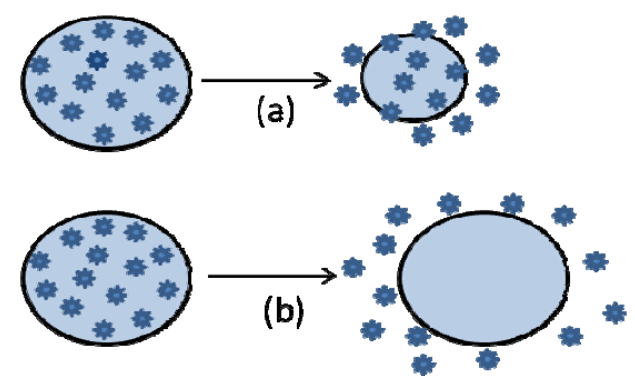

Figure 4.1 a) Surface erosion and b) bulk erosion in polymer matrix

Polylactic acid (PLA), polyglycolic acid (PGA) and the copolymer polylactic-coglycolic acid (PLGA) are some of the biodegradable polymers that are widely used for medical applications, such as sutures, orthopedic and drug eluting devices [194, 195]. Both PGA and PCL are known to degrade by bulk erosion process. The aforementioned biodegradable polymers when used as DES coatings will ensure the gradual release of the 
drug due to hydrolytic degradation of their ester bonds [196]. Subsequently, enzymatic degradation of lactic and glycolic acids will result in production of water and carbon dioxide [197]. The physiochemical properties of a polymer coating, such as cross linked density, water content, isoelectric point and molecular weight between cross links should be considered while tailoring the stent coating for drug delivery [198]. The degradation rate of PGA/PCL polymer can be controlled by varying the composition and molecular weight of its corresponding monomers.

\subsection{Magneto-electropolishing treatment}

Magneto-electropolishing (MEP) is known to increase the hydrophilicity and fatigue resistance of implant materials, in addition to improve oxide formation and corrosion resistance [199]. In the case of stainless steel, MEP has resulted in improved surface hydrophilicity as compared with that of electropolished surfaces. Hydrophilicity plays a major role in improved biocompatibility of implant materials [40]. Tadeusz et. al., [200] showed that MEP treatment of SS 316L has not only enhanced its corrosion resistance, wettability, surface energy and cleanability, but also reduced its external surface soiling and micro roughness. Therefore, MEP treatment can be applied to medical implantable devices, such as stents and intravenous vascular devices, to improve their overall biocompatibility by enhancing their surface chemistry and morphology.

The magnetoelectropolishing (MEP) process utilizes an externally applied uniform magnetic field below $500 \mathrm{mT}$ (produced by a neodymium ring) around an electrolytic cell to achieve a smooth surface with improved and uniform corrosion resistance. The strength of the external magnetic field applied to the electrode controls its 
electrochemical reaction either by increasing or decreasing the dissolution rate (which is independent on the composition of dissolved metal and the electrolyte) [200]. When MEP is conducted below the oxygen evolution regime, it not only prevents hydrogen absorption but also removes residual hydrogen from the metal. Additionally, the quality of MEP treatment is dependent on parameters such as duration of the process, voltage level, type of electrolyte and its temperature.

In general, every metallic surface has irregularities in its surface layer (1-100 nm), which consists of foreign materials, metallic and non-metallic inclusions and a layer of pre-existing oxides that is also known as a beilby layer (formed either due to machining or processing) [201]. In the initial stages of MEP treatment on Nitinol, this beilby layer will be removed from its surface. A Lorentz force (a cross product of a magnetic field and current) is created by the externally applied magnetic field during MEP treatment (performed at fixed potential and below the oxygen evolution regime or plateau region) and this rotates the electrolyte around the axis in a direction parallel to that of the magnetic field [202]. The circular motion of the electrolyte causes a reduction in the thickness of the diffusion layer (viscous layer) due to increased mass transport and this eventually speeds up the dissolution process. An opposite effect is observed when MEP is conducted at a fixed-potential and beyond the plateau current densities in the oxygen evolution regime [202]. Kim, et al. [203] mentioned that the usage of a magnetic field during electropolishing activates the electrolyzed ions by the Lorenz force, which eventually leads to electrolysis. This is followed by the formation of a uniform and dense $\mathrm{TiO}_{2}$ oxide layer, which improves corrosion resistance. 


\subsection{Dip coating}

Initially, the polymer was dissolved in $\mathrm{CCl}_{4}$ solvent to obtain a $5(\mathrm{w} / \mathrm{v}) \%$ solution and then it was applied as a thin coating on the MEP treated ternary Nitinol alloys using a dip coating method. A schematic of the dip coating technique used to polymer coat the alloys is illustrated in Figure 4.2, where a linear motion stage was used to move the sample in and out of the dipping suspension.

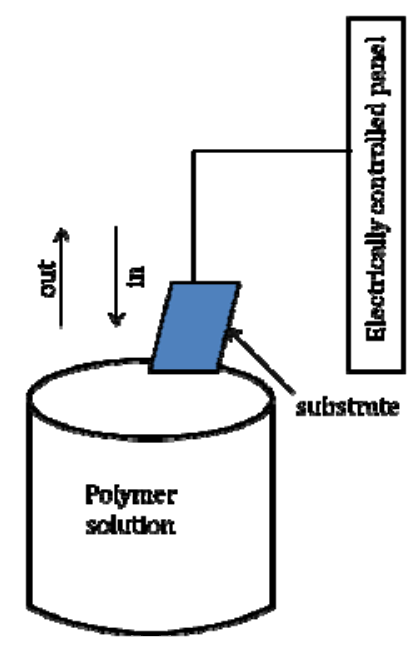

Figure 4.2: Schematic of dip coating setup.

The thickness of the polymer coating was controlled by varying the dipping time.

Later, these samples were dried at $40{ }^{\circ} \mathrm{C}$ (a temperature just below the glass transition temperature of the co-polymer) in vacuum (10 mbar) for 24 hours to obtain a polymer coating that is intact and free of any remnant solvent. 


\section{CHAPTER 5}

\section{BIOCOMPATIBILITY STUDIES}

\subsection{Restenosis}

Prior to 1980s, atherosclerosis (hardening of coronary arteries due to the gradual deposition of lipid and cholesterol plaques on the inner layer, or intima of the arteries) was treated using balloon angioplasty. But at times, this process was known to damage the inner lining wall of arteries exposing the extracellular matrix. This damage leads to neointimal hyperplasia, which is an immune system's reaction to the disruption of an artery wall. The exposed extracellular matrix triggers the hyper-proliferation of smooth muscle cells into the intima, where they cluster and form a lesion. As a result, a thick scar tissue developed form at this location, which eventually lead to arterial blockage and obstructed flow is known as restenosis. Within 3 to 6 months after balloon angioplasty, at least $40-50 \%$ of patients suffered from restenosis. As a result, stents were introduced into the market in order to overcome the incidence of restenosis.

\subsection{Thrombosis}

Thrombosis ( $\sim 0.5$ to 0.8 episodes/year/patient) is the primary cause of vascular access failure in dialysis patients $[204,205]$. At least $41 \%$ of the central venous catheters $(\mathrm{CVC})$, which play a major role in oncology, urology and general medicine, result in thrombotic occlusion of blood vessels [206]. In general, implants with surfaces in contact with blood flow can initiate activation, secretion, adherence, aggregation of platelets and trigger subsequent plasmatic coagulation, and immunological responses, depending on 
the material's hemocompatibility [207]. Spreading of platelets and "opening" of their integrin receptors such as, $\alpha \operatorname{IIb} \beta 3$ (fibrinogen receptor) and $\alpha 2 \beta 1$ (collagen receptor) will lead to platelet aggregation [208, 209]. Indeed, blood contacting devices are prone to clotting and inflammatory responses, which impair their performance and can be detrimental to patients. For example, the migration of thrombus to vasculature within the brain may lead to stroke and in some cases, even death.

During and immediately following stent implantation, disruption of the endothelial layer can trigger the adhesion of proteins, such as fibrinogen, fibronectin, vitronectin, immunoglobulin and von Willebrand factor (vWF) (a blood glycoprotein) onto the newly exposed sub-endothelial layer. This ultimately leads to activation, adhesion and deposition of platelets [207, 210, 211], and subsequently to thrombus formation. In the case of a biomaterial, when it is exposed to blood, a rapid adsorption of plasma proteins will occur. Adsorption of higher amounts of fibrinogen on the surface of biomaterial renders increased thrombogenicity, whereas adsorption of higher amounts of albumin convert it into a hemo-compatible surface [212]. An ideal biomaterial used for cardiovascular implants is expected to withstand such thrombus formation as well as inflammatory host responses at least until a de novo superficial endothelial layer is formed. In the case of metallic implant materials, properties such as surface free energy, surface charge [213-215], roughness, wettability, surface composition (oxide layer, functional groups) [216], metal ion leaching and corrosion resistance ultimately affect their interaction with the surrounding blood proteins, platelets and extracellular material $[217,218]$. 
In the case of cardiovascular stents, thrombogenicity is dependent on intrinsic properties such as corrosion resistance, hemocompatibility and mechanical dexterity. However, the extrinsic properties of a stent, such as its dimensions, design, combination of the drug and polymer coating affect its thrombogenicity via platelet activation [22, 219-222]. Additionally, its placement relative to the vessel wall, which imposes specific flow disruptions such as stagnation and recirculation, also has a similar effect. Activation is immediate and reaches a maximum state approximately 2 to 4 hours following implantation of the device [223].

\subsection{Cytotoxicity of biomaterials}

In addition to the high risk of thrombus formation, additional problems associated with stents on the market include leaching of metal ions, (e.g. Ni, Co and Cr), which can lead to carcinogenic [224] and allergic reactions [225] as well as restenosis [226], inflammation and activation of platelets $[227,228]$. As a result, there is still an urgent need for cardiovascular implant materials that are more hemo and biocompatible. In the case of Nitinol, in addition to its surface properties, alloying and surface treatment directly regulate the material's hemo and biocompatibility [229-231]. For example, the addition of $\mathrm{Cr}$, a highly passivating element to Nitinol, has been reported to enhance hemocompatibility [232], corrosion resistance and endothelial cell proliferation [233].

\subsubsection{Inductively coupled plasma mass spectroscopic analysis}

The corrosion liquids obtained during in-vitro corrosion tests of polymer-coated and un-coated Nitinol alloys were subjected to inductively coupled plasma mass 
spectroscopic (ICPMS) (ELAN-DRC-ICPMS, Perkin-Elmer, Waltham, Massachusetts) analysis to determine the extent of dissolved metal ion content under the following acquisition parameters of ICP RF power 1225: nebulizer gas flow $0.94 \mathrm{~L} /$ min, plasma gas flow $16 \mathrm{~L} / \mathrm{min}$ and lens voltage $8.75 \mathrm{~V}$. Each sample was analyzed in 3 replicates by ICPMS analysis. The average values of 3 replicates along with the standard deviation error bar are shown in Figures 5.3 to 5.8 .

The average concentration of dissolved metal ions ( $\mathrm{Ni}, \mathrm{Cr}$, Ti and $\mathrm{Ta}$ ) in the PBS electrolyte after corrosion tests of Nitinol alloys is displayed in Table 5.1. The concentration of $\mathrm{Cr}$ ions eluted from NiTi5Cr alloys was reduced by MEP treatment and application of polymer coating. Concentration of Ta and Ti ions eluted into PBS from Nitinol alloys during corrosion tests was below the detectable levels of the ICPMS.

Table 5.1: ICPMS analysis of $\mathrm{Cr}$ and $\mathrm{Ni}$ ions leached from the surface of Nitinol alloys

\begin{tabular}{|c|c|c|c|c|c|c|}
\hline \multirow{2}{*}{ Material } & \multicolumn{2}{|c|}{$\operatorname{Cr}(\mu \mathrm{g} / \mathrm{L})$} & \multicolumn{2}{|c|}{ Ni $(\mu \mathrm{g} / \mathrm{L})$} & \multirow{2}{*}{$\begin{array}{c}\mathbf{T i} \\
(\mu \mathrm{g} / \mathrm{L})\end{array}$} & \multirow{2}{*}{$\begin{array}{c}\text { Ta } \\
(\mu \mathrm{g} / \mathrm{L})\end{array}$} \\
\hline & Avg & SD & Avg & SD & & \\
\hline MP NiTi5Cr & 92.7 & 1.52 & 30.7 & 2.92 & ND & ND \\
\hline MP NiTi10Ta & ND & - & 31.2 & 3.45 & ND & ND \\
\hline MEP NiTi5Cr & $68.2^{*}$ & 8.9 & $4.7^{*}$ & 0.95 & ND & ND \\
\hline MEP NiTi10Ta & ND & - & 18.5 & 4.16 & ND & ND \\
\hline MEP + PC NiTi5Cr & $11.4^{*}$ & 2.92 & $1.2^{*}$ & 0.12 & ND & ND \\
\hline MEP + PC NiTi10Ta & ND & - & 22.1 & 3.98 & ND & ND \\
\hline MP NiTi ${ }^{\mathrm{a}}$ & ND & - & 69.9 & 0.35 & ND & ND \\
\hline
\end{tabular}

Note: * refers top $<0.05$ in one-way ANOVA analysis, $\mathrm{n}=3$ and a-correspond to reference [59] 
The amount of ions such as, $\mathrm{Ni}$, and $\mathrm{Cr}$ eluted into PBS during potentiodynamic corrosion studies of Nitinol alloys are presented in Figures 5.1 and 5.2 respectively.

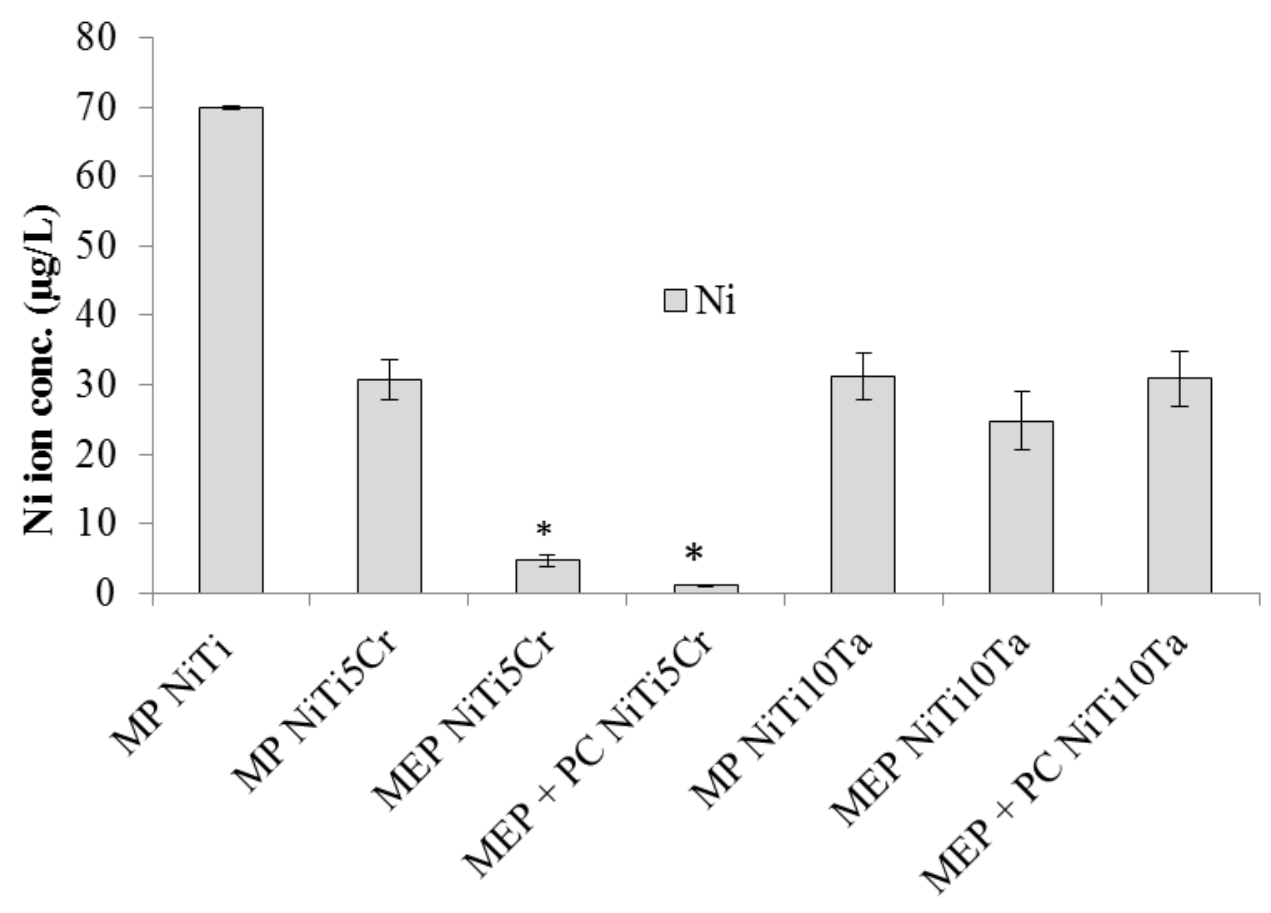

Figure 5.1: ICPMS results showing the concentration of $\mathrm{Ni}$ ions in the corrosion liquids obtained from different surface treated Nitinol alloys; * refers to $p<0.05$ in one-way ANOVA analysis

ICPMS results as shown in Figure 5.1 indicate the effect of surface treatments and alloying on Ni ion leaching from Nitinol alloys. Haider et al.[59] mentioned that the amount of Ni ions leached during potentiodynamic corrosion of mechanically polished binary Nitinol was $69.9 \mu \mathrm{g} / \mathrm{L}$. From the current study, ICPMS analysis revealed that the amount of Ni ions released from MP NiTi5Cr $(30.7 \mu \mathrm{g} / \mathrm{L})$ and MP NiTi10Ta $(31.2 \mu \mathrm{g} / \mathrm{L})$ was less as compared with that of MP NiTi. 
In the case of NiTi5Cr alloy, MEP treatment has tremendously reduced the Ni ion leaching from its surface $(4.7 \mu \mathrm{g} / \mathrm{L})$. This reduction in Ni ion leaching from MEP NiTi5Cr can be attributed to the formation of a protective oxide layer on its surface during MEP treatment. The increase in the intensity of $\mathrm{NiO}$ peak observed during XRD analysis of MEP NiTi5Cr alloys (Chapter 6) can be attributed to lower Ni ion release. Additionally, MEP + PC NiTi5Cr $(1.2 \mu \mathrm{g} / \mathrm{L})$ showed the lowest amount of $\mathrm{Ni}$ ions leached as compared with the rest of the alloys. One way ANOVA analysis of the ICPMS analysis revealed that the amount of $\mathrm{Ni}$ leached from MEP and MEP $+\mathrm{PC}$ NiTi5Cr was significantly low $(\mathrm{p}<0.05)$ as compared with that of MP NiTi5Cr. This reduction in Ni ion leaching can be directly correlated to the reduced corrosion rate of MEP + PC and MEP NiTi5Cr as compared with that of MP NiTi5Cr. Although a slight reduction in Ni ion leaching was observed in MEP NiTi10Ta $(24.85 \mu \mathrm{g} / \mathrm{L})$, as compared with the MP NiTi10Ta $(31.2 \mu \mathrm{g} / \mathrm{L})$ and MEP + PC NiTi10Ta $(30.87 \mu \mathrm{g} / \mathrm{L})$, it was statistically insignificant.

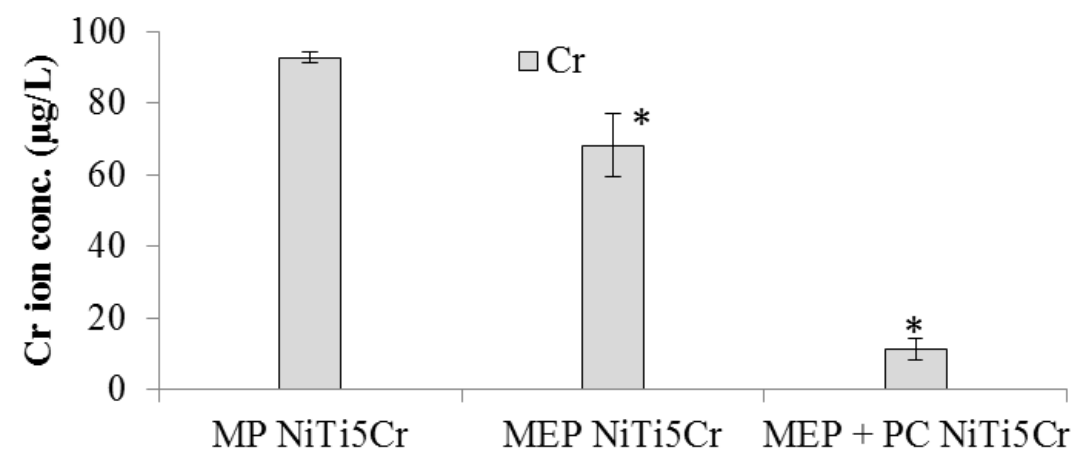

Figure 5.2: ICPMS results showing the concentration of $\mathrm{Cr}$ ions in the corrosion liquids obtained from different surface treated NiTi5Cr alloys; * refers to $\mathrm{p}<0.05$ in one-way ANOVA analysis 
Figure 5.2 indicates that the amount of $\mathrm{Cr}$ ions leached from $\mathrm{NiTi5Cr}$ samples has reduced after MEP treatment $(68.2 \mu \mathrm{g} / \mathrm{L})$ as compared with $\mathrm{MP} \operatorname{NiTi5Cr}(92.7 \mu \mathrm{g} / \mathrm{L})$. Furthermore, application of polymer coating on MEP NiTi5Cr has substantially reduced the $\mathrm{Cr}$ ion elution $(11.4 \mu \mathrm{g} / \mathrm{L})$ during corrosion tests. One-way ANOVA analysis revealed that the Cr ions leached from each group of surface treated NiTi5Cr was significantly different from each other.

\subsection{Sulforhodamine B (SRB) assay}

SRB assay serve as a simple, effective and reproducible cytotoxic test to determine the growth of an adherent cell line ${ }^{101}$ in a given toxic environment. The basic principle of this method involves the absorption of a negatively charged dye called sulphorhodamine B (SRB) by the amino acids present in the living cells [234]. In these experiments, live endothelial cells stay attached to the well plate and these will absorb the SRB dye. During the experiment, the optical density of the absorbed dye is directly proportional to the cell density. Additionally, in this method, the results were observed to be linear over a 20-fold range of cell number [234]. This technique was inexpensive and productive, especially when a large number and a wide variety of samples are to be tested in a limited period.

\subsubsection{Cell culturing and media for SRB assay}

Human Primary Umbilical Vein Endothelial Cells - HUVEC (ATCC® PCS-100$010^{\mathrm{TM}}$ ), obtained in a frozen state, were thawed to room temperature before culturing them. The cell culture media as recommended by the ATCC company was prepared by 
thawing and mixing one Endothelial Cell Growth Kit-VEGF (ATCC® PCS-100-041 ${ }^{\mathrm{TM}}$ ) into one bottle of Vascular Cell Basal Medium (ATCC $\left(\right.$ PCS-100-030 ${ }^{\mathrm{TM}}$ ) under aseptic conditions. The cells along with cell culture media were placed in a $75 \mathrm{~cm}^{2}$ flask and incubated at $37{ }^{\circ} \mathrm{C}$ at $5 \% \mathrm{CO}_{2}$. The cell culture medium was changed in the flask after every 48 hours to remove the dead cells and provide sufficient nutrients for the existing cells. Once the cells reached confluency in the cell culture flask, approximately after 7 to 8 days, they were tripsinized. These cells were utilized in subsequent cytotoxicity and cell growth tests.

\subsubsection{Cytotoxicity assay (SRB assay) protocol}

A sulforhodamine B (SRB) assay (In Vitro Toxicology Assay Kit, Sulforhodamine B based-TOX6, Sigma-Aldrich, Saint Louis, MO) was conducted to assess cell proliferation in the presence of the Ni ions leached during corrosion tests.

1. A 96 well-plate was used for seeding the human umbilical vein endothelial cells (HUVEC), in which $200 \mu \mathrm{L}$ of cell suspension of optimum density $(20,000$ cells/well or $1 \times 10^{5}$ cells $/ \mathrm{ml}$ ) was used in each well.

2. The PBS solution obtained from the corrosion tests of different samples, namely MP NiTi10Ta, MP NiTi5Cr, MEP NiTi10Ta, MEP NiTi5Cr, MEP + PC NiTi10Ta and MEP + PC NiTi5Cr, were filtered using a 0.2 micron filter, and the final solution for the cytotoxicity test was made by adding 10\% Fetal Bovine Serum, 1\% penicillin and $0.3 \mathrm{mg} / \mathrm{L}$ G418 powder. This was referred to as the corrosion electrolyte. 
3. After 24 hours of incubation, the cell culture media in the wells was removed and replaced by various proportions of cell culture media and corrosion electrolyte to produce the following: $10 \%$ corrosion electrolyte and $90 \%$ cell culture media; $50 \%$ corrosion electrolyte and 50\% cell culture media; $100 \%$ corrosion electrolyte; and finally with $100 \%$ cell culture media as a control.

4. HUVEC cells incubated in $100 \%$ cell culture medium were considered as the control samples for SRB studies.

5. At the end of the 48 -hour incubation period, $50 \mu \mathrm{L}$ of cold $\left(4{ }^{\circ} \mathrm{C}\right) 50 \%$ TCA was added to $200 \mu \mathrm{L}$ of the liquid already present in each well.

6. The well plates were left at room temperature for 30 minutes for the HUVEC cells to be fixed to the well plates.

7. TCA was removed from the wells and the well plate was rinsed using tap water at least 5 times and allowed to dry overnight.

8. $100 \mu \mathrm{L}$ of $0.4 \%(\mathrm{w} / \mathrm{v})$ sulforhodamine B (SRB) dissolved in $1 \%$ acetic acid solution was added to the wells (staining of the cells). The greater the number of endothelial cells, the greater the amount of SRB dye (negatively charged pink color aminoxanthine dye) bound to the amino acids of endothelial cells [235]. The wells were then placed in the incubator for 30 minutes.

9. After the staining period, the wells were rinsed with $1 \% \mathrm{v} / \mathrm{v}$ acetic acid at least 4 times to remove the unbound SRB dye and then allowed to dry.

10. $200 \mu \mathrm{L}$ of $10 \mathrm{mM}$ Trizma Base solution was added into each well to solubilize the bound SRB dye. 
11. The fluorescence of the viable cells was determined by placing the 96 well plate into a multiplate reader (TECAN GENios multiplate reader,Tecan, Männedorf, Schweiz) to obtain SRB readings of absorbance.

12. Before obtaining the readings, the well plate was shaken for 5 minutes, by the plate reader, followed by the data analysis.

13. Additionally, these SRB assays were repeated on the aforementioned liquids, for duration of 4 and 7 days, to determine the prolonged effects of these corrosion liquids on HUVEC cells.

14. Absorbance values were subsequently presented in the form of normalized cell proliferation values with respect to a negative control (absorbance of cells grown in cell culture media alone).

\subsubsection{Cytotoxicity data}

Figures 5.3 to 5.8 illustrate the cytotoxic behavior of corrosion extracts obtained from in-vitro potentiodynamic analysis of different surface treated ternary Nitinol alloys in PBS at $37{ }^{\circ} \mathrm{C}$. All samples exhibited a gradual increase in cell growth in extracts of $10 \%, 50 \%$ and $100 \%$ over periods of 2,4 and 7 days. SRB assay on the corrosion liquids obtained from different surface treated Nitinol samples is as follows: 


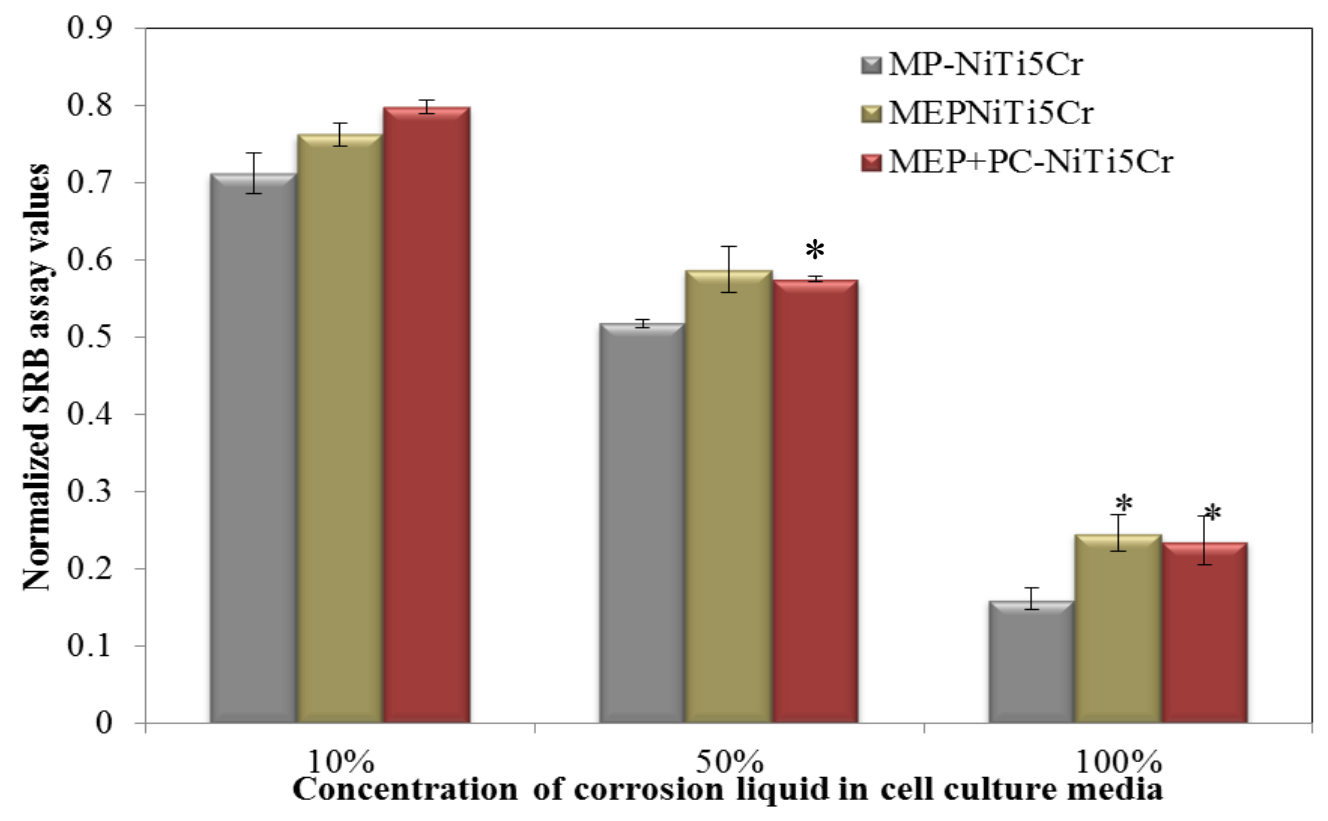

Figure 5.3: Net growth rate of HUVEC cells after 2 days of exposure to leached ions from potentiodynamic corrosion tests of different surface treated $\mathrm{NiTi5Cr}$ (mean $\pm \mathrm{SD}, \mathrm{n}$ $=3$ ); ${ }^{*}$ refers to $\mathrm{p}<0.05$ in one-way ANOVA analysis.

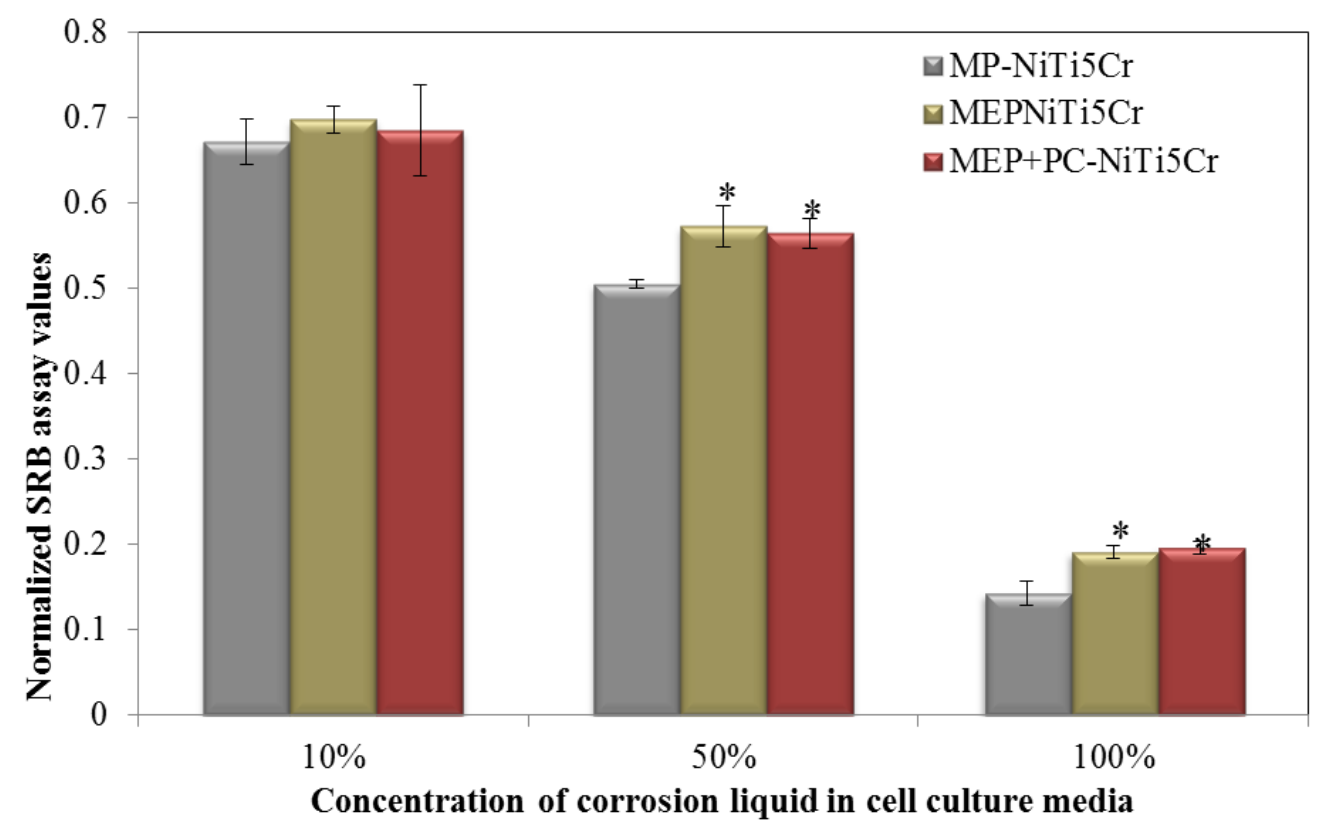

Figure 5.4: Net growth rate of HUVEC cells after 4 days of exposure to leached ions from different surface treated NiTi5Cr during potentiodynamic corrosion tests (mean \pm $\mathrm{SD}, \mathrm{n}=3$ ); * refers to $\mathrm{p}<0.05$ in one-way ANOVA analysis. 


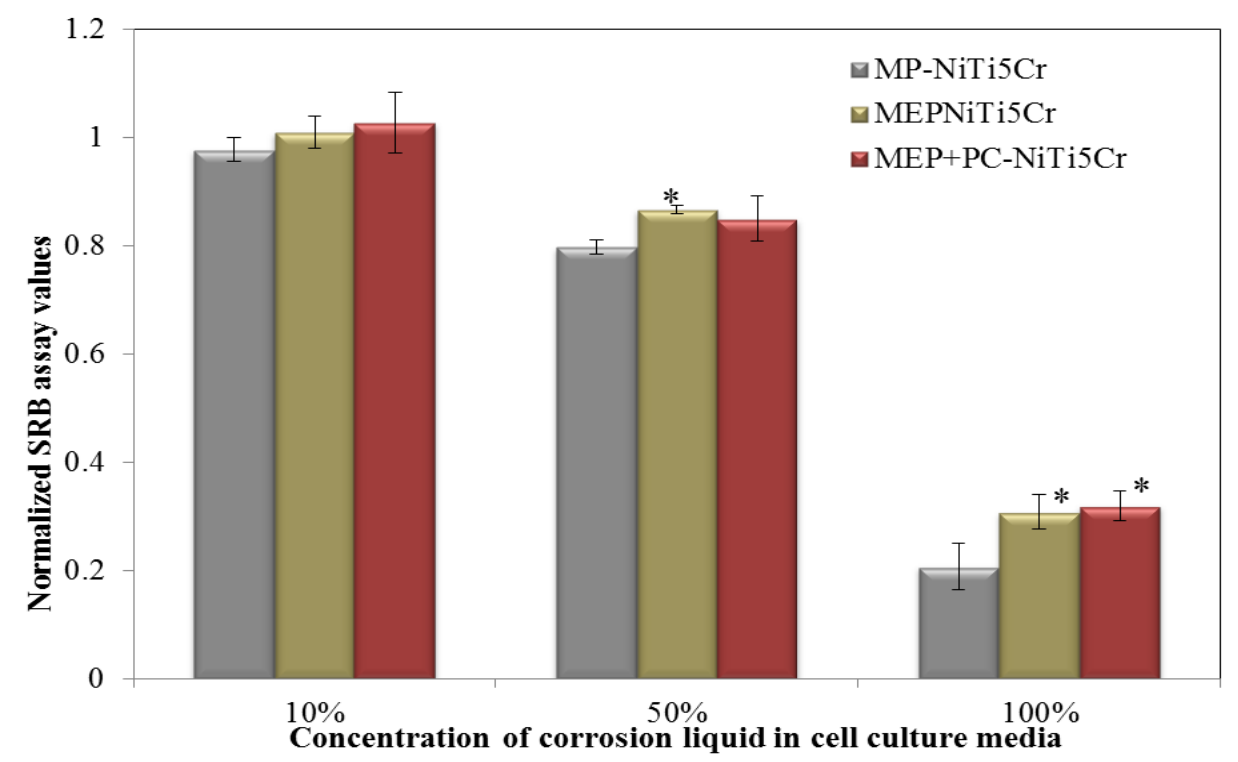

Figure 5.5: Net growth rate of HUVEC cells after 7 days of exposure to leached ions from different surface treated NiTi5Cr during potentiodynamic corrosion tests (mean \pm $\mathrm{SD}, \mathrm{n}=3) ;{ }^{*}$ refers to $\mathrm{p}<0.05$ in one-way ANOVA analysis.

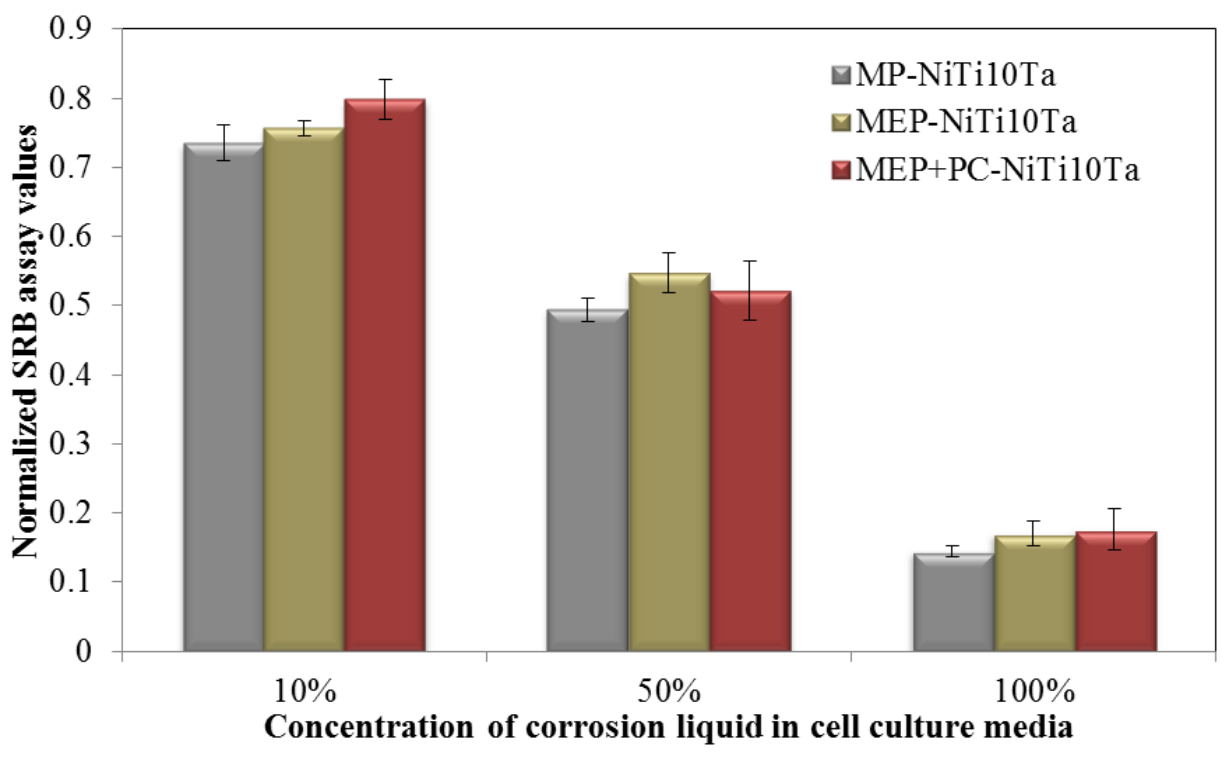

Figure 5.6: Net growth rate of HUVEC cells after 2 days of exposure to leached ions from different surface treated NiTi10Ta during potentiodynamic corrosion tests (mean \pm $\mathrm{SD}, \mathrm{n}=3)$. 


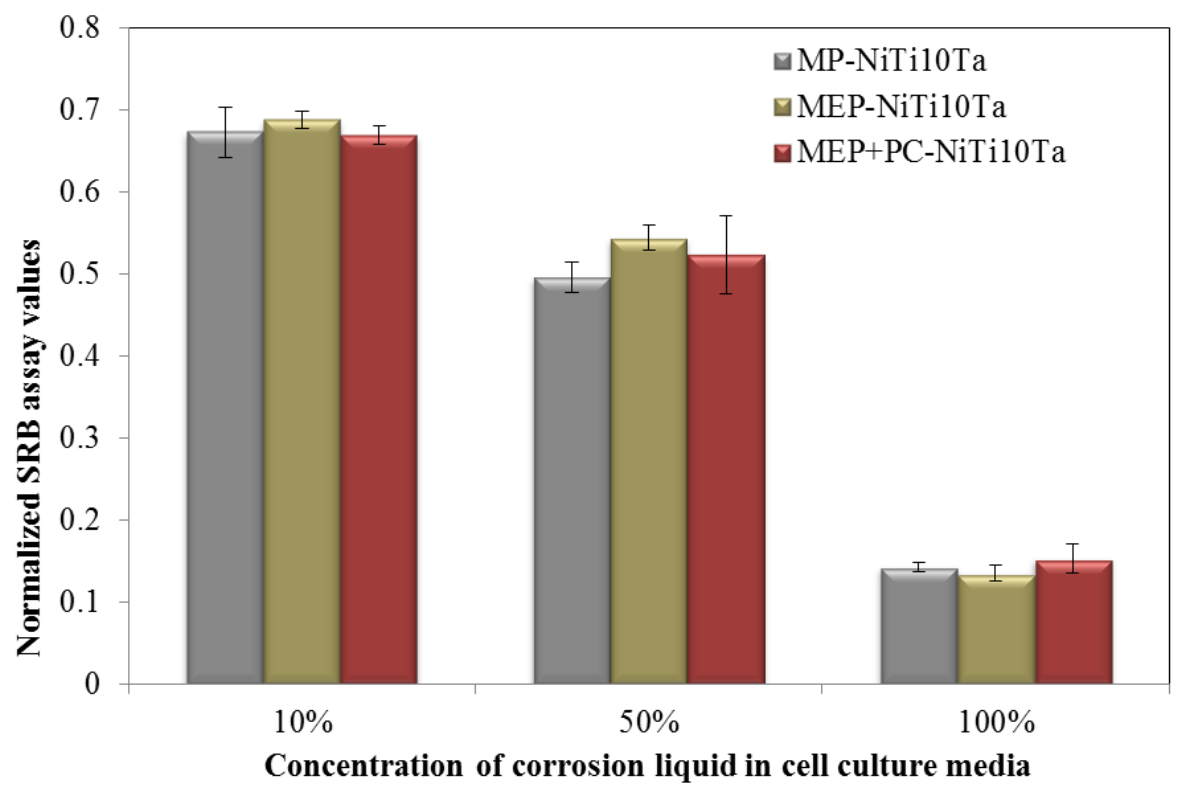

Figure 5.7: Net growth rate of HUVEC cells after 4 days of exposure to leached ions from different surface treated NiTi10Ta during potentiodynamic corrosion tests (mean \pm $\mathrm{SD}, \mathrm{n}=3)$.

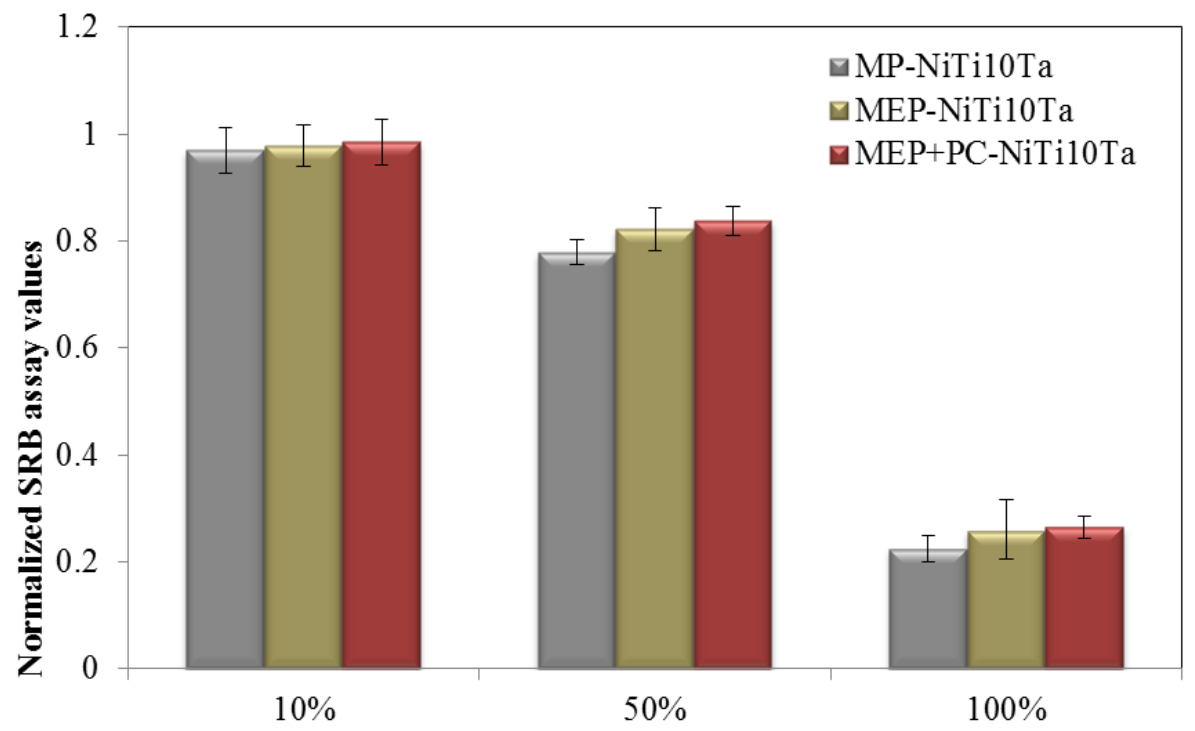

Concentration of corrosion liquid in cell culture media

Figure 5.8: Net growth rate of HUVEC cells after 7 days of exposure to leached ions from different surface treated NiTi10Ta during potentiodynamic corrosion tests (mean \pm $\mathrm{SD}, \mathrm{n}=3)$. 
Cytotoxicity of $100 \%$ and $50 \%$ corrosion liquid extracts from different surface treated NiTi5Cr alloys on HUVEC cells after 2, 4 and 7 days show that, cell viability in MEP NiTi5Cr and MEP + PC NiTi5Cr groups were significantly high $(\mathrm{p}<0.05)$ as compared with that of MP NiTi5Cr group. These results are supported by ICP-MS analysis (Figure 5.3), where the concentration of $\mathrm{Ni}$ in the MEP and MEP + PC NiTi5Cr extracts was at least 1 order of magnitude lower than that in MP NiTi5Cr. The statistically low amount of $\mathrm{Cr}$ ions leached from MEP and MEP + PC NiTi5Cr (Figure 5.4), during corrosion tests can be considered as an additional factor for increased cell viability in SRB assays.

In the case of SRB values for different surface treated NiTi10Ta alloys, no significant difference $(\mathrm{p}>0.05)$ in cell viability between MP NiTi10Ta, MEP NiTi10Ta and MEP + PC NiTi10Ta was observed at 10\%, 50\% and 100\% corrosion extracts after 2, 4 and 7 days duration (Figures 5.6 to 5.8). This corroborates with the amount of Ni ions leached from different surface treated NiTi10Ta alloys during potentiodynamic corrosion tests (Figure 5.3).

\subsection{Endothelial cell growth}

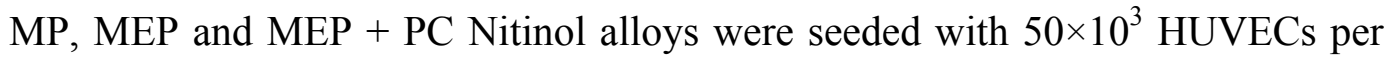
well (placed into a 24-well plate) and were subsequently immersed in cell culture media and incubated for 48 hours in a controlled environment at $37{ }^{\circ} \mathrm{C}, 5 \% \mathrm{CO}_{2}$ and $95 \%$ air, i.e., standard incubator conditions. After the incubation period of 48 hours, the cell culture media in the wells was removed and the samples were gently washed with DPBS four times to remove the dead cells and cell culture media. Three test samples for each 
type of material were used for cell growth analysis. Then, the samples were fixed in $70 \%$ ethanol at $2^{0} \mathrm{C}$ for 6 hours and then dried in a desiccator for 24 hours. Later, they were gold-sputter coated to be observed under Scanning Electron Microscopy (SEM - JEOL JSM 6330F) at a low vacuum of 5KV, 110X magnification and SEI mode.

\subsubsection{Cell growth on metallic and polymer coated samples}

Cell behavior, such as adhesion, cell division and differentiation, is influenced by the surface properties of an implant. Consequently, integration and tolerance of an implant in the body are decisively influenced by the surface properties of the materials used. HUVEC cell growth on MEP + polymer-coated samples and MP Nitinol samples were observed using SEM, as shown in Figures 5.9 and 5.10. 


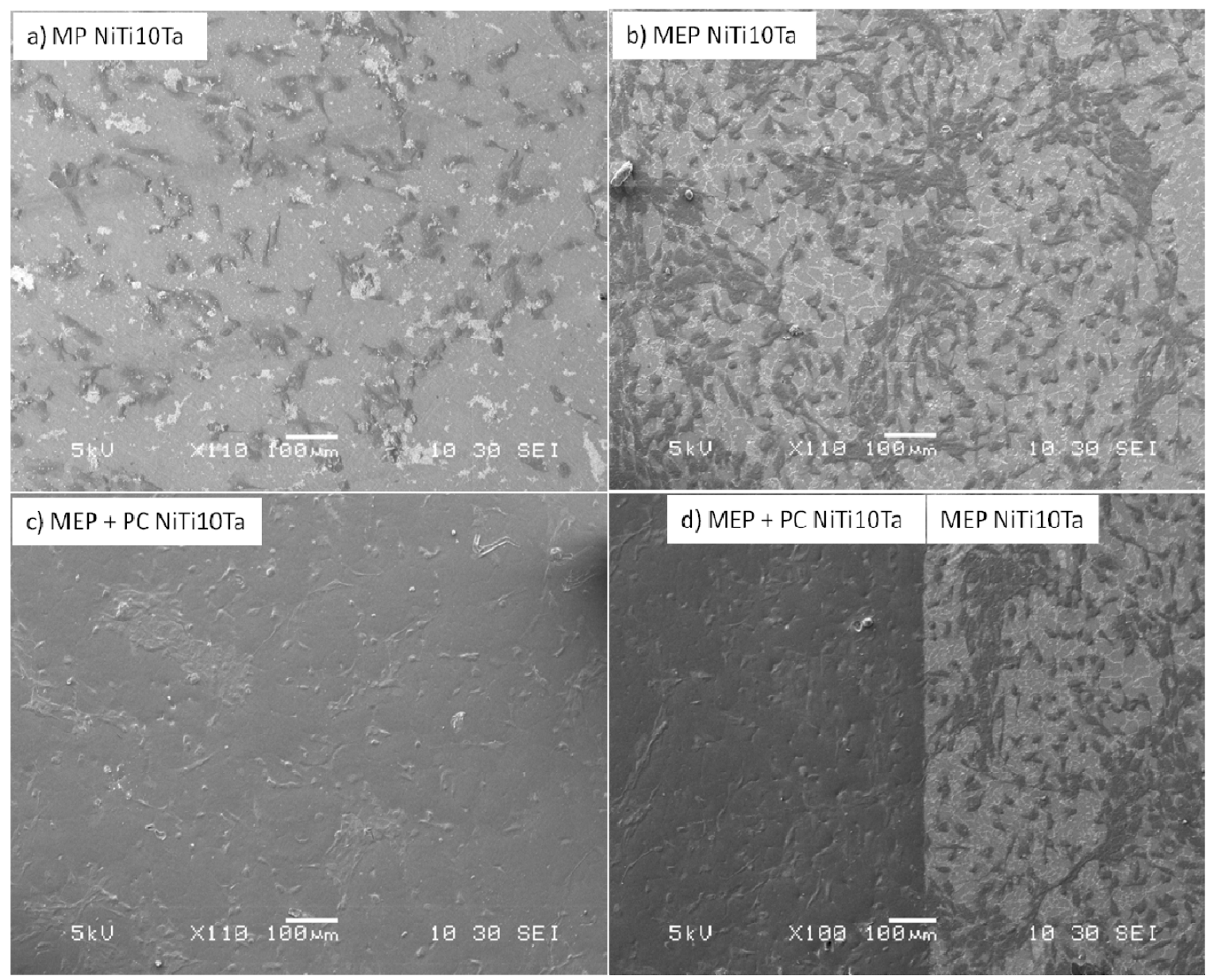

Figure 5.9: SEM photomicrographs of HUVEC cell growth on a) MP NiTi10Ta, b) MPE NiTi10Ta, c) MEP + PC NTi10Ta and d) A comparative analysis on polymer-coated and uncoated MEP NiTi10Ta alloy. 

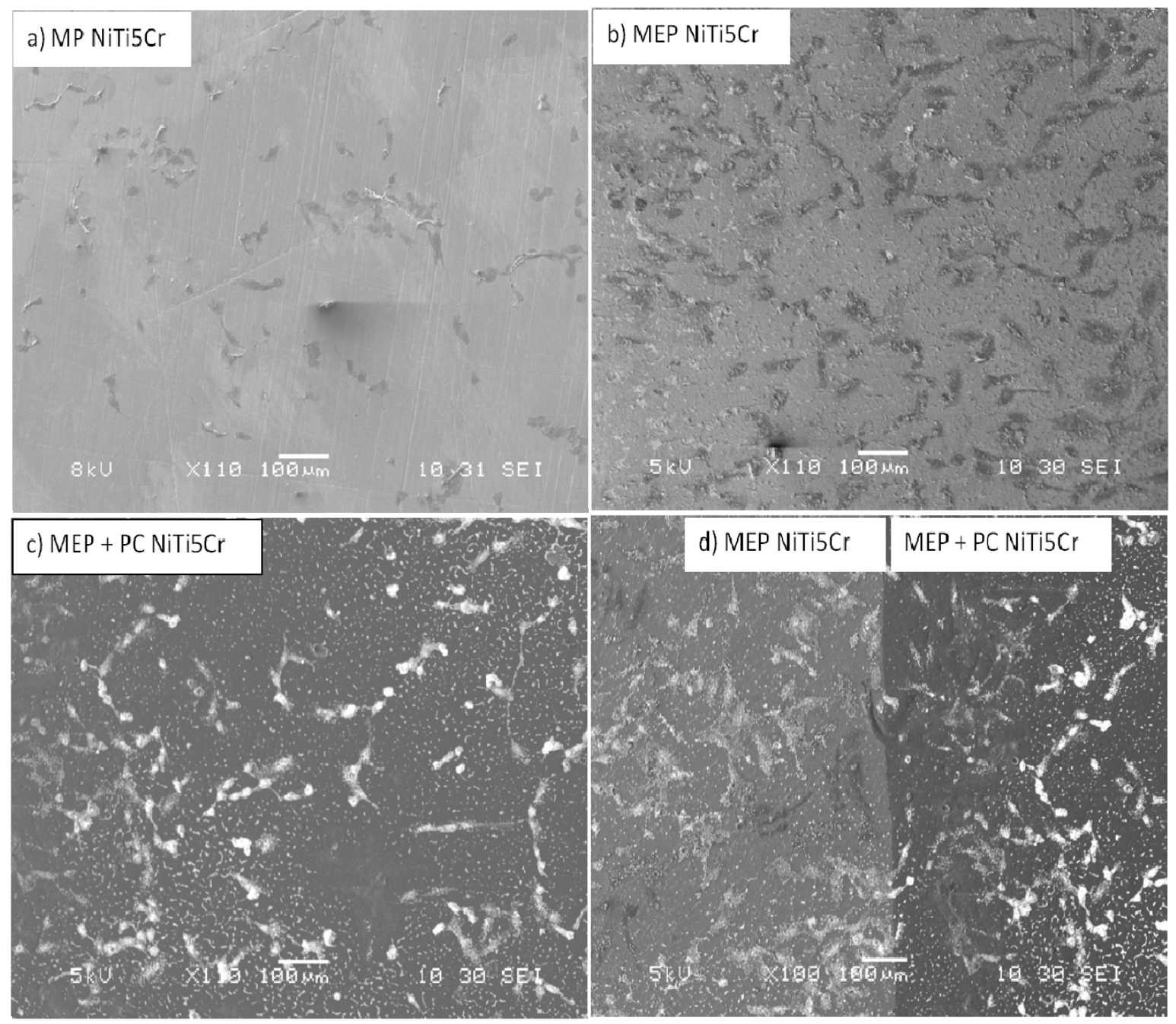

Figure 5.10: SEM photomicrographs of HUVEC cell growth on a) MP NiTi5Cr, b) MPE NiTi5Cr, c) MEP + PC NiTi5Cr and d) A comparative analysis on polymer-coated and uncoated MEP NiTi5Cr alloy.

By qualitative observation and comparison of cell growth on both the alloys, it was apparent that HUVEC cell growth on various surfaces was as follows:

MEP NiTi10Ta / MEP + PC NiTi10Ta $>$ MP NiTi10Ta > MEP NiTi5Cr / MEP + PC NiTi5Cr $>$ MP NiTi5Cr. 
Figure 5.9 shows SEM photomicrographs of confluent HUVEC cell growth on both PGA/PCL polymer-coated and bare MEP alloys, as compared with that of MP Nitinol alloys. The density of cell growth on MEP alloys was high, compared with that of MP alloys, which can be attributed to the improved surface topography, wettability and composition of MEP alloys. In the case of PGA/PCL co-polymeric coatings [236], cell growth is dependent on its crystallinity, composition, and topography. The presence of a monolayer of HUVEC cells, with extended fillopodia after 48 hours of incubation, indicates that the co-polymeric coating was conducive for cell growth. Helen et al. showed improved osteoblast cell growth on PGA/PCL (65/25) co-polymer with increased concentration of PGA monomer [236] [237]. Additionally, molecular weight of the polymer has been reported to affect cell growth, protein adhesion and its degradation rates [236].

\subsection{Platelet adhesion test}

A custom-built, multi-specimen, laminar flow chamber was used to investigate the adhesion of blood components on implant materials (Figure 5.11a).

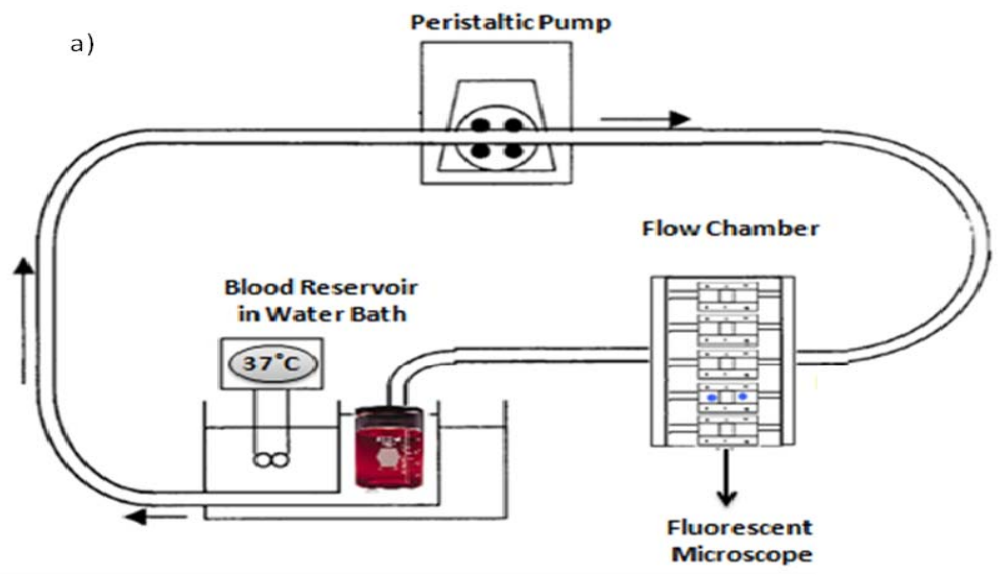




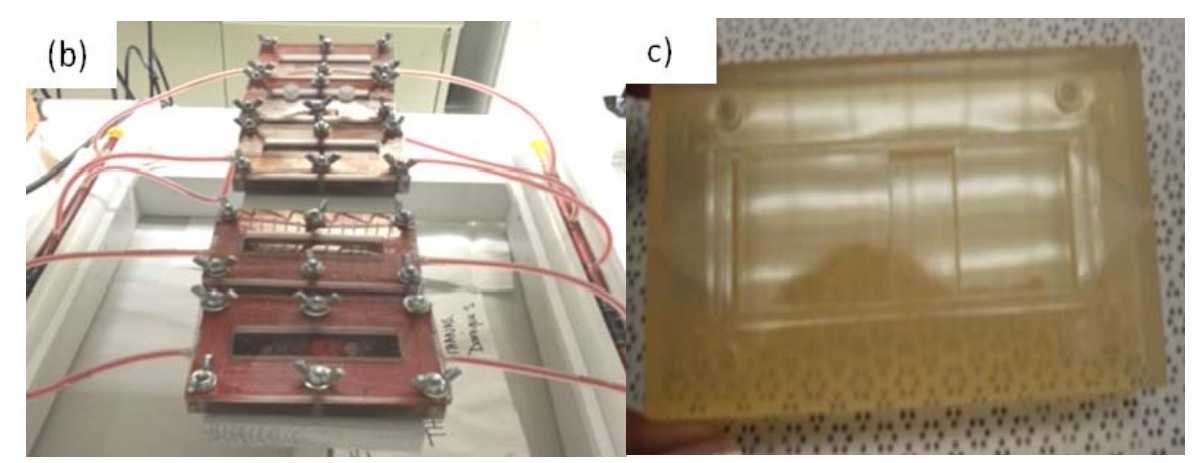

Figure 5.11: (a) Schematic of a closed-loop system for platelet adhesion studies, (b) Five flow chambers connected in a parallel circuit to the main inlet and outlet paths, (c) The dynamic flow chamber for platelet adhesion studies.

\subsubsection{Materials for platelet adhesion test}

MP NiTi10Ta, MP NiTi5Cr, MEP NiTi10Ta, MEP NiTi5Cr, MEP + PC NiTi10Ta and MEP + PC NiTi5Cr were used as the experimental samples to determine their platelet adhesion properties. Additionally, mechanically polished (MP) stainless steel (SS) (Online Metals, Seattle, WA) and binary Nitinol (NiTi) (NDC Alloys Inc. Fermont, CA) of dimensions $\sim 2 \mathrm{~cm} \mathrm{X} 2 \mathrm{~cm} \mathrm{X} 0.5 \mathrm{~mm}$ were studied for comparative analysis. The aforementioned alloys were mechanically polished (MP) using three different waterproof silicon carbide papers (MSC Industrial Supply, \#s 320, 1200 and 4000 Melville, NY) applied in the order of increasing grit size, using a plate grinder (Cat \# 78156056, MSC Industrial Supply, Melville, NY) at $30 \mathrm{rpm}$ for 10 minutes for each paper. Each of the eight test samples was placed in a recessed cavity within five flow chambers (Figure 5.11b). The flow loop for platelet adhesion studies consisted of a peristaltic pump to drive blood flow, silicon tubes to connect the flow chambers, a blood reservoir and a water bath to maintain the temperature of whole blood at $37{ }^{\circ} \mathrm{C}$ (Figure 
$5.11 \mathrm{c})$. The velocity of blood flow was maintained at $113 \mathrm{~cm} / \mathrm{s}$, which is within the dynamic range of velocities measured in the veins of the upper limbs [238]. Prior to hemocompatibility testing, metallic samples (MP and MEP) were ultrasonically cleaned for 5 minutes in DI water, followed by cleaning in $70 \%$ ethanol for 5 minutes to eliminate impurities and foreign particles on the surface. The polymer-coated samples were sterilized by exposing them to UV radiation for 40 minutes, before conducting the platelet adhesion tests. Once all the samples were placed in the chambers of the flow loop ( $\mathrm{n}=5$ samples at a time), a phosphate buffer saline (PBS) solution was used to prime the loop for 10 minutes. Approximately $500 \mathrm{ml}$ of freshly collected whole porcine blood (Mary's Ranch Inc., Miami, FL) was mixed with $150 \mathrm{ml}$ of sodium citrate anticoagulant. $333.5 \mathrm{ml}$ of $10 \mathrm{mM}$ mepacrine dye solution was added for every $500 \mathrm{ml}$ of whole porcine blood to fluorescently label the platelets [239]. The blood was passed over the metallic samples in the loop for 35 minutes. After each run, samples were extracted and carefully washed with PBS three times to remove any residual blood components. Platelets that adhered on to the samples were observed under a fluorescent microscope (Nikon Eclipse E 200, Nikon, Melville, NY). The number of platelets adhered on each sample were counted carefully using an image analysis software (Image J, NIH, Bethesda, MD).

\subsubsection{Statistical analysis}

A statistical analysis was performed on platelet adhesion data using a one-way ANOVA analysis, followed by post-hoc testing (Tukey HSD). The 8 type of materials subjected to the testing were SS, NiTi, MP NiTi5Cr, MP NiTi10Ta, MEP NiTi5Cr, MEP 
NiTi10Ta, MEP + PC NiTi5Cr and MEP + PC NiTi10Ta. A significant difference between materials was interpreted to occur at $\mathrm{p}<0.05$.

\subsubsection{Platelet adhesion results}

Blood clotting on a foreign implant surface is still a complex mechanism which has to be thoroughly investigated before further understanding is accomplished. Platelet adhesion and aggregation are controlled by the composition of the surface oxide film on a metal due to its relative permittivity (electrostatic forces), which influences the amount of adsorbed proteins [240]. Data collected from platelet adhesion studies include the fluorescent images of platelets adhered to various surfaces.

In this investigation, platelets adhered on the aforementioned metallic samples during platelet adhesion tests were observed under SEM as shown in Figure 5.12.

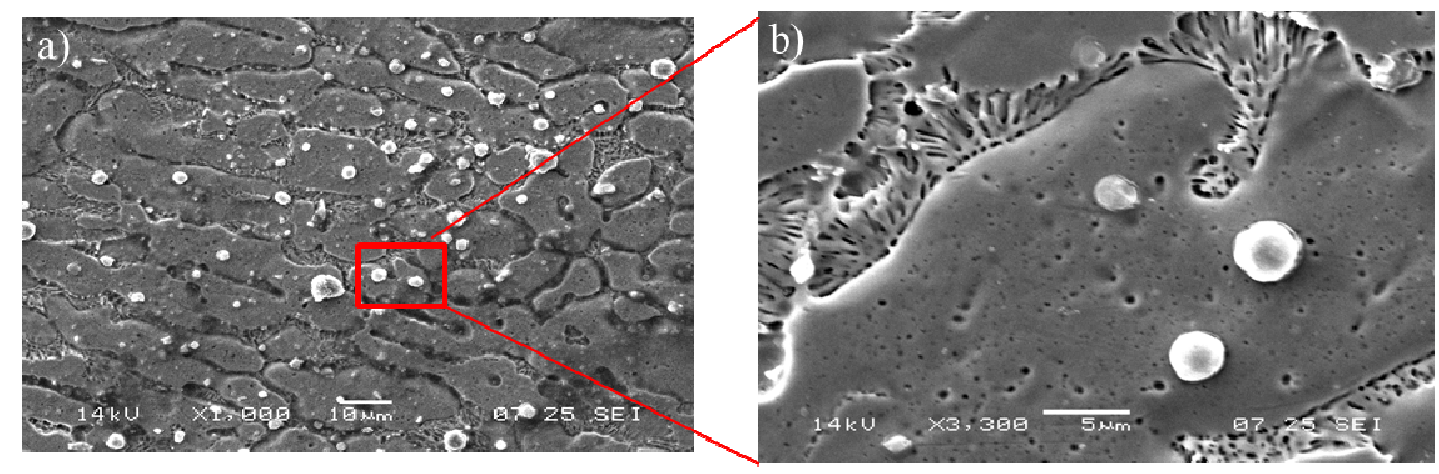

Figure 5.12: SEM photomicrograph of platelets adhered MEP NiTi5Cr (a) $1000 \mathrm{X}$ and (b) $3300 \mathrm{X}$

Figure 5.12 shows that platelets adhered on MEP NiTi5Cr were in the stages of discoid shape (no pseudopodia) to early dendritic shape (one or more pseudopodia with no evident flattening) after 35 minutes of blood on the metal's surface [241]. 
Fluorescent images of platelets adhered to different surface treated metallic alloys are shown in Figure. 5.13.

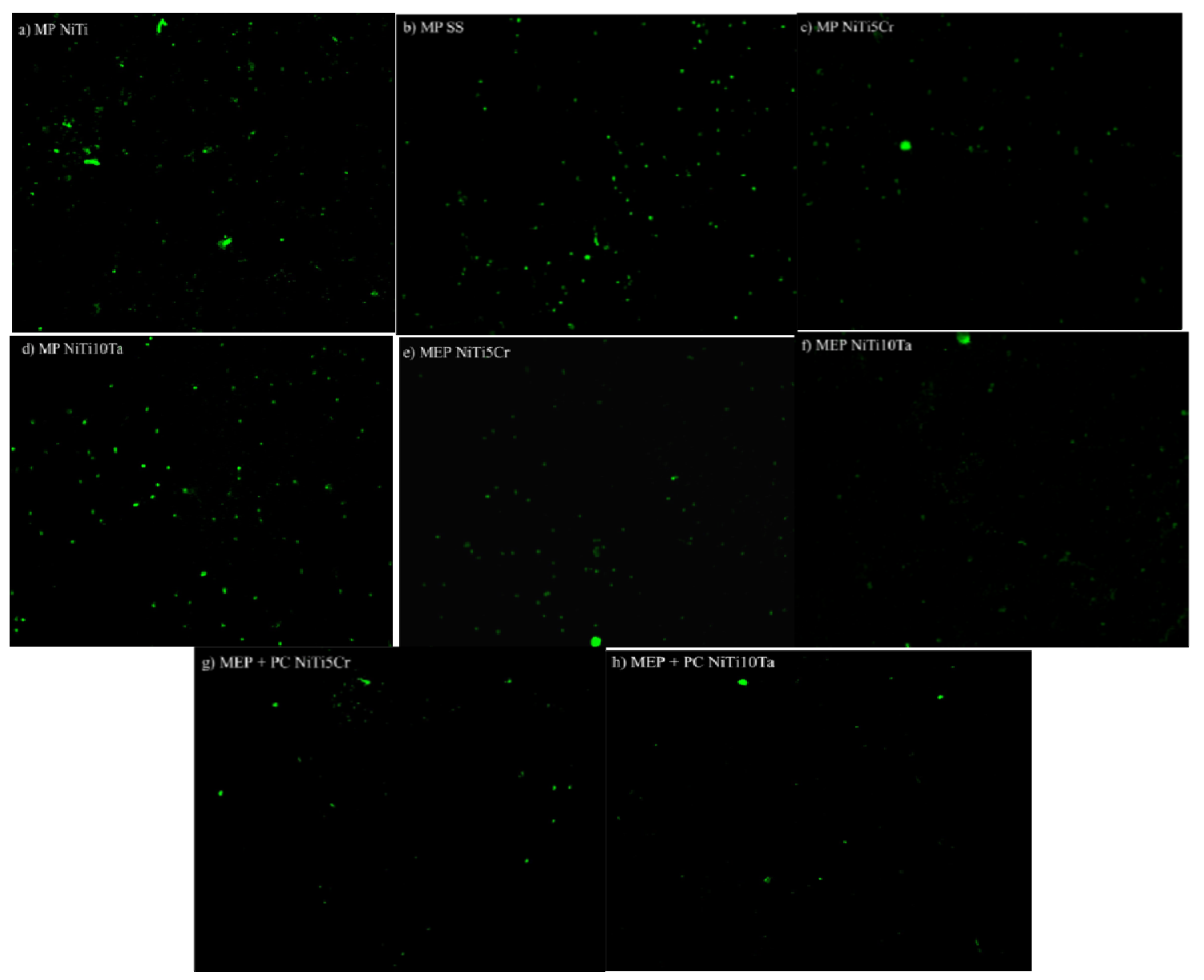

Figure 5.13: Fluorescent microscopic images of porcine platelets adhered to various alloys a) MP NiTi, b) MP SS, c) MP NiTi5Cr, d) MP NiTi10Ta, e) MEP NiTi5Cr, f) MEP NiTi10Ta g) MEP + PC NiTi5Cr and h) MEP + PC NiTi10Ta.

Platelet adhesion tests revealed that the highest number of platelets (platelets adhered $/ \mathrm{mm}^{2}$ ) was found on the SS surfaces, followed by MP Nitinol alloys and MEP Nitinol alloys and next, on MEP +PC Nitinol alloys (Figure 5.14). 


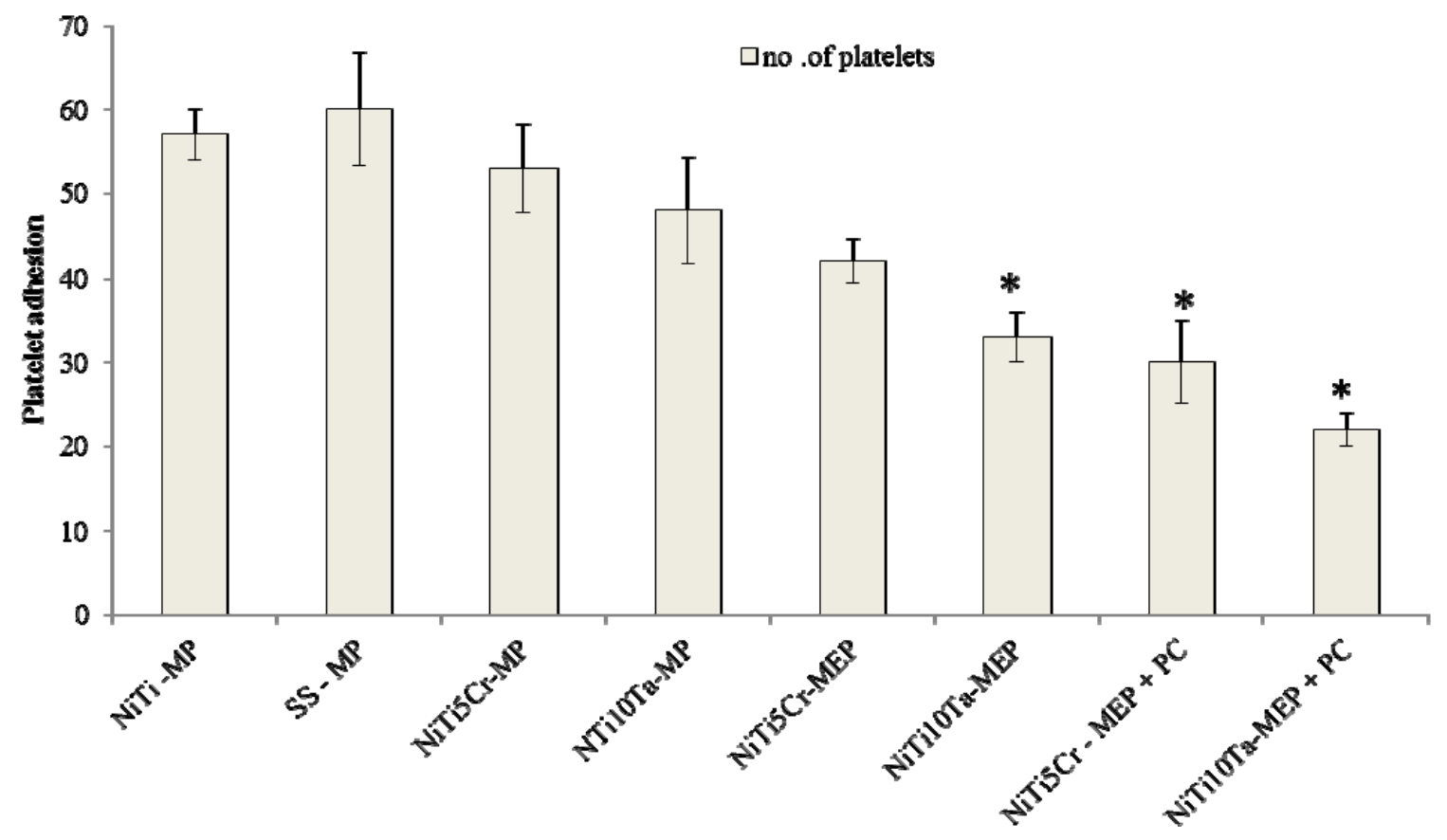

Figure 5.14: Porcine platelets adhered to the surface of different alloys; NiTi - Nitinol, SS

- stainless steel, NiTi5Cr and NiTi10Ta - ternary Nitinol alloys, MP - mechanically polished, MEP - magneto electropolished $(\mathrm{n}=5$, mean $\pm \mathrm{SD}) ; * \mathrm{p}<0.05$ indicates values are significantly different from MP alloys.

A one-way ANOVA analysis followed by a post-hoc test (Tukey HSD) of platelet adherence values revealed that MEP + PC ternary Nitinol alloys were the least thrombogenic $(\mathrm{P}<0.05)$ in comparison to all the other MP alloys (Figure 5.14).

\subsubsection{Correlation between platelet adhesion and surface free energy}

Figure 5.15 depicts a reduction in platelet adhesion on various surfaces with an increase in interfacial free energy. These results indicate that thrombogenicity is reduced 
with an increase in interfacial free energy of a material as was reported by Rokicki et al.[242].

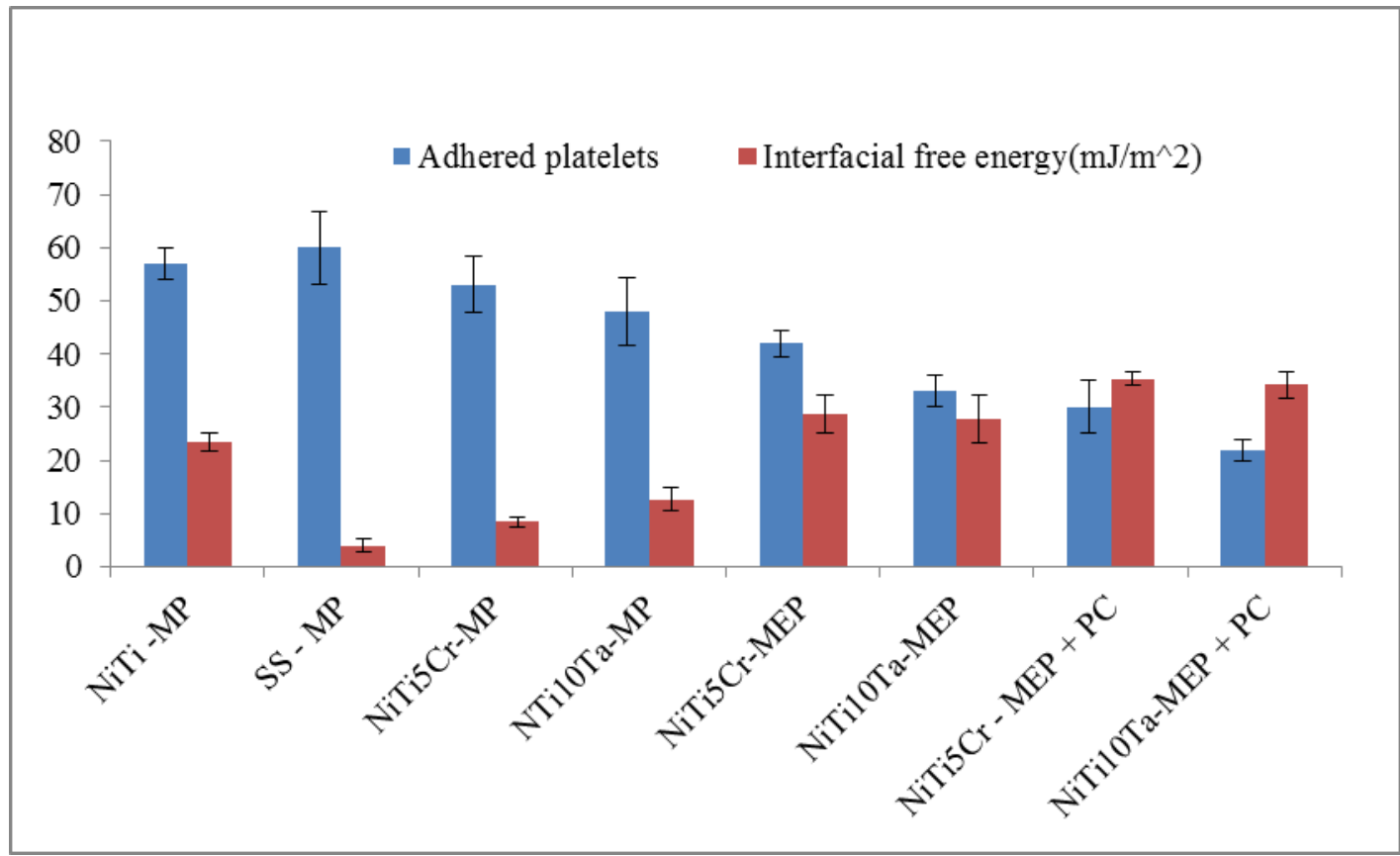

Figure 5.15 Correlation between the number of platelets adhered and interfacial free energy $(n=5$, mean $\pm S D)$. 


\section{CHAPTER 6}

\section{SURFACE CHARACTERIZATION}

\subsection{Surface morphology by scanning electron microscopy (SEM) analysis}

Scanning Electron Microscopy (SEM) was used to determine the morphologies of MP, MEP and MEP + PC Nitinol alloys. The Nitinol samples were studied using a JEOL JSM-5900 Low Vacuum SEM. SEM provides both qualitative and quantitative data regarding the morphology of Nitinol alloys. Two types of images were obtained in this study namely, secondary electron image (SEI) and back scattered electron image (BEI).

\subsubsection{Secondary electron image (SEI)}

This image is produced when the high energy electron beam from the tungsten filament of the SEM hits the weakly bound electrons of the outer layer atoms of the specimen, resulting in their ejection from the atoms. This results in the formation of a SEI, which produces a clear and detailed picture of the materials surface morphology.

\subsubsection{Back scattered electron image (BEI)}

When the high energy SEM electron beam hits the nucleus of the atoms on the surface of the specimen they become scattered back. These electrons are recorded as the BEI. The samples with higher atomic number will produce more back scattered electrons. This helps in the determination of the different species present on the specimen surface. 


\subsection{Energy dispersive X-ray spectroscopy (EDS)}

Energy Dispersive X-Ray Spectroscopy (EDS) works in conjunction with SEM to study the elemental distribution and microanalysis on the surface of a given material. In this method a high energy electron beam was utilized to excite the atoms of a metal to higher energy states in order to produce the characteristic X-rays from them. The X-rays produced were peculiar for each and every element and thereby used to study the different elements present in a given specimen.

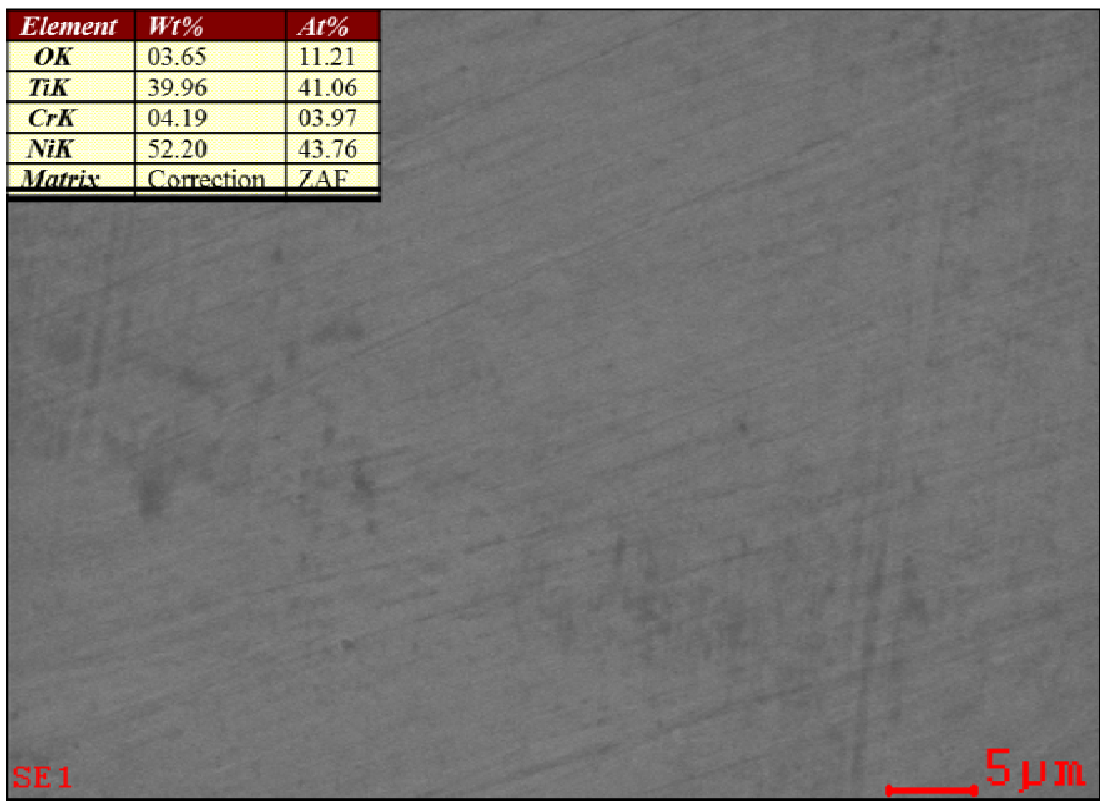

Figure 6.1: SEM photomicrographs/EDS analysis of MP NiTi5Cr 


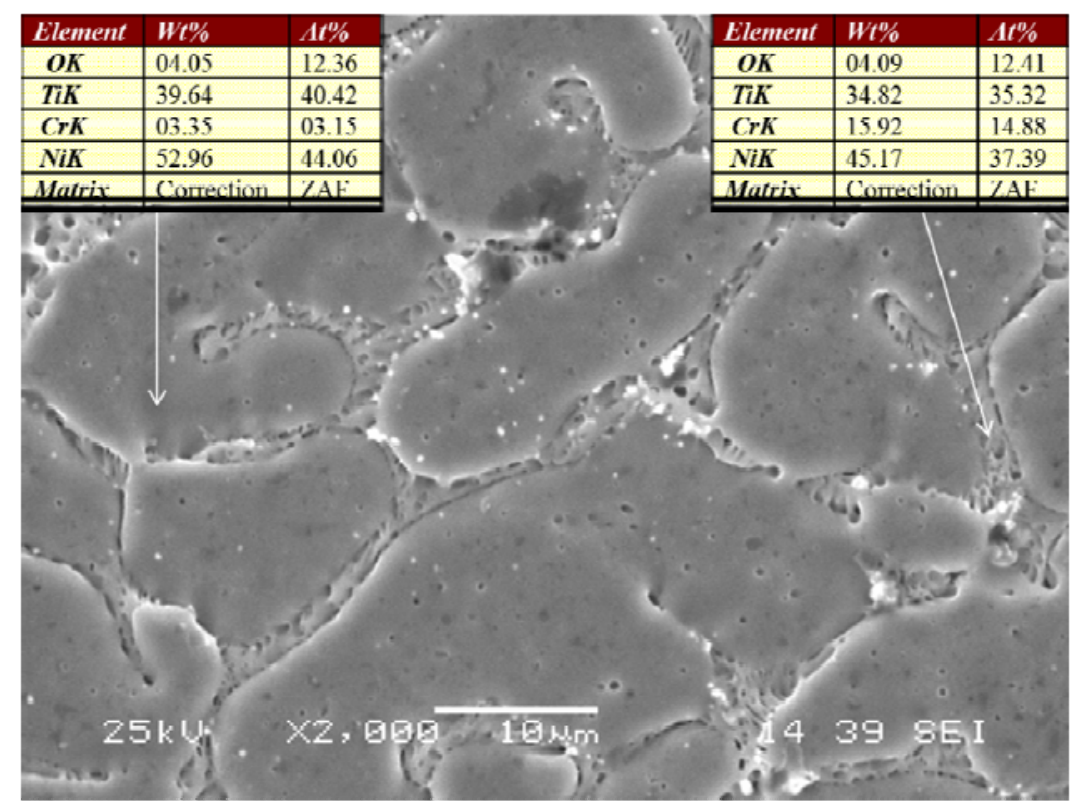

Figure 6.2: SEM photomicrographs/EDS analysis of MEP NiTi5Cr

Application of MEP treatment to mechanically polished (MP) ternary Nitinol alloys has resulted in a change in their surface morphology, topography and chemistry. Figure 6.1 and 6.2 are SEM/EDS photomicrographs of NiTi5Cr before and after MEP treatment. These figures reveal that MEP resulted in depletion of $\mathrm{Ni}$ and $\mathrm{Ti}$ metal and enrichment of $\mathrm{Cr}$ at the grain boundaries, whereas, MEP treatment on NiTi10Ta resulted in depletion of metal within the grain as compared to the grain boundary. As a result, opposing variations in surface chemistry and morphology were observed at the grain boundaries of both alloys. 


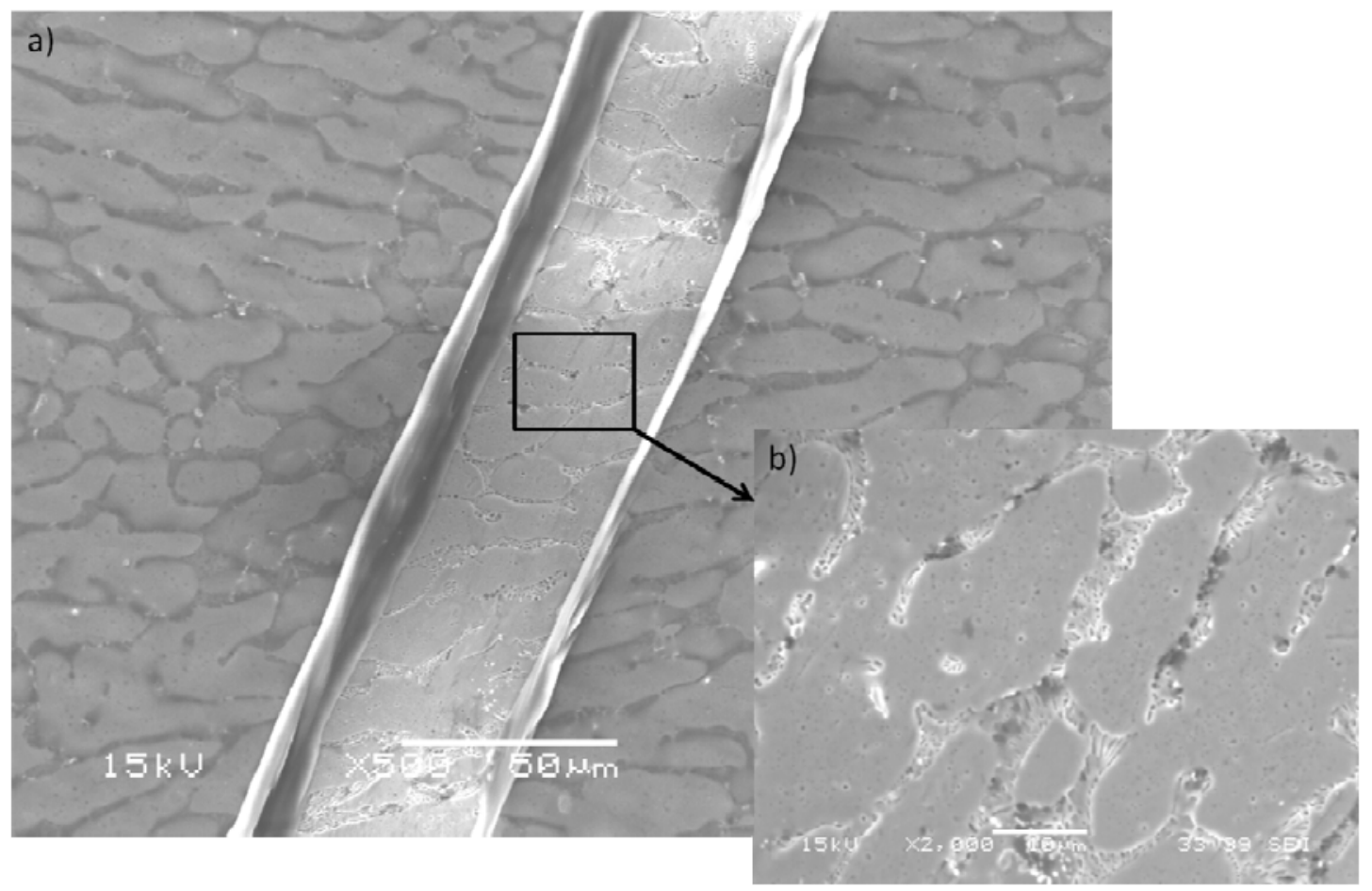

Figure 6.3: SEM photomicrograph of a) MEP + PC NiTi5Cr, inset view is b) MEP NiTi5Cr

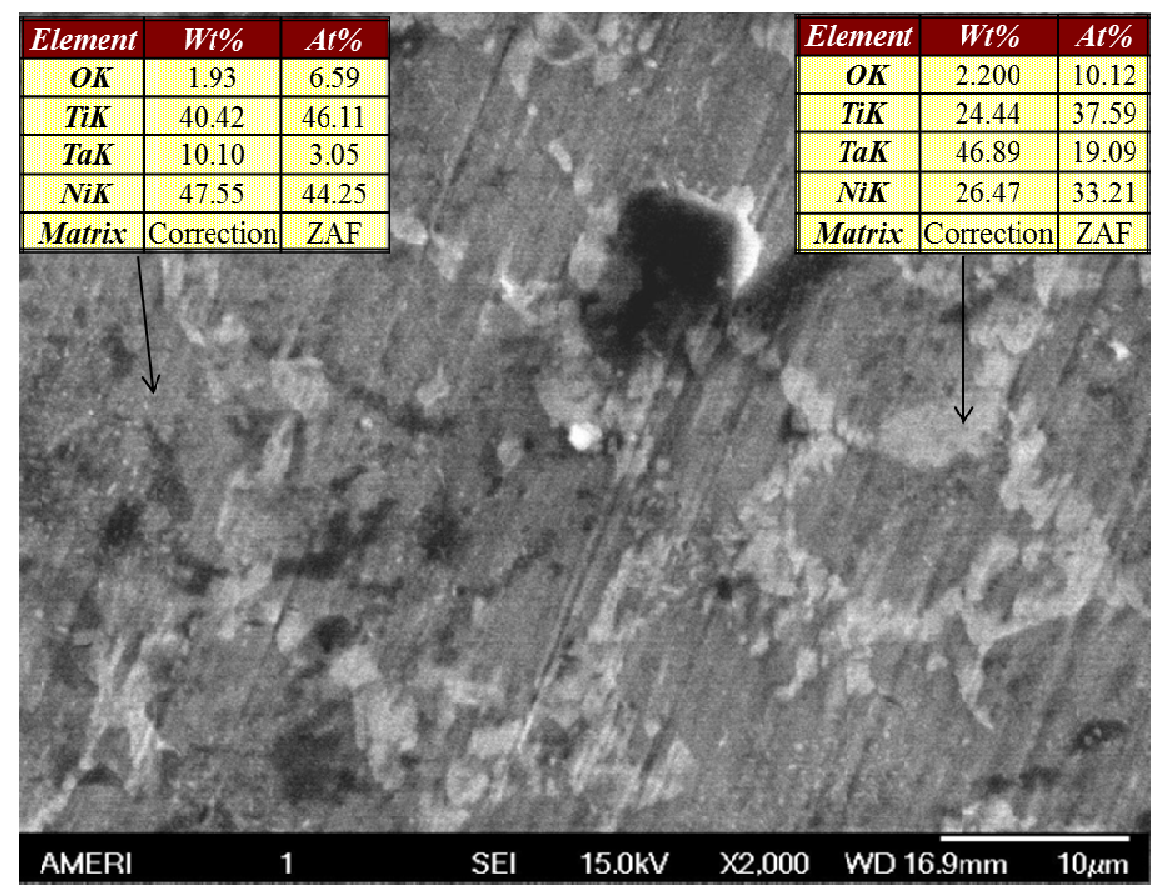

Figure 6.4: SEM photomicrographs/EDS analysis of MP NiTi10Ta 


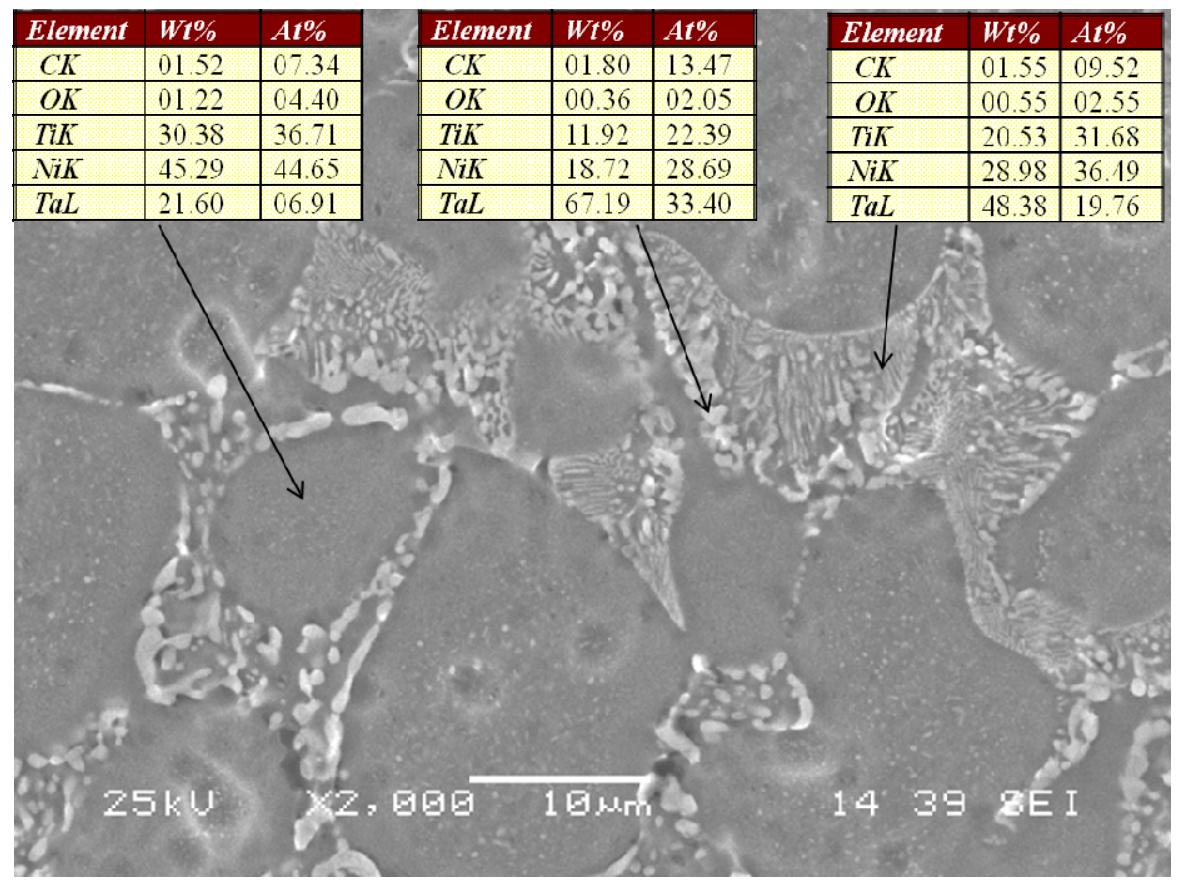

Figure 6.5: SEM photomicrographs/EDS analysis of MEP NiTi10Ta

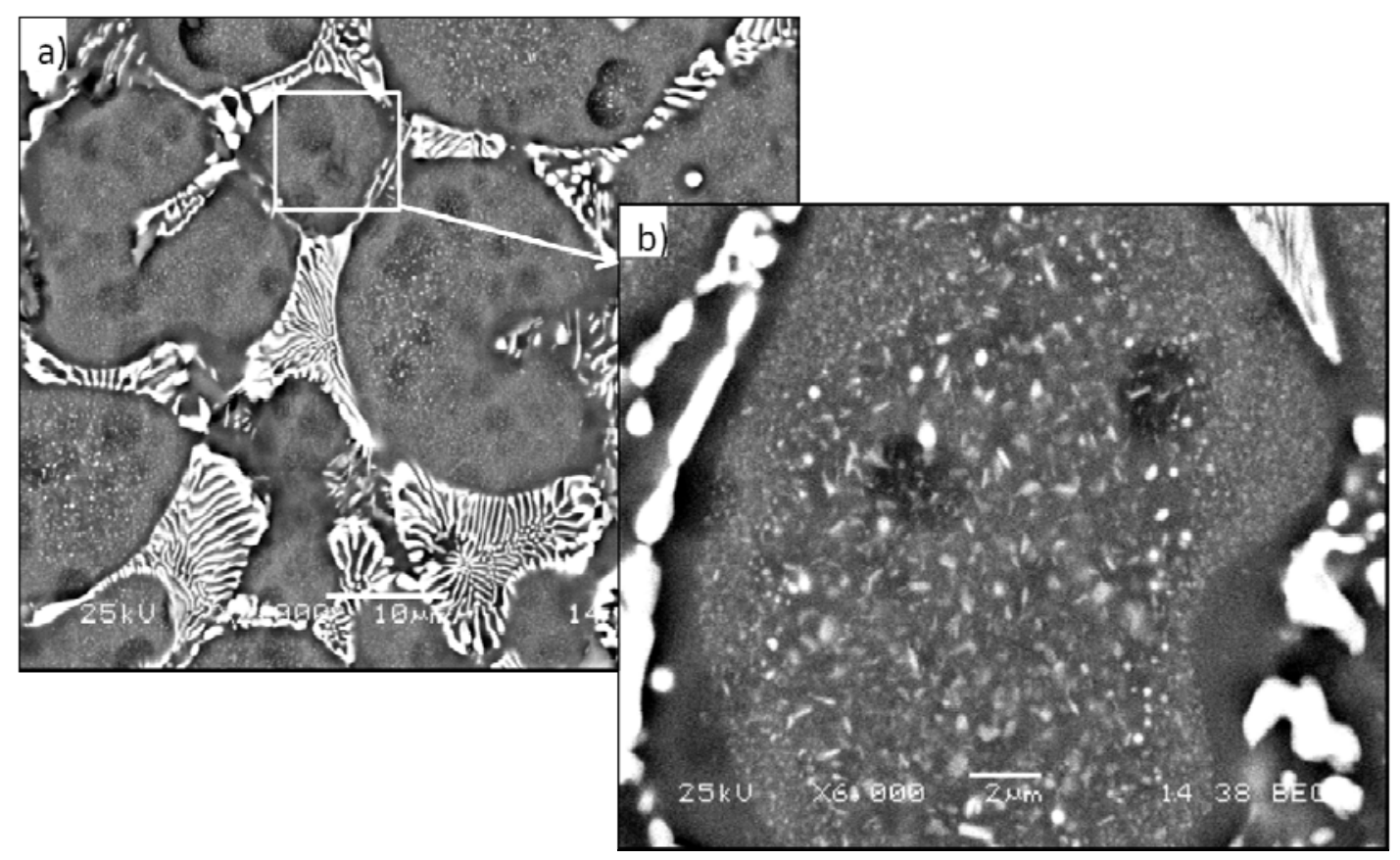

Figure 6.6: SEM photomicrographs of MEP NiTi10Ta a) 2000X BEI image, b) inset

view at $6000 \mathrm{X}$ BEI image

SEM/EDS analysis of MP and MEP NiTi10Ta indicated the presence of high amounts of $\mathrm{Ta}$ in dendritic structures at grain boundaries due to grain boundary 
segregation that occurred during processing of the material as shown in Figures 6.4 and 6.5. Similar tantalum segregation was observed by Olson [243] when Ta was used in ferrous shape memory alloys. When NiTi10Ta was observed under BEI mode using SEM, the NiTi matrix appeared as greyish due to its low molecular weight and Ta appeared bright due to its higher molecular weight. From Figure 6.6, it can be observed that within each grain of NiTi10Ta, Ta was visible as a dispersed secondary phase.

Additionally, the 3D topography of MEP treated NiTi10Ta and NiTi5Cr were observed using a Phenom Tabletop SEM. Figure 6.7 indicated that, during MEP, the grain area of NiTi10Ta was preferentially depressed (valley) with respect to the grain boundaries leading to raised grain boundaries (crests). In the case of NiTi5Cr, MEP treatment has resulted in opposite morphology, where the grains became the crest and the depletion occurred along the grain boundaries forming the valleys (Figure 6.8).

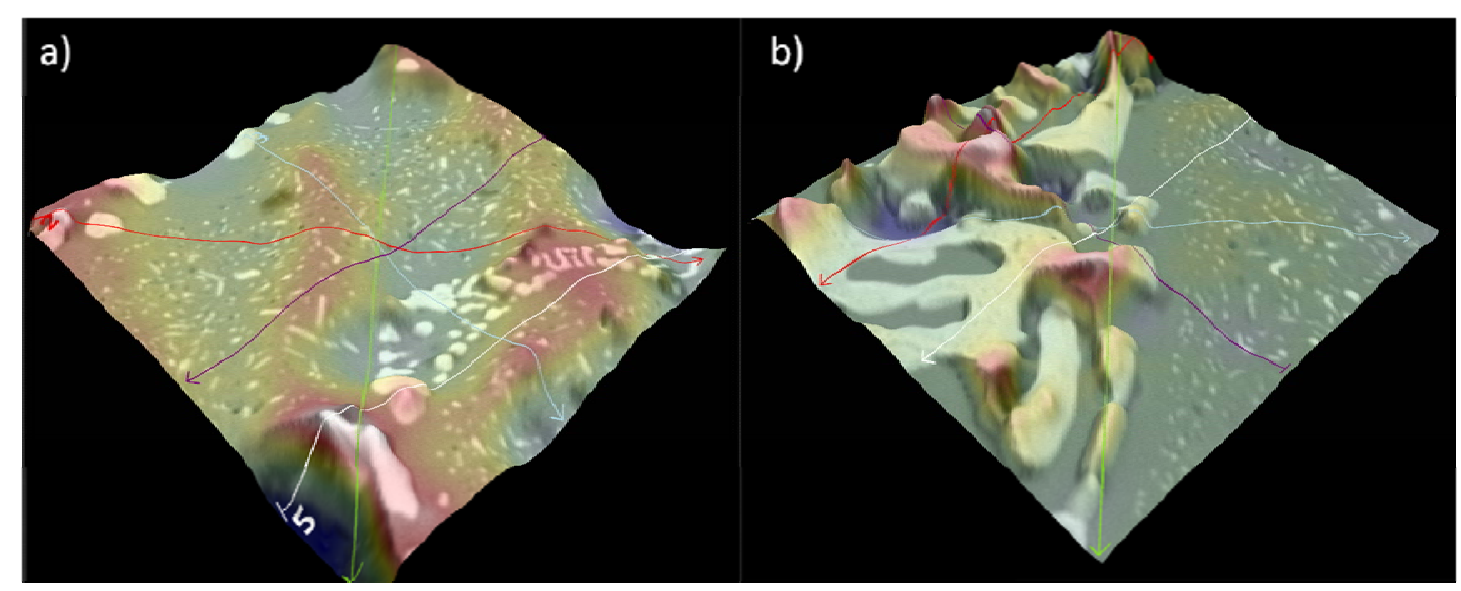

Figure 6.7: Phenom SEM photomicrographs of MEP NiTi10Ta a) at grain b) at grain boundary 


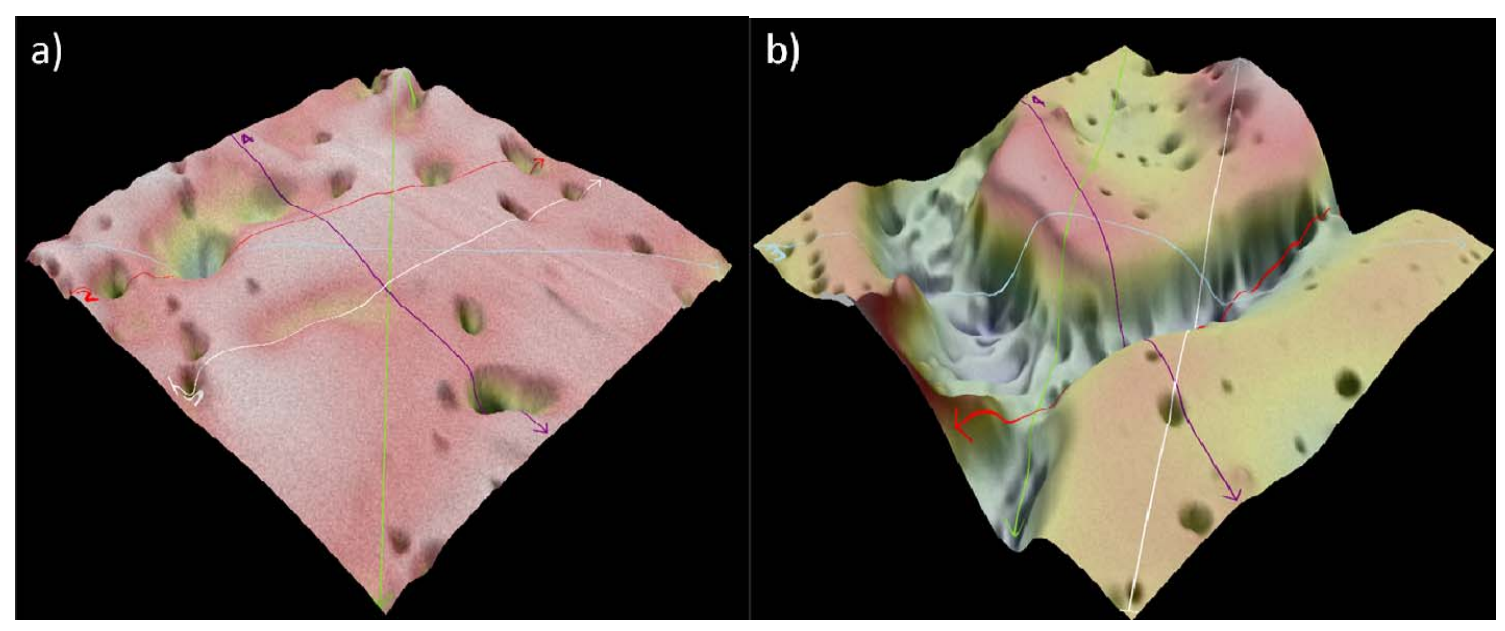

Figure 6.8: Phenom SEM photomicrographs of MEP NiTi5Cr, a) at grain b) at grain boundary

\subsection{Roughness of Nitinol alloys and polymer coating thickness by optical profilometer}

The roughness of different surface treated Nitinol alloys was determined using a Nanovea optical profilometer.

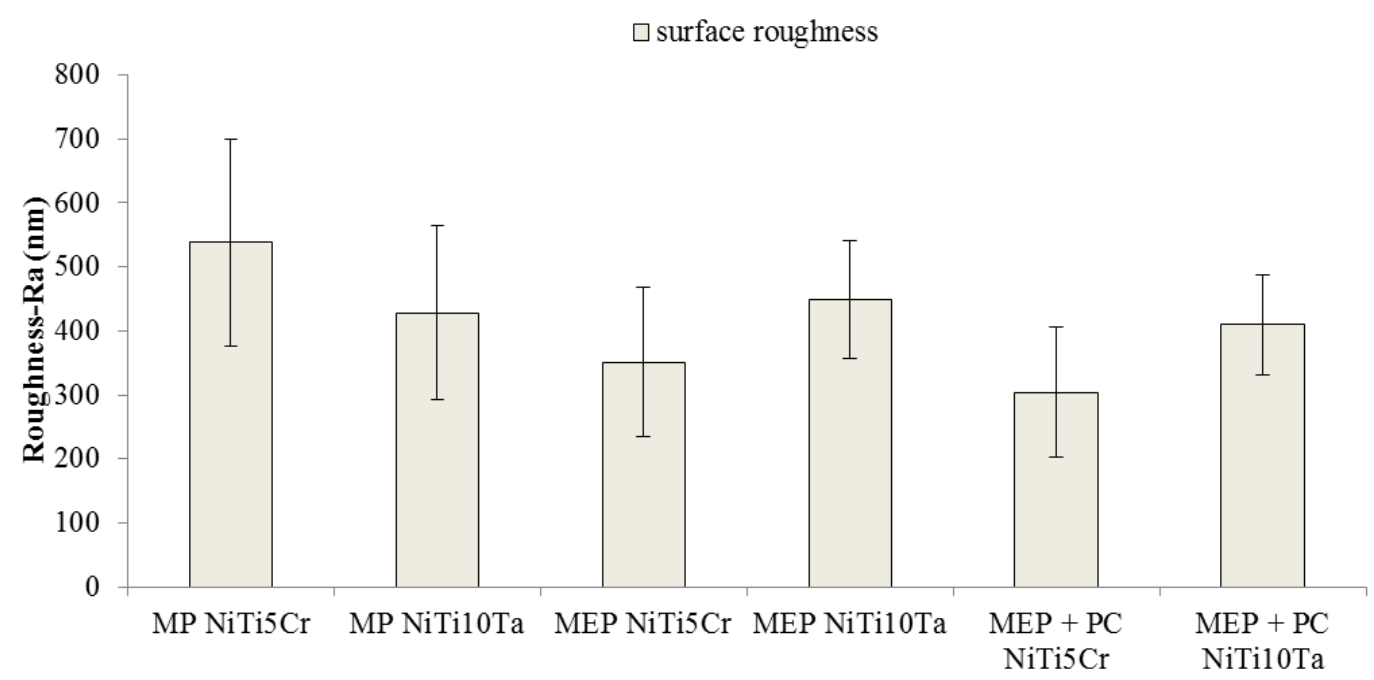

Figure 6.9: Roughness of surface treated and untreated ternary Nitinol alloys $(n=3$, mean $\pm \mathrm{SD}$ ) 
The roughness data was analyzed using a Scanning Probe Image Processor (SPIP) and the average roughness $\left(\mathrm{R}_{\mathrm{a}}\right)$ values were plotted in Figure 6.9. A slight reduction in roughness was observed for MEP NiTi5Cr $\left(\mathrm{R}_{\mathrm{a}}=350 \pm 116 \mathrm{~nm}\right)$ as compared with that of MP NiTi5Cr $\left(\mathrm{R}_{\mathrm{a}}=540 \pm 150 \mathrm{~nm}\right)$. No significant difference in surface roughness was observed before and after application of polymer coating on MEP Nitinol alloys.

The thickness of the polymer coated samples was determined using an optical profilometer as shown in Figure 6.10. It was observed that the polymer coating thickness on MEP Nitinol alloys varied from $2.4 \mu \mathrm{m}$ to $3.5 \mu \mathrm{m}$.

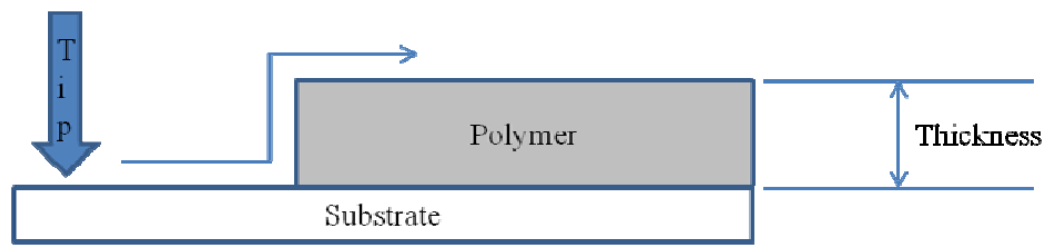

Figure 6.10: Schematic of the thickness measurement using optical profilometer.

Additionally, thickness measurements conducted by phenom tabletop SEM revealed a similar thickness in the range from $2.5 \mu \mathrm{m}$ to $3.3 \mu \mathrm{m}$ as shown in Figure 6.11.

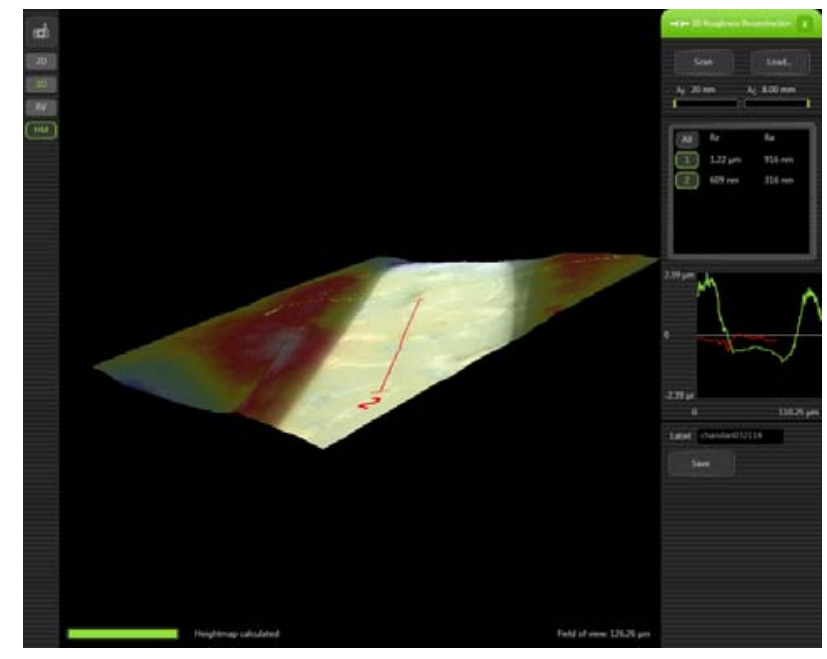

Figure 6.11: Phenom SEM image of thickness of a polymer coating 


\subsection{Morphology of polymer coated alloys before and after corrosion by SEM}

The surface morphology of polymer coated alloys before and after corrosion tests were observed using a SEM to identify the effects of corrosion.
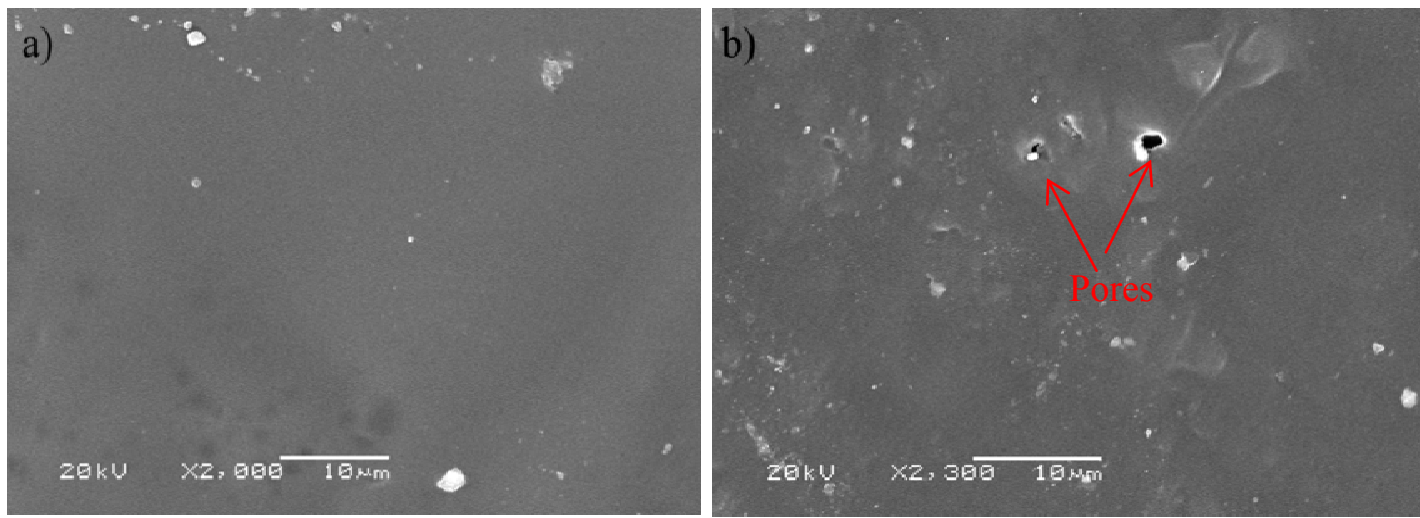

Figure 6.12: SEM photomicrographs of the surface of PC + MEP NiTi10Ta, a) before corrosion and b) after corrosion

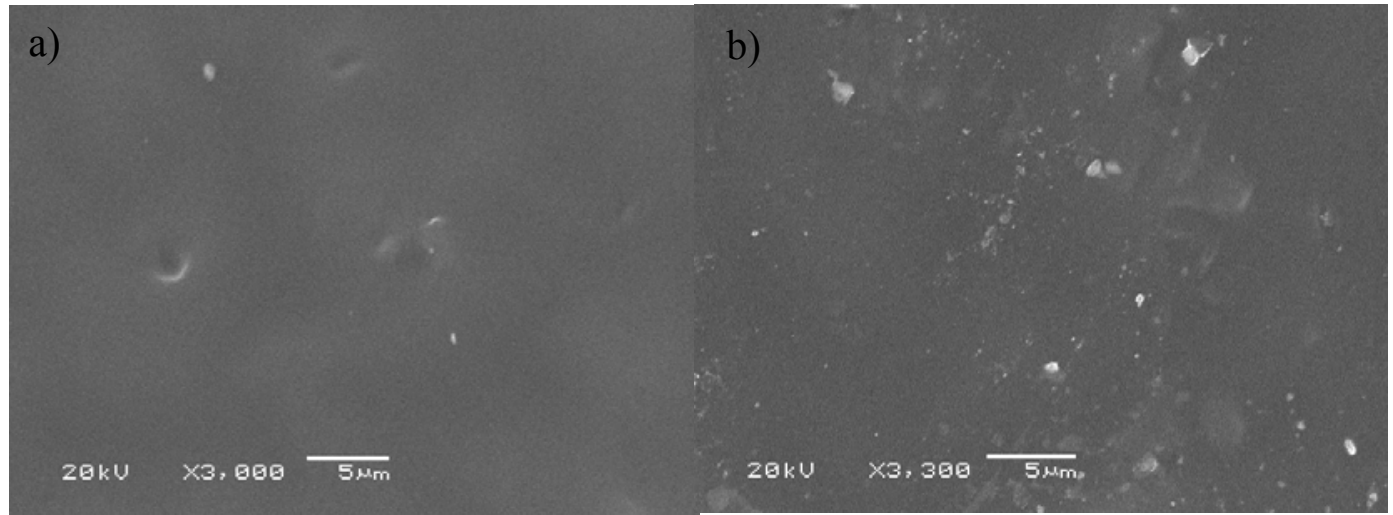

Figure 6.13: SEM photomicrographs of the surface of PC + MEP NiTi5Cr a) before corrosion and b) after corrosion

Small pores ( $\sim 1$ to $2 \mu \mathrm{m}$ in diameter) were observed on the surface of polymer coated NiTi10Ta alloys after potentiodynamic corrosion analysis (Figure 6.12). The corrosion of the underneath metal and the $\mathrm{Ni}$ ion dissolution from NiTi10Ta which were observed and discussed in chapters 3 and 5 respectively, can be attributed to the formation of these pores during corrosion. 
Figure 6.13 indicates that the surface morphology of the polymer coating on NiTi5Cr alloy did not change much after conducting corrosion tests on it.

\subsection{Surface chemistry of bare Nitinol alloys by XPS analysis}

The amount of $\mathrm{Ti}, \mathrm{Ni}, \mathrm{Cr}, \mathrm{Ta}$, their respective oxides and their thickness on the surfaces of the MEP Nitinol alloy samples were determined with a scanning X-ray photo electron spectroscopy (XPS) microprobe ( Minnesota) using monochromatic Al Ka Xray radiation (sputter etch rate of $6.5 \mathrm{~nm} / \mathrm{min}$ ). A schematic of the XPS analysis is shown in Figure 6.14.

\subsubsection{Analytical Objectives}

1. Sputter profile to a depth where the composition of the major components stabilizes.

2. Evaluate the XPS spectra to obtain chemical state information that may be available.

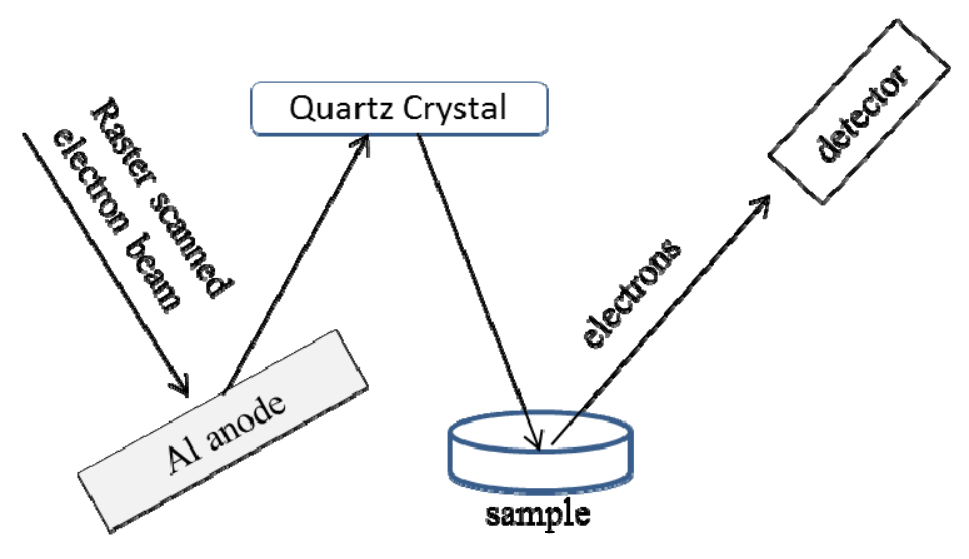

Figure 6.14: Schematic diagram of XPS analysis

\subsubsection{Measurement Approach}

1. Wide energy survey spectra were collected in a large area analysis mode to determine which elements were present at the surface using monochromatic Al Ka X-ray beam. 
2. Sputter depth profiles were obtained by using $1 \mathrm{kV}$ argon ions rastered over a $1 \mathrm{x} 1 \mathrm{~mm}$ area.

\subsubsection{Montage plots}

Titanium present on the surface of Nitinol is known to form a spontaneous titanium oxide layer. The titanium oxide is mainly composed of a tetravalent $\left(\mathrm{Ti}^{4+}\right) \mathrm{Ti}$ atom as shown in Ti montage plots. The intensity of the peaks for different species of Ti in the titanium oxide layer is dependent on the type of surface treatment that it underwent [59]. Montage plots are useful in classifying different chemical states of an element by identifying its corresponding binding energy peaks. Figures 6.15 and 6.16 correspond to the Ti montage plots for MEP NiTi10Ta and MEP NiTi5Cr respectively. Based on these montage plots, the surface of these alloys consists of a mixed oxide layer mainly composed of $\mathrm{Ti}^{0}$ (metallic) $2 \mathrm{p}^{3 / 2}$ peak at $454.0 \mathrm{eV}$ and $2 \mathrm{p}^{1 / 2}$ peak at $460.5 \mathrm{eV} ; \mathrm{Ti}^{2+}(\mathrm{TiO})$ $2 \mathrm{p}^{3 / 2}$ peak at $455.5 \mathrm{eV}$ and $2 \mathrm{p}^{1 / 2}$ peak at $461.8 \mathrm{eV}$; and $\mathrm{Ti}^{4+}\left(\mathrm{TiO}_{2}\right) 2 \mathrm{p}^{3 / 2}$ peak at $458.4 \mathrm{eV}$ and $2 \mathrm{p}^{1 / 2}$ peak at $464.5 \mathrm{eV}$.

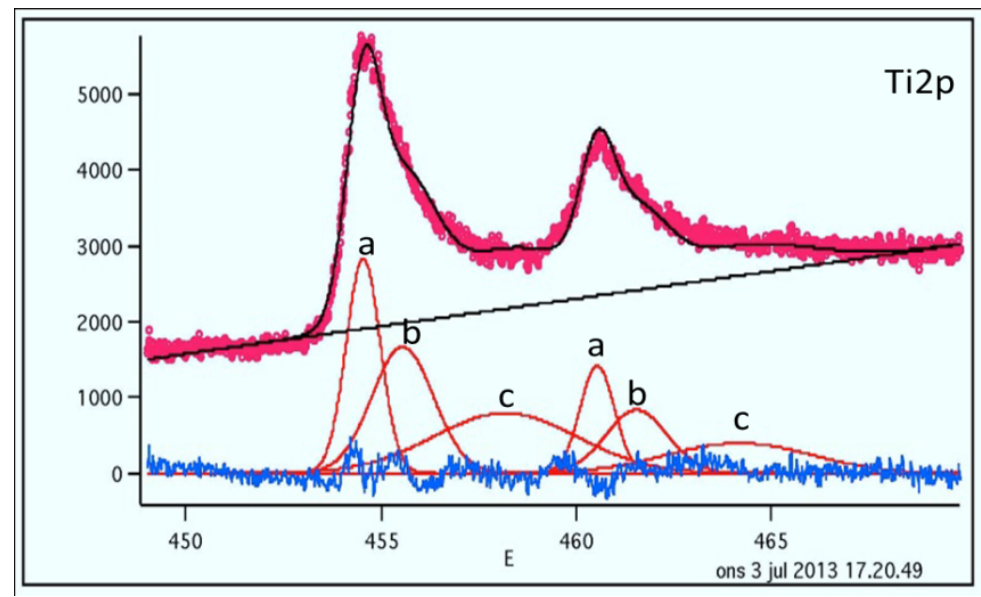

Figure 6.15: Deconvoluted montage plot for titanium Ti 2p spectra from a MEP

NiTi10Ta surface; a - Ti metal, b - TiO oxide and c- $\mathrm{TiO}_{2}$ 


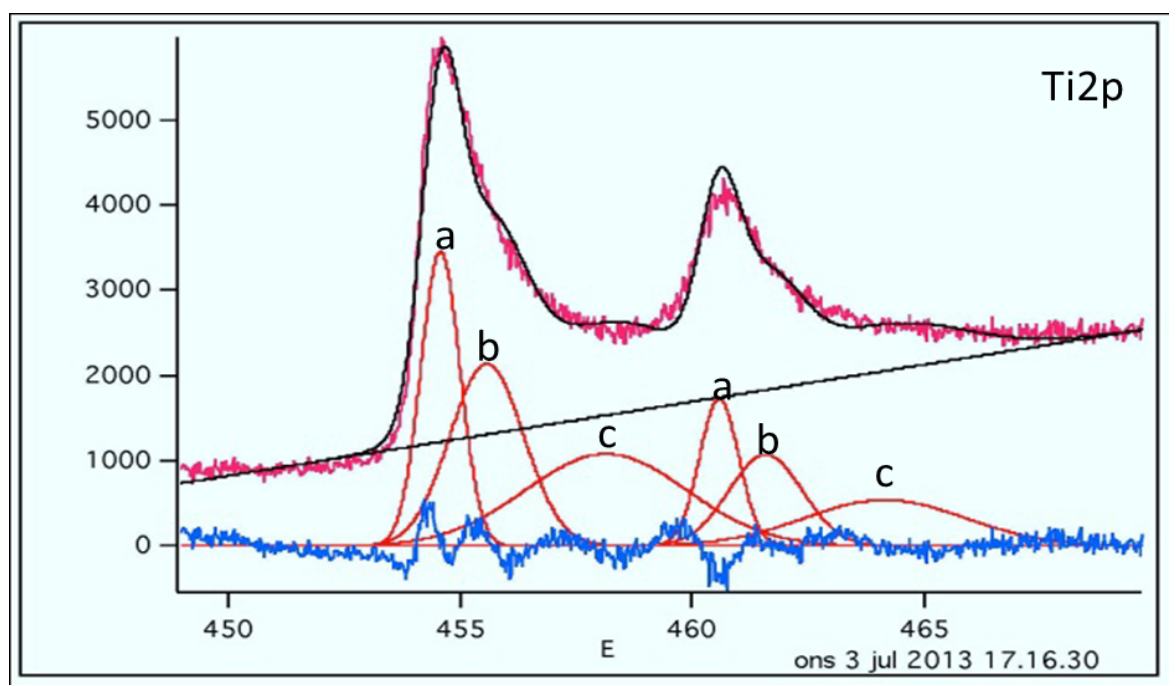

Figure 6.16: Deconvoluted montage plot for titanium Ti $2 p$ spectra from a MEP NiTi5Cr surface; a - Ti metal, b - TiO oxide and c- $\mathrm{TiO}_{2}$

Nickel present on the surface of Nitinol is known to exist in metallic $\left(\mathrm{Ni}^{0}\right), \mathrm{NiO}$ $\left(\mathrm{Ni}^{2+}\right)$ and $\mathrm{NiOH}\left(\mathrm{Ni}^{2+}\right)$. The Ni montage plots in Figures 6.17 and 6.18 exhibited $\mathrm{Ni}^{0}$ and $\mathrm{Ni}^{2+}$ peaks on the surface of MEP NiTi10Ta and MEP NiTi5Cr respectively. Based on these montage plots, the surface of these alloys consisted of $\mathrm{Ni}^{0}$ (metallic) $2 \mathrm{p}^{3 / 2}$ peak at $853.3 \mathrm{eV}$ and $\mathrm{Ni}^{2+}\left(\mathrm{NiO}\right.$ and $\left.\mathrm{Ni}(\mathrm{OH})_{2}\right) 2 \mathrm{p}^{3 / 2}$ peak at $854.3 \mathrm{eV}$ and $2 \mathrm{p}^{1 / 2}$ peak at $861.5 \mathrm{eV}$.

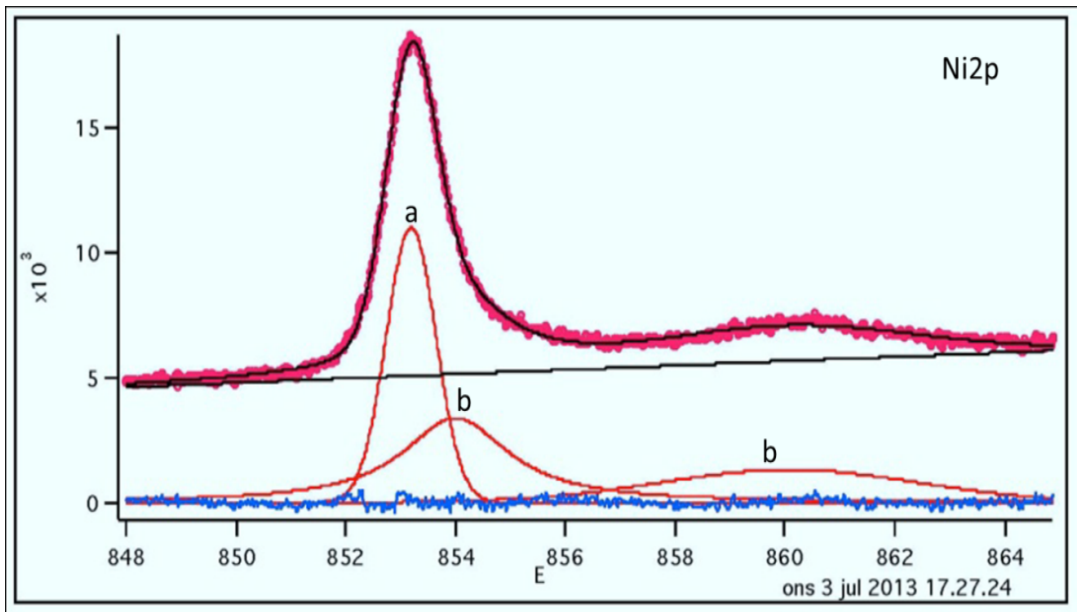

Figure 6.17: Deconvoluted montage plot for titanium Ni 2p spectra from a MEP NiTi10Ta surface; $\mathrm{a}$ - Ni metal and $\mathrm{b}$ - NiO oxide 


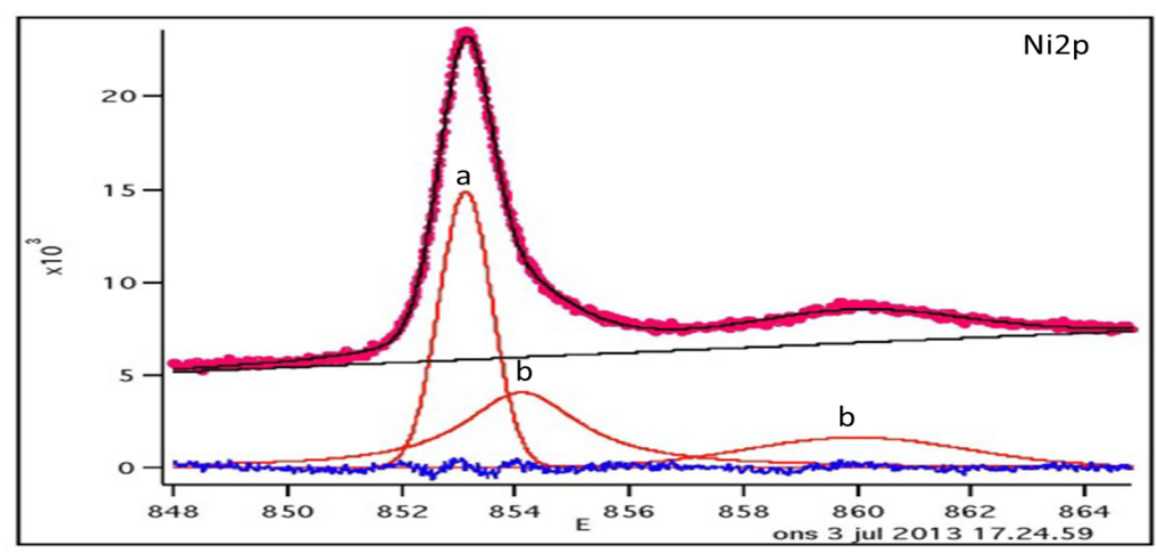

Figure 6.18: Deconvoluted montage plot for Nickel Ni 2p spectra from a MEP NiTi5Cr surface; $\mathrm{a}$ - Ni metal and $\mathrm{b}-\mathrm{NiO}$ oxide

Figure 6.19 indicates the presense of tantalum on the surface of MEP NiTi10Ta alloy. These peaks at Ta $4 \mathrm{f}^{7 / 2}(23.2 \mathrm{eV}), 4 \mathrm{f}^{5 / 2}(24.8 \mathrm{eV})$ and $5 \mathrm{p}^{3 / 2}(34.2 \mathrm{eV})$ correspond to metallic Ta. These results were consistent with those obtained by XRD (section 6.6) of MEP NiTi10Ta, which showed the presence of Ta on its surface.

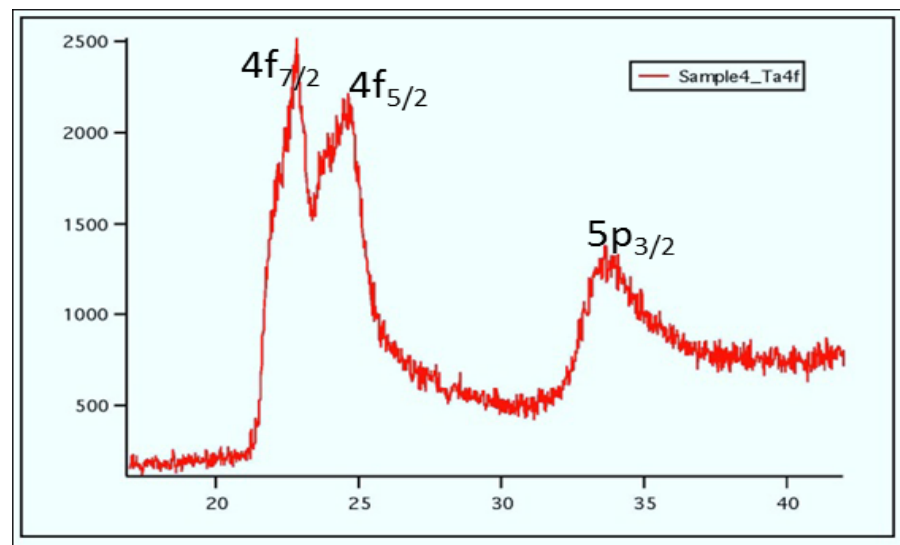

Figure 6.19: Montage plot of tantalum Ta 4f peak obtained for MEP NiTi10Ta surface.

The Cr montage plot in Figure 6.20 exhibited $\mathrm{Cr}^{0}$ and $\mathrm{Cr}^{3+}$ peaks on the surface of MEP NiTi5Cr. Based on these montage plots, the surface of these alloys consisted of $\mathrm{Cr}^{0}$ (metallic) $2 \mathrm{p}^{3 / 2}$ peak at $574.5 \mathrm{eV}$ and $2 \mathrm{p}^{1 / 2}$ peak at $584.7 \mathrm{eV} ; \mathrm{Cr}^{3+}\left(\mathrm{Cr}_{2} \mathrm{O}_{3}\right) 2 \mathrm{p}^{3 / 2}$ peak at $577.4 \mathrm{eV}$ and $2 \mathrm{p}^{1 / 2}$ peak at $588.2 \mathrm{eV}$. 


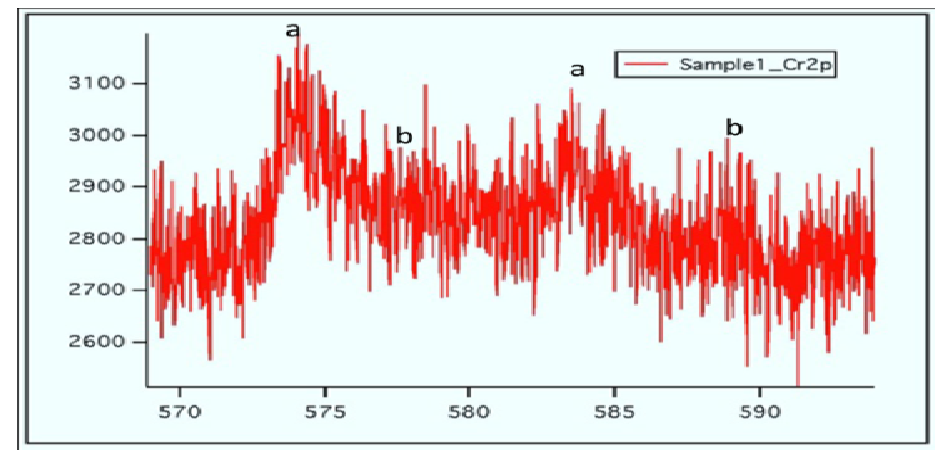

Figure 6.20: Montage plot for chromium Cr 2p spectra from MEP NiTi5Cr surface; $\mathrm{a}-\mathrm{Cr}$ metal and $\mathrm{b}-\mathrm{Cr}_{2} \mathrm{O}_{3}$ oxide

A summary of all the XPS peaks observed on the surface of MEP ternary Nitinol alloys and their corresponding reference values are tabulated in Tables 6.1 and 6.2.

Table 6.1: XPS binding energies for different elements present on the surface of MEP ternary Nitinol alloys [29, 244-247].

\begin{tabular}{|c|c|c|c|c|}
\hline \multirow{2}{*}{ Type of species } & \multicolumn{2}{|c|}{ Experimental values } & \multicolumn{2}{|c|}{ Reference values } \\
\hline & $2 p^{3 / 2}(e V)$ & $2 p^{1 / 2}(e V)$ & $2 p^{3 / 2}(e V)$ & $2 p^{1 / 2}(e V)$ \\
\hline $\mathrm{Ti}^{\mathbf{0}}$ (metallic) & 454 & 460.5 & $454,454.2,454.5$ & 460 \\
\hline $\mathrm{Ti}^{2+}(\mathrm{TiO})$ & 455.5 & 461.8 & 455.1 & 462 \\
\hline $\mathrm{Ti}^{3+}\left(\mathrm{Ti}_{2} \mathrm{O}_{3}\right)$ & NA & NA & 457.8 & 463.3 \\
\hline $\mathrm{Ti}^{4+}\left(\mathrm{TiO}_{2}\right)$ & 458.4 & 464.5 & 458.4 & 464.6 \\
\hline $\mathrm{Cr}^{0}$ (metallic) & 574.5 & 584.7 & 574.4 & 583.6 \\
\hline $\mathrm{Cr}^{2+}\left(\mathrm{Cr}_{2} \mathrm{O}_{3}\right)$ & 577.4 & 588.2 & 577.5 & 587.5 \\
\hline $\mathrm{Ni}^{0}$ (metallic) & 853.3 & NA & $851.8,852.6$ & 858.3 \\
\hline $\mathrm{Ni}^{2+}(\mathrm{NiO})$ & 854.3 & 861.5 & $853.7,854.6$ & 861.8 \\
\hline $\mathrm{Ni}^{3+}\left(\mathrm{Ni}_{2} \mathrm{O}_{3}\right)$ & $\mathrm{NA}$ & NA & $856.3,856.1$ & \\
\hline
\end{tabular}


Table 6.2: Ta element XPS peaks obtained on the surface of MEP NiTi10Ta.

\begin{tabular}{|c|c|c|c|c|}
\hline \multirow{2}{*}{ sype of } & \multicolumn{2}{|c|}{ Experimental values } & \multicolumn{2}{c|}{ Reference values } \\
\cline { 2 - 5 } & $\mathbf{4 f}^{\mathbf{7 / 2}}(\mathbf{e V})$ & $\mathbf{4 f}^{\mathbf{5 / 2}}(\mathbf{e V})$ & $\mathbf{4 f}^{\mathbf{7 / 2}}(\mathrm{eV})$ & $\mathbf{4 f}^{\mathbf{5 / 2}}(\mathrm{eV})$ \\
\hline Ta (metallic) & 23.2 & 24.8 & 21.8 & 23.8 \\
\hline $\mathbf{T a}^{\mathbf{5 +}}\left(\mathbf{T a}_{\mathbf{2}} \mathbf{O}_{\mathbf{5}}\right)$ & NA & NA & 26.2 & 29.2 \\
\hline
\end{tabular}

The amount of $\mathrm{Ni}, \mathrm{NiO}$ and $\mathrm{Ni}(\mathrm{OH})_{2}$ present on the surface of MEP NiTi5Cr and MEP NiTi10Ta are shown in Table 6.3. These results indicated that the amount of metallic Ni and NiO present on the surface of MEP NiTi10Ta were double the amount that was present on MEP NiTi5Cr. This higher Ni content on the surface of MEP NiTi10Ta as compared with that on MEP NiTi5Cr, has led to higher Ni release from its surface during corrosion and this correlated with the ICPMS results (as shown in Figure 5.1 and described in Chapter 5).

Table 6.3: The amount (at $\%$ ) of different species of Ni present on the surface of MEP NiTi5Cr and MEP NiTi10Ta

\begin{tabular}{|c|c|c|}
\hline Chemical species & MEP NiTi5Cr & MEP NiTi10Ta \\
\hline $\mathbf{N i}$ & 0.150 & 0.384 \\
\hline $\mathbf{N i O}$ & 0.133 & 0.371 \\
\hline $\mathbf{N i}(\mathbf{O H})_{2}$ & 0.716 & 0.245 \\
\hline
\end{tabular}




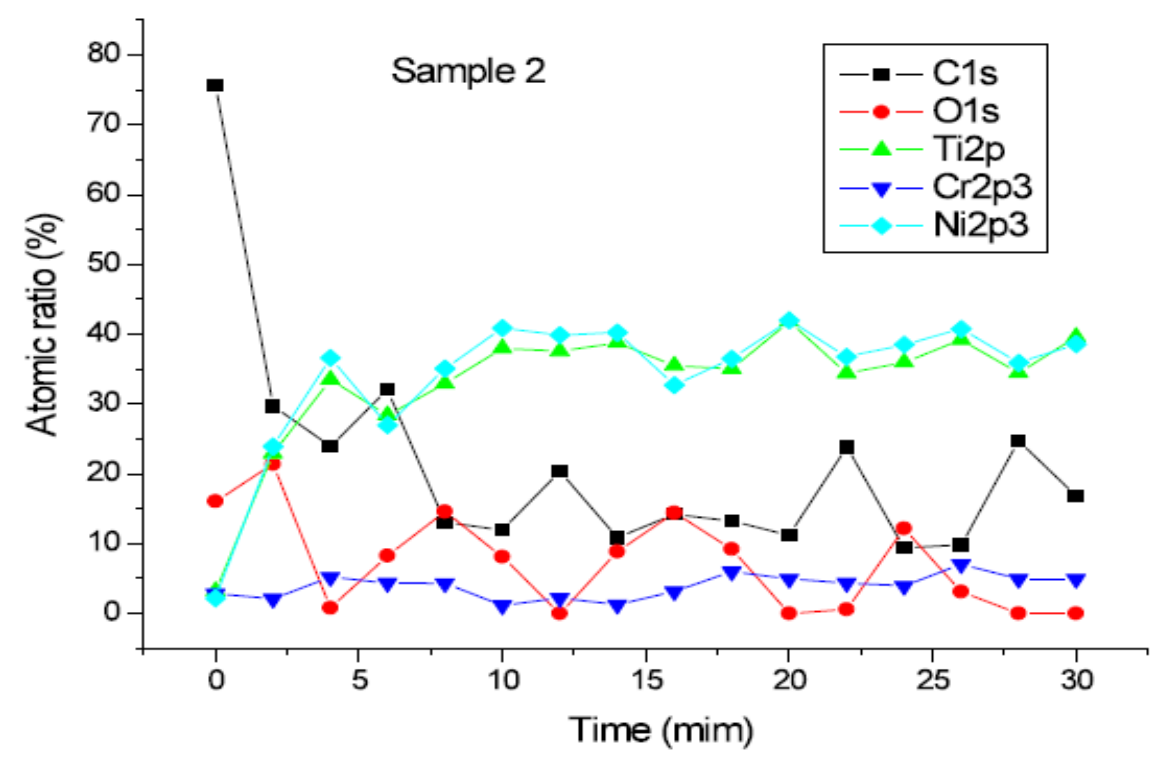

Figure 6.21: Depth profile analysis obtained from the surface of MEP NiTi5Cr

Depth profile analysis of different elements present on the surface of MEP NiTi5Cr is shown in Figure 6.21.

\subsection{XRD analysis of surface oxides on Nitinol alloys}

X-ray Diffractometer (XRD) analysis was conducted on MP and MEP treated ternary Nitinol alloys, in an effort to determine the presence of different metallic phases (martensite or austenite), types of oxides (such as $\mathrm{TiO}_{2}, \mathrm{NiO}$, etc.) and metallic ions (Ni), which are known to affect their corrosion and bio-compatibility properties. The crystallinity of the oxide layers was determined using a Siemens D 500 XRD (Siemens, Munich, Germany). The XRD results for treated and untreated Nitinol are shown in Figure 6.22. 


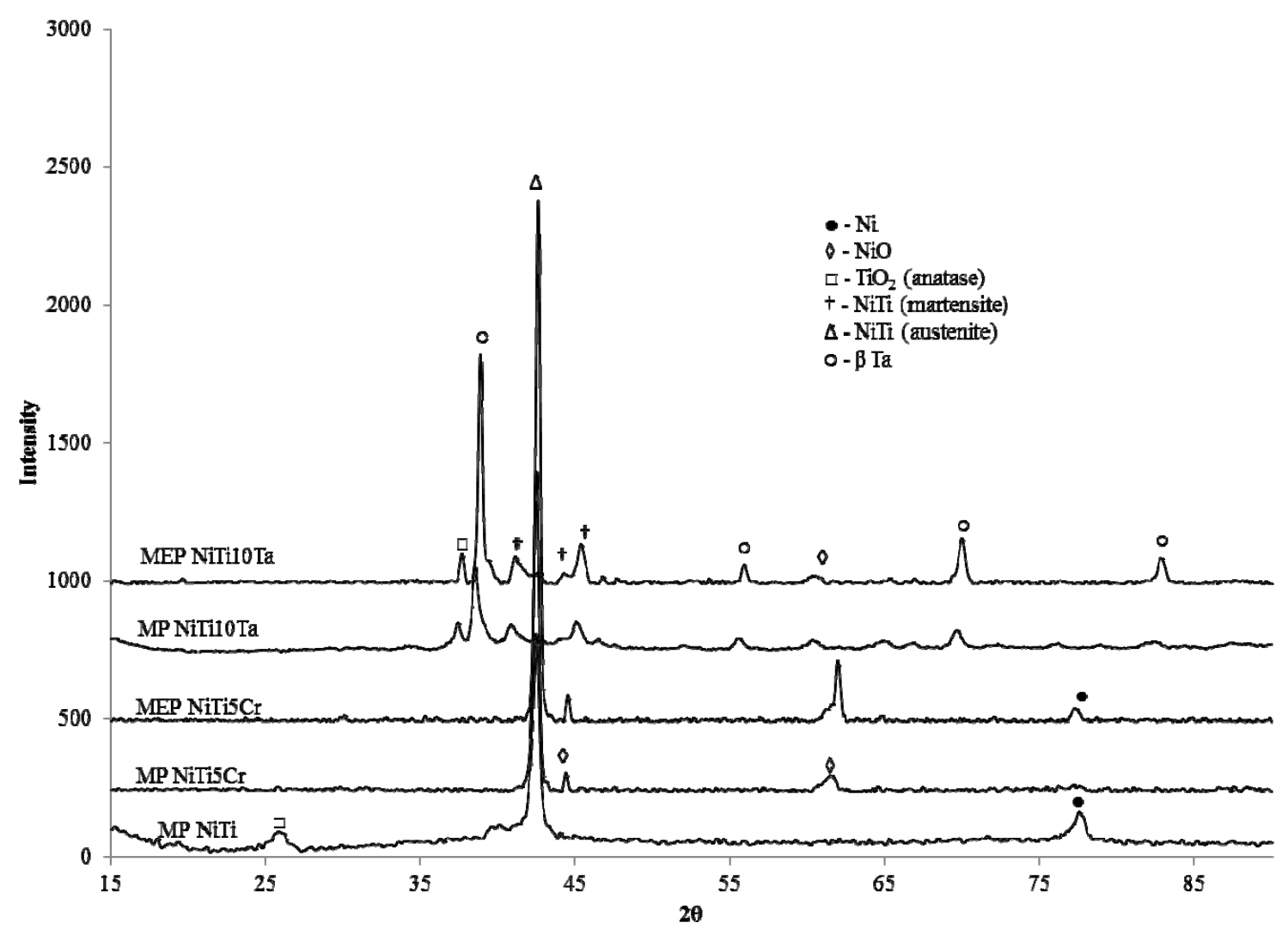

Figure 6.22: XRD analysis of MP NiTi, MEP NiTi5Cr and MEP NiTi10Ta.

Based on XRD analysis, nickel in its metallic form and titanium oxide $\left(\mathrm{TiO}_{2}\right)$ in anatase form were found on the surface of MP NiTi. The presence of elemental Ni was detected on the surface of MP-NiTi and MEP NiTi5Cr. In addition to all the phases detected on MP NiTi, the MEP NiTi5Cr surface possessed a greater amount of nickel oxide and less elemental $\mathrm{Ni}$. These results are comparable to the $\mathrm{Ni}$ and $\mathrm{NiO}$ concentrations provided by XPS analysis (Table 6.3). Whereas, nickel oxide (NiO), amorphous $\mathrm{TiO}_{2}(42)$ and $\beta$-Ta $[179,248]$ were observed on the surface of MEP NiTi10Ta (Figure 6.22). Additionally, it was observed that MP NiTi and MEP NiTi5Cr were austenitic phases, whereas MEP NiTi10Ta was martensitic. Similarly, Gong et al. [248] cited the presence of $\beta$-Ta and martensitic NiTi (Monoclinic B-19') in the Ni-Ti-Ta 
alloy system. The $\beta$-Ta is known for its high resistivity $(180-220 \mu .0 h m . c m)$ and disordered structure[249]. Alloying and MEP treatment has resulted in the conversion of metallic Ni on the surface of Nitinol into NiO.

\subsection{Determination of mechanical properties of NiTi alloys by Nano-indentation}

The bulk hardness and Young's modulus of elasticity were determined using a MTS Nanoindenter XP with a diamond Berkovich indenter. At least 10 indentations spaced 100 microns apart were used to estimate the modulus and hardness of the specimens adopting the Oliver-Pharr approach [250]. This experimental method was created in order to minimize errors due to thermal drift, machine compliance, etc. The stiffness was evaluated from the unloading curve by taking the derivative at the inception of the best fitted polynomial function with respect to the displacement, i.e. $\mathrm{dP} / \mathrm{dh}$. The contact area was defined by using a polynomial function obtained by using reference data from a fused silica specimen with a known modulus (72.1 GPa from ultrasonic measurements) and hardness. The area function was calculated for a depth greater than the maximum depth penetrated in the specimens, where the tip radius was calibrated using a tungsten specimen.

The plot of load vs displacement at $500 \mathrm{mN}$ and $200 \mathrm{mN}$ peak loads on different surface treated Nitinol alloys are shown in Figure 6.23. Each sample was indented with 20 indents at different peak loads. Figure 6.23 (a) and (b) show the modulus and hardness calculated by using the Oliver Pharr approach (depths above $1000 \mathrm{~nm}$ and peak loads above $25 \mathrm{mN}$ ). The modulus of NiTi alloys (79-98 GPa) increased with the addition of alloying elements as did the hardness (3-7.4 GPa) (see Table 6.4 and Figure 6.23). 

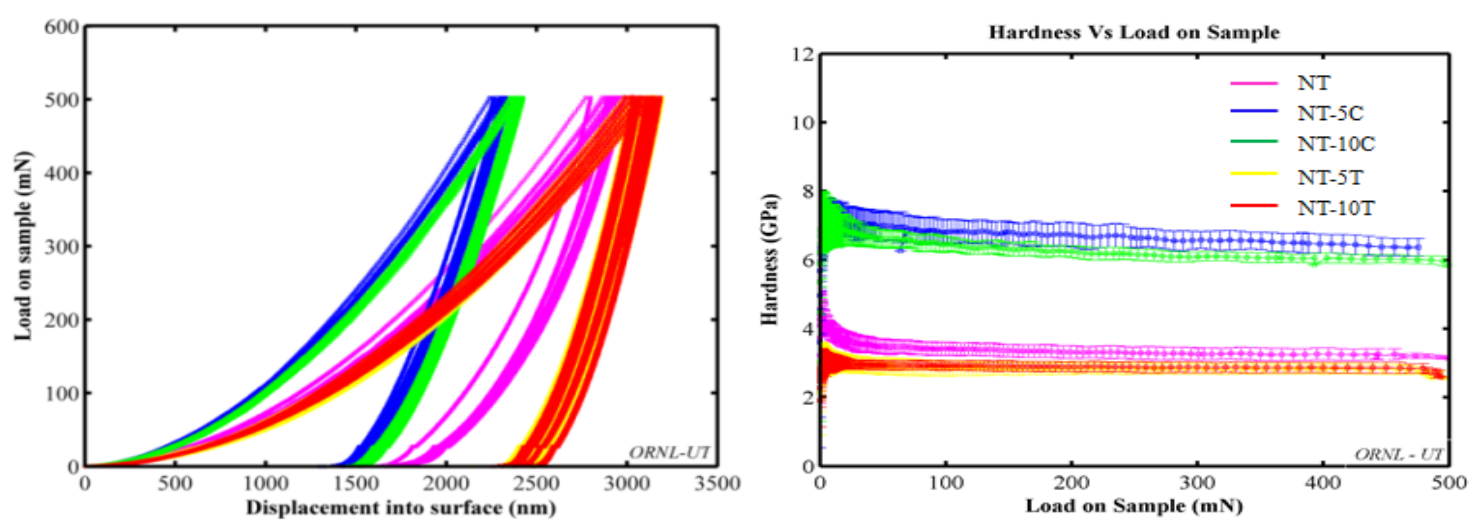

Figure 6.23: Nanoindentation: (a) Peak load vs. displacement and (b) load vs. hardness curves for NiTi Alloys.

Table 6.4: Modulus and hardness calculated from Nano-indentation.

\begin{tabular}{|c|c|c|c|c|c|c|}
\hline & \multicolumn{2}{|c|}{ NiTi } & \multicolumn{2}{c|}{ NiTi5Cr } & \multicolumn{2}{c|}{ NiTi10Ta } \\
\hline & E (GPa) & H (GPa) & E (GPa) & H (GPa) & E (GPa) & H (GPa) \\
\hline Mean & 79.4 & 3.6 & 97.9 & 7.4 & 78.9 & 3 \\
\hline Std. Dev. & 1.4 & 0.2 & 2.0 & 0.2 & 4.9 & 0.2 \\
\hline
\end{tabular}

\subsection{Surface composition of polymer coated Nitinol by FTIR analysis}

Fourier transform infrared spectroscopy (FTIR) analysis was conducted on polymer coated MEP Nitinol alloys. The FTIR peaks for MEP + PC NiTi10Ta and MEP + PC NiTi5Cr are shown in Figure 6.24. 
- MEP+PC NITi5C $\mathrm{M}-\mathrm{MEP}+\mathrm{PC}$ NiTi10Ta

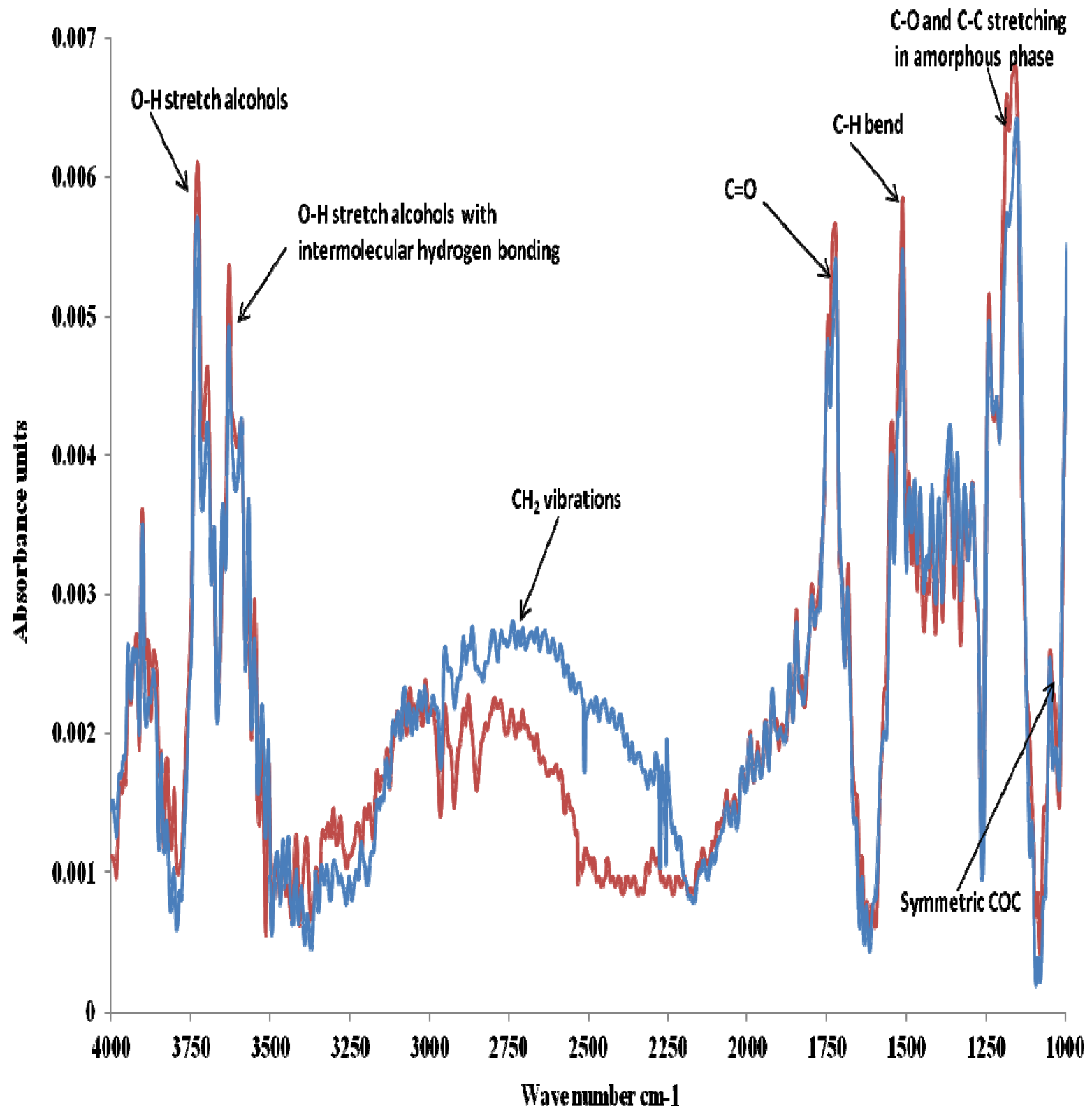

Figure 6.24: FTIR spectrum of PGA/PCL polymer coated MEP NiTi5Cr and MEP PC NiTi10Ta

The significance of each peak observed in the aforementioned FTIR spectra is tabulated in Table 6.5. 
Table 6.5: Interpretation of FTIR spectra for PGA/PCL polymer coatings

\begin{tabular}{|c|c|c|c|}
\hline $\begin{array}{l}\text { Experimental } \\
\text { peak }\left(\mathrm{cm}^{-1}\right)\end{array}$ & $\begin{array}{l}\text { Theoretical } \\
\text { peak }\left(\mathrm{cm}^{-1}\right)\end{array}$ & Possible functional groups & $\begin{array}{c}\text { Characteristic } \\
\text { material }\end{array}$ \\
\hline 3733.5 & $3720-3770$ & $\begin{array}{l}\text { Alcoholic } \mathrm{OH} \text {, vibrational } \\
\text { stretching without hydrogen } \\
\text { bonding }\end{array}$ & - \\
\hline 3632 & $3610-3670$ & $\begin{array}{l}\text { Vibrational stretching of } \mathrm{OH} \text { with } \\
\text { intermolecular hydrogen bonding }\end{array}$ & - \\
\hline $3050-2750$ & $2980-3040$ & $\mathrm{CH}_{2}$ vibrations & PCL \\
\hline 2942 & 2949 & Asymmetric C-H stretching & PCL \\
\hline 1747 & $\begin{array}{l}1750 \text { very } \\
\text { strong }\end{array}$ & $\mathrm{C}=\mathrm{O}$ carbonyl stretch (anhydride) & PGA, PCL \\
\hline 1500 , & 1500 & Aromatic $\mathrm{C}=\mathrm{C}$ & - \\
\hline 1546 & 1540 & $\mathrm{C}-\mathrm{H}$ bend & PGA \\
\hline 1455 & $1380-1480$ & $\begin{array}{l}\text { Vibrational bending of } \mathrm{CH} \text { group of } \\
\text { alcoholic group }\end{array}$ & - \\
\hline 1300,1350 & $1300-1360$ & $\begin{array}{l}\text { Vibrational bending of double bond } \\
(\mathrm{C}=\mathrm{C}) \text { vinyl and bending of } \mathrm{CH} \\
\text { from alcoholic groups }\end{array}$ & - \\
\hline 1300 & 1294 & $\begin{array}{l}\mathrm{C}-\mathrm{O} \text { and } \mathrm{C}-\mathrm{C} \text { stretching in the } \\
\text { crystalline phase }\end{array}$ & - \\
\hline 1241 & 1245 strong & Asymmetric COC stretching & PCL \\
\hline 1186 & 1190 strong & OC-O stretching, & PCL \\
\hline 1164 & 1170 & Symmetric COC stretching & PCL \\
\hline 1157 & $\begin{array}{l}1160 \text { very } \\
\text { strong }\end{array}$ & $\begin{array}{c}\mathrm{C}-\mathrm{O} \text { and } \mathrm{C}-\mathrm{C} \text { stretching in the } \\
\text { amorphous phase }\end{array}$ & PCL \\
\hline 1047 & 1050 short & symmetric COC & PCL, PGA \\
\hline
\end{tabular}


The broad peak from $2800-3000 \mathrm{~cm}^{-1}$ belongs to $\mathrm{CH}_{2}$ vibrations displayed by a PCL molecule; a strong peak at $1740 \mathrm{~cm}^{-1}$ belongs to $\mathrm{C}=\mathrm{O}$ stretching vibrations and it is a characteristic peak for both PCL and PGA molecules; a strong peak at $1540 \mathrm{~cm}^{-1}$ corresponds to $\mathrm{CH}$ bent vibrations and is a characteristic peak for PGA; $1300-1500 \mathrm{~cm}^{-1}$ attributed to deformational $\mathrm{CH}_{2}$ vibrations and these peaks are characteristic of aliphatic polyesters [251], [252]; a very strong peak at $1157 \mathrm{~cm}^{-1}$ corresponds to C-O and C-C stretching vibrations of PCL in amorphous phase; a short peak at $1047 \mathrm{~cm}^{-1}$ corresponds to COC vibrations that are characteristic for both PCL and PGA molecules. These FTIR peaks denote the presence of amorphous PCL/PGA polymer coatings on the surface of MEP treated Nitinol alloys.

\subsection{Wettability and work of adhesion of polymer coated and uncoated NiTi} Alloys by contact angle meter

The surface properties of a material are dependent on its surface treatment, which can produce different surface texture, surface chemistry, surface energy and wettability [59]. It has been reported that the wettability and surface free energy of NiTi significantly influence its biological response [253].

In order to assess the biological response of NiTi alloys, both their wettability and surface energy were determined by measuring their contact angles (CA). A kyova contact angle meter was used to determine the contact angle and surface energy of the Nitinol alloys. A sessile drop method was used to study the samples using DI water (polar), ethylene glycol (neutral) and diiodomethane (non-polar) as the three probe liquids. Young-Dupre Equation (6.1) [254] was used to calculate the contact angle: 


$$
\gamma_{1 \mathrm{v}} \cos \theta=\gamma_{\mathrm{sv}}-\gamma_{\mathrm{sl}}
$$

where $\gamma_{1 v}$ - is surface energy of the liquid with respect to vapor, $\gamma_{s l}$ - surface free energy related with the interface between solid and probe liquid, ${ }_{\mathrm{sv}}$ - surface energy of the solid with respect to vapor and $\Theta$ is the contact angle between the probe liquid and the examined surface.

All tests were conducted on each specimen at locations with sufficient spacing, in order to prevent any influence of the previous tests. Five samples of each alloy were used to measure contact angles.

A comparative analysis of contact angles for different materials is shown in Figure 6.25.

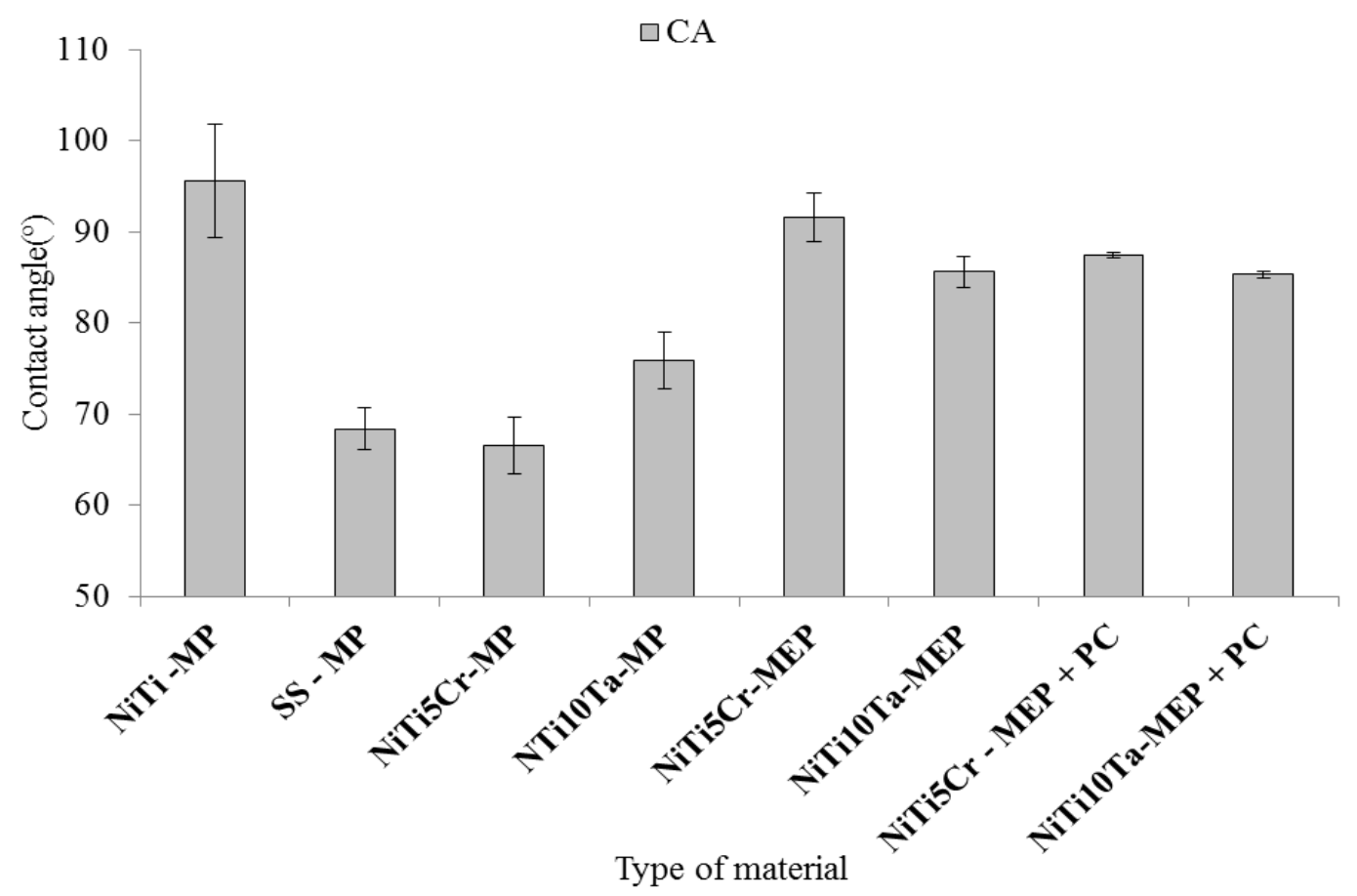

Figure 6.25: A comparison of CA values for different bio-materials $(n=5$, mean \pm SD). 
Figure 6.25 indicates that the CA of MP NiTi varied from slightly hydrophobic ( 95.6 degree) to slightly hydrophilic behavior (MP NiTi5Cr $\sim 66.6$ and MP NiTi10Ta $~$ 75.9 degree) after alloying of Nitinol with ternary elements such as Ta and Cr. However, MEP treatment to MP ternary Nitinol alloys has increased their contact angles and the alloys became slightly hydrophobic in nature (MEP NiTi5Cr 91.6 and MEP NiTi10Ta $\sim$ 85.6). Based on our previous investigation, magneto-electropolished (MEP) surfaces were more hydrophobic than the untreated NiTi surfaces. Additionally, the application of the biodegradable polymer coating on the MEP Nitinol alloys did not induce any significant difference in their CA values.

CA of biodegradable co-polymer PGA/PCL (90/10) was measured and compared with that of the CA values of each individual polymer (from literature) as shown in Figure 6.26. The sessile drop contact angle measurements show that the wettability of monomeric PCL[255] and PGA/PCL co-polymer are similar, whereas, monomeric PGA [256] is slightly hydrophilic in nature.

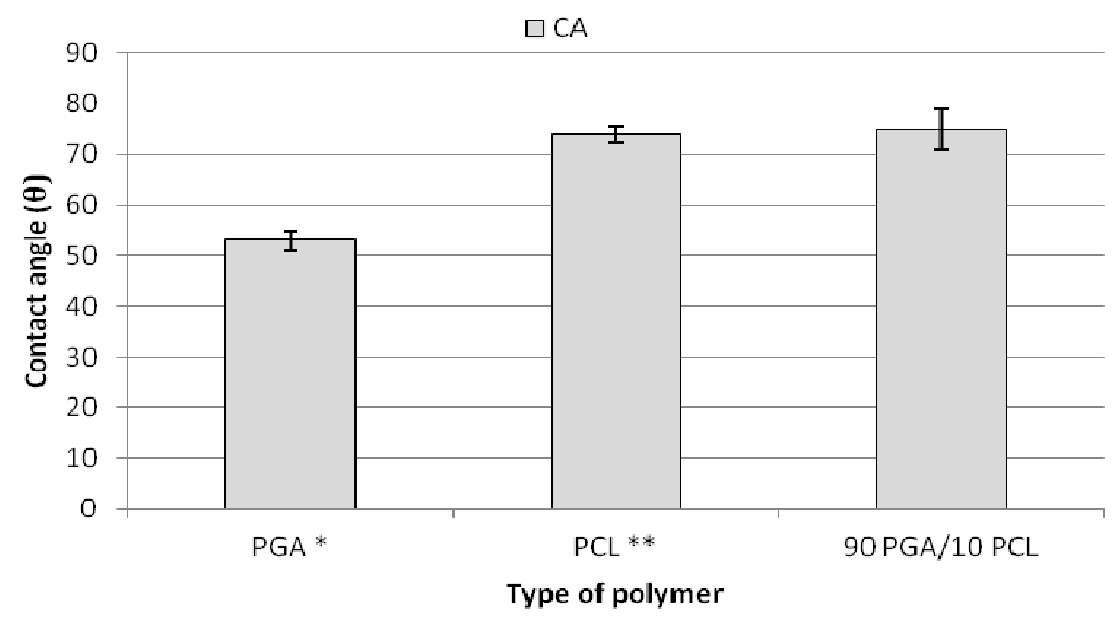

Figure 6.26: Comparison of contact angles for PGA/ PCL co-polymer with that of monomeric polymers $*[256],{ }^{*}[255](\mathrm{n}=5$, mean $\pm \mathrm{SD})$. 
Depending on the surface chemistry of a biomaterial, its surface properties such as work of adhesion, wettability and surface free energy will vary. Among these factors, work of adhesion [253] is one such property that effects the adhesion of blood components to biomaterials after implantation.

Mathematically, the work of adhesion (W) [257] of an adhering cell on to a solid substrate is expressed as

$$
W=\gamma_{S L}+\gamma_{A L}-\gamma_{S A}
$$

Whereas, the subscripts S, A and L stand for the phases (the solid substrate, the adhering cell and liquid respectively) and the $\gamma$ values refer to the interfacial tensions between the phases considered.

In this research, work of adhesion of blood cells on biomaterials (the ease with which cells can adhere) can be determined by using Equation (6.2), where the biomaterial is considered as the solid substrate, the blood as the liquid and the platelets as adhering cells. So the parameters in Equation (6.2) are: $\gamma_{S L}$ corresponds to interfacial tension between substrate and liquid, $\gamma_{\mathrm{PL}}$ corresponds to interfacial tension between platelet and liquid, $\gamma_{S P}$ corresponds to interfacial tension between substrate and platelet. Determination of work of adhesion between platelets and biomaterials (used in blood contacting implants) acts as a parameter to interpret their long-term hemocompatibility properties. The surface free energy parameters for platelets and liquids used in the experiment are shown in Table 6.6. 
Table 6.6: Surface free energy parameters (in $\mathrm{mN} / \mathrm{m}$ )

\begin{tabular}{|c|c|c|c|}
\hline Component & $\gamma^{+}$ & $\gamma^{-}$ & $\gamma^{\mathrm{LW}}$ \\
\hline Platelet membrane[253] & 12.26 & 7.44 & 99.14 \\
\hline Distilled water & 25.50 & 25.50 & 21.80 \\
\hline Diiodomethane & 0 & 0 & 50.80 \\
\hline Ethylene glycol & 1.90 & 47.00 & 29.00 \\
\hline
\end{tabular}

Table 6.7: Surface free energy parameters (in $\mathrm{mN} / \mathrm{m}$ )

\begin{tabular}{|c|c|c|c|c|c|c|}
\hline \multirow{2}{*}{ Material } & \multicolumn{5}{|c|}{ Lewis acid base theory } \\
\cline { 2 - 7 } & \multicolumn{2}{|c|}{$\gamma^{\text {LW }}$} & \multicolumn{2}{c|}{$\gamma^{+}$} & \multicolumn{2}{c|}{$\gamma^{-}$} \\
\cline { 2 - 7 } Avg & SD & Avg & SD & Avg & SD \\
\hline NiTi -MP & 23.7 & 0.75 & 0.04 & 0.02 & 7.75 & 1.69 \\
\hline SS - MP & 30.78 & 0.76 & 0 & 0 & 26.2 & 2.53 \\
\hline NiTi5Cr-MP & 30.02 & 0.09 & 0.1 & 0.05 & 22.7 & 0.24 \\
\hline NTi10Ta-MP & 30.4 & 0.52 & 0 & 0 & 18.73 & 2.23 \\
\hline NiTi5Cr-MEP & 32.6 & 0.64 & 0.2 & 0.06 & 3.28 & 1.28 \\
\hline NiTi10Ta-MEP & 33.3 & 0.44 & 0 & 0 & 6.12 & 1.16 \\
\hline NiTi5Cr - MEP + PC & 38.6 & 0.00 & 0 & 0 & 3.2 & 0.14 \\
\hline NiTi10Ta-MEP + PC & 40.1 & 0.14 & 0 & 0 & 3.75 & 0.21 \\
\hline PGA/PCL & 44.4 & 0.13 & 0 & 0 & 8.6 & 0.25 \\
\hline
\end{tabular}


In Equation (6.1), the interfacial tension $\gamma_{i j}$ between any two condensed phases $\mathrm{i}$ and $\mathrm{j}$ can be determined using Equation (6.2) as suggested by Good and van Oss et al. [258].

$$
\gamma_{i j}=\left(\sqrt{ } \gamma_{i}^{\mathrm{LW}}-\sqrt{ } \gamma_{j}^{\mathrm{LW}}\right)^{2}+2 \cdot\left(\sqrt{ } \gamma_{i}^{+} \gamma_{i}^{-}+\sqrt{ } \gamma_{j}^{+} \gamma_{j}^{-}-\sqrt{ } \gamma_{i}^{+} \gamma_{j}^{-}-\sqrt{ } \gamma_{i}^{-} \gamma_{j}^{+}\right)
$$

The surface free energy parameters presented in Tables 6.6 and 6.7 for each individual component were incorporated into Equation (6.2) to determine their respective interfacial tension values as shown in Table 6.8. Later, interfacial tension values were plugged into Equation (6.1) to determine the work of adhesion (W) between platelets and each substrate material as shown in Table 6.8.

Table 6.8: Interfacial tension $\left(\gamma_{\mathrm{ij}}\right)$ and work of adhesion $(\mathrm{W})$ parameters for different substrate materials with respect to platelets

\begin{tabular}{|c|c|c|c|c|}
\hline Material & $\begin{array}{c}\gamma_{\mathrm{SL}} \\
(\mathrm{mN} / \mathrm{m})\end{array}$ & $\begin{array}{c}\gamma_{\mathrm{Pl}} \\
(\mathrm{mN} / \mathrm{m})\end{array}$ & $\begin{array}{c}\gamma_{\mathrm{SP}} \\
(\mathrm{mN} / \mathrm{m})\end{array}$ & $\begin{array}{c}\mathrm{W} \\
(\mathrm{mN} / \mathrm{m})\end{array}$ \\
\hline NiTi - MP & 90.96031 & 213.9244 & 215.7929 & 89.09 \\
\hline SS - MP & 104.3875 & 213.9244 & 232.4861 & 85.83 \\
\hline NiTi5Cr-MP & 102.9839 & 213.9244 & 231.391 & 85.52 \\
\hline NTi10Ta-MP & 103.6867 & 213.9244 & 232.6458 & 84.97 \\
\hline NiTi5Cr-MEP & 107.7172 & 213.9244 & 243.082 & 78.56 \\
\hline NiTi10Ta-MEP & 108.9865 & 213.9244 & 243.5328 & 79.38 \\
\hline NiTi5Cr - MEP + PC & 118.4165 & 213.9244 & 258.7004 & 73.64 \\
\hline NiTi10Ta-MEP + PC & 121.0331 & 213.9244 & 262.353 & 72.60 \\
\hline
\end{tabular}


This data indicates that as the interfacial tension increases, the work of adhesion reduces i.e, $\boldsymbol{\gamma}_{\mathrm{ij}}$ is inversely proportional to $\mathrm{W}$.

Therefore, in an effort to understand this effect, the platelet adhesion (PA) and work of adhesion (W) values for different substrate materials were plotted in Figure 6.27. It can be inferred that less platelets adhered on PC + MEP Nitinol alloys as compared with that on all other materials. Also the lowest work of adhesion was observed for MEP + PC Nitinol alloys. Additionally, MEP treatment resulted in a reduction of platelet adhesion and work of adhesion as compared with that of MP Nitinol alloys.

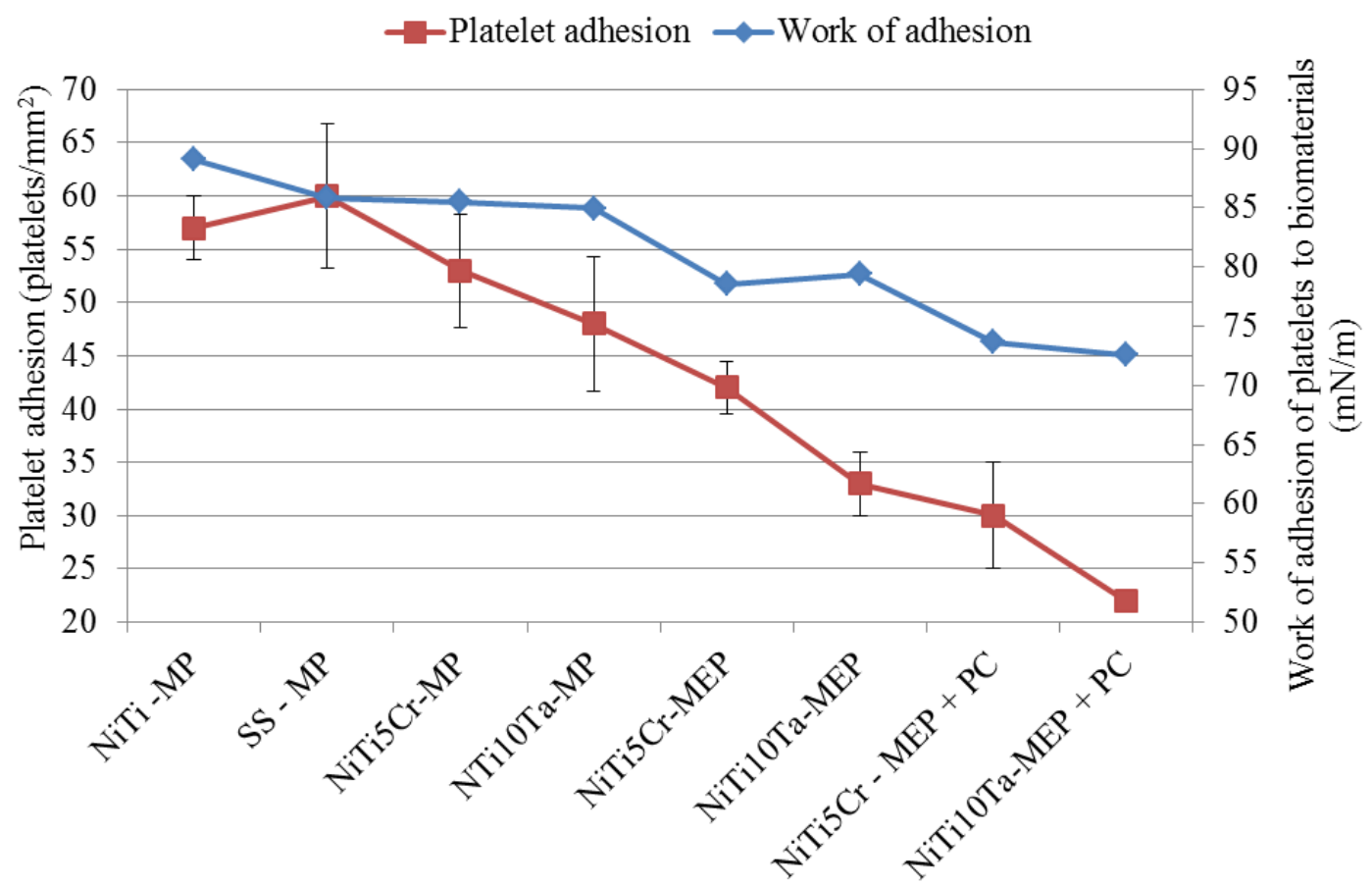

Figure 6.27: A comparison of work of adhesion and platelet adhesion for various alloys 
A correlation between platelet adhesion and work of adhesion for different materials considered under in this hemocompatibility study was shown in Figure 6.28 .

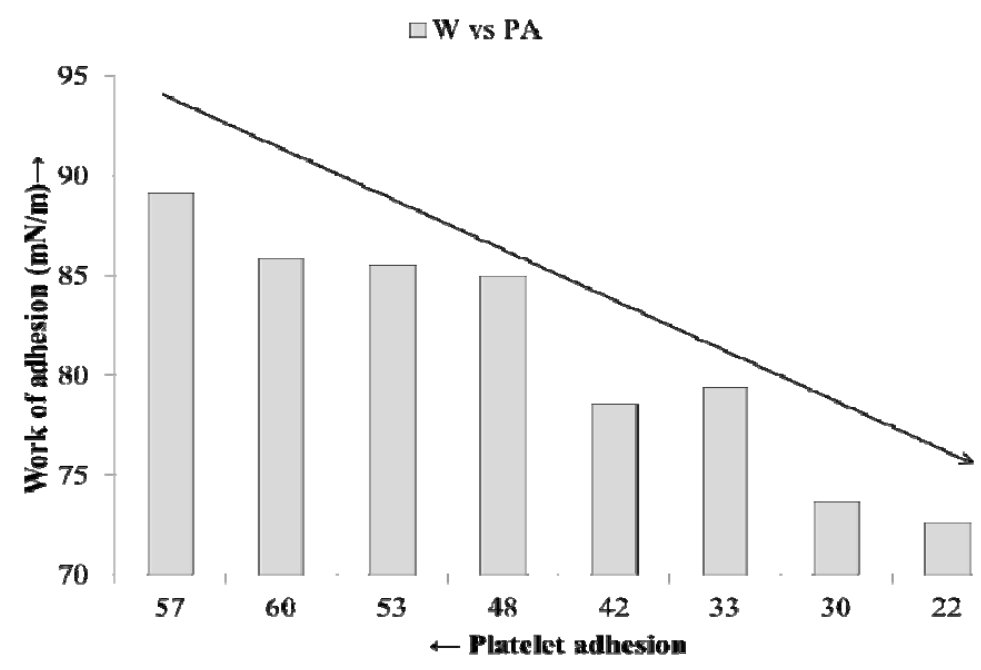

Figure 6.28: Correlation between work of adhesion and platelet adhesion.

It can be observed that platelet adhesion increased with an increase in work of adhesion, and vice versa. Absolom et al. [259] and Vijayanand et al. [253] have mentioned that the adherence of blood components such as platelets and erythrocytes is directly proportional to their work of adhesion with a biomaterial. Hence it can also be inferred that platelet adhesion is dependent on the work of adhesion of platelets to these alloys.

Similarly, using Equations 6.1 and 6.2 the theoretical work of adhesion values between polymer and MEP ternary Nitinol alloys were calculated and are shown in Table 6.9.

Table 6.9: Work of adhesion between polymer and MEP Nitinol substrates. 


\begin{tabular}{|c|c|c|c|c|}
\hline Component & $\begin{array}{c}\gamma_{\mathrm{SL}} \\
(\mathrm{mN} / \mathrm{m})\end{array}$ & $\begin{array}{c}\gamma_{\mathrm{PL}} \\
(\mathrm{mN} / \mathrm{m})\end{array}$ & $\begin{array}{c}\gamma_{\mathrm{SP}} \\
(\mathrm{mN} / \mathrm{m})\end{array}$ & $\begin{array}{c}\mathbf{W} \\
(\mathrm{N} / \mathrm{m})\end{array}$ \\
\hline MEP NiTi5Cr & 107.71 & 128.42 & 161.08 & $75.05 \mathrm{E}-3$ \\
\hline MEP NiTi10Ta & 108.98 & 128.42 & 169.11 & $68.29 \mathrm{E}-3$ \\
\hline
\end{tabular}

In this case, $\gamma_{\mathrm{SL}}$ corresponds to the interfacial tension between the substrate and water, $\gamma_{\mathbf{P L}}$ corresponds to the interfacial tension between the polymer and water and $\gamma_{\mathbf{S P}}$ corresponds to the interfacial tension between the polymer and substrate. The data given in Table 6.8 indicates that the work of adhesion of polymer on MEP NiTi5Cr was slightly high as compared with that of MEP NiTiıTa.

\subsection{Mechanical properties of polymer coated Nitinol by nano-scratch tests}

Drug eluting stents consist of a polymeric carrier coating that elutes antiproliferative drugs (sirolimus, novolimus, paclitaxel, etc.) in order to mitigate postangioplasty coronary restenosis. Depending on the type of polymer coating ie., either biodegradable or durable, the duration of drug elution varies from 3 to 6 months. Polymer cracking, delamination, bridging, flaking and non-uniform degradation of polymer coating before and after expansion of the stent and during drug elution, might lead to emboli formation and inflammatory reactions.

Generally, scratch tests are used to identify the performance of a material in terms of its wear resistance and deformation properties [260]. Scratch induced deformation of a coated material can be characterized using either a micro or nano scratch tests depending on the material properties [261]. Wolf et al. [262] has demonstrated the usage of atomic force micrograph (AFM) to quantify the adhesion forces between the polymer coating 
and substrate and cohesive forces within the polymeric layers of a drug-eluting stent (DES). A model coupon that represents each pair of layers in CYPHER1 Sirolimuseluting coronary stent was used to study the aforementioned properties. This DES consists of a stainless steel stent substrate, a parylene $\mathrm{C}$ primer layer, and a drug-eluting layer that contains poly (ethylene-co-vinyl acetate), poly (n-butyl methacrylate), and sirolimus (rapamycin).

Shan et al. [263] developed a push-out testing technique that utilized a probe to determine the critical force for failure of the film substrate interface (adhesion) and critical force for penetration of the film (cohesion). A model drug-eluting stent (the Nevo $^{\text {TM }}$ Sirolimus Eluting Coronary Stent) containing suspended microscopic polymeric films in metallic Co-Cr alloy reservoirs was used for the measurement of adhesion and cohesion forces.

In this study a nano-scratch test method was applied to characterize the adhesion properties of the polymer coating on MEP treated Nitinol substrates. The nano scratch tests were performed by using a CSM nano-scratch tester at Uppsala University (Uppsala, Sweden) with a cube-corner diamond tip (C-B37).

\subsubsection{Principle of scratch test}

In the scratch test method, an indentor of defined geometry is drawn across the surface of a coated test specimen at a constant speed and a defined normal force, $\mathrm{F}_{\mathrm{N}}$ (progressively increasing) for a defined distance. The damage along the scratch track is microscopically assessed as a function of the applied force. Specific levels of progressive damage are associated with increasing normal stylus forces. According to ASTM D7187, critical failure load (Lc1) is defined as the onset of fracture at the point 
where the normal force $\left(\mathrm{F}_{\mathrm{N}}\right)$, tangential force $\left(\mathrm{F}_{\mathrm{T}}\right)$ and penetration depth $\left(\mathrm{P}_{\mathrm{D}}\right)$ begin to fluctuate wildly. A sudden drop in $\mathrm{P}_{\mathrm{D}}$ and an increase in $\mathrm{F}_{\mathrm{N}}$ corresponds to complete delamination of polymer coating from the substrate. The driving forces for coating damage in the scratch test are a combination of elastic-plastic indentation stresses, frictional stresses and the residual internal stresses. The test method also describes the use of tangential force and acoustic emission signals as secondary test data to identify different coating failure types. The viscoelastic characteristics of the polymer greatly influence how the material deforms under the indenter tip, and how it recovers after the deformation has occurred.

\subsubsection{Methodology of scratch test:}

During nano-scratch testing, each sample was first cleaned with compressed air to remove any comtaminants and then it was mounted on the stage to perform the analysis. The working parameters used during nano-scratch testing are provided in Table 6.10.

Table 6.10: The operating parameters for nano scratch tests

\begin{tabular}{|c|c|}
\hline Working parameters & Nano-indentation test \\
\hline Initial load (mN) & 0.3 \\
\hline Final load (mN) & 120 \\
\hline Speed $(\boldsymbol{\mu m} / \mathbf{m i n})$ & 700 \\
\hline Length $(\boldsymbol{\mu m})$ & 2500 \\
\hline Indentation tip & Cube corner diamond tip (C-B 37) \\
\hline
\end{tabular}

A typical progressive load- depth of penetration curve obtained during scratch tests for MEP + PC NiTi5Cr is shown in Figure 6.29. 


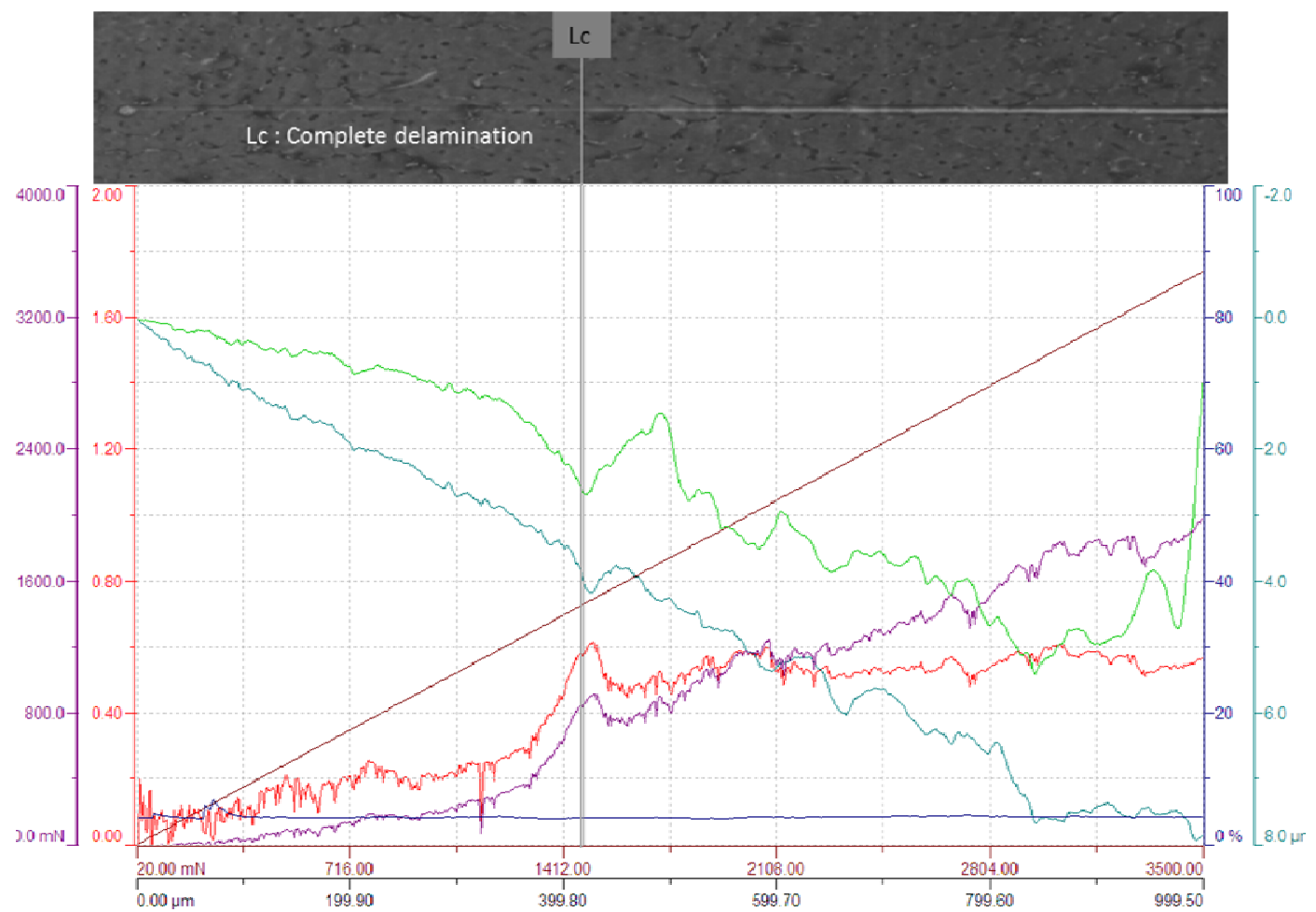

Figure 6.29: A typical scratch test curve for MEP + PC NiTi5Cr. The measurement signals are identified and color coded as $\mathrm{F}_{\mathrm{N}}$ : Applied normal load (Brown), $\mathrm{P}_{\mathrm{D}}$ : Penetration depth during scratch (Turquoise) $\mathrm{R}_{\mathrm{D}}$ : Residual Depth after scratch (Green), AE: Acoustic Emission (Dark Blue), $\mu$ : Friction coefficient (Red), and $\mathrm{F}_{\mathrm{f}}$ : Friction force (Purple).

As mentioned earlier, at critical failure load (Lc) or $\mathrm{F}_{\text {critical }}$ for $\mathrm{MEP}+\mathrm{PC}$ NiTi5Cr, a sudden drop in $\mathrm{P}_{\mathrm{D}}$ and an increase in $\mathrm{F}_{\mathrm{N}}$ were observed and this point corresponds to the complete delamination of polymer coating from the substrate. The failure load (Lc) obtained from nano-scratch test is directly proportional to interfacial adhesion strength between the polymer and the substrate. The critical delamination loads for both polymer coated MEP ternary Nitinol alloys are shown Table 6.11. 
Table 6.11: Adhesion energies of polymer coated Nitinol obtained from nano-scratch

\begin{tabular}{|c|c|c|c|c|c|c|}
\hline Variable & $F_{i}(\mathrm{mN})$ & $\begin{array}{c}\mathrm{F}_{\mathrm{i}+1} \\
(\mathrm{mN})\end{array}$ & $\begin{array}{c}\mathrm{F}_{\text {critical }} \\
(\mathrm{mN})\end{array}$ & $\begin{array}{c}\mathrm{X}_{\mathrm{i}} \\
(\mathrm{mm})\end{array}$ & $\begin{array}{c}\mathrm{X}_{\mathrm{i}+1} \\
(\mathrm{~mm})\end{array}$ & $\mathrm{E}(\mathrm{J})$ \\
\hline $\begin{array}{c}\text { MEP + PC } \\
\text { NiTi10Ta }\end{array}$ & 0.2121 & 84.84 & 7.847 & 0 & 0.23 & $8.669 \mathrm{E}-05$ \\
\hline $\begin{array}{c}\text { MEP + PC } \\
\text { NiTi5Cr }\end{array}$ & 0.2121 & 84.84 & 7.635 & 0 & 0.22 & $8.722 \mathrm{E}-05$ \\
\hline
\end{tabular}

$$
\mathrm{E}=\sum_{F_{i}^{i+1}}^{F_{i}}\left[\left(X i+1-X_{i}\right) \times\left(\left(\mathrm{F}_{\mathrm{i}}+\mathrm{F}_{\mathrm{i}+1}\right) / 2-\mathrm{F}_{\text {critical }}\right)\right]
$$

Equation (1) was used to determine the polymer adhesion energy values (E) utilizing lateral critical failure loads $\left(\mathrm{F}_{\text {critical }}\right)$ obtained from nano-scratch analysis [264], where, $x_{i}$ corresponds to the starting point at which the load was applied and $x_{i+1}$ corresponds to the point where maximum load was applied. Similarly, $\mathrm{F}_{\mathrm{i}}$ corresponds to the initial lateral load, $F_{i+1}$ correspond to the final lateral load and $F_{\text {critical }}$ corresponds to the critical lateral delamination load where polymer coating delamination occurs. The adhesion energy values are also provided in Table 6.11. 


\section{CHAPTER 7}

\section{DISCUSSIONS}

\subsection{Biocompatibility of Nitinol alloys}

In this investigation, emphasis was placed on determining the bio and hemocompatibility properties of biodegradable polymer coated and surface treated ternary Nitinol alloys. Both these properties of polymer coated Nitinol alloys were controlled by their inherent characteristics such as, corrosion resistance, surface topography, surface chemistry and wettability. Surface treatment and application of polymer coatings on Nitinol alloys in turn affected the aforementioned properties. Reduced corrosion rate, lower amount of leached metallic ions, reduced platelet adhesion and improved endothelial cell growth were observed for MEP treated and polymer coated Nitinol alloys as compared with their respective MP alloys. Under the specified hemocompatibility tests conditions, a correlation between the number of platelets adhered on a substrate and its corresponding work of adhesion with the platelets was observed.

\subsection{Surface characterization of Nitinol alloys}

MEP Ternary Nitinol alloys displayed a micro textured surface. The preferential dissolution resulted in morphological changes that were dependent on the alloying element, whereby, grain boundaries in the case of MEP NiTi10Ta produced crests, whereas those on MEP NiTi5Cr produced valleys. SEM/EDS analysis of MEP NiTi10Ta indicated that, the dispersion of the ternary element Ta was non-homogenous throughout the alloy with precipitates of high Ta composition (> 20 at \%) at the grain boundaries as compared with that within the grain ( $\sim 8$ at \%). Similarly, the concentration of $\mathrm{Cr}$ in MEP 
NiTi5Cr was high ( $>15$ at \%) at the grain boundaries as compared with that in the grain ( 5 at \%). Whereas, prior to MEP, EDS analysis of MP NiTi5Cr revealed that the concentration of $\mathrm{Cr}$ on the surface was homogenous. This was attributed to preferential dissolution of $\mathrm{Ni}$ at grain boundaries leaving behind the chromium oxide during MEP. Increased amounts of $\mathrm{Cr}$ and $\mathrm{O}$ at the grain boundaries after MEP of NiTi5Cr might lead to the formation of a passive $\mathrm{Cr}_{2} \mathrm{O}_{3}$ layer at the grain boundaries and could have resulted in reduced corrosion and metallic ion leaching.

The surface roughness of MP NiTi5Cr alloys was slightly reduced after MEP treatment, and even polymer coating made little difference; whereas that of NiTi10Ta alloy remained unchanged even after the surface treatment.

XPS analysis revealed that higher amounts on metallic $\mathrm{Ni}$ and $\mathrm{NiO}$ and lower amounts of $\mathrm{Ni}(\mathrm{OH})_{2}$ were found on the surface of MEP NiTi10Ta as compared with that of MEP NiTi5Cr (Table 6.3). This presence of metallic Ni on the surface of a Nitinol can cause leaching of Ni during its corrosion. ICPMS analysis of corrosion liquids obtained from potentiodynamic in-vitro corrosion tests revealed higher amounts of leached Ni ions indicated MEP NiTi10Ta as compared with that of MEP NiTi5Cr (Table 5.1). These results show that surface composition of Nitinol is one factor that controls the leaching of Ni ions from its surface. Haider et al. [233] showed that MEP treatment on Nitinol resulted in lower Ni release during in-vitro corrosion studies.

\subsection{Corrosion analysis of polymer coated Nitinol alloys}

Potentiodynamic corrosion studies revealed that, application of MEP treatment to NiTi10Ta and NiTi5Cr ternary Nitinol alloys resulted in reduced corrosion rates. This 
reduction in corrosion rate can be attributed to the formation of an improved oxide layer on the surface of these ternary Nitinol alloys during MEP treatment. Additionally, the application of polymer coating on MEP treated Nitinol alloys further reduced their corrosion rate by one order of magnitude as compared with their MP counterparts. This can be attributed to the presence of polymer coating on the metal's surface which acts as a protective barrier against corrosion. Similarly, Mazumder et al. [265] showed that application of polyurethane-coating on Nitinol cardiovascular stents has reduced their invitro corrosion rate from $275 \mu \mathrm{m} /$ year to less than $13 \mu \mathrm{m} / \mathrm{year}$.

Cyclic potentiodynamic polarization curves of MP, MEP and MEP+PC NiTi10Ta showed a similar anodic dissolution behavior with a positive hysteresis loop. This revealed that they all undergo pitting corrosion after the break down of passive layer $\left(\mathrm{E}_{\mathrm{b}}\right)$ in the forward scan and undergo pitting corrosion until the repassivation of oxide layer occurs $\left(\mathrm{E}_{\mathrm{p}}\right)$ in the reverse scan. Whereas, MP, MEP and MEP + PC NiTi5Cr alloys displayed cyclic polarization curves with negative hysteresis loop. This revealed that during the reverse scan, no localized corrosion occurred at the surface of NiTi5Cr alloy. In general, the MEP surface treatment and application of polymer coating on MP ternary Nitinol alloys have reduced the corrosion rate of by one order of magnitude as shown in Table 3.1. The corrosion rates for NiTi5Cr alloy were in the following order: MP NiTi5Cr $>$ MEP NiTi5Cr $>$ MEP + PC NiTi5Cr and the corrosion rate for NiTi10Ta alloy were: MP NiTi10Ta $>$ MEP NiTi10Ta $>$ MEP + PC NiTi10Ta.

EIS analysis of polymer coated ternary Nitinol alloys revealed that the polymer coating acts as a protective barrier during corrosion, with a high coating pore resistance $\left(R_{\text {pore }}\right)$. As the $\mathrm{R}_{\text {pore }}$ and charge transfer resistance $\left(\mathrm{R}_{\mathrm{P}}\right)$ of MEP + PC NiTi5Cr were higher 
than that of MEP + PC NiTi10Ta, it indicated that the polymer coating on the former alloy was superior.

\subsection{Adhesion and interfacial bond between polymer and substrate}

Adhesion is defined [266] as "the state in which two surfaces are held together by interfacial forces which may consist of valence forces or interlocking forces or both." The nature of bond formed at the interface between a coating and its substrate affects its adhesion properties. Figure 7.1 [267] shows the bonding energy related to different interfacial bonds formed across the coating/substrate interface. The effective contact area between coating and its substrate is directly proportional to its adhesion properties.

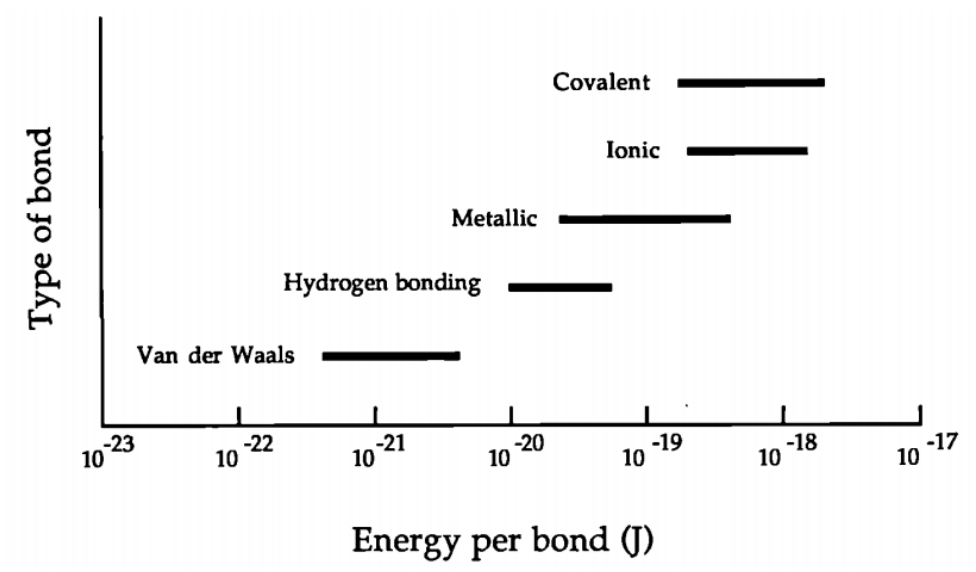

Figure 7.1: Relative bond strengths for a range of potential interfacial bonding [267]

Antico, et al. [268] utilized chemical functionalization to improve adhesion between NiTi surfaces and a thermoplastic polyolefin (TPO) matrix. Smith, et al. [269] observed that covalent bonding of silane group to NiTi substrates prior to poly (methylmethacrylate, plexiglas) polymer coating substantially improved the interfacial interactions between them. In this research, MEP Nitinol alloys were coated with a biodegradable polymer composed of PCL/PGA as a precursor to investigate the efficacy 
of drug elution, which is instrumental in reducing the risk of in-stent and late-stent thrombosis. The MEP treatment on these alloys will result in better adhesion and mechanical interlocking between the polymer and substrate.

XPS analysis revealed the presence of $\mathrm{Ni}(\mathrm{OH})_{2}$ on the surface of MEP treated ternary Nitinol alloys. As mentioned earlier, the presence of $-(\mathrm{OH})$ bonds on the surface of these alloys can lead to the formation of hydrogen bonding between the polymer and the substrate. The two steps involved in polymer coating the metallic samples and the hydrogen bond formed between the polymer/substrate are shown in Figure 7.2.

\section{Dip coating}

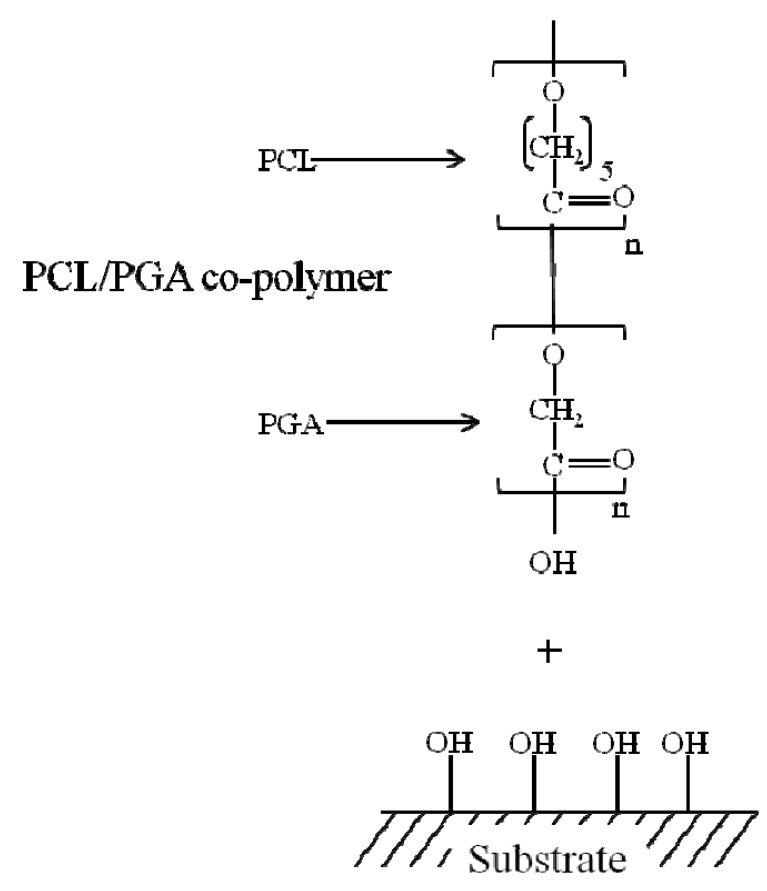




\section{Hydrogen bonding}

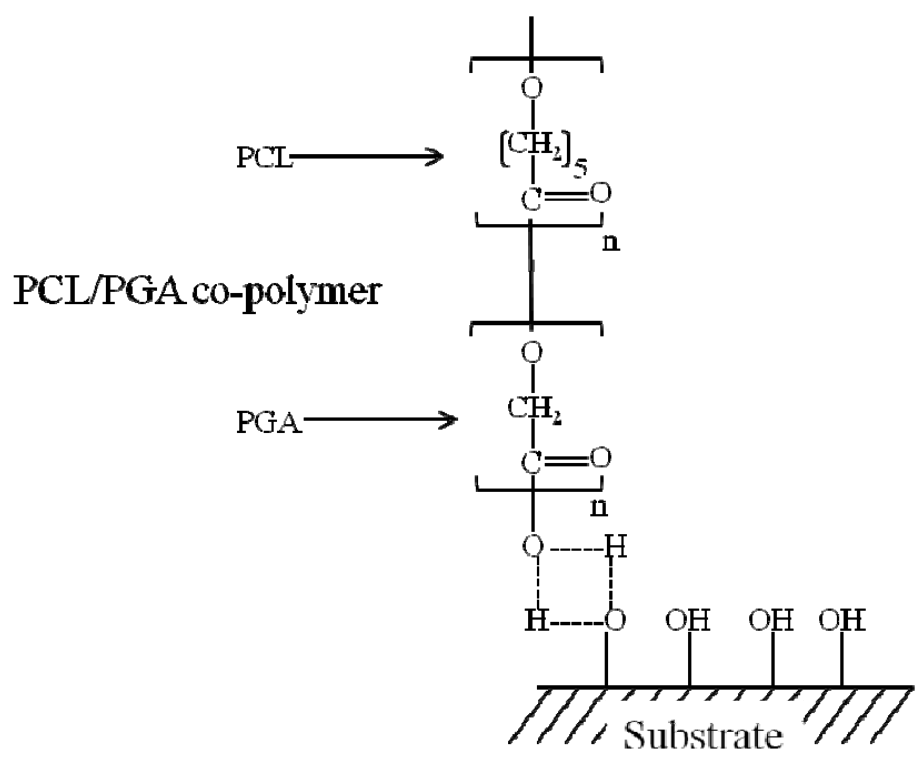

Figure 7.2: Formation of hydrogen bond at the interface of polymer/substrate due to dip coating

It can be emphasized that MEP treatment of Nitinol alloys can result in mechanical interlocking and hydrogen bond formation between the polymer coating and the metal surface.

Biodegradable polymer coated MEP ternary Nitinol alloys were subjected to nano-scratch test to identify the adhesion strength of the polymer coating. These tests revealed that the critical delamination force $(\mathrm{Lc})$ required to completely delaminating the polymer coating from these alloys was similar for both the alloys (MEP + PC NiTi5Cr $10.8 \mathrm{mN}$ and MEP + PC NiTi10Ta $-11.1 \mathrm{mN}$. Critical delamination load obtained from scratch test of a coated substrate is a direct indicator of the adhesion strength between the coating and the substrate. 


\subsection{Endothelial cell viability and cytotoxicity of polymer coated Nitinol alloys}

Proper endothelialization of cardiovascular implants after implantation plays a key role in avoiding in-stent restenosis [270] and growth of neointimal proliferation [271]. Additionally, endothelialization is to reduce thrombosis by around $52 \%$ [272]. In this investigation, approximately $50 \times 10^{3}$ HUVEC cells were seeded on to polymer coated and uncoated samples (placed into a 24-well plate) and incubated for 48 hours to assess the proliferation. After fixing the samples, the cell growth was observed using an SEM. The presence of a monolayer of HUVEC cells, with extended fillopodia after 48 hours of incubation, indicated that both the MEP surface and co-polymeric coating were conducive for cell growth. The number of cells observed on the MEP NiTi10Ta appeared to be greater than that on the MEP NiTi5Cr (Figures 5.9 and 5.10). This was attributed to its surface topography, wettability and composition. However, further studies should be conducted on actual stent designed from the aforementioned material to confirm this preferential growth.

The cytotoxicity of ions leached during corrosion of polymer coated and uncoated ternary Nitinol alloys was studied on HUVEC cells for a duration of 2, 4 and 7 days. These studies revealed that, significantly lower cytotoxicity on HUVEC cells was observed for corrosion liquids obtained from MEP NiTi5Cr and MEP + PC NiTi5Cr as compared with that of MP NiTi5Cr (Figures 5.3 to 5.5). This was directly related to the reduced concentration of $\mathrm{Ni}$ and $\mathrm{Cr}$ released from the uncoated and coated MEP NiTi5Cr by ICPMS analysis (Figures 5.1 and 5.2). Since a biodegradable polymer was used as a coating on Nitinol alloys, it is expected to degrade completely after a certain period, 
which exposes the metallic surface to the complex arterial environment. Even with the absence of polymer coating, MEP treated ternary Nitinol displayed better hemo and biocompatibility properties as compared to just MP alloys. So it can be predicted that MEP treatment and polymer coating will result in better longevity of Nitinol alloys for cardiovascular stent applications.

\subsection{Hemocompatibility of polymer coated Nitinol alloys}

In general, implants with surfaces in contact with blood can initiate activation, secretion, adherence, and aggregation of platelets and trigger subsequent plasmatic coagulation and immunological responses, depending on the material's hemocompatibility [207]. Spreading of platelets and the secretion of their stored constituents lead to further platelet aggregation [208]. Hemocompatibility of a cardiovascular implant material plays a major role in its thrombogenicity. Surface properties of a material mainly control its hemocompatibility which can be understood by investigating the affinity of various blood components (platelets, fibrinogen, etc.) towards its surface. In this study, the polymer coated and uncoated Nitinol alloys were subjected to platelet adhesion studies to determine their hemocompatibility. These studies revealed that the polymer coated MEP ternary Nitinol alloys were more hemocompatible than the mechanically polished ternary Nitinol alloys and were less thrombogenic as compared with the standard material, stainless steel commonly used for manufacturing stent (Figure 5.14).

Even though the initial findings indicate that polymer coated MEP ternary Nitinol alloys for blood contacting applications appears to be promising, further conclusive 
testing is still needed. A primary limitation of this study was that the concentration of activated blood proteins such as prothrombin and fibrinogen, critical precursors to thrombus formation, were not assessed. Moreover, even though platelet adhesion on the materials surfaces was determined, the total number of activated platelets in the circulating blood was not examined.

\subsection{Correlation between work of adhesion and cellular adhesion}

The net change in surface free energy is the main driving factor that decides the extent of cellular adhesion and interaction on to a given solid substrate [253]. A reduction in surface free energy (possible minimum equilibrium value) will favor cell adhesion process. Work of adhesion of cells (which is the negative of surface free energy change) on to a substrate reflects the ease with which cells adhere to a given solid substrate from a given liquid environment [253]. Additionally, attractive van der Waal's forces and plurivalent cation bridging control the cell adhesion process on various substrates such as glass, polymers, metals, lipids and collagens [273].

Mathematically, the work of adhesion [274] of an adhering cell on to a blood contacting biomaterial in blood is expressed as:

$$
\mathrm{WA}=\gamma_{S L}+\gamma_{C L}-\gamma_{S C}
$$

where the subscripts L - liquid or blood, $\mathrm{S}$ - substrate or implant and C - adhering cell and $\gamma$ represents interfacial tensions between the given two phases.

The interfacial tension between any two condensed phases $\mathrm{j}$ and $\mathrm{i}$ in terms of their surface energy parameters is expressed by below Equation (7.1) [275]. 


$$
\gamma_{i j}=\left(\sqrt{ } \gamma_{i}^{L W}-\sqrt{ } \gamma_{j}{ }^{L W}\right)^{2}+2 \cdot\left(\sqrt{ } \gamma_{i}^{+} \gamma_{i}^{-}+\sqrt{ } \gamma_{j}^{+} \gamma_{j}^{-}-\sqrt{ } \gamma_{i}^{+} \gamma_{j}^{-}-\sqrt{ } \gamma_{i}^{-} \gamma_{j}^{+}\right)
$$

The platelet adhesion values and work of adhesion values for different materials under hemocompatibility study are plotted in Figure7.3. This shows that as the work of adhesion between the platelets and the substrate material reduced, the amount platelets adhered to their surface also reduced. The MEP + PC Nitinol alloys displayed the lowest amount of platelets adhered as well as lowest work of adhesion values as compared to the rest of the MP alloys.

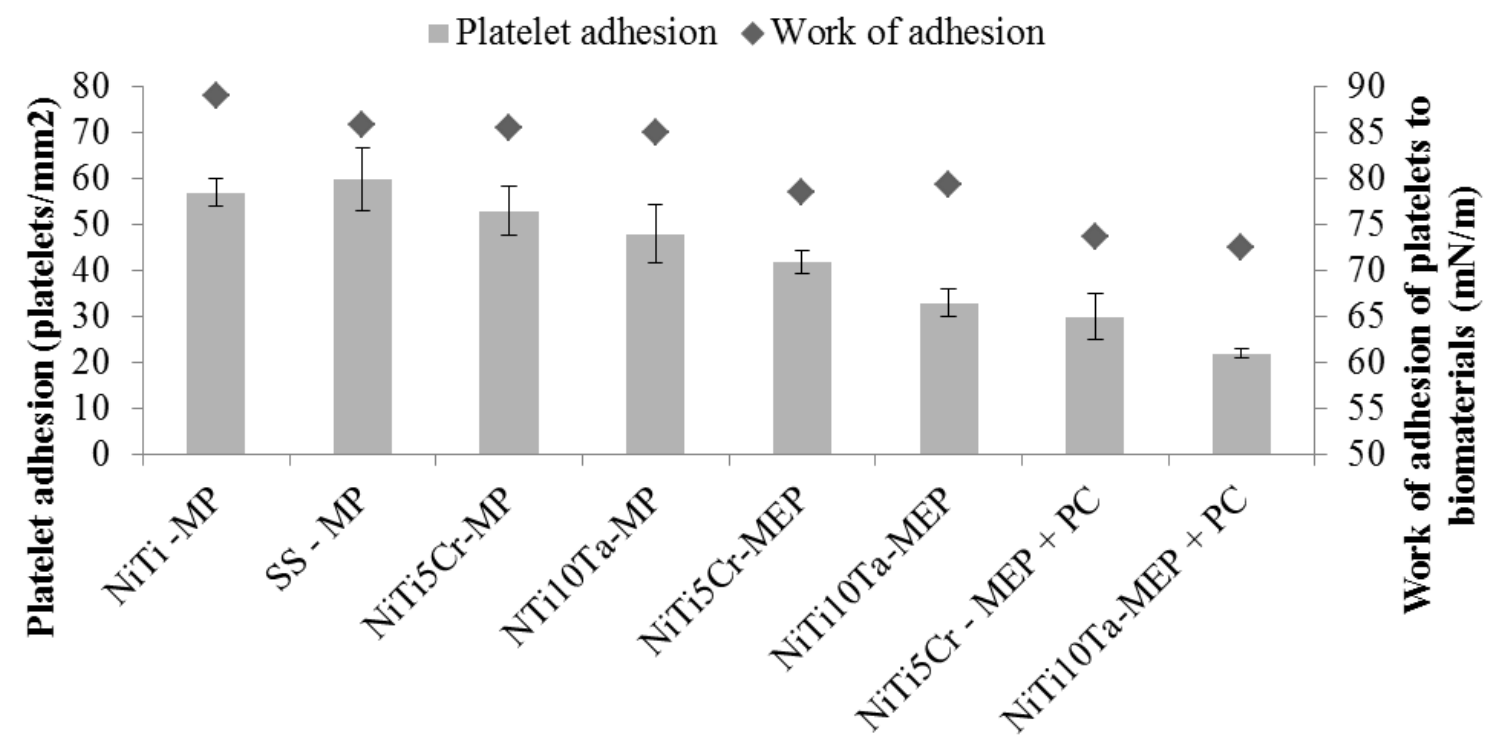

Figure 7.3: Variation of platelet adhesion w. r. to work of adhesion for different materials

The correlation between platelet adhesion (PA) and work of adhesion (W) of platelet to substrate were plotted against each other, where they followed a relationship as shown in Figure 7.4. Similarly, absolom et al. [276] showed that the adhesion of erythrocytes reduced as the work of adhesion of the biomaterial reduced. These results 
indicate that based on the work of adhesion of the biomaterial its hemocompatibility can be predicted.

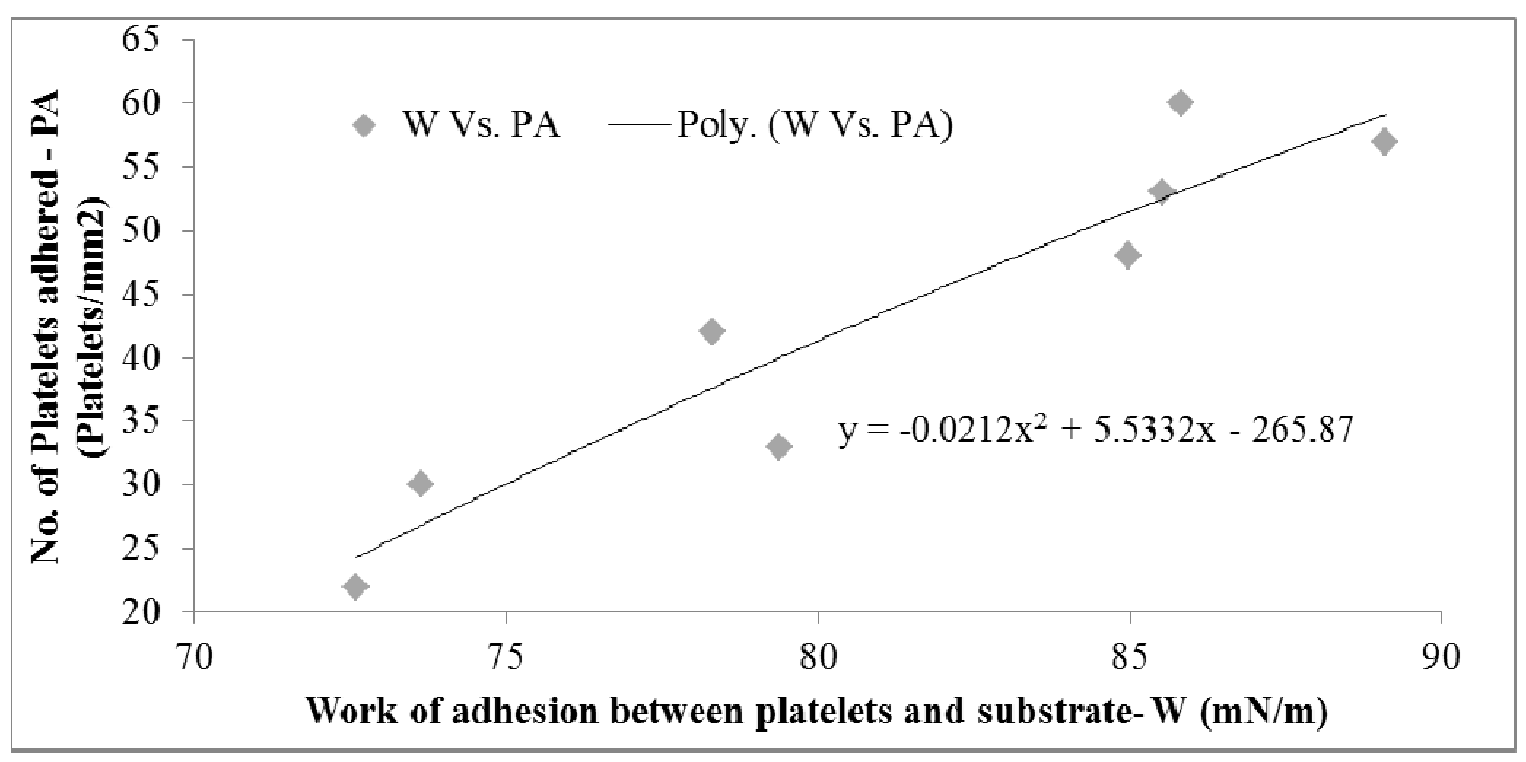

Figure 7.4: A correlation between work of adhesion and platelet adhesion

The number density of platelet adhesion (PA) on biomaterials directly correlates with their work of adhesion between the substrate and platelets (W), according to $y=$ $0.0212 \mathrm{x}^{2}+5.5332 \mathrm{x}-265.87$, where $\mathrm{x}$ is $\mathrm{W}(\mathrm{mN} / \mathrm{m})$ and $\mathrm{y}$ is PA (platelets $\left./ \mathrm{mm}^{2}\right)$. This equation can be used to predict the platelet that can get adhered (thrombogenic nature) to the surface of a biomaterial by using its work of adhesion values. 


\section{CHAPTER 8}

\section{CONCLUSIONS}

The work conducted in this dissertation was mainly on investigating the bio and hemocompatibility properties of biosorbable polymer coated and surface treated ternary Nitinol alloys for drug eluting stent applications. The ternary Nitinol alloys were first subjected to magneto-electropolishing (MEP) treatment and then coated with a novel biodegradable co-polymer, polycaprolactone (PCL)/poly glycolic acid (PGA) in the ratio of 90/10. The electrochemical, surface morphological and mechanical properties were assessed for both the individual materials as well as the polymer coated alloys.

The results obtained in this investigation have indicated that biosorbable polymer coated MEP ternary Nitinol alloys have great potential as an implant material for cardiovascular stent and other implant applications. The following are conclusions derived from this research:

- Electrochemical properties were assessed by EIS and potentiostat. MEP treatment and application of polymer coating have resulted in reduction of corrosion rate in the following order:

o $\quad$ MP NiTi5Cr (3.80E-01 mpy) > MEP NiTi5Cr (9.43E-02 mpy) > MEP + PC NiTi5Cr (1.27E-02 mpy)

o MP NiTi10Ta (1.35E-01 mpy) > MEP NiTi10Ta (8.81E-02 mpy) $>$ MEP + PC NiTi10Ta (4.79E-02 mpy)

- EIS analysis of uncoated and coated MEP ternary Nitinol alloys indicated that MEP + PC NiTiCr has higher pore resistance $\left(\mathrm{R}_{\text {pore }}\right)$ and charge transfer resistance $\left(\mathrm{R}_{\mathrm{p}}\right)$ as compared with that of MEP + PC NiTi10Ta alloy, which indicates that the 
polymer coating on the former alloy has a better corrosion resistance than the latter alloy.

- Polymer coating acts as a protective layer that inhibits the contact of electrolyte from reaching the metal surface on MEP NiTi5Cr. It also prevents the migration of $\mathrm{Ni}$ ions into the environment which corresponds to reduced toxicity on human primary umbilical vein endothelial cells (HUVEC).

- Polymer coated MEP Nitinol alloys displayed lower platelet adhesion as compared with that on MEP and MP Nitinol alloys, 316 SS and binary Nitinol alloys. Lowest work of adhesion (W) between the platelets and the substrate surfaces was observed for MEP + PC Nitinol alloys. As the $\mathrm{W}$ value for a material decreased, the no. of platelets adhered on its surface decreased, showing that $\mathrm{W}$ is directly proportional to the platelet adhesion.

- XPS analysis revealed that MEP treatment on NiTi5Cr has reduced the amounts of $\mathrm{Ni}$ and $\mathrm{NiO}$ which corroborates with the low $\mathrm{Ni}$ in the electrolyte after corrosion is consistent with the low Ni release from MEP NiTi5Cr.

- $\mathrm{Ni}(\mathrm{OH})_{2}$ on the surface of MEP alloys might have contributed to formation of hydrogen bonding (-OH bond) between the polymer and the metal surface.

- Nano-scratch analysis revealed the lateral critical failure loads $\left(\mathrm{L}_{\mathrm{c}}\right)$ for MEP NiTi5Cr and MEP NiTi10Ta in the range of $7.8 \mathrm{mN}$ to $7.6 \mathrm{mN}$ respectively. The adhesion between the polymer and the alloys can be attributed to the formation of hydrogen bonds.

- The viability and confluency of HUVEC cell growth on MEP and MEP +PC Nitinol alloys were high as compared with MP Nitinol alloys. 
- Coating ternary NiTi5Cr and NiTi10Ta with a PCL/PGA polymer enhanced their anti-thrombogenic nature.

- The number density of platelet adhesion (PA) on biomaterials directly correlates with their work of adhesion between the substrate and platelets (W), according to the equation $\mathrm{y}=-0.0212 \mathrm{x}^{2}+5.5332 \mathrm{x}-265.87$, where $\mathrm{x}$ is $\mathrm{W}(\mathrm{mN} / \mathrm{m})$ and $\mathrm{y}$ is $\mathrm{PA}$ (platelets $/ \mathrm{mm}^{2}$ )

The findings of this research will be useful for introducing novel biosorbable polymeric coated MEP Nitinol alloys for enhanced drug eluting stents (DES) applications. Based on the results from the current work, the DES manufactured from these alloys is expected to provide improved biocompatibility with reduced thrombogenicity as compared with currently used implant materials. 


\section{CHAPTER 9}

\section{RECOMMENDATIONS FOR FUTURE RESEARCH}

The aim of the current research was to explore the potential of the polymer coated and MEP treated ternary Nitinol alloys for drug-eluting stent and other cardiovascular implant applications. Preliminary studies were conducted in this dissertation and further research in terms of fibrinogen and other protein adhesion, need to be conducted to further elucidate the thrombogenicity and in-vivo response of these alloys.

The results obtained are very promising, however, further investigation of hemo and biocompatibility properties of polymer coatings with an anti-proliferative drug embedded into it will determine the usefulness of proposed compositions and surface treatments.

Some of the other recommendations for future work:

- Analyze the effect of polymer composition on its bio and hemocompatibility properties

- Conduct fatigue failure analysis of the PC + MEP treated ternary Nitinol stents/wires

- Determine in-vitro and in-vivo drug elution profiles of polymer coated stents

- Design and manufacture stents for in-vivo implantation in rabbits

- Thrombogenicity studies of polymer coating: fibrinogen and other protein adhesion on polymer coated alloys 


\section{REFERENCES}

1. Park, J.-B. and R.S. Lakes, Biomaterials: An Introduction. 1991.

2. Doherty, P.H., et al., Biomaterial-Tissue Interfaces: Proceedings of the Ninth European Conference on Biomaterials, Chester, U.K., September 9-11, 1991 (Advances in , V). Advances in , V. 1992: Elsevier Science Ltd.

3. Ratner, B.D., Biomaterials science : an introduction to materials in medicine. 2004, San Diego: Elsevier Academic Press.

4. Xin, Y., Degradation mechanism and surface modification of biomedical magnesium alloy, in Department of Physics and Materials Science. 2010, City University of Hong Kong: Hong Kong.

5. Mercer, R., Anthology of orthopaedics. . British Journal of Surgery, 1966. 53(5): p. 483-483.

6. Albee, F.H., Bone-graft surgery. 1915, Philadephia: W. B. Saunders Company.

7. A Brief History of Heart Transplantation. herat transplant.

8. Heness, G. and B. Nissan, Innovative bioceramics. Materials Forum, 2004. 27: p. 104-114.

9. Buddy, D., Ratner, et al., Biomaterials science : an introduction to materials in medicine. 1996: Academic press.

10. Park, J. and R.S. Lakes, Biomaterials: An Introduction. 2007: Springer. 564.

11. Alan, S., Go and a. et., Heart Disease and Stroke Statistics-2013 Update A Report From the American Heart Association. Circulation, 2013. 127: p. 6-245.

12. Park, J., Lakes, R. S., Biomaterials an introduction. 2007: springer.

13. Parida, P., A. Behera, and S.C. Mishra, Classification of Biomaterials used in Medicine. International Journal, 2012.

14. PATRICK, J., An overview of the regulatory aspects of medical devices from the viewpoint of research and device manufacturing. Regional Anesthesia and Pain Medicine, 1993. 18(6): p. 424-427.

15. Suh, H., Recent advances in biomaterials.

16. Van Eck, C.F., et al., The Classification of Implants: Class I, II, III. Journal of long-term effects of medical implants, 2009. 19(3). 
17. What does it mean for FDA to "classify" a medical device? 2014; Available from: http://www.fda.gov/AboutFDA/Transparency/Basics/ucm194438.htm.

18. Overview of Medical Device Classification and Reclassification. 2014; Available from:

http://www.fda.gov/AboutFDA/CentersOffices/OfficeofMedicalProductsandToba cco/CDRH/CDRHTransparency/ucm378714.htm.

19. Heness, G. and B. Ben-Nissan, Innovative bioceramics. 2004.

20. Witte, F., et al., Biodegradable magnesium scaffolds: Part 1: appropriate inflammatory response. J Biomed Mater Res A, 2007. 81(3): p. 748-56.

21. Pihlajamaki, H.K., et al., Tissue restoration after implantation of polyglycolide, polydioxanone, polylevolactide, and metallic pins in cortical bone: an experimental study in rabbits. Calcif Tissue Int, 2010. 87(1): p. 90-8.

22. DF, W., On the mechanisms of biocompatibility. Biomaterials, 2008. 29: p. 29412953.

23. Williams, D., The Williams Dictionary of Biomaterials. 1988, Liverpool University Press. p. 368.

24. Williams, D.F., The Williams dictionary of biomaterials. 1999: Liverpool University Press.

25. Kauffman, G.B. and I. Mayo, The story of nitinol: the serendipitous discovery of the memory metal and its applications. The chemical educator, 1997. 2(2): p. 121.

26. PRINCE, M.R., et al., Local intravascular effects of the nitinol wire blood clot filter. Investigative radiology, 1988. 23(4): p. 294-300.

27. Stoeckel, D., A. Pelton, and T. Duerig, Self-expanding nitinol stents: material and design considerations. Eur Radiol, 2004. 14(2): p. 292-301.

28. Poncet, P.P. Nitinol medical device design considerations. in Shape Memory and Superelastic Technologies 2000. Pacific grove, California: SMST.

29. Milošev, I. and B. Kapun, The corrosion resistance of Nitinol alloy in simulated physiological solutions: Part 1: The effect of surface preparation. Materials Science and Engineering: C, 2012. 32(5): p. 1087-1096.

30. Kujala, S., Biocompatibility and biomechanical aspects of Nitinol shape memory metal implants, in Department of Surgery. 2003, University of Oulu. 
31. International, A., Handbook of Materials for Medical Devices, ed. J.R.Davis. 2003: ASM International. 341.

32. Hansen, D.C., Metal corrosion in the human body: the ultimate bio-corrosion scenario. The Electrochemical Society Interface, 2008. 17(2): p. 31.

33. Black, J., Does corrosion matter? The journal of bone and joint surgery $(\mathrm{Br})$, 1988. 70(B): p. 517-520.

34. Gilbert, J.L., Buckley, C.A and J.J. Jacobs, In vivo corrosion of modular hip prosthesis components in mixed and similar metal combinations. The effect of crevice, stress, motion, and alloy coupling. J Biomed Mater Res, 1993. 27(12): p. 1533-44.

35. Sivakumar, M. and S. Rajeswari, Investigation of failures in stainless steel orthopaedic implant devices: pit-induced stress corrosion cracking. Journal of Materials Science Letters, 1992. 11(15): p. 1039-1042.

36. Christine Trepanier, R.V., Alan R. Pelton, Corrosion Resistance and Biocompatibility of Passivated NiTi, in Shape Memory Implants L. Yahia, Editor. 2000, Springer. p. 35-45.

37. Chan, T., Duerig, Oxidation of a NiTi Alloy Surface and Interface Analysis, 1990. 5: p. 349-354.

38. Venugopalan, R. and C. Trepanier, Assessing the corrosion behaviour of Nitinol for minimally-invasive device design. Minimally Invasive Therapy \& Allied Technologies, 2000. 9(2): p. 67-73.

39. Haider, W., et al., Cytotoxicity of metal ions released from nitinol alloys on endothelial cells. Journal of materials engineering and performance, 2011. 20(45): p. 816-818.

40. Hallab, N., K. Merritt, and J.J. Jacobs, Metal sensitivity in patients with orthopaedic implants. J Bone Joint Surg Am, 2001. 83-a(3): p. 428-36.

41. Ho, J., et al., Oxygen plasma treatment to restrain nickel out-diffusion from porous nickel titanium orthopedic materials. Surface and Coatings Technology, 2007. 201(9): p. 4893-4896.

42. Shabalovskaya, S., G. Rondelli, and M. Rettenmayr, Nitinol surfaces for implantation. Journal of materials engineering and performance, 2009. 18(5-6): p. 470-474.

43. Andreasen, G., A clinical trial of alignment of teeth using a 0.019 inch thermal nitinol wire with a transition temperature range between $31^{\circ} \mathrm{C}$. and $45^{\circ} \mathrm{C}$. American journal of orthodontics, 1980. 78(5): p. 528-537. 
44. Bensman G, B.F., Haaster J., Osteosyntheseklammern aus nickel titan: herstelung, versuche und klinischer einsatz. Tech Mitt Forsch Ber, 1982. 14: p. 123-134.

45. Buehler, J.W. William, and F. E, A summary of recent research on the Nitinol alloys and their potential application in ocean engineering. Ocean Engineering, 1968. 1(1): p. 105-120.

46. Cragg, A.H., et al., Nitinol intravascular stent: results of preclinical evaluation. Radiology, 1993. 189(3): p. 775-778.

47. Gil, F. and J. Planell, Shape memory alloys for medical applications. Proceedings of the Institution of Mechanical Engineers, Part H: Journal of Engineering in Medicine, 1998. 212(6): p. 473-488.

48. Kambic, H., et al., Biological performance of TiNi shape memory alloy vascular ring prostheses: a two year study. The International journal of artificial organs, 1988. 11(6): p. 487-492.

49. Simon, M., et al., Simon nitinol inferior vena cava filter: initial clinical experience. Work in progress. Radiology, 1989. 172(1): p. 99-103.

50. Wever, D., et al., Cytotoxic, allergic and genotoxic activity of a nickel-titanium alloy. Biomaterials, 1997. 18(16): p. 1115-1120.

51. Go, A.S., et al., Heart disease and stroke statistics--2013 update: a report from the American Heart Association. Circulation, 2013. 127(1): p. e6.

52. Stone, G.W., et al., Safety and Efficacy of Sirolimus- and Paclitaxel-Eluting Coronary Stents. New England Journal of Medicine, 2007. 356(10): p. 998-1008.

53. Go, A.S., et al., Heart disease and stroke statistics--2014 update: a report from the American Heart Association. Circulation, 2014. 129(3): p. e28-e292.

54. Schiller, J.S., J.W. Lucas, and J.A. Peregoy, Summary Health Statistics for U.S. Adults: National Health Interview Survey, 2011. 2012: Hyattsville.

55. Heidenreich, P.A., et al., Forecasting the future of cardiovascular disease in the United States: a policy statement from the American Heart Association. Circulation, 2011. 123(8): p. 933-44.

56. Li, Y., et al., Comparison of drug-eluting stents and coronary artery bypass surgery for the treatment of multivessel coronary disease: three-year follow-up results from a single institution. Circulation, 2009. 119(15): p. 2040-50.

57. Serruys PW, Luijten HE, and B. KJ, Incidence of restenosis after successful coronary angioplasty: a time- related phenomenon: a quantitative angiographic 
study in 342 consecutive patients at 1, 2, 3, and 4 months. Circulation, 1988. 77: p. $361-371$.

58. Hanawa, T., Materials for metallic stents. J Artif Organs, 2009. 12(2): p. 73-9.

59. Haider, W., Enhanced Biocompatibility of NiTi (Nitinol) Via Surface Treatment and Alloying, in Mechanical Engineering. 2010, Florida International University. p. 177.

60. Trepanier, et al. Effect of Passivation Treatments on Nickel Release from Nitinol. in Society for Biomaterial - 6th World Biomaterials Congress Transactions. 2000.

61. Stoeckel, D., A. Pelton, and T. Duerig, Self-expanding nitinol stents: material and design considerations. European radiology, 2004. 14(2): p. 292-301.

62. P. Poncin, C.M., J. Chevy, J. L. Proft, Comparing and Optimizing Co-Cr Tubing for Stent Applications, in Materials and processes for medical devices conerence, D.M. Mike Helmus Editor. 2004, Medical Device Materials II: St. Paul, Minnesota. p. 6.

63. Hendra Hermawan, D.R.a.J.R.P.D., Metals for Biomedical Applications, in Biomedical Engineering - From Theory to Applications, R. Fazel-Rezai, Editor. 2011, InTech. p. 486.

64. Elias, C., et al., Biomedical applications of titanium and its alloys. Jom, 2008. 60(3): p. 46-49.

65. Burnat, B., et al., Corrosion behaviour of polished and sandblasted titanium alloys in PBS solution. Acta Bioeng Biomech, 2013. 15(1): p. 87-95.

66. Bandar AL-Mangour, R.M., Stephen Yue, Coronary Stents Fracture: An Engineering Approach (Review). Materials Sciences and Applications, 2013. 4: p. 606-621.

67. Gu, X.-N. and Y.-F. Zheng, A review on magnesium alloys as biodegradable materials. Frontiers of Materials Science in China, 2010. 4(2): p. 111-115.

68. W. H. Maisel, W.K.L., Drug-Eluting Stents. Circulation, 2007. 115: p. 426-427.

69. Tepe, G., et al., Reduced thrombogenicity of nitinol stents-In vitro evaluation of different surface modifications and coatings. Biomaterials, 2006. 27(4): p. 643650.

70. Lewis, A.L., et al., Phosphorylcholine-based polymer coatings for stent drug delivery. J Mater Sci Mater Med, 2001. 12(10-12): p. 865-70. 
71. Stone, G.W., et al., A polymer-based, paclitaxel-eluting stent in patients with coronary artery disease. N Engl J Med, 2004. 350(3): p. 221-31.

72. Moses, J.W., et al., Sirolimus-eluting stents versus standard stents in patients with stenosis in a native coronary artery. N Engl J Med, 2003. 349(14): p. 1315-23.

73. Farb, A., et al., Pathological analysis of local delivery of paclitaxel via a polymercoated stent. Circulation, 2001. 104(4): p. 473-9.

74. Iakovou I, S.T.B.E. and et al., Incidence, predictors, and outcome of thrombosis after successful implantation of drug-eluting stents. JAMA: The Journal of the American Medical Association, 2005. 293(17): p. 2126-2130.

75. Ong, A.T.L., et al., Late Angiographic Stent Thrombosis (LAST) Events With Drug-Eluting Stents. Journal of the American College of Cardiology, 2005. 45(12): p. 2088-2092.

76. wood, S. New mwta-analysis, registry data stoke stent- thrombosis debate. Interventional surgery, 2006.

77. Na, J.O., et al., Bare-metal stents versus drug-eluting stents in large ( $\geq 3.5 \& \# x a 0 ; \mathrm{mm})$ single coronary artery: Angiographic and clinical outcomes at 6 months. Journal of Cardiology, 2009. 54(1): p. 108-114.

78. Virmani, F. ABCs of Stent Healing (Lessons from Pathology). in Transcatheter Cardiovascular Therapeutics (TCT) conference. 2010.

79. Virmani, F. Pathogenesis of Stent Thrombosis After DES Implantation, The Pathologist's Perspective. in Transcatheter Cardiovascular Therapeutics (TCT) conference. 2007.

80. Gaku Nakazawa, M.V., Aloke V. Finn, Jagat Narula, Renu Virmani, One Step Forward and Two Steps Back With Drug-Eluting-Stents. J Am Coll Cardiol Img, 2009. 2: p. 625-628.

81. al., F.A.e., Coronary Aneurysms After Drug-Eluting Stent Implantation. J Am Coll Cardiol, 2009. 53: p. 2053-2060.

82. Hong MK, M.G., Lee CW, Park DW, Park KM, Lee BK, Kim YH, Song JM, Han $\mathrm{KH}$, Kang DH, Cheong SS, Song JK, Kim JJ, Park SW, Park SJ., Late stent malapposition after drug-eluting stent implantation: an intravascular ultrasound analysis with long-term follow-up. Circulation, 2006. 113(3): p. 414-419.

83. Kotani, J.-i., et al., Incomplete Neointimal Coverage of Sirolimus-Eluting StentsAngioscopic Findings. Journal of the American College of Cardiology, 2006. 47(10): p. 2108-2111. 
84. Joner, M., et al., Pathology of Drug-Eluting Stents in HumansDelayed Healing and Late Thrombotic Risk. Journal of the American College of Cardiology, 2006. 48(1): p. 193-202.

85. Meier, P., et al., Coronary Collateral Function Long After Drug-Eluting Stent Implantation. Journal of the American College of Cardiology, 2007. 49(1): p. 1520.

86. Aloke V. Finn, M.M.J., MD*; Gaku Nakazawa, MD; Frank Kolodgie, PhD; John Newell, AB; Mike C. John, MPH; Herman K. Gold, MD; Renu Virmani, MD, Pathological correlates of latedrug-eluting stent thrombosis: strut coverage as a marker of endothelialization. Circulation, 2007. 11: p. 2435-441.

87. Gaku Nakazawa, M.A.V.F., MD; Michael Joner, MD; Elena Ladich, MD; Robert Kutys, MS; Erik K. Mont, MD; Herman K. Gold, MD†; Allen P. Burke, MD; Frank D. Kolodgie, PhD; Renu Virmani, MD, Delayed Arterial Healing and Increased Late Stent Thrombosis at Culprit Sites After Drug-Eluting Stent Placement for Acute Myocardial Infarction Patients. Circulation, 2008. 118: p. 1138-1145.

88. Cook, S., et al., Incomplete stent apposition and very late stent thrombosis after drug-eluting stent implantation. Circulation, 2007. 115(18): p. 2426-34.

89. Wiskirchen, J., et al., The effects of paclitaxel on the three phases of restenosis: smooth muscle cell proliferation, migration, and matrix formation: an in vitro study. Invest Radiol, 2004. 39(9): p. 565-71.

90. Rodriguez, A.E., et al., Efficacy and safety of a double-coated paclitaxel-eluting coronary stent: the EUCATAX trial. Catheter Cardiovasc Interv, 2011. 77(3): p. $335-42$.

91. Joner, M., et al., Endothelial cell recovery between comparator polymer-based drug-eluting stents. J Am Coll Cardiol, 2008. 52(5): p. 333-42.

92. Windecker, S., et al., Biolimus-eluting stent with biodegradable polymer versus sirolimus-eluting stent with durable polymer for coronary revascularisation (LEADERS): a randomised non-inferiority trial. Lancet, 2008. 372(9644): p. 1163-73.

93. Chevalier, B., et al., Randomized comparison of the Nobori Biolimus A9-eluting coronary stent with the Taxus Liberte paclitaxel-eluting coronary stent in patients with stenosis in native coronary arteries: the NOBORI 1 trial--Phase 2. Circ Cardiovasc Interv, 2009. 2(3): p. 188-95.

94. Lakshmi S. Naira, C.T.L., Biodegradable polymers as biomaterials. Prog. Polym. Sci., 2007. 32: p. 762-798. 
95. Gunatillake, P.A., G.F. Meijs, and S.J. McCarthy, Developments in design and synthesis of biostable polyurethanes. 2001.

96. Alfonso Rodriguez-Galan, L.F., Jordi Puiggali, Degradable Poly(ester amide)s for Biomedical Applications. Polymers, 2011. 3: p. 65-99.

97. Patrick, D. Worldwide Market for Drug-Eluting, Bare and Other Coronary Stents, 2008-2017. 2009; Available from: http://mediligence.com/rpt/rpt-c245.htm.

98. AK, S., Global Coronary Stents Market (Drug Eluting \& Bare Metal) Is Expected To Reach USD 8.3 Billion By 2016: Transparency Market Research. 2013, PR Web ebooks.

99. Tsai, T.T., et al., Safety and Efficacy of Drug-Eluting Stents in Older Patients With Chronic Kidney DiseaseA Report From the Linked CathPCI Registry-CMS Claims Database. Journal of the American College of Cardiology, 2011. 58(18): p. 1859-1869.

100. Abdel-Latif, A., et al., Drug-eluting stents in patients with end-stage renal disease: Meta-analysis and systematic review of the literature. Catheterization and Cardiovascular Interventions, 2010. 76(7): p. 942-948.

101. Lagerqvist, B., et al., Long-term outcomes with drug-eluting stents versus baremetal stents in Sweden. New England Journal of Medicine, 2007. 356(10): p. 1009-1019.

102. Palmerini, T., et al., Stent thrombosis with drug-eluting and bare-metal stents: evidence from a comprehensive network meta-analysis. The Lancet, 2012. 379(9824): p. 1393-1402.

103. Uhlig, H.H., Corrosion and corrosion control: an introduction to corrosion science and engineering. 1971: John Wiley \& Sons Inc,.

104. R Winston Revie, H.H.U., Corrosion and corrosion control: an introduction to corrosion science and engineering. 4th ed. 1971, New York: Wiley-Interscience. 419.

105. J.J. Jacobs, J.L.G., R.M. Urbani, Corrosion of metal orthopaedic implants. J Bone Joint Surg, 1998. 80: p. 1-2.

106. Rahul Bhola, S.M.B., Brajendra Mishra and David L. Olson, Corrosion in Titanium Dental Implants/Prostheses - A Review. Trends Biomater. Artif. Organs, 2011. 25(1): p. 34-46.

107. Maeng, S.M., Corrosion studies on alpha tantalum and beta tantalum coated steels, in Department of Civil and Environmental Engineering. 2005, New Jersey Institute of Technology: New Jersey. 
108. Klemme, S. and H.S. O'Neill, The reaction $\mathrm{MgCr} 2 \mathrm{O} 4+\mathrm{SiO} 2=\mathrm{Cr} 2 \mathrm{O} 3+\mathrm{MgSiO} 3$ and the free energy of formation of magnesiochromite ( $\mathrm{MgCr} 2 \mathrm{O} 4)$. Contributions to Mineralogy and Petrology, 1997. 130(1): p. 59-65.

109. Hong, H.S. and Y.S. Kim, A thermodynamic study of the tantalum-oxygen system. 2001, Argonne National Lab., IL (US).

110. Cabrera, N. and N. Mott, Theory of the oxidation of metals. Reports on Progress in Physics, 1949. 12(1): p. 163.

111. Fehlner, F.P. and N.F. Mott. Oxidation in the Thin-Film Range, in Oxidation of Metals and Alloys. in American Society For Metals. 1971. Materials Park: American Society For Metals.

112. Bardal, E., Corrosion and protection. 2003.

113. Strehblow, H.-H., Mechanisms of Pitting Corrosion, in Corrosion Mechanisms in Theory and Practice, P. Marcus, Editor. 2002, Marcel Dekker, Inc.: NY.

114. Trepanier, C., et al., Preliminary investigation of the effects of surface treatments on biological response to shape memory NiTi stents. J Biomed Mater Res, 1999. 48(2): p. 165-71.

115. Trépanier, C. and A.R. Pelton. Effect of temperature and $\mathrm{pH}$ on the corrosion resistance of passivated nitinol and stainless steel. in SMST-2004: Proceedings of the International Conference on Shape Memory and Superelastic Technologies. 2006. ASM International.

116. Trépanier, C., et al. Effect of Wear and Crevice on the Corrosion Resistance of Overlapped Stents. in Proceedings of the International Conference on Shape Memory and Superelastic Technologies. 2006.

117. Jones, R.H., Stress-Corrosion Cracking. Materials Performance and Evaluation, ed. A. International. 1992. 448.

118. Ng, K., Stress Corrosion Cracking in biomaedical (metallic) implants titaniumnickel (TiNi) alloy in Materials Science and engineering. 2003, San Jose State University.

119. Wang, J., et al., Stress corrosion cracking of NiTi in artificial saliva. Dental materials : official publication of the Academy of Dental Materials, 2007. 23(2): p. 133-137.

120. Wang, J., et al., A surface-eroding poly (1, 3-trimethylene carbonate) coating for fully biodegradable magnesium-based stent applications: Toward better biofunction, biodegradation and biocompatibility. Acta biomaterialia, 2013. 9(10): p. 8678-8689. 
121. Jones, D.A., Principles and prevention of corrosion. 2 ed. 1996: Prentice Hall.

122. Oldfield, J.W., Electrochemical theory of galvanic corrosion, in Galvanic corrosion, H.P. Hack, Editor. 1988, ASTM.

123. Venugopalan, T., Pelton, Alan, Galvanic Corrosion Behaviour of Passivated Nitinol, in Society for Biomaterials - 6th World Biomaterials Congress Transactions 2000 2000, Society for Biomaterials.

124. Scales, J.T., Implants in surgery. D. F. Williams, Liverrpool, and Robert Roaf Liuerpool. $254 \times 158$ nm. Pp. $598+x$. Illustrated. 1973. London: W. B. Saunders Company. £9.50. British Journal of Surgery, 1974. 61(12): p. 987-987.

125. Örnberg, A., Study of electrochemical behaviour and corrosion resistance of materials for pacemaker lead applications, in Department of chemistry. 2007, School of Chemical Science and Engineering Royal Institute of Technology: Stockholm.

126. Tengvall, P., et al., Interaction between hydrogen peroxide and titanium: a possible role in the biocompatibility of titanium. Biomaterials, 1989. 10(2): p. $118-20$.

127. Gill, P.K.S., Assessment of biodegradable magnesium alloys for enhanced mechanical and biocompatible properties, in Materials Science and Engineering. 2012, Florida International University: Miami.

128. ASTM, ASTM G102 - 89(2010) Standard Practice for Calculation of Corrosion Rates and Related Information from Electrochemical Measurements. 2010, Cross Ref.

129. ASTM, ASTM F 2129 -08 Standard Test Method for Conducting Cyclic Potentiodynamic Polarization Measurements to Determine the Corrosion Susceptibility of Small Implant Devices. Medical and Surgical Materials and Devices (I). Vol. 13.01. 2008, West Conshohocken, PA: ASTM International.

130. Wing, C., Boatowner's Illustrated Electrical Handbook. 2006: International Marine/McGraw-Hill.

131. Ahmad, Z., Principles of Corrosion Engineering and Corrosion Control. 2006, Great britan: Butterworth-Heinemann.

132. Cisse, O., et al., Effect of surface treatment of NiTi alloy on its corrosion behavior in Hanks' solution. J Biomed Mater Res, 2002. 61(3): p. 339-45.

133. Vanderkerkhove R, T.E. Electrochemical research on the corrosion of NiTi. in Proceedings of international conference on shape memory and superelastic technologies. 1999. Belgium: Antwerpen. 
134. Videla, H.A., Manual of biocorrosion. 1996: CRC press.

135. Darabara, M., et al., Susceptibility to localized corrosion of stainless steel and NiTi endodontic instruments in irrigating solutions. International endodontic journal, 2004. 37(10): p. 705-710.

136. Services, W.c.c.c., Electrochemical Techniques.

137. Vandana P. Shinde, P.P.P., A study on the electrochemical polymerization, characterization, and corrosion protection of o-toluidine on steel. Journal of Solid State Electrochemistry, 2013. 17(1): p. 29-41.

138. Zaid, B., et al., Effects of $\mathrm{pH}$ and chloride concentration on pitting corrosion of AA6061 aluminum alloy. Corrosion Science, 2008. 50(7): p. 1841-1847.

139. L.M. Callea, M.R.K., R.D. Vinje, M.C. Whitten, W. Li, Electrochemical Investigation of Corrosion in the Space Shuttle Launch Environment. NASA Center for Aerospace Information (CASI)

140. Gill, P., et al., Effect of manufacturing process on the biocompatibility and mechanical properties of Ti-30Ta Alloy. Journal of materials engineering and performance, 2011. 20(4-5): p. 819-823.

141. Cano, E., D. Lafuente, and D. Bastidas, Use of EIS for the evaluation of the protective properties of coatings for metallic cultural heritage: a review. Journal of Solid State Electrochemistry, 2010. 14(3): p. 381-391.

142. Scully, J.R., Electrochemical Techniques in Corrosion Science and Engineering. 2003, New York: Marcel Dekker 125.

143. Kelly, J.R.S.a.R.G., Methods for DeterminIng Aqueous Corrosion Reaction Rates, in ASM Handbook, Corrosion: Fundamentals, Testing, and Protection B.S. Jr. Covino, Stephen D. Carmer, Editor. 2003, ASM International. p. 1135.

144. Qi, K., et al., The Protection Performance of Polypyrrole Coating Doped with Different Counter Anions for the Corrosion of NiTi Alloy. Open Corrosion Journal, 2011. 4.

145. Grgur, B., et al., The influence of polypyrrole films on the corrosion behavior of iron in acid sulfate solutions. Progress in organic coatings, 1998. 33(1): p. 1-6.

146. Ren, Y. and C. Zeng, Effect of conducting composite polypyrrole/polyaniline coatings on the corrosion resistance of type 304 stainless steel for bipolar plates of proton-exchange membrane fuel cells. Journal of Power Sources, 2008. 182(2): p. 524-530. 
147. Hirschorn, B., et al., Constant-phase-element behavior caused by resistivity distributions in films I. Theory. Journal of The Electrochemical Society, 2010. 157(12): p. C452-C457.

148. Kim, C.-H., S.-I. Pyun, and J.-H. Kim, An investigation of the capacitance dispersion on the fractal carbon electrode with edge and basal orientations. Electrochimica Acta, 2003. 48(23): p. 3455-3463.

149. Song, H.-K., et al., The effect of pore size distribution on the frequency dispersion of porous electrodes. Electrochimica Acta, 2000. 45(14): p. 2241-2257.

150. Cimpoesu, H. R., et al., Preliminary testing of corrosion characteristics of NiTi alloy coated with various polymers. JOURNAL OF OPTOELECTRONICS AND ADVANCED MATERIALS, 2011. 13(10): p. 1305 - 1308.

151. Mareci, D., et al., Electrochemical characteristics of electrochemically patinated bronze. European Journal of Science and Theology, 2011. 7(4): p. 121-129.

152. P., Ż., On the electrical capacitance of interfaces revealing constant phase element behaviour. J. Electroanal. Chem., 1998. 443: p. 149-154

153. Flyvholm MA, N.G., Andersen A., Nickel content of food and estimation of dietary-intake. Z Lebensmittelunters Forsch., 1984. 179: p. 427-437.

154. Cluett, M.L. and J.H. Yoe, Spectrophotometric Determination of Submicrogram Amounts of Nickel in Human Blood. Analytical Chemistry, 1957. 29(9): p. 12651269.

155. Arndt, M., et al., Nickel ion release from orthodontic NiTi wires under simulation of realistic in-situ conditions. Journal of Materials Science, 2005. 40(14): p. 36593667.

156. Shabalovskaya, S.A., et al., Surface conditions of Nitinol wires, tubing, and ascast alloys. The effect of chemical etching, aging in boiling water, and heat treatment. J Biomed Mater Res B Appl Biomater, 2003. 65(1): p. 193-203.

157. Shabalovskaya, S.A., et al., The influence of surface oxides on the distribution and release of nickel from Nitinol wires. Biomaterials, 2009. 30(4): p. 468-77.

158. W, H., et al., Review on Surface Modifications of Nitinol. J Long Term Effects Med Implant, 2010. 19(2): p. 15-24.

159. Shen, H.M. and Q.F. Zhang, Risk assessment of nickel carcinogenicity and occupational lung cancer. Environ Health Perspect, 1994. 102 Suppl 1: p. 27582. 
160. Cempel, M. and G. Nikel, Nickel: A Review of Its Sources and Environmental Toxicology. Polish Journal of Environmental Studies, 2005. 15(3): p. 375-382.

161. Waldron, H., Nickel in the human environment. Br J Ind Med, 1985. 42(9): p. 647-648.

162. Wu, S., et al., Nickel release behavior and surface characteristics of porous NiTi shape memory alloy modified by different chemical processes. J Biomed Mater Res A, 2009. 89(2): p. 483-9.

163. Bansiddhi, A., et al., Porous NiTi for bone implants: a review. Acta Biomater, 2008. 4(4): p. 773-82.

164. Chu, C.L., P.H. Lin, and C.Y. Chung, Characterization of transformation behavior in porous Ni-rich NiTi shape memory alloy fabricated by combustion synthesis. Journal of Materials Science, 2005. 40(3): p. 773-776.

165. Ryhanen, J., et al., Biocompatibility of nickel-titanium shape memory metal and its corrosion behavior in human cell cultures. J Biomed Mater Res, 1997. 35(4): p. 451-7.

166. Michiardi, A., et al., New oxidation treatment of NiTi shape memory alloys to obtain Ni-free surfaces and to improve biocompatibility. J Biomed Mater Res B Appl Biomater, 2006. 77(2): p. 249-56.

167. Brunette, D., The effects of implant surface topography on the behavior of cells. International Journal of Oral \& Maxillofacial Implants, 1988. 3(4).

168. Ong, J., et al., Effect of surface topography of titanium on surface chemistry and cellular response. Implant dentistry, 1996. 5(2): p. 83-90.

169. Bowers, K.T., et al., Optimization of surface micromorphology for enhanced osteoblast responses in vitro. International Journal of Oral \& Maxillofacial Implants, 1992. 7(3).

170. Setzer, B., et al., The gene-expression and phenotypic response of $h F O B 1.19$ osteoblasts to surface-modified titanium and zirconia. Biomaterials, 2009. 30(6): p. 979-990.

171. Gu, Y., et al., In vitro bioactivity and osteoblast response of porous NiTi synthesized by SHS using nanocrystalline Ni-Ti reaction agent. Journal of Biomedical Materials Research Part A, 2006. 78(2): p. 316-323.

172. Sargeant, A. and T. Goswami, Hip implants: paper $V$. Physiological effects. Materials \& design, 2006. 27(4): p. 287-307. 
173. Wirth, C., et al., Nitinol surface roughness modulates in vitro cell response: a comparison between fibroblasts and osteoblasts. Materials Science and Engineering: C, 2005. 25(1): p. 51-60.

174. W. Jaschke, K.J.K., E. P. Strecker, A new balloon-expandable tantalum stent (Strecker-Stent for the biliary system: Preliminary Experience. Cardiovasc Intervent Radiol, 1992. 15(6): p. 356-359.

175. Black, J., Biologic performance of tantalum. Clinical Materials, 1994. 16(3): p. 167-173.

176. Kato H, N.T., Nishiguchi S, Matsusue Y, Kobayashi M, Miyazaki T, et al., Bonding of alkali-and heat-treated tantalum implants to bone. . J Biomed Mater Res, 2000. 53: p. 28-35.

177. Bermudez MD, C.F., Martinez-Nicolas G, Lopez R, Erosion-corrosion of stainless steels, titanium, tantalum and zirconium. Wear, 2005. 258: p. 693-700.

178. Vamsi Krishna Balla, S.B., Susmita Bose, Amit Bandyopadhyay, Porous tantalum structures for bone implants: Fabrication, mechanical and in vitro biological properties. Acta Biomaterialia 2010. 6: p. 3349-3359.

179. Jianlu MA, J.L., Zhengpin WANG et al., Effects of Ta addition on NiTi shape memory alloys. J. Mater. Sci. Technol., 2000. 16(05): p. 534-536.

180. Chan, D.C., et al., Radiopacity of tantalum oxide nanoparticle filled resins. Dent Mater, 1999. 15(3): p. 219-22.

181. Hinchcliffe, W.A., et al., Roentgenographic Study of the Human Trachea with Powdered Tantalum. Radiology, 1970. 97(2): p. 327-330.

182. Horvath, J. and H. Uhlig, Critical Potentials for Pitting Corrosion of $\mathrm{Ni}, \mathrm{Cr}-\mathrm{Ni}$, $\mathrm{Cr}-\mathrm{Fe}$, and Related Stainless Steels. Journal of the Electrochemical society, 1968. 115(8): p. 791-795.

183. Frotscher, M., et al., Characterization of the mechanical properties of ultra-fine grained NiTiCr-wires. Materialwissenschaft und Werkstofftechnik, 2009. 40(1-2): p. 17-22.

184. Hsueh-Chang Wu, F.-W.S., Xuan Hong, Wenji V. Chang, Howard Winet, Monitoring the degradation process of biopolymers by ultrasonic longitudinal wave pulse-echo technique. Biomaterials 2003. 24: p. 3871-3876.

185. Pitt, C.G., Marks, T. A. \& Schindler, A., Controlled Release of Bioactive Materials, ed. R.W. Baker. 1980, New York: Academic Press. 
186. Callister, W.D., Materials Science and Engineering: An Introduction. 1999, John Wiley and Sons: New York.

187. Gopferich, A., Mechanisms of polymer degradation and erosion. Biomaterials, 1996. 17: p. 103-114.

188. Tamada, J. A., Erosion kinetics of hydrolytically degradable polymers. Chemistry, 1993. 90: p. 552-556.

189. Katti, D. S., Langer, R, Laurencin, C. T., Toxicity, biodegradation and elimination of polyanhydrides. Advanced Drug Delivery Reviews, 2002. 54: p. 933-961.

190. Nair, L. S., Laurencin, C. T., Biodegradable polymers as biomaterials. Progress in Polymer Science, 2007. 32: p. 762-798.

191. D.S Kattia, S.L., R Langerb, C.T Laurencin, Toxicity, biodegradation and elimination of polyanhydrides. Advanced Drug Delivery Reviews, 2002. 54(7): p. 16.

192. Langer, R., New methods of drug delivery. Science, 1990. 249(4976): p. 15271533.

193. Anthony Atala, D.J.M., Synthetic Biodegradable Polymer Scaffolds. 1997: Springer.

194. Athanasiou, K.A., et al., Orthopaedic applications for PLA-PGA biodegradable polymers. Arthroscopy, 1998. 14(7): p. 726-37.

195. Middleton, J.C. and A.J. Tipton, Synthetic biodegradable polymers as orthopedic devices. Biomaterials, 2000. 21(23): p. 2335-46.

196. Barry O'Brien, W.C., The evolution of cardiovascular stent materials and surfaces in response to clinical drivers: A review. Acta Biomaterialia, 2009. 5: p. 945-958.

197. Commandeur, S., H.M.M. Van Beusekom, and W.J. Van Der Giessen, Polymers, Drug Release, and Drug-Eluting Stents. Journal of Interventional Cardiology, 2006. 19(6): p. 500-506.

198. Whelan, D.M., et al., Biocompatibility of phosphorylcholine coated stents in normal porcine coronary arteries. Heart, 2000. 83(3): p. 338-45.

199. Hryniewicz, T., K. Rokosz, and R. Rokick, Magnetoelectropolishing process improves characteristics of finished metal surfaces: Intensity of externally applied magnetic field, plus oxygen control, manipulates rate of dissolution in electropolishing. Metal finishing, 2006. 104(12): p. 26-33. 
200. T. Hryniewicz, R.R., K. Rokosz, Biomaterial Studies on AISI 316L Stainless Steel after Magnetoelectropolishing Materials, 2009. 2: p. 129-145.

201. Chatterjee, S., Tribological Properties of Pseudo-elastic Nickel-titanium, in Mechanical Engineering. 2008, University of California: Los angles.

202. Hryniewicz, T., R. Rokicki, and K. Rokosz, Magnetoelectropolishing for metal surface modification. Transactions of the IMF, 2007. 85(6): p. 325-332.

203. Du Kim, J. and M.S. Choi, Electropolishing apparatus and method. 2001, Google Patents.

204. Schwab, P.-Y.F.a.S.J., Vascular Access: Concepts for the 1990s. J. Am. Soc. Nephrol., 1992. 3: p. 1-11.

205. SJ, S., Hemodialysis vascular access, in The Principles and Practice of Nephrology, G. H Jacobson, Striker, S Klahr, Philadelphia, B.C. Decker, Editor. 1990. p. 766-771.

206. DJ, K., Thrombotic complications of central venous catheters in cancer patients. Oncologist. , 2004. 9(2): p. 207-16.

207. Jung F, W.C., and Lendlein A, Degradable, multifunctional cardiovacsular implants: Challenges and hurdles. MRS bulletin, 2010. 35.

208. Ruggeri ZM, D.J., Saldívar E, Contribution of distinct adhesive interactions to platelet aggregation in flowing blood. Blood., 1999 Jul 1. 94(1): p. 172-178.

209. Gawaz, M., Role of platelets in coronary thrombosis and reperfusion of ischemic myocardium. Cardiovascular Research, 2004. 61(3): p. 498-511.

210. Pytela R, P.M., Ginsbergh MH, Platelet membrane glycoprotein IIb/IIIa: member of a family of Arg.Gly. Asp - specific adhesion receptors. Science, 1986. 231(4745): p. 1559-1562.

211. Ann L Adams, G.C.F., Leo Vroman, The complexity of blood at simple interfaces. J. Colloid Interface Sci., 1978. 65: p. 468.

212. Packham, M.A., et al., The effect of plasma proteins on the interaction of platelets with glass surfaces. J Lab Clin Med, 1969. 73(4): p. 686-97.

213. Swayer PN, P.J., Bio electric phenomena as etiological agents in intravascular thrombosis. Surg., 1953. 34: p. 491-500.

214. Jörg M. Schmehl, C.H., Hans P. Wendel, Claus D. Claussen, Gunnar Tepe, Silicon carbide coating of nitinol stents to increase antithrombogenic properties 
and reduce nickel release. Cardiovascular Revascularization Medicine 2008. 9: p. 255-262.

215. Baurschmidt P, S.M., The electrochemical aspects of the thrombogenicty of a material. J Bioeng, 1977. 1: p. 261-278.

216. Nygren, H., Initial reactions of whole blood with hydrophilic and hydrophobic titanium surfaces. Colloids and Surfaces B: Biointerfaces, 1996. 6: p. 329-333.

217. Peek GJ, F.R., The inflammatory and coagulative response to prolonged extracorporeal membrane oxygenation. ASAIO J., 1999 Jul-Aug. 45(4): p. 25063.

218. Salzman EW, M.E., Kent KC, Hemostasis and Thrombosis: Basic Principles and Clinical Practice. 2000.

219. Courtney JM, L.N., Sundaram S and Forbes CD., Biomaterials for bloodcontacting applications. Biomaterials, 1994. 15(10): p. 737-744.

220. Haycox CL, R.B., In vitro platelet interactions in whole human blood exposed to biomaterial surfaces: insights on blood compatibility. J Biomed Mater Res, 1993 Sep. 27(9): p. 1181-93.

221. Kolandaivelu K, E.E., Environmental influences on endovascular stent platelet reactivity: an in vitro comparison of stainless steel and gold surfaces. J Biomed Mater Res A, 2004. 70: p. 186-193.

222. Chang X, G.M., The effect of shear on in vitro platelet and leukocyte materialinduced activation. Journal of Biomaterials Applications, 2012. 28(3): p. 407-415.

223. Michelson AD, B.M., Krueger LA, Valeri CR, Furman MI, Michelson AD, Barnard MR, KCirculating monocyte-platelet aggregates are a more sensitive marker of in vivo platelet activation than platelet surface P-selectin: studies in baboons, human coronary intervention, and human action myocardial infarction. Circulation, 2001 Sep 25. 104(13): p. 1533-1537.

224. Lamberti M, P.B., Costabile T, Canozo N, Baroni A, Liotti F, Sannolo N, Giuliano M, In vitro evaluation of matrix metalloproteinases as predictive testing for nickel, a model sensitizing agent. Toxicology and Applied Pharmacology, 2004. 195(3): p. 321-330.

225. D, B., Effects of carcinogenic metals on gene expression. Toxicology Letters, 2002. 127(1): p. 63-68.

226. Köster R, V.D., Kiehn M, Sommerauer M, Kähler J, Baldus S, Meinertz T, Hamm $\mathrm{CW}$, Nickel and molybdenum contact allergies in patients with coronary in-stent restenosis. Lancet, 2000. 356(9245): p. 1895-1897. 
227. Klein CL, N.P., Wanger M, Kohler H, Bittinger F, Kirckpatrick CJ and Lewis JC, The role of metal corrosion in inflammatory processes: induction of adhesion molecules by heavy metal ions. Journal of Materials Science Materials in Medicine, 1994. 5(11): p. 798-807.

228. Gutensohn K, B.C., Bau J, Fenner T, Grewe P, Koester R, Padmanaban K, Kuehnl P, In vitro analyses of diamond-like carbon coated stents. Reduction of metal ion release, platelet activation, and thrombogenicity. Thrombosis Research, 2000. 99(6): p. 577-585.

229. Norman, M., et al. Corrosion behavior of cardiovascular stent materials. in SMST-2007. 2007. Proceedings of the International Conference on Shape Memory and Superelastic Technologies.

230. Cura, M. and E. Sprague, Bare-Stent Technology and Its Utilization in the Treatment of Atherosclerotic Obstructive Disease. Vascular Disease Management, 2010. 7: p. E95-E102.

231. Strecker, E., et al., Expandable tubular stents for treatment of arterial occlusive diseases: experimental and clinical results. Work in progress. Radiology, 1990. 175(1): p. 97-102.

232. Tanaka, Y., et al., In vitro short-term platelet adhesion on various metals. Journal of Artificial Organs, 2009. 12(3): p. 182-186.

233. Haider, W. and N. Munroe, Assessment of corrosion resistance and metal ion leaching of nitinol alloys. Journal of materials engineering and performance, 2011. 20(4-5): p. 812-815.

234. Vichai, V. and K. Kirtikara, Sulforhodamine B colorimetric assay for cytotoxicity screening. Nat Protoc, 2006. 1(3): p. 1112-6.

235. Skehan P, S.R., Scudiero D, Monks A, McMahon J, Vistica D, Warren JT, Bokesch H, Kenney S, Boyd MR., New colorimetric cytotoxicity assay for anticancer-drug screening. Journal of National Cancer Institute, 1990. 82(13): p. 1107-1112.

236. Cui, H., An investigation of poly (caprolactone-co-glycolide) interaction with bioactive protiens and cellular resopnses, in Graduate Program in Pharmaceutical Science. 2010, The State University of New Jersey: New Jersey.

237. Cui, H. and P.J. Sinko, The role of crystallinity on differential attachment/proliferation of osteoblasts and fibroblasts on poly (caprolactone-coglycolide) polymeric surfaces. Frontiers of Materials Science, 2012. 6(1): p. 4759. 
238. Decorato I, K.J., Lgeallais C and Salsac A V, Consequenses of a stensoed Artery in an Arteriovenous Fistula on the efficiency of the hemodialysis access. Meditech IFMBE proceedings, 2011. 36: p. 324-327.

239. Crewe KH, F.I., Platelet adhesion to fibrinogen-coated glass at an abrupt tubular expansion viewed with fluorescent video-microscopy. Biorheology, 1986. 23(5): p. 443-52.

240. Tanaka, Y., et al., In vitro short-term platelet adhesion on various metals. J Artif Organs, 2009. 12(3): p. 182-6.

241. Shabalovskaya, S., J. Anderegg, and J. Van Humbeeck, Critical overview of Nitinol surfaces and their modifications for medical applications. Acta Biomaterialia, 2008. 4(3): p. 447-467.

242. Rokicki, R., Magnetic Fields and Electropolished Metallic Implants, in Medical devices and diagnostic industry. 2006: Medical devices and diagnostic industry. p. 116-123.

243. Olson, S.M., Development of Superelastic Effects in Ferrous Shape Memory Alloy. 2013.

244. Konishi, K., T. Kubo, and A. Nakahira, Characterization of Some Properties of TiO2 on Ti surface by Anodization in Acid Solution.

245. Chu, C.L., et al., Surface structure and properties of biomedical NiTi shape memory alloy after Fenton's oxidation. Acta Biomater, 2007. 3(5): p. 795-806.

246. Nesbitt, H., D. Legrand, and G. Bancroft, Interpretation of Ni2p XPS spectra of Ni conductors and Ni insulators. Physics and Chemistry of Minerals, 2000. 27(5): p. 357-366.

247. Grosvenor, A.P., et al., New interpretations of XPS spectra of nickel metal and oxides. Surface Science, 2006. 600(9): p. 1771-1779.

248. Gong, C., Y. Wang, and D. Yang, Phase transformation and second phases in ternary $\mathrm{Ni}-\mathrm{Ti}-\mathrm{Ta}$ shape memory alloys. Materials chemistry and physics, 2006. 96(2): p. 183-187.

249. Jiang, A., et al., Investigation of the structure of $\beta$-tantalum. Thin Solid Films, 2003. 437(1): p. 116-122.

250. Kan, Q., et al., Oliver-Pharr indentation method in determining elastic moduli of shape memory alloys - A phase transformable material. Journal of the Mechanics and Physics of Solids, 2013. 61(10): p. 2015-2033. 
251. Pamuła, E., et al., FTIR study of degradation products of aliphatic polyesterscarbon fibres composites. Journal of Molecular Structure, 2001. 596(1): p. 69-75.

252. Pamula, E., and E. Dryzek., Structural changes in surface-modified polymers for medical applications. Acta Physica Polonica-Series A General Physics, 2008. 113(5): p. 1485-1494.

253. K. Vijayanand, K.D., D. K. Pattanayak, T. R. Rama Mohan and R. Banerjee, Interpenetring Blood-Biomaterial Interactions from Surface Free Energy and Work of Adhesion. Trends in Biomaterials and Artificial Organs, 2005. 18(2): p. 73-83.

254. Stokes, R.J. and D.F. Evans, Fundamentals of interfacial engineering. 1997: John Wiley \& Sons.

255. Yeh, C.-C., et al., The Effect of Polymer Molecular Weight and UV Radiation on Physical Properties and Bioactivities of PCL Films. Cellular Polymers, 2011. 30(5).

256. Gao, J., L. Niklason, and R. Langer, Surface hydrolysis of poly (glycolic acid) meshes increases the seeding density of vascular smooth muscle cells. J Biomed Mater Res, 1998. 42(3): p. 417-24.

257. J.H. Clint, A.C.W., Adhesion under water: surface energy considerations. International Journal of Adhesion and Adhesives, 2001. 21(267).

258. C.J Van Oss, R.J.G., M.K Chaudhury, The role of van der Waals forces and hydrogen bonds in "hydrophobic interactions" between biopolymers and low energy surfaces. Journal of Colloid and Interface Science, 1988. 111(2): p. 378390.

259. D.R. Absolom, W.Z., C. Thomson, Z. Policova, C.J. Van Oss, A.W. Neumann, Erythrocyte adhesion to polymer surfaces. Journal of Colloid and Interface Science, 1985. 104 (1): p. 51.

260. Michler, J., et al., Investigation of wear mechanisms through in situ observation during microscratching inside the scanning electron microscope. Wear, 2005. 259(1): p. 18-26.

261. Pitchuka, S., et al., Scratch-Induced Deformation Behavior of Cold-Sprayed Aluminum Amorphous/Nanocrystalline Coatings at Multiple Load Scales. Journal of Thermal Spray Technology, 2014. 23(3): p. 502-513.

262. Wolf, K.V., et al., An investigation of adhesion in drug-eluting stent layers. J Biomed Mater Res A, 2008. 87(1): p. 272-81. 
263. Shan, W.L., et al., Adhesion and cohesion in structures containing suspended microscopic polymeric films. Acta Biomater, 2012. 8(4): p. 1469-80.

264. Vodnick, D. and R. Nay. Interfacial Adhesion of Viscoelastic Coatings on Medical Stents: A Quantitative Energy-Based Approach for Interfacial Fracture Toughness Determination.

265. Mazumder, M.M., et al., Corrosion resistance of polyurethane-coated nitinol cardiovascular stents. J Biomater Sci Polym Ed, 2003. 14(12): p. 1351-62.

266. D907, A., standard terminology of adhesives. 2012, American Society for Testing Material (ASTM) p. 12.

267. Gissler, W., Jehn, H.A. Advanced Techniques for Surface Engineering. in Eurocourse on Advanced Techniques for Surface Engineering. 1992. Ispra, Italy.

268. Antico, F., et al., Adhesion of nickel-titanium shape memory alloy wires to thermoplastic materials: theory and experiments. Smart Materials and Structures, 2012. 21(3): p. 035022.

269. Smith, N.A., et al., Improved adhesion between nickel-titanium shape memory alloy and a polymer matrix via silane coupling agents. Composites Part A: Applied Science and Manufacturing, 2004. 35(11): p. 1307-1312.

270. Asahara, T., et al., Local delivery of vascular endothelial growth factor accelerates reendothelialization and attenuates intimal hyperplasia in ballooninjured rat carotid artery. Circulation, 1995.91(11): p. 2793-2801.

271. Reidy, M. and M. Silver, Endothelial regeneration. VII. Lack of intimal proliferation after defined injury to rat aorta. The American journal of pathology, 1985. 118(2): p. 173.

272. JH., Z., Biostatistical Analysis, ed. E. Cliffs. 1984, NJ Prentice-Hall.

273. Absolom, D.R., et al., Erythrocyte adhesion to polymer surfaces. Journal of Colloid and Interface Science, 1985. 104(1): p. 51-59.

274. Clint, J.H. and A.C. Wicks, Adhesion under water: surface energy considerations. International Journal of Adhesion and Adhesives, 2001. 21(4): p. 267-273.

275. Lobato, E.M.d.C., Determination of Surface Free Energies and Aspect Ratio of Talc, in Materials Science and Engineering. 2004, Virginia Polytechnic Institute and State University: Virginia.

276. Absolom, D., et al., Erythrocyte adhesion to polymer surfaces. Journal of Colloid and Interface Science, 1985. 104(1): p. 51-59. 
VITA

\section{CHANDAN PULLETIKURTHI}

2003-2007

2007-2009
B.Tech., Chemical Engineering

Osmania University

Hyderabad, India

M.S., Materials Science and Engineering

Florida International University

Miami, Florida

\section{PUBLICATIONS AND PRESENTATIONS}

C. Pulletikurthi, N. Munroe, D. Stewart, W. Haider, S. Amruthaluri, R. Rokicki, M. Dugrot, S. Ramaswamy, "Utility of Magneto-electropolished Ternary Nitinol Alloys for Blood-Contacting Applications", Journal of Biomedical Materials Research Part B (Submitted).

R. Rokicki, T. Hryniewicz, C. Pulletikurthi, N. Munroe, K. Rokosz, " The Novel Methods for Improving Corrosion Resistance and Biocompatibility of Nitinol Medical Implantable Devices”, The lancet (Submitted).

C. Pulletikurthi, N. Munroe, R. Rokicki, "Assessment of the electrochemical characteristics of a biodegradable polymer coated ternary Nitinol alloys", ECS 2014, 225th ECS Meeting, May 1116, 2014, in Orlando, FL (Under preparation).

P. Gill, N. Munroe, C. Pulletikurthi, S. Pandya, W. Haider, "Effect of manufacturing process on the biocompatibility and mechanical properties of Ti-30Ta alloy" $J$ Mater Eng Perform, 20(4), 2011, p 819-823.

C. Pulletikurthi, N. Munroe, P. Gill, S. Pandya, D. Persaud, W. Haider, K. Iyer, A. Mc Goron, "Cytotoxicity of Ni from Surface Treated Porous Nitinol (PNT) on Osteoblast Cells", J Mater Eng Perform , 20 (4-5), 2010, $p$ 824-829.

C. Pulletikurthi, N. Munroe, V. Tek, P. Gill, S. Pandya, W. Haider, "Assessing the Cytotoxicity of Ni from Porous Nitinol (PNT) on osteoblast cells", SMST 2010 The International Conference for Shape Memory and Superelastic Technologies (SMST) Proceedings, May 16-20, 2010, Pacific Grove, CA.

P. Gill, N. Munroe, C. Pulletikurthi, S. Pandya, V. Tek, W. Haider, "In-Vitro Localized Corrosion Studies of Ti-Ta Alloy”, SMST Proceedings, May 16-20, 2010, Pacific Grove, CA. 
C. Pulletikurthi, N. Munroe, R. Rokicki, "A Study on the Effect of Heat Treatment and MagnetoElectropolishing on in-Vitro Corrosion and Surface Properties of Ternary Nitinol", 225th ECS Meeting, May 11-16, 2014, in Orlando, FL.

C. Pulletikurthi, N. Munroe, "A Study On the Effect of Novel Surface Treatments and Biodegradable Polymer Coatings On Corrosion and Surface Properties of Ternary Nitinol Alloy", 224th ECS Meeting, Oct 27-Nov 1, 2013, San Francisco, CA.

D. Stewart, C. Pulletikurthi, N. Munroe, S. Ramaswamy, M. Dugort, "Platelet Adhesion Characteristics of Materials for Use in Blood-Contacting Applications", Southern Biomedical Engineering Conference 2013, Miami, FL.

C. Pulletikurthi, N. Munroe, S. Amruthaluri, S. Rao, "Biocompatibility Studies on Nano Textured Biodegradable Polymer-Coated Titanium Alloys for Implant Applications”, Nano Florida 2011, Sep 30- Oct 1, Miami, FL.

C. Pulletikurthi, N. Munroe, P. Gill, D. Persaud, "Correlation between porous Nitinol implant surface characteristics and osteoblast cell proliferation”, TMS 2011, Feb 27-Mar 3, San Diego, CA.

W. Haider, N. Munroe, P. Gill, C. Pulletikurthi, "The Electrochemical Characteristics of Surface Treated Nitinol Alloys", NACE-Corrosion 2010 conference, Research in Progress Symposium, 2010, March 14-18, San Antonio, TX. 